\title{
The relationship between structural and in vivo dynamic mechanical properties of the thoracic aorta in rats : influence of ageing and hypertension
}

Citation for published version (APA):

van Gorp, A. W. (1999). The relationship between structural and in vivo dynamic mechanical properties of the thoracic aorta in rats : influence of ageing and hypertension. [Doctoral Thesis, Maastricht University]. Universiteit Maastricht. https://doi.org/10.26481/dis.19990609ag

Document status and date:

Published: 01/01/1999

DOI:

10.26481/dis.19990609ag

Document Version:

Publisher's PDF, also known as Version of record

Please check the document version of this publication:

- A submitted manuscript is the version of the article upon submission and before peer-review. There can be important differences between the submitted version and the official published version of record.

People interested in the research are advised to contact the author for the final version of the publication, or visit the DOI to the publisher's website.

- The final author version and the galley proof are versions of the publication after peer review.

- The final published version features the final layout of the paper including the volume, issue and page numbers.

Link to publication

\footnotetext{
General rights rights.

- You may freely distribute the URL identifying the publication in the public portal. please follow below link for the End User Agreement:

www.umlib.nl/taverne-license

Take down policy

If you believe that this document breaches copyright please contact us at:

repository@maastrichtuniversity.nl

providing details and we will investigate your claim.
}

Copyright and moral rights for the publications made accessible in the public portal are retained by the authors and/or other copyright owners and it is a condition of accessing publications that users recognise and abide by the legal requirements associated with these

- Users may download and print one copy of any publication from the public portal for the purpose of private study or research.

- You may not further distribute the material or use it for any profit-making activity or commercial gain

If the publication is distributed under the terms of Article $25 \mathrm{fa}$ of the Dutch Copyright Act, indicated by the "Taverne" license above, 
THE RELATIONSHIP BETWEEN STRUCTURAL AND IN VIVO

DYNAMIC MECHANICAL PROPERTIES OF THE THORACIC AORTA

IN RATS:

INFLUENCE OF AGEING AND HYPERTENSION

\section{Proefschrift}

ter verkrijging van de graad van doctor aan de Universiteit Maastricht, op gezag van Rector Magnificus

Prof. Dr A.C. Nieuwenhuijzen Kruseman, volgens het besluit van het College van Decanen, in het openbaar te verdedigen op woensdag 9 juni 1999 om 14.00 uur.

Door

\section{Adrianus Wilhelmus van Gorp}

geboren op 4 februari 1963 te Tilburg 
IK WERD GEGREPEN DOOR DE ONWETENDHEID

DE TIJD SPEELDE ME PARTEN

(Ad van Gorp, 1993)

DIT PROEFSCHIFT IS OPGEDRAGEN AAN ALLE MENSEN

DIE IK HEB ONTMOET EN NOG ZAL ONTMOETEN 


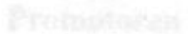

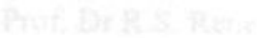

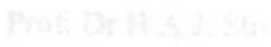

- 


\section{CONTENTS}

Chapter 1: General Introduction:

1.1 The cardiovascular system.

1.2 Mechanical properties of arteries.

1.2.1 The mechanical coupling between heart and large arteries

1.2.2 Mechanical parameters

1.3 The vascular wall

1.3.1 structural components

1.3.2 regulatory mechanisms

1.4 Changes in mechanical behavior of arteries with ageing and hypertension

1.4.1 Ageing

1.4.2 Hypertension

1.4.3 Relationship between ageing and hypertension

1.4.4 Pharmacotherapy

1.5 Spontaneously hypertensive rats.

1.6 Aims of the study.

Chapter 2: A technique to assess aortic distensibility and compliance in anesthetized and awake rats.

Chapter 3: Effects of smooth muscle tone on aortic compliance in conscious normotensive and spontaneously hypertensive rats.

Chapter 4: Alterations in spontaneously hypertensive rats in aortic wall properties precede the development of hypertension.

Chapter 5: Aortic wall properties in normotensive and hypertensive rats of various ages in vivo.

Chapter 6: Hypertension does not aggravate the changes in artery wall properties and structure with advancing age in older rats.

Chapter 7: The influence of anti-hypertenisve medication on the conscious in vivo dynamic mechanical properties of the thoracic aorta in spontaneously hypertensive rats.

Chapter 8: Arterial stiffning in hypertensive mREN-2 transgenic rats.

Chapter 9: General discussion and conclusions.

\section{Summary \\ Samenvatting \\ Cirruculum Vitae \\ Nawoord}




\section{Chapter 1}

INTRODUCTION 


\subsection{THE CARDIOVASCULAR SYSTEM}

As the multicellular organism evolved on earth a cardiovascular system was needed to shorten the distance of diffusion in order to preserve a constant environment, i.e., homeostasis. The cardiovascular system has the ability to induce motion of the fluid in the internal environment by which the distance of diffusion is shortened and the diffusion gradient is enhanced. In most circulatory systems the driving force is provided by contractions of a pumping organ or heart.

The hearts of vertebrates are analogous to mechanical positive displacement pumps that are characterized by a pulsatile activity during which blood is pumped into one direction by appropriately positioned valves. The heart operates by converting the potential energy of chemical compounds into kinetic energy for fluid movement emerging as a pressure gradient between the heart and the blood vessels in the vascular system.

The large arterial system links the left ventricle to the peripheral circulation. In this respect the large arteries have two functions: 1) to act as a conduit and 2) as a system to store volume energy. As conduit, the arteries deliver blood to the periphery of the body with a small fall in mean pressure. By the ability to store volume energy, arteries dampen the oscillations of pressure and flow that are a consequence of the heart's pulsatile action, so that blood flow into the arterioles and through the capillaries is more or less continuous with minimal pulsations. Under normal circumstances the arterial system is very efficient. In pulsatile flow only $5-10 \%$ extra energy is lost along the vascular tree as compared to non-pulsatile flow, i.e., the heart's output is continuous (O'Rourke M,1990a).

Arteries ramify into smaller vessels, the smallest ones being the arterioles, the wall of which contains a substantial number of smooth muscles cells to control lumen diameter. Arterioles regulate blood flow by directing blood to the organs and tissues that are active and shunt blood away from resting or less active tissues. Such a mechanism is necessary, since the volume of blood available is much less than the total capacity of the animal's circulatory system. Arterioles, as major resistance vessels, are also involved in the regulation of blood pressure, locally and systemically.

Arterioles branch into numerous smaller vessels, the capillaries. Although capillaries are the smallest of the closed circulatory system, their enormous number means that the total cross-sectional area of all the capillary beds is immense and, consequently, the blood flow velocity in these vessels is very low. This, in combination with their thin walls (only one endothelial cell layer thick), makes them especially suitable for the exchange of materials between the blood and interstitial space.

Capillaries fuse into collecting vessels, the venules, which in turn fuse into large vessels, the veins. The venous side of the circulation returns blood to the heart for recirculation. The relatively large size of the veins reduces the forces needed to propel blood through them. Veins are thin walled and distensible and serve as blood reservoirs in the organism. In humans, about $75 \%$ of the blood is stored in the venous system. Large veins regulate the cardiac preload. 


\subsection{Mechanical properties of ARTERIES}

\subsubsection{The mechanical coupling between heart and large arteries}

Stroke work or external work output of the heart is the amount of energy that the heart converts to work during each heart beat while pumping blood into the arteries (Guyton AC,1991). The ratio of work output to chemical energy expenditure is called the efficiency of the heart. This efficiency is determined by the intrinsic properties of the cardiac muscle and the functional vascular/ventricular interaction, i.e., the hydraulic load the vascular system exerts on the heart. The entire hydraulic load can be expressed as input impedance of the systemic circulation (O'Rourke MF et al., 1967). The input impedance is approximately constant throughout ejection and independent of the characteristics of the left ventricle, and thus characterizes the external factors opposing left ventriclar ejection (Merillon JP et al., 1982a; Sunagawa K et al., 1983; Milnor WR, 1975; Gourgon R et al.,1994). Aortic imput impedance provides a quantitative description of the entire relationship between pressure and flow (O'Rourke MF et al., 1967). Aortic impedance depends on peripheral resistance, total arterial compliance and aortic characteristic impedance (N. Westerhof et al., 1987). Another way to explain impedance is on basis of reflections of pressure and flow waves. These reflections make the impedance oscillate around the characteristic impedance of the aorta. (Milnor WR, 1975).

The load on the heart during systole is mainly determined by the mechanical properties of the aorta and therefore an increase in aortic stiffness may have important consequences for the heart (Safar ME et al., 1987a). In hypertensive patients, for example, increased stiffness of the aorta has been shown to be associated with cardiac hypertrophy (Pannier BM et al., 1990; Merillon J.P et al.,1982b). Similar observations have been made in hypertensive rats (Levy BI et al., 1988b; Pfeffer MA et al., 1985; Merillon JP et al., 1981; Tatchum-Talom R et al., 1995). It might even be that aortic stiffness contributes to the development of left ventricular hypertrophy independent of blood pressure (Roman MJ et al., 1995; Saba PS et al., 1993). Cardiac hypertrophy is a risk factor for ischemic heart diseases and cardiac arrhythmias (Fananapazir L et al., 1989; Masaki $\mathrm{H}$ et al., 1993) and may therefore result in heart failure and/or sudden death.

Cardiac hypertrophy is better correlated with systolic than with diastolic and mean pressure and the level of systolic pressure is largely influenced by modifications in aortic elasticity (Tarazi R. 1982; Safar ME et al.,1987a). Systolic blood pressure and pulse pressure are determined by the ejection velocity of the blood from the heart, and the elasticity of and the pulse wave velocity in the aorta (Pannier BM et al., 1990). Ejection velocity of the blood from the heart is largely determined by the performance of the heart. The pulse wave velocity depends on the visco-elastic properties of the aorta (O'Rourke MF, 1982). Ventricular ejection and large artery elasticity influence the level of systolic and pulse pressure in the early phase of systole. In the later phase, wave reflections may be responsible for a further rise in arterial pressure. Therefore, systolic blood pressure may be considered as a superposition of an incident wave (depending on ventricular ejection) and a reflected wave (depending on the velocity of the pulse wave and the distance between the heart and points of reflection). An increased pulse wave velocity caused by an increased stiffness of the aorta results in early reflected waves an consequently in an increase in systolic blood pressure.

In summary, aortic stiffness increases the imposed load on the heart and 
could therefore induce cardiac hypertrophy which is a risk factor for ischemic heart disease and cardiac arrhythmias.

\subsubsection{Mechanical parameters}

\section{Stress, strain and incremental elastic modulus}

Mechanical parameters describe the intrinsic characteristics of materials that determine the relationship between imposed load or stress (a force acting across a given plane in a body) and the resulting displacement or strain (ratio of deformation to the initial form). In the case of blood vessels, in vivo the imposed loads consist primarily of transmural pressure. The relationship between stress and strain is called the elastic or Young's modulus and describes the intrinsic properties of the material (Reneman R.S et al., 1996). In the general case of a material, composed of a number of components with different mechanical properties like arteries, the mechanics of such a composite material depend on the mechanical properties of the individual components in a complex way, i.e., their relative content and the manner in which the components are coupled (Cox R.H., 1989). This results in a non-linear stress-strain relationship and an elastic modulus that depends on the level of stress or strain. Therefore, Bergel (Bergel DL, 1961) introduced the incremental elastic modulus, defined as the local slope of the stress-strain relation. In addition, the incremental elastic modulus of the arterial wall is believed to be determined by the relative contribution or recruitment of different wall components. This relative contribution or recruitment is considered to depend on the magnitude of distention of the artery wall and on activation of the smooth muscle cells (Roach MR et al., 1973; Armentano RL et al., 1995; Barra JG et al.,!993). The contribution of the activity of the smooth muscle cells to the elastic behavior in large arteries, however, is still a controversial topic. At physiological pressures, the elastic modulus is determined by smooth muscle cell tone and the elasticity of the elastin fibers. At high pressure values, the recruitment of collagen fibers increases, which results in an increase in elastic modulus and nonlinearity of the mechanical behavior of arteries.

\section{Circumferential wall stress and shear stress}

A blood volume pumped into the aorta generates two main stress components on the aortic wall, circumferential stress and shear stress (Hoeks APG et al.,1995). In vivo arterial motion occurs predominantly in the circumferential direction (Reneman RS et al., 1986; Reneman R.S et al., 1996; Laurent S, 1993). This circumferential motion generates a circumferential stress. This circumferential stress is comparable to the wall tension (T) given by the Law of Laplace. This Law states that tension in a thin cylindrical shell is related to transmural pressure $(\mathrm{Pt})$ and radius $(\mathrm{r})$ :

$\mathrm{T}=\mathrm{Pt} \times \mathrm{r} \quad$ in Pa.m

The circumferential stress on the wall depends on this relation and wall thickness:

$$
\sigma=(\mathrm{Pt} x \mathrm{r}) / \mathrm{h} \quad \text { in } \mathrm{Pa}
$$

In which $\sigma$ is circumferential stress and $\mathrm{h}$ is wall or media thickness.

Flowing blood exerts a tangential stress on the endothelial cells of the arterial wall, which is called shear stress (Hoeks APG et al.,1995). 


$$
\mathrm{T}=(4 \eta \mathrm{Q}) / \pi \mathrm{r}^{3} \quad \text { in } \mathrm{Pa} \quad \text { (3) }
$$

in which T represents shear stress, $\eta$ blood viscocity, $\mathrm{Q}$ blood flow and $\mathrm{r}$ vessel radius.

\section{Distensibility and compliance}

Parameters commonly used to describe the mechanical properties of elastic cylindrical structures, like arteries, are distensibility and compliance, defined as the relative $(\Delta \mathrm{V} / \mathrm{V})$ and absolute $(\Delta \mathrm{V})$ change in arterial volume (V) for a change in pressure $(\Delta \mathrm{P})$, respectively. The increase in volume and pressure in the systolic phase of the cardiac cycle is commonly used to describe arterial distensibility and compliance. Since it is practically impossible to accurately determine volume and volume changes non-invasively in vivo, distensibility and compliance are generally expressed in terms of changes in lumen cross-sectional area, $\mathrm{A}((\Delta \mathrm{A} / \mathrm{A}) / \Delta \mathrm{P}$ and $\Delta \mathrm{A} / \Delta \mathrm{P}$, respectively). The terms compliance and distensibility coefficient are often used for these relations. This simplification is allowed because in thethered arteries length is nearly constant so that the change in volume during the cardiac cycle is caused by a change in lumenal cross-sectional area alone (Patel DJ et al., 1966; L'Italien GJ et al., 1994; Reneman RS et al., 1986; Reneman R.S et al., 1996; Laurent S, 1993). The expression for the distensibility coefficient (DC) in terms of lumen crosssectional area is

$\mathrm{DC}=(\Delta \mathrm{A} / \mathrm{A}) / \Delta \mathrm{P}$ in $\mathrm{Pa}^{-1}(4)$

Similarly, the compliance coefficient can be expressed in terms of lumen crosssectional area, providing

$\mathrm{CC}=\Delta \mathrm{A} / \Delta \mathrm{P}$ in $\mathrm{m}^{2} \cdot \mathrm{Pa}^{-1}$

\section{Pulse wave velocity}

Another parameter often used as an index of arterial stiffness is pulse wave velocity (PWV): the stiffer the artery is, the higher this velocity will be (Bramwell JC et al,1922: Lehmann ED et al.,1993). The use of PWV has the advantage that no arterial pressure recordings are necessary, but the simultaneous recording of the two waves requires some skill. PWV provides an average value of the artery segment studied and does not allow the assessment of local changes in arterial distensibility and compliance, which can be considered to be a limitation. In relation to distensibility, PWV can be written as

$\mathrm{PWV}=(\rho \mathrm{DC})^{-1 / 2} \quad$ in $\mathrm{m} \cdot \mathrm{s}^{-1}$

Where $\rho$ is the density of blood.

According to the Moens-Korteweg equation PWV can be calculated as follows:

$\mathrm{PWV}=(\mathrm{Eh} / \rho \mathrm{d})^{1 / 2}$ in $\mathrm{m} \cdot \mathrm{s}^{-1}$

where $\mathrm{E}$ is elastic modulus and $\mathrm{h}$ is wall thickness. Using equation (5) and (6), the elastic modulus can be calculated as follows:

$(\rho \mathrm{DC})^{-1 / 2}=(\mathrm{Eh} / \rho \mathrm{d})^{1 / 2}$

$\mathrm{E}=\mathrm{d} /(\mathrm{DC} \cdot \mathrm{h}) \quad$ in $\mathrm{Pa}$

If $\mathrm{E}$ is assessed based upon small perturbations in diameter and pressure, it is indicated as incremental elastic modulus. 


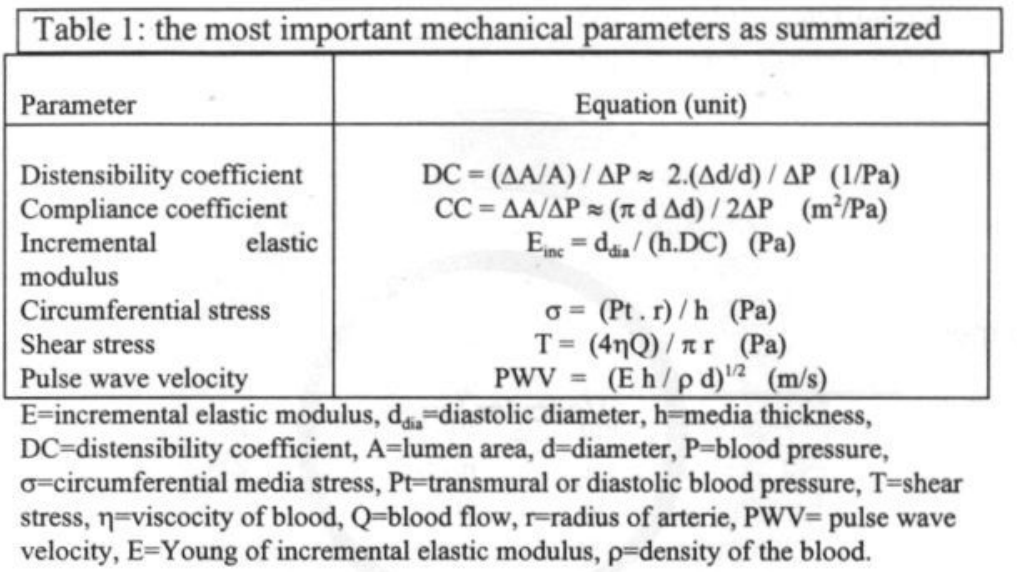

\subsection{THE VASCULAR WALL}

In general, blood vessels consist of three main layers: the tunica intima, the tunica media and the tunica adventitia.

The tunica intima consists of a monolayer of squamous endothelial cells that are separated from the elastic lamina by the subendothelial space. The endothelium plays an important role in the regulation of vascular tone through the release of vasoactive substances (Furchgott RF et al.,1980; De Mey JGR et al.,1982; Smiesko $\mathrm{V}$ et al.,1985; Pohl U et al.,1986; Rubanyi GM et al.,1986; Vanhoutte PM,1988; Olensen SP et al.,1988; Bevan JA et al.,1988; Koller A et al.,1990; Bevan JC et al.,1990). The endothelium plays a key role in the adaptation of the arterial wall to changes in flow and resulting alterations in shear stress and, therefore, the endothelium acts as a signaling interface for the mechanically stimulated remodeling process (Davies PF,1995).

The tunica media is mainly composed of extracellular matrix proteins and smooth musclè cells. In elastic arteries, such as the thoracic aorta, the wall mainly consists of elastic fibers. There are several layers of elastic fibers, which appear as thick, plate-like structures (lamellae) with a few fine elastic fibers connecting them.
The smooth muscle cells are embedded in a network of connective tissue consisting mainly of elastin and collagen (Greenwald SE et al.,1978). The tunica adventitia contains the perivascular nerves. The nerve endings, from which transmitters are released, lie in the media-adventitia border (Burnstock G et al.,1984). Besides connective tissue, the adventitia contains cells such as fibroblasts and mast cells (Mulvany MJ,1989).

\subsubsection{Structural components}

\section{Smooth muscle cells}

Anatomical and physiological evidence indicates that the smooth muscle cells in the walls of large arteries are oriented predominantly in a helical organization (Dobrin PB,1980), in such a way that individual smooth muscle cells appear to bridge concentric elastic lamellae, the presence of this pattern being confirmed by electron-microscopy (Dobrin PB,1978). A helical organization of the smooth muscle cells endows blood vessels with the ability to change the diameter in order to modify resistance and, therefore, blood volume flow. 


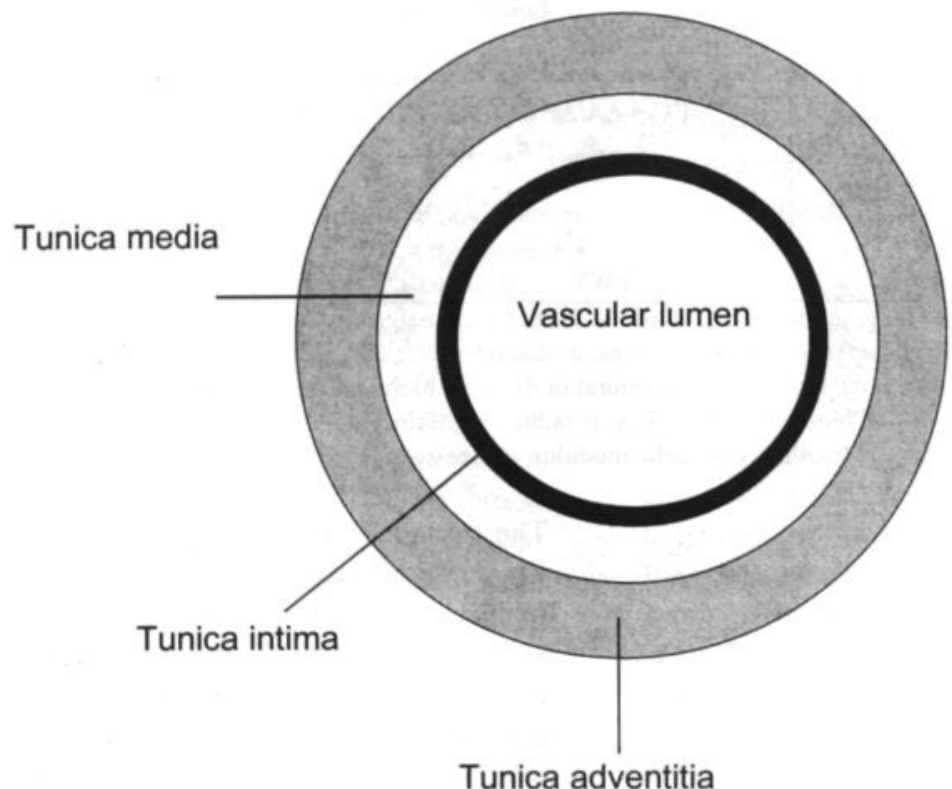

Figure 2: Schematic presentation of the structural layers in an artery.

The viscoelastic behavior of smooth muscle cells is most probably determined by the number and different kinds of dynamic interaction of actine and myosine that form cross-bridges (VanDijk A et al.,1984). The study of Warshaw et al. (Warshaw et al.,1988), performed on single stomach smooth muscle cells, indicate that cell elasticity resides within cross-bridges serially connected with an elastic component. In this respect the number and the different states of force bearing of cross bridges are important. As myosine phosphorylation increases, additional cross-bridges attach and result in an increase in muscle stiffness. This mechanism should result in comparable increases in steady-state force and steadystate stiffness. Alternatively, agonist activation could enhance steady-state force by shifting the distribution of cross-bridges such that the relative population of crossbridges in force-producing state is increased. This mechanism should result in a greater increase in steady-state force than in steady state stiffness. According to Meiss et al., active dynamic stiffness in smooth muscle cells is believed to be an estimate of the number of cross-bridges attached (Meiss et al.,1978; Singer et al.,1986; Singer et al.,1987) whether or not they bear force (Meiss et al.,1996). The study of Brozovich et al. (Brozovich FV et al.,1993) on single vascular smooth muscle cells implies that agonist stimulation results in an increase in cross-bridge attachment and produces a shift in the population of crossbridges to force-producing states, increasing steady-state force more than steady-state stiffness. Under unstimulated control conditions, however, the 
relationship between force and stiffness is linear.

Arteries are under control of a number of regulatory systems, like the sympathetic nervous and the reninangiotensin system. These systems can modulate the caliber of the artery by changing the activity of the smooth muscle cells. Changing the diameter can be a mechanism by which arteries regulate their elastic behavior and, therefore, the afterload on the heart. The influence of smooth muscle contraction and relaxation on arterial elasticity, however, is controversial. It is generally assumed that there are two opposing effects, the net outcome of which causes the observed mechanical behavior. Smooth muscle contraction can increase arterial stiffness by direct addition of a tensile force to the arterial wall, which opposes the distending blood pressure and results therefore in a stiffer artery. This effect may be offset by the ability of the active smooth muscle cells to reduce the size of the artery and shift stress bearing from the relatively stiff collagen fibers to the more distensible elastin fibers (Roach MR et al.,1957), assuming that smooth muscle cells are in series with collagen (Benetos et al.,1992a).

In the past the contribution of smooth muscle to the mechanical behavior of large arteries has been investigated in in vitro and in vivo models of different species, including humans. In these studies smooth muscle cell activity was challenged by different vasoactive compounds. Many early studies utilized arterial strips (Banick $\mathrm{N}$ et al.,1970; Shibata S et al.,1973; Hansen TR et al.,1974). These preparations were studied under isometric conditions and were ususally activated by a maximum dose of a contractile agent. The outcome of such studies is controversial. Bauer et al. (Bauer et al.,1982) reported that, in contrast to the static incremental modulus, the dynamic elastic modulus was virtually uninfluenced by smooth muscle tone, when various arterial segments were activated by norepinephrine and relaxed by papaverine. Dobrin and Rovick (Dobrin PB et al.,1969) showed an increase in incremental elastic modulus $\left(\mathrm{E}_{\text {inc }}\right)$, suggesting reduced elasticity, in phenylephrine treated dog carotid artery strips, when compared with non-stimulated preparations and at the same degree of strain. Under isobaric conditions, however, the same aortic strips showed a decreased $E_{\text {inc }}$ after phenylephrine treatment. Results, comparable to the ones found by Dobrin et al., were obtained in a study performed on the thoracic aorta in conscious instrumented dogs (Barra JG et al.,1993). Under normal physiological conditions a small degree of aortic smooth muscle cell activation did not affect the dynamic incremental elastic modulus (Barra JG et al.,1993). Peterson et al. (Peterson LH et al.,1960) found an increase in $\mathrm{E}_{\text {inc }}$ with topical and intravenous norepinephrine and a decrease in $E_{\text {inc }}$ with the vasodilator acetylcholine. Similarly, Yano et al. (Yano et al.,1989) demonstrated an increase in canine aortic distensibility with diltiazem. Studies on humans have predominantly shown increased compliance in response to vasodilator drugs (Safar ME et al.,1986; Safar ME et al.,1987b; Fitchett et al.,1984; Westling et al.,1984). Systemic administration of these drugs, however, usually decreased blood pressure in concert with conduit vessel smooth muscle relaxation. In muscular non-capacitance brachial artery, Bank et al. (Bank et al.,1995) determined the effects of nitroglycerine and norepinephrine on the mechanical properties in humans without the confounding effects of blood pressure changes on the mechanical properties. Nitroglycerine and norepinephrine significantly shifted the stress-strain and $\mathrm{E}_{\text {inc }}$ curves in opposite directions. Although nitroglycerine decreased and norepinephrine increased $\mathrm{E}_{\text {inc }}$ under isometric conditions, there was no significant change in $\mathrm{E}_{\text {inc }}$ with alterations in 
smooth muscle tone under isobaric conditions.

In summary, in previous studies opposite conclusions were drawn, regarding the effect of smooth muscle activity on the elastic properties of arteries and therefore the buffering capacity of large arteries. Two phenomenan direct the outcome of studies on the involvement of smooth muscle on arterial mechanical behavior: 1). the direct opposing effect of the force generated and 2). the consequences of the alteration in diameter that modulate the distribution of stress bearing by the different extracellular matrix components.

\section{Extracellular matrix components}

\section{Collagen and elastin, introduction}

Collagen molecules are a family of fibrous proteins found in all multicellular animals. The characteristic feature of a typical collagen molecule is its long, stiff, triplestranded helical structure, in which three collagen polypeptide chains, called the $\alpha$ chains, are wound around one another in a ropelike superhelix (Alberts B et al.,1994). In the arterial wall, the soluble precursor "procollagen" is synthesized in polysomes of the smooth muscle cells or fibroblasts and secreted into the extracellular space where collagen molecules are cross-linked and become fibers (Ito $\mathrm{H}, 1989$ ). Intramolecular and intermolecular crosslinks are formed in several steps. Certain lysine and hydroxyproline residues are covalently coupled by the enzyme lysyl oxidase. In the blood vessels, collagen type I (media and adventitia), III (media), IV (basement membrane) and V (around smooth muscle cells) are found (Ito H,1989).

The main component of elastic fibers is the highly hydrophobic protein elastin. Elastin is covered with a sheath of microfibrils. Microfibrils are composed of a number of distinct glycoproteins, including the large glycoprotein fibrillin, which seems to be essential for the integrity of elastic fibers (Alberts B $e t$ al.,1994).

There is a relationship between the scleroproteins, i.e., collagen and elastin, and the elastic properties of the rat blood vessel wall (Roach MR et al.,1957; Wolinsky H et al.,1964; Fisher GM et al.,1966; Berry CL et al.,1976; Cox RH et al.,1974; Cox RH,1977b; Fernandez PG et al.,1984). The exact way in which collagen and elastin are involved in determining the mechanical properties of arteries, however, is incompletely understood. Factors to be considered are (1) the absolute and relative amounts of collagen and elastin; arteries tend to be stiffer: if more collagen and less elastin is present in their wall, (2) the cross-linking of collagen and elastin, (3) differences in the absolute or relative amount of various subtypes of collagen.

\section{Absolute and relative amount of collagen and elastin}

The results obtained in studies on the absolute and relative collagen and elastin contents in relation to vessel wall mechanics are inconsistent. Cox et al. found a very close correlation between the ratio of collagen and elastin content and the passive mechanical properties at a given arterial site (Cox RH et al.,1976a; Cox RH,1977a; Cox RH,1978). In another study of these investigators, however, no significant difference in the collagen/elastin ratio was found between the carotid artery of Wistar Kyoto rats (WKY) and spontaneously hypertensive rats (SHR), whereas the total connective tissue content was lower in the SHR (Cox RH,1979a). These conflicting results were explained by a model in which collagen and elastin fibers are assumed to be arranged in parallel with the fraction of collagen supporting wall stress variations with transmural pressure or wall strain (Dobrin et al.,1969; Cox RH,1979a; Barra et al.,1993). In this model the elastic modulus 
of a blood vessel $(\mathrm{E})$ is determined by the elastic moduli of elastin $\left(E_{e}\right)$ and collagen $\left(E_{c}\right)$, the relative amount of elastin and collagen in the blood vessel $\left(\mathrm{W}_{\mathrm{e}}\right.$ and $\left.\mathrm{W}_{\mathrm{c}}\right)$ and the fraction of collagen fibers supporting wall stress at a given strain or pressure $\left(\mathrm{f}_{\mathrm{c}}\right)$.

$\mathrm{E}=\mathrm{E}_{\mathrm{e}} \mathrm{W}_{\mathrm{e}}+\mathrm{f}_{\mathrm{c}} \mathrm{E}_{\mathrm{e}} \mathrm{W}_{\mathrm{c}}$

\section{At physiological blood pressure} and under passive conditions arteries reveal an incremental elastic modulus which resembles that of elastin (Young's modulus $3 * 10^{5} \mathrm{~N} / \mathrm{m}^{2}$ ) (Roach MR et al.,1957). At increasing strain, under passive conditions, the incremental elastic modulus increases, indicating that more tension is developed by collagen (Young's modulus $1^{*} 10^{8} \mathrm{~N} / \mathrm{m}^{2}$ ). These findings were supported by the results obtained by Levy et al. (Levy BI et al.,1988a), who showed in renal hypertensive rats treated with the ACE-inhibitor perindopril that, despite a reduction in blood pressure and media thickness and an increase in compliance, the collagen content of the vessel was not reduced as compared to untreated renal hypertensive rats. This indicates that at lower distending blood pressures less collagen is recruited, resulting in a more compliant blood vessel.

Insight into the relationship between mechanical properties and elastin and collagen can be obtained from studies performed on humans with disorders in elastin and collagen synthesis and maturation. In patients with Marfan syndrome, in whom the intrigity of the elastin fiber is disturbed, compliance of the aorta was found to be increased (Pyeritz R et al.,1979). In patients with Ehlers-Danlos Type IV disease, a genetic connective tissue disorder in which processing and maturation of collagen is deranged, aortic compliance was significantly larger than in control subjects (Neil-Dwyer G et al.,1983).

\section{Cross-linking}

It has been proposed that the elasticity of arteries is not so much determined by the total content of collagen, but by the degree of collagen cross-links. Non-cross-linked collagen molecules do not have tight interaction with the existing extracellular matrix and therefore are a less important determinant of arterial wall mechanical properties (RK Vadlamudi et al.,1993).

Evidence exist that there is a relationship between arterial stiffness and collagen cross-linking. The collagen crosslinking inhibitor beta-aminoproprionitrile decreased the passive stiffness of cylindrical segments of the carotid artery (Iwatsuki K et al.,1977; Cox RH et al.,1988). In the aorta it has been demonstrated that the enzyme lysyl oxidase, that catalyses the formation of collagen cross-links, has a diminished activity in response to dietary copper deficiency (Rayton JK et al.,1979; Opsahl W et al.,1982). The catalytic activity of lysyl oxidase demands a copper ion at its active site (Stryer L,1988). Therefore, the left cardiac ventricle of cupper deficient pigs, in which there was no difference in collagen content as compared with normal fed animals, showed a reduction in collagen cross-linking and concomitantly an increase in compliance (Vadlamudi RK et al.,1993). In humans, evidence in support of the role of cross-linking in determining artery wall mechanical properties, is derived from studies in patients with inherited connective tissue diseases, like osteogenesis imperfecta. In these patients the observed increased stiffness of the aorta is consistent with an increased crosslinking of collagen within the aortic wall (Kalath S et al.,1987).

Other evidence for the existence of the relationship between collagen crosslinks and arterial mechanical properties comes from the investigation of nonenzymatic formation of collagen crosslinks. The accumulating chemically irreversible advanced product of 
nonenzymatic glycation participate in glucose derived cross-link formation (Monnier VM et al.,1984). These products accumulate on vascular wall collagen as a function of age and glycemia (Brownlee $\mathrm{M}$ et al.,1988). A direct relationship between mechanical properties of the carotid artery and glucose derived cross-link formation was investigated by Huijberts et al. (Huijberts MSP et al.,1993). Treatment with aminoguanidine, a nucleophilic hydrazine compound which decreases the glucose derived collagen cross-linking, enlarges the static carotid compliance and decreases the characteristic aortic input impedance in diabetic rats (Huijberts MSP et al.,1993).

\section{Absolute and relative amounts of Type I and Type III collagen.}

It is generally believed that collagen type I and III have different constituting $\alpha$ chains, resulting in characteristic intra- and inter-molecular interactions and, hence, a particular three dimensional structure, both of which could be responsible for a distinct mechanical behavior. Stiffness and tensile strength are usually associated with type I collagen, whereas compliance and elasticity are associated with type III collagen (Weber KT et al.,1987; Weber KT et al.,1991). Several lines of evidence substantiate a relationship between tissue mechanical behavior and differences in the amounts of collagen type I or III. Connective tissues with a high content of type III collagen are more extensible than tissues that are predomminantly composed of type I collagen (Birk DE et al.,1984).

The joint mobility syndrome, a dominant inherited disorder of collagen production, is characterized by structural cardiovascular weakness associated with an increased aortic wall compliance. This increase in compliance is caused by an apparent deficiency of collagen type I production and an overproduction of .collagen type III (CE Handler et al.,1985).
In summary, the relationship between collagen and elastin and mechanical properties of large arteries was investigated in several studies, but the exact way in which these scleroproteins are involved in the mechanical behavior of arteries is not clear. The relative and absolute amount of collagen and elastin and their isoforms as well as the degree of cross-linking might be important determinants of the mechanical characteristics of blood vessels.

\subsubsection{Regulatory mechanism}

Vascular tone is influenced by neurohumoral systems, like the sympathetic nervous (Bolton TB,1979; VanHoutte PM et al.,1981) and the reninangiotensin system (Dzau VJ et al.,1988a). The endothelial cell layer plays an important role in the regulation of the vascular tone (Levy BI et al.,1989; Rubanyi GM et al.,1990). For example, shear forces, i.e., forces exerted on the vessel wall by the flowing blood, induce the release of the vasodilator Nitric Oxide (Cooke JP et al.,1991; Buga GM et al.,1991).

Alterations in arterial wall stress are believed to be an important trigger for arterial structural and functional changes (Leung DYM et al.,1976; Levy BI et al.,1994). Additionally, the activation of different neurohumoral systems can induce functional and structural changes in large arteries (Owens GK,1978; Geisterfer AAT et al.,1986; Benetos A et al.,1992b) and thereby regulate the mechanical properties on a long-term basis. Long-term regulatory mechanisms affecting the mechanical properties of arteries include alterations in the composition of extracellular matrix proteins, enlargment of the diastolic diameter, enlargment of or an increase in the number of smooth muscle cells and changes in reponsiveness of smooth muscle cells to vasoactive substances. 


\section{Renin-angiotensin system}

In general, the renin-angiotensin system is a major system in the regulation of structural and functional properties of arteries (Kawasaki H et al.,1984; Dzau VJ et al.,1988a). The local arterial reninangiotensin system causes autocrine and paracrine actions which activate vasoactive systems and growth factors (Dzau VJ et al.,1987b; Levy BI et al.,1990; Safar ME et al.,1997) and therefore angiotensin II has multiple effects on aortic wall function and structure. These include direct, short-term, and chronic or long-term effects. Alteration in vascular tone by angiotensin II (Bolton TB,1979) can influence mechanical properties by its own activity or passively by the increase in blood pressure. Subsequently, angiotensin II enhances sympathetic tone through central and peripheral mechanisms (Zimmerman BG et al.,1984 Story DR et al.,1987; Wong PC et al.,1992). Chronic or long-term effects include vascular smooth muscle cell growth in vitro (Campbell-Bosswell $\mathrm{M} e t$ al..,1981; Geisterfer A.A et al.,1988; Schiffers PMH et al.,1993;) and in vivo (Daemen M.J.A.P et al.,1991; Griffin S.A et al.,1991; Boonen H et al.,1993; Brouwers-Ceiler et al.,1997), and extracellular matrix formation (Dzau VJ,1987a; Kato H et al.,1991; Keeley FW et al.,1992).

The putative effects of angiotensin II on the structural and functional properties and thereby on mechanical characteristics of the arterial wall are confirmed by the improving acute and chronic effects of ACE inhibition on the elastic properties of the wall of elastic arteries (Dzau VJ et al.,1988a; Levy BI et al.,1988a; Safar ME,1989a; Benetos A et al.,1992b).

In summary, it might be concluded that angiotensin II, the active component of the renin-angiotensin system, affects mechanical properties of arteries by increasing vascular tone, stimulation of smooth muscle growth, an increased synthesis of collagen and an increase in blood pressure.

\section{Sympathetic nervous system}

The acute effect of sympathetic activation on large arteries is expressed as a constriction of vascular smooth muscle and a reduction in arterial diameter (Dobrin PB et al.,1969; Cox RH,1976b; Megerman J et al.,1986).

Sympathetic outflow to blood vessels also serves as an important trophic signal regulating normal development and maintenance of arterial wall structure and function (Bevan RD,1975; Cox RH,1976b; Bevan RD et al.,1985; Cox RH et al.,1988; Todd ME et al.,1991; Daemen M et al.,1995;). In vitro (Bevan RD et al.,1985) and in vivo (Rusterholz DB et al.,1972) studies on the long term effect of sympathetic denervation described a reduction in distensibility associated with a decreased smooth muscle mass and an increase in extracellular connective tissue (Bevan RD,1975; Bevan RD et al.,1985; Todd ME et al.,1991). Denervation is further associated with a decrease in arterial wall thickness, medial crosssectional area, contractility and sensitivity, and vascular reactivity (Bevan RD et al.,1985). Lacolley et al. described a reduction in the in situ static compliance and distensibility and elastin content in the abdominal aorta of male Wistar rats as the result of chemical sympathetic denervation with guanethidine after 3 months (Lacolley $\mathrm{P}$ et al.,1995). In arteries of adult rabbits and rats, on the other hand, surgical denervation and 6-hydroxydopamine induce an increase in smooth muscle cell size and ultrastructural changes compatible with increased synthetic activity (Froneck K et al.,1978; Froneck K,1983; Dimitriadou V et al.,1988; Albino-Teixeria A et al.,1990). According to Daemen and De Mey (Daemen MJAP et al.,1995) sympathetic nerves seem to exert a trophic action on vascular smooth muscle during development, but show an opposite effect in adult animals. 
The cause of this heterogenity in time is not known, but sympathetic cotransmitters, like ATP and neuropeptide Y, may be involved.

In summary, the sympathetic nervous system may influence the acute mechanical properties of large arteries by increasing the vascular tone and long-term mechanical properties by reducing smooth muscle mass and elastin content. Depending on the developmental stage, arteries need a constant input of catecholamines to maintain arterial structure.

\section{The effect of endothelial cells on mechanical properties}

Blood flow induced shear stress activates endothelial cells and thereby the production of vasodilator mediators (Frangos JA et al.,1985; Rubanyi GM et al.,1986; Olensen CP et al.,1988). These vasoactive mediator can alter the vascular tone and diameter and thereby change the mechanical behavior of large arteries (Mourlon legrand MC et al.,1993; Davies $\mathrm{PF}, 1995)$. The effect of endothelium on mechanical properties of large arteries can be investigated by the removal of the endothelium cells. Removal of the endothelium enlarges the compliance of the carotid artery in WKY and SHR, implying a inhibiting role of the endothelial cells on the buffering capacity of large arteries (Levy BI et al.,1990; Mourlon Legrand MC et al.,1993; Glaser et al.,1997). Another way to investigate the role of endothelium in the determination of mechanical behavior of large arteries is to administer agents that have the ability to donate or produce NO. In humans, administration of isosorbide nitrate, an NO donor, decreases blood pressure and improves compliance. The mechanism underlying the enlargement of compliance depends on the vascular territory investigated. Improvement of compliance of the carotid artery results from an increase in diameter and of the brachial artery from an increase in distension. The common femoral artery shows a pattern of compliance which is intermediate between the other two arteries (Laurent S et al.,1992).

The relationship

between

endothelium and the alterations in structure and function of large arteries has been investigated by long-term inhibition of NO-synthase. Long-term inhibition of Nitric Oxide production induces an elevation of blood pressure in WKY rats but has no effect on the mechanical properties of the carotid artery despite the increase in wall thickness (Delacretaz E et al.,1994).

The endothelium plays a key role in the adaptation of the arterial wall to changes in flow and the resulting alterations in shear stress and, therefore, the endothelium acts as a signaling interface for the mechanically stimulated remodeling process (Davies PF,1995). Structural changes resulting from low flow induced alteration in shear stress on endothelium cells, encompass, intimal thickening and the reduction of lumen diameter (Langille BL et al.,1986). An increased flow results in a chronically enlarged lumen diameter (Kamiya A et al.,1980). Both of these responses involve fundamental changes in artery wall thickness, matrix composition, and the organization of the artery wall (Zarins CK et al.,1987; Zarins CK,1989; Pourageaud F et al.,1997; Pourageaud F et al.,1998). In both situations, i.e., low and high flow and shear stress, removal of the endothelium results in a failure of the vascular wall to adapt (Davies PF,1995).

In summary, endothelium may influence the mechanical behavior of large arteries acutely by changing vascular tone and diameter and, on a long-term basis by changing the structure and geometry. These effects are mediated by the flow induced shear stress. 


\subsection{ARTERIAL MECHANICAL PROPERTIES WITH AGEING AND IN HYPERTENSION}

\subsubsection{Ageing}

Early studies on arterial mechanics in humans and rats show that ageing reduces the buffering capacity, characterized by compliance and distensibility, and increases the stiffness of large arteries, characterized by Young's or incremental elastic modulus (Busby DE et al.,1965; Bader H,1967; O'Rourke MF et al.,1968; Ting CT et al.,1986). It is becoming clear, however, that the susceptibility for alteration in functional mechanical properties with ageing is dependent on the location of the arteries in the vascular tree. For example, common carotid artery compliance and distensibility decrease linearly with age (Reneman RS et al.,1985). The distensibility of the common femoral artery is also reduced at older age (Van Merode T et al.,1996), but the compliance of the brachial artery (Kawasaki T et al.,1987) and the distensibility of the deep and superficial femoral arteries are not (Van Merode $\mathrm{T}$ et al.,1996). The Young's modulus of the carotid artery (Riley WA et al.,1992) and the pressure-strain modulus (Mozersky DJ et al.,1972) of the femoral artery increase with age, indicating loss of elastic properties of the artery wall.

Ageing is associated with characteristic changes in arterial morphology and structure. In different species, ageing has been shown to be associated with an increased diameter of the aorta and other large arteries (Learoyd BM et al.,1966; Bader H,1967; Pagani M et al.,1979; Reneman RS et al.,1985; Sumitani M et al.,1986; Safar M,1990; Hansen F et al.,1995) and an increase in thickness of the media and intima of the aorta (Learoyd BM et al.,1966; Bader H,1967; Wolinsky H et al.,1972; Berry CL et al.,1975; Sumitani M et al.,1986 Benetos A et al.,1993a;).

Increased collagen content is a consistent finding in senescent vessels (Kohn RR,1977; Benetos A et al.,1993a). In aged rats, Fornieri et al. (Forieri C et al.,1992) described an increase in the volume density of collagen, but a reduction of the total amount per cross-sectional area. Collagen becomes more insoluble with ageing, because of increased intermolecular crosslinking (Vater CA et al.,1979; Yamauchi M et al.,1988). Elastin synthesis is efficient in the aorta of newborn and very young rats. In old animals, however, the elastin synthesis is significantly reduced as compared to young animals concomitantly with a dramatic reduction in elastin mRNA expression (Quaglino D Jr. et al.,1989; Forieri C et al.,1992). Studies in a large number of species indicate increased elastin fragmentation with ageing which could be the effect of fatigue, caused by the longterm oscillating stress exerted upon the elastin fibers and/or by an increased activity of proteolytic enzymes (Kohn RR,1977; Osborne Pellegrin MJ et al.,1990; Robert L et al.,1984).

The overal efficiency of $\beta$ adrenergic stimulation declines with ageing, probably due to a diminished responsiveness to catecholamines (Fleg $\mathrm{L}$ et al.,1986). An age related reduction of the vasoconstrictor properties to noradrenaline has been described at the level of the aorta (Wanstall et al 1988). However, a distiction should be made between the different adrenergic receptor isoforms. In the carotid artery of rats, ageing did not affect $\alpha_{1}$ adrenoceptor affinity and density, whereas it decreased $\beta$-adrenoceptor density without changing the affinity (Benetos A et al.,1993a). The responsiveness of aortic smooth muscle cells to $\alpha$-adrenergic stimulation, by infusion of methoxamine, increased with ageing in conscious sheep (Pagani M et al.,1979).

In summary, the structural and morphological organization of large arteries showed remarkable alterations with ageing because of continuous rearrangements of cells and extracellular matrix components. However, it remains to be established whether these alterations are 
related to observed deterioration of the buffering function and changes in elastic properties encountered in certain large arteries with ageing.

\subsubsection{Hypertension}

For many years there has been a general agreement that the buffering capacity and the elasticity of large arteries are reduced in established hypertension in humans (Gribbin B et al.,1979; Simon A et al.,1983) and in different rat models of genetic or experimental hypertension (Folkow B et al.,1973; Dobrin PD,1981; Cox RH,1979a; Levy BI et al.,1985; Levy BI et al.,1988a; Levy BI et al.,1994; Zanchi A et al.,1997). In humans it has been shown that the loss of arterial distensibility and compliance is not a generalized phenomenon along the arterial tree. In the carotid artery, for example, distensibility and compliance are reduced in untreated hypertensive patients, as compared to age matched controls (Safar ME et al.,1984; Riley WA et al.,1992; Roman MJ et al.,1992;), while this is not the case in the radial artery (Hayoz D et al.,1992).

It has been a matter of debate whether the differences in arterial wall properties between normotensive and hypertensive patients results from an increased blood pressure alone or that additional factors are involved. For example, it has been shown that isobaric distensibility of carotid arteries of SHR and renal hypertensive rats are not decreased as compared to control rats (Hayoz D et al.,1993). On the other hand in relatively young borderline hypertensive patients aortic compliance and distensibility of the carotid artery were found to be significantly reduced, as compared to age-matched control subjects, despite the fact that differences in blood pressure between these patients and control subjects are only small (Ventura $\mathrm{H}$ et al.,1984; Van Merode T et al.,1988; Van Merode T et al..,1993;). In addition, in these patients different parts of the carotid artery bifurcation are differently affected, as far as the reduction of distensibility is concerned, while these parts are subjected to the same mean blood pressure (Van Merode $\mathrm{T}$ et al.,1993). Especially the latter observation indicates that in hypertension changes in artery wall properties may occur independent of blood pressure. These discrepancies raise the question as to whether the decreased buffering capacity observed in hypertension is the consequence of the elevated blood pressure as such (Hayoz D et al.,1992; Laurent S et al.1994a; Laurent S et al.,1994b) or that alterations of the arterial wall associated with hypertension contribute to the changes in the viscoelastic properties of the wall, altering the buffering capacity of the artery (O'Rourke M,1990b; Safar M et al.,1997). Another topic of debate is the causal relationship between the observed structural changes and blood pressure elevation. The structural changes may precede the blood pressure elevation or may be an adaptation to the increased blood pressure.

Structural alterations that may influence elastic properties, and thereby the buffering capacity of large arteries, are hypertrophy of the smooth muscle cells and changes in the amount and composition of extracellular matrix proteins.

Hypertension is associated with increased arterial wall thickness most probably caused by an increase in smooth muscle mass (Wolinsky H,1970; Levy BI et al.,1988a). It has been shown that in SHR increased blood pressure acts as a stimulus for aortic medial smooth muscle cell hypertrophy (Owens GK,1987). Smooth muscle hypertrophy in hypertension is widely considered to be an adaptation to increased arterial wall stress to maintain it at a certain level (Levy BI et al.,1994).

The role of an elevation in blood pressure or stress on the arterial structure has been elegantly demonstrated in the study by Leung et al. (Leung DYM et 
al.,1977). Nearly identical in size, weight and composition at birth, the ascending aorta and the pulmonary trunk remained similar in length and diameter, but diverged markedly in wall thickness and mass as differences in intraluminal pressure became manifest. By 2 months, 3 times more elastin and almost twice as much collagen had accumulated in the ascending aorta as compared to the pulmonary trunk. At this time total medial tension, equal for the two vessels at birth, was about 6 times higher in the ascending aorta than in the pulmonary trunk (Leung DYM et al.,1977). The continuing, steady increase of medial tension in the ascending aorta did not appear to influence the relative proportion of its fibrous proteins once the concentrations of $48 \%$ elastin and $11 \%$ of collagen has been established at 2 weeks. Media circumferential stress was defined as media tension normalized for the media thickness.

From morphological and chemical studies on large arteries from hypertensive humans and different rat models of hypertension it is well known that elevated blood pressure is associated with an increase in the synthesis and deposition of collagen. (Folkow B et al.,1973; Iwatsuki K et al.,1977; Ooshima A et al.,1977; Berry CL et al.,1981; Levy BI et al.,1994). Collagen content appears to increase with the severity of hypertension and with the duration of the elevation in blood pressure (Wolinsky H,1972; Fisher GM.,1976). Although elastin synthesis seems to take place only in newborn and young organisms (Forieri $\mathrm{C}$ et al.,1992), in hypertension some smooth muscle cells are able to produce large amounts of elastin (Mecham RP et al.,1991). The increase in collagen, however, can be questioned because in these early studies absolute amounts were considered. If the amounts of collagen and elastin are related to the enlargement of the wall, in hypertension a decrease in the density of collagen and elastin is observed (Wolinsky
H,1970; Wolinsky H,1972; Wolinsky H et al.,1975; Cox RH,1979a; Cox RH,1979b; Cox RH,1981).

A dissociation between arterial pressure reduction and reversal of aortic wall hypertrophy and reduction in collagen content has been reported in hypertensive rats treated with antihypertensive agents (Freslon Jl et al.,1983; Owens GK, 1985; Levy BI et al.,1988a). These studies suggest that functional and structural changes in large arteries could be the result of the activation of different neurohumoral systems independent of blood pressure levels (Owens GK,1978; Geisterfer AAT et al.,1986; Benetos A et al.,1992b).

In summary, the putative reduction in arterial buffering capacity observed in hypertension depends on the localization of the vessel in the vascular system. This reduction may even vary from site to site in an arterial bifurcation for the same blood pressure. Structural alterations observed may be the result of the elevated blood pressure itself or by activation of the neurohormonal system independent of blood pressure. In hypertension, the relationship between structural changes, elastic properties and the buffering capacity of arteries is as yet unknown.

\subsubsection{The relationship between ageing and hypertension}

It has been proposed that hypertension aggrevates the changes in arterial wall mechanical properties as observed with ageing (Lakatta EG,1987; Michel JB et al.,1994). Compliance and distensibility of the elastic arteries are reduced in established hypertension and with ageing (Reneman RS et al.,1986; Cox RH,1989; Safar ME,1990; Michel JB et al.,1994; Sonesson B et al.,1997), but in adult SHR the changes in arterial wall properties with age, as assessed in vivo, were not significantly different from those in age matched WKY (Waeber B et al.,1992). The increase in media thickness with age was found to be more pronounced in adult renal hypertensive rats than in age matched 
normotensive rats, but no differences in the changes of mechanical properties of the aorta with age could be detected between the strains (Sumitani M et al.,1997). Similar observation were made by Zanchi et al. (Zanchi A et al.,1997). Ageing is associated with a progressive increase in systemic arterial pressure which could influence the relationship between ageing and hypertension and their effects on the vascular wall (Safar ME,1990).

In summary, whether hypertension accelerates the reduction of arterial elasticity and deteriorates arterial wall structure, as observed in aged humans and rats, is unknown. The conflicting results as obtained in several studies do not allow to draw straightforward conclusions.

\subsubsection{Pharmacotherapy}

In hypertension, treatment was originally aimed at lowering arterial blood pressure, with the objective to reduce cardiac afterload and lower the risk of cardiovascular complications. Compliance reflects the buffering capacity of the large vessels and is therefore an important determinant of the afterload on the heart. An increased afterload is believed to induce cardiac hypertrophy. In addition, cardiac hypertrophy is better correlated with systolic than with diastolic pressure and the level of systolic pressure is largely influenced by modifications in aortic buffering capacity and elasticity (Tarazi $\mathrm{R}, 1987$ ). Therefore, in addition to blood pressure lowering effects, antihypertensive treatment should also enlarge aortic compliance.

In hypertensive humans and rats, large artery compliance can be increased by antihypertensive drugs such as calciumantagonists (Levenson JA et al.,1983; Levenson J et al.,1985; Bouthier JD et al.,1986b; Safar ME et al.,1989; Van Merode T et al.,1990; Levy BI et al.,1994), ACE-inhibitors (Ooshima A et al.,1977; Levenson J et al.,1985; Bouthier JD et al.,1986b; Dzau VJ et al.,1988a; Simon AC, Asmar RG et al.,1988; Levy BI et al.,1988a; Benetos A et al.,1992b; Levy BI et al.,1993), $\beta$-blocking agents with vasodilating properties and $\beta_{1}$ adrenoceptor antagonists (Maarek BL et al.,1986; Levenson J et al.,1987; Pithois-Merli I et al.,1989; Kelly RP et al.,1989; Van Bortel LMAB et al.,1991; Asmar RG et al.,1991) and nitrates (Simon AC et al.,1982; Bouthier JD et al.,1986b; Glaser et al.,1997). In WKY, chronic treatment with prazosin, an $\alpha_{1}$ adrenoceptor antagonist, improves compliance of the carotid artery (Benetos A et al.,1993a).

Improvement of the buffering capacity of large arteries induced by antihypertensive agents can be the result of the blood pressure reduction itself and/or changes in structural and functional arterial properties. Drug induced effects on vascular smooth muscle cells, induction of counterregulatory mechanisms (sympathetic nervous and reninangiotensin system) or flow dependent endothelial vasodilation may play a role (Safar ME et al.,1993) in the improvement of vascular function induced by antihypertensive drugs. In SHR, acute and chronic administration of ACE-inhibitors in non-antihypertensive doses do not improve compliance of the carotid artery, corroborating the important role of elevated blood pressure (Benetos A et al.,1992a; Benetos A et al.,1992b; Benetos A et al.,1993b). Antihypertensive agents may lower blood pressure by a reduction in pheripheral resistance and early wave reflection (Kelly RP et al.,1989; Kelly RP et al.,1990; Laurent S et al.,1992), and because of the non-linearity of the stress-strain relationship, this results in a improvement of elasticity. Laurent et al. (Laurent et al.,1993; Laurent et al.,1994a), however, described an improvement in compliance of the carotid artery after the administeration of non-antihypertensive doses of ACE-inhibitors without an effect on blood pressure, illustrating the importance of structural and functional properties in determining mechanical 
behavior of large arteries. Despite a marked fall in blood pressure, the nonselective $\beta$-blocker propranolol (Maarek BL et al.,1986), diuretics (Laurent $S$ et al.,1990), vasodilators of the hydralazine group (Bouthier JA et al.,1986a), and the centrally acting $\alpha_{2}$-agonist clonidine (Achimastos $\mathrm{A}$ et al.,1987) do not increase arterial compliance. The latter findings indicate that improvement of buffering capacity by antihypertensive agents is not only the result of a reduced blood pressure.

In several studies it has been shown that structural changes observed in arteries of hypertensive rats can be reversed by the chronic administration of different antihypertensive drugs (Dzau VJ et al.,1988b; Perret F et al.,1991). ACE-inhibitors were found to decrease collagen content and medial smooth muscle cell hypertrophy in SHR and hypertrophy in renovascular hypertensive rats (Ooshima A et al.,1977; Levy BI et al.,1988a; Levy BI et al.,1993;). The calcium entry blocker, isradipine induced a significant increase in compliance and reduction in collagen content and hypertrophy in the aortic media in SHR, in addition to the blood lowering effect (Levy BI et al.,1994).

In summary, in hypertension the buffering capacity and elastic properties of arteries can be improved by the administration of drugs through a blood pressure lowering effect and/or structural alterations. However, not all antihypertensive compounds have the same effect on the buffering capacity, elastic properties and arterial structure, despite a blood pressure lowering effect. Investigating the effects of antihypertensive agents on the buffering and elastic properties of large arteries is not only interesting from a therapeutic point of view, but can also give insight into the regulatory mechanisms responsible for the modulation and adaptation of the buffering capacity, and the role played by the different wall components.

\subsection{SPONTANEOUSLY HYPERTENSIVE RATS}

Genetically hypertensive rat strains have been regarded as models for primary hypertension in humans. Most notably this has been the case for spontaneously hypertensive rats (SHR) developed by Okamoto and co-workers (Okamoto $\mathrm{K}$ et al.,.1963) by selection of Wistar Kyoto rats (WKY) with increased blood pressure. Objections can be raised against the consideration of SHR being suitable models for human essential hypertension. The polygenetic nature of hypertension due to inbreeding and the different time scale of hypertension development in rat strains create limitations regarding the extent to which this animal model can be compared to humans. Nevertheless, the manifold similarities in hemodynamics during the different phases of hypertension development between SHR and both borderline and essential hypertension in humans have been recognized (Trippodo NC et al.,1981).

The exact time point at which a state of elevated blood pressure is established is a subject of controversy. Some authors describe that SHR have already an increased blood pressure at birth (Bruno L et al.,1979; Lee et al.,1986), but others noticed blood pressure elevation few weeks after birth (Lais LT et al.,1977; Gray SD,1984). The discrepancies could be explained by different SHR substrains or by differences in blood pressure measurement techniques (McGiff $\mathrm{JW}$ et al.,1981).

The arterial blood pressure is determined by the stroke volume output of the heart and by the total peripheral resistance (Guyton AC.,1991). In the first weeks after birth, cardiac output enlarges by an increase in heart rate (Smith TL $e t$ al.,1979; Lundin SA et al.,1980; Rickstein SE et al.,1981; Evenwel et al.,1983;). With the 
progression of spontaneous hypertension the increased cardiac output is gradually normalized and by the age of 12-16 weeks it is not different from control WKY (Evenwel RT et al.,1983; Iriuchijima J,1983). At the same time, in most vascular beds vascular resistance increases to levels above those in WKY (Nishiyama K et al.,1976; Evenwel RT et al.,1983; Iriuchijima J,1983).

The development and maintenance of high blood pressure in SHR is associated with an increase in the activity of the sympathetic nervous system. In SHR, an increased arterial nerve density is described (Lee R et al.,1986; Lee RMKW et al.,1991). Under resting conditions, noradrenaline levels were normal in SHR (McCarty R et al.,1978), but increased under stressful conditions as compared to WKY (McCarty R et al.,1978). Arterioles show a hyperresponsiveness to adrenergic stimuli in adult SHR (Bohlen HG,1979; Mulvany MJ et al.,1980a). Chemical or immunological destruction of the sympathetic nervous system abolishes or reduces spontaneuous hypertension in rats, especially when started at an early age (Gutilleta $\mathrm{AF}$ et al.,1980). Direct nerve recordings provide evidence in favor of an increased sympathetic nerve activity in SHR (Schramm LP et al.,1979).

In SHR, left ventricular mass is already significantly increased as compared to WKY in the first 40-50 days of life without an increase in blood pressure (Pfeffer MA et al.,1972; Pfeffer MA et al.,1973; Gray SD,1984). At this age hypertrophy is present along the whole vascular tree, on both the arterial and the venous side including the thoracic aorta (Gray SD,1984). These data suggest that in SHR the early changes in arterial wall properties are not necessarily related to an increase in blood pressure. In other studies, however, left ventricular hypertrophy was found to follow the increase in blood pressure (Harrap SB et al.,1993) or arterial wall hypertrophy was found to occur concomitantly with the rise in blood pressure (Olivetti G et al.,1982).

The mechanism responsible for the increase in media mass in SHR is as yet unknown. A possible cause of the increase in media thickness could be the enhanced activity of the sympathetic nervous system, which is known to be present before the onset of blood pressure elevation (Judy WV et al.,1976). Moreover, in SHR sympathetic innervation density of the vasculature is increased (Head RJ,1986), while the response to norepinephrine is enhanced already during the prehypertensive phase (Mulvany MJ et al.,1980a; Mulvany MJ et al.,1980b; Smeda JS et al.,1988; Kong JQ et al.,1991; Rizzoni D et al.,1994). This overall increase in activation of and sensitivity to the sympathetic nervous system could induce hypertrophy of smooth muscle cells by its growth promoting effect (Simpson P et al.,1982; Bevan $D$ et al.,1984). A possible role for the reninangiotensin system can not be excluded because several studies on neonatal SHR have reported increased renin-angiotensinaldosterone activity (Sen S et al.,1972; Sinaiko A et al.,1974; Mullins MM et al.,1982). It has been described that angiotensin converting enzyme (Saavedra JM et al.,1992) and the mRNA of angiotensinogen (Lodwick D et al.,1995) are increased in the aorta's of prehypertensive SHR as compared to WKY. Angiotensin II has a growth inducing activity on vascular smooth muscle cells in cell cultures (CampbellBosswell M et al.,1981; Geisterfer AA et al.,1988) and on large and small arteries even at subpressor doses (Daemen MJAP et al.,1991; Griffin SA et al.,1991). Inhibition of this system, by means of ACE-inhibitors, is associated with a reduction in medial thickness (Wang DH et al.,1990; Schelling P et al.,1991).

In summary, SHR are characterized by hemodynamic properties which resemble those encountered in humans with essential hypertension. Several early studies imply that the activity of 
sympathetic nervous and reninangiotensin system is increased and that hypertrophy of the vascular system is present before an elevation in blood pressure can be detected. The sympathetic nervous and renin-angiotensin system can induce aortic wall hypertrophy and influence aortic wall structural and mechanical properties as discussed in section 1.3.2.. Prehypertensive SHR allow to investigate the putative role of the sympathetic nervous and renin-angiotensin system, and the dependency on blood pressure elevation, in the determination of aortic wall structural and mechanical properties. 


\subsection{Aims Of THE STUdY}

Cardiac hypertrophy is better correlated with systolic than with diastolic pressure (Tarazi R et al.,1982; Safar ME et al.,1987a). The load on the heart during systole is mainly determined by the buffering capacity or compliance of the aorta and therefore an increase in aortic stiffness may have important consequences for the heart (Safar ME et al.,1987a).

The buffering capacity is defined by the diastolic diameter and the elastic properties of the aortic wall. The diameter is determined by the activity of the smooth muscle cells and the operating blood pressure. Controversy exists on the exact way in which pulsatile elastic behavior of the arterial wall is determined. Factors that are believed to influence the elastic properties are the arterial wall components, diameter, wall thickness, and the operating blood pressure. In previous studies opposite conclusions were drawn regarding the effect of vascular tonus or smooth muscle activity on the elastic properties of large arteries. The relationship between collagen and elastin and elastic properties of large arteries has been approached in several descriptive studies, but the exact role of these scleroproteins in arterial elastic behavior of arteries is not clear. The relative and absolute amounts of collagen and elastin and their isoforms as well as the degree of cross-linking can be important determinants of the elastic characteristics of blood vessels. Conflicting results were obtained concerning the influence of an increased wall thickness on elastic properties (Brouwers-Ceiler BL et al.,1997). It has been proposed that an increase in wall thickness decreases, increases or does not affect mechanical properties.

Another problem encountered is that the structural organization of large arteries displays remarkable alterations with ageing and in hypertension, because of continuous rearrangements of cells and extracellular matrix components. It remains to be established, however, whether these alterations are related to the deterioration of the buffering capacity due to changes in elastic properties observed in certain large arteries with ageing and in hypertension. In addition, it is as yet unclear whether structural alterations observed in hypertension are a direct consequence of elevated blood pressure or result from the (neurohormonal) mechanisms that are responsible for the development of the chronic state of high blood pressure. It has been proposed that hypertension accelerates the ageing of the arterial mechanical properties. The accelerating role of hypertension, however, can be questioned because conflicting results have been reported.

Buffering capacity and elastic properties of arteries can be impoved by the administration of drugs either by a blood pressure lowering effect and/or a direct effect on the vessel wall. It is of interest to note that not all antihypertensive compounds have the same effect on buffering capacity, elastic properties and structure of arteries, despite a blood pressure lowering effect. Investigating the effects of antihypertensive agents on the buffering and elastic properties of large arteries is not only interesting from a therapeutic point of view, but may give insight into the regulatory mechanisms responsible for the modulation and adaptation of the buffering capacity, and the role played by the different wall components.

SHR are characterized by hemodynamic properties which resemble those encountered in human essential hypertension. Several early studies imply that the activities of the sympathetic nervous and renin-angiotensin system are increased and that hypertrophy of the vascular system is present before an elevation in blood pressure can be detected, but in other studies the opposite 
was found. The sympathetic nervous and renin-angiotensin system can induce aortic wall hypertrophy and influence structure and mechanical properties of the aortic wall. Young, prehypertensive SHR allow to investigate the putative role of the sympathetic nervous and renin-angiotensin system and the dependency on blood pressure elevation of structure and mechanical properties of the aortic wall. In this light, the aims of the present study were to:

Aim 1: to investigate effects of smooth muscle tone on the mechanical properties of the thoracic aorta in conscious normotensive and hypertensive rats. Smooth muscle activity was altered by modulation of $\alpha_{1}$-adrenergic and angiotensin II receptor activity.

Aim 2: to study the relationship between aortic media structure and mechanical properties in hypertension and ageing. The structural part of the study focused on media thickness and cross-sectional area, and on collagen and elastin content and density. The functional part focused on compliance and distensibility of the thoracic aorta, and its incremental elastic or Young's modulus.

Aim 3: to investigate the aggravating effect of hypertension, if any, on the changes in mechanical properties observed with ageing.

Aim 4: to study the effects of long term antihypertensive therapy on the aortic mechanical properties in hypertensive rats during the development of high blood pressure. This approach allows the investigation of the influence of aortic blood pressure and the activity of neurohormonal systems on mechanical and structural properties.

Aim 5: to examine the influence of the enhanced expression of renin on the structural and mechanical properties of the thoracic aorta.

In the past, many investigations of mechanical properties of large arteries have been performed on isolated arterial strips or rings. These approaches, however, do not respect the in vivo anatomy, the vascularization and innervation of the arteries and, therefore, may not reflect mechanical arterial properties in vivo. Different groups used an in situ method to determine static compliance (Benetos A et al,1992a; Levy et al.,1988a). Because of the oscillating blood pressure changes and the visco-elastic properties of the arterial wall material a difference between static and dynamic mechanical properties has to be considered (Burton et al ; Glaser et al.,1997). The present study was performed on the thoracic aorta of WKY and SHR and the mechanical properties of this vessel were determined by means of a noninvasive ultrasound system, as developed in our own institute, and invasively assessing aortic blood pressure. Therefore this thesis consists of the following chapters:

- A description and evaluation of the reliability and reproducibility of the method used to assess dynamic aortic mechanical properties in rats in vivo are discussed in Chapter 2. 
- The influence of vascular tone on mechanical properties is described in Chapter 3.

- The effects of ageing and hypertension on mechanical properties is described in the Chapters 4 and 5 .

- The aggrevating effects of hypertension on the effects of ageing on aortic wall structure and functional properties is described in chapter 6.

- The effect of anthypertensive agents are presented in Chapter 7 .

- The influence of an enhanced expression of renin-2 on mechanical properties is described in Chapter 8.

- The thesis starts with a survey of the literature (chapter 1 ) and ends with a general discussion of the experimental findings (chapter 9). 


\section{REFERENCES}

Achimastos A, Girerd X, Simon AC, PithoisMerli I, Levenson J. The efficacy of transdermal formulation of clonidine in mild to moderate hypertension and its effects on the arterial and venous vasculature of the forearm. Eur. J. Pharmacol. 33:111-114, 1987

Alberts B. Molecular biology of the cell. Third edition. Garland Publishing, Inc. New York \& London, 1994

Albino-Teixeria A, Azevedo I, Branco D, Osswald W. Purine agonists prevent trophic changes caused by sympathetic denervation. Eur. J. Pharmacol. 179:141149,1990

Armentano RL, Barra JG, Levenson J, Simon A, Pichel RH. Arterial wall mechanics in conscious dogs:assessment of viscous, inertial, and elastic moduli to characterize aortic wall behavior. Circ. Res. 76:468478,1995

Asmar RG, Pannier B, Santoni JP, Laurent S, London GM, Levy BI, Safar ME. Reversion of cardiac hypertrophy and reduced arterial compliance after converting enzyme inhibition in essential hypertension. Circulation 78:941-950, 1988

Asmar RG, Kerihuel JC, Girerd XJ, Safar ME. Effects of bisoprolol on blood pressure and arterial hemodynamics in systemic hypertension. Am. J. Cardiol. 86:61-64, 1991

Bader H. Dependencee of wall stress in the human thoracic aorta on age and pressure. Circ. Res. 20:354-361, 1967

Banick N, Sparks HV. Contractile responses of vascular smooth muscle of renal hypertensive rats. Am. J. Physiol. 219:340, 1970

Bank AJ, Wilson RF, Kubo SH, Holte JE, Dresling TJ, Wang $\mathrm{H}$. Direct effects of smooth muscle relaxation and contraction on in vivo human brachial artery elastic properties. Circ. Res. 77:1008-1016, 1995

Barra JG, Armentano RL, Levenson J, Cabrera, Fischer EI, Pichel RH, Simon A. Assessment of smooth muscle contribution to descending thoracic aortic elastic mechanics in conscious dogs. Circ. Res. 73:1040-1050, !993

Bauer RD, Busse R, Schabert A. Mechanical properties of arteries. Biorheology 19:409-424, 1982

Benetos A, Bouaziz H, Albaladejo P, Levy BI, Safar ME. Physiological and pharmacological changes in the carotid artery pressure-volume curve in situ in rats. J. Hypertens. 10(Suppl 6):S127S131, 1992a

Benetos A, Levy BI, Safar M. Effects of converting enzyme inhibition on carotid artery compliance in spontaneously hypertensive rats. J. Cardiovasc. Pharmacol. 20 (Suppl B):S22-S27, 1992b

Benetos A, Huguet F, Albaladejo P, Brisac AM, Pappo M, Safar ME, Levy BI. Role of adrenergic tone in mechanical and functional properties of carotid artery during ageing. Am. J. Physiol. 265:H1132-H1138, 1993a

Benetos A,Pannier B, Brahimi M, Safar ME, Levy BI. Dose-related changes in the mechanical properties of the carotid artery WKY rats and SHR following relaxation of arterial smooth muscle. $J$. Vasc. Res. 30:23-29, 1993b

Bergel DL. The static elastic properties of the arterial wall. J. Physiol. 156:445-457, 1961

Berry CL, Greenwald SE, Rivett JF. Static mechanical properties of the developing and mature rat aorta Cardiovasc. Res. 9:669-678, 1975

Berry CL and Greenwald SE. Effects of hypertension of the static mechanical properties and chemical compostion of the rat aorta. Cardiovasc. Res. 10:437, 1976

Berry CL, Greenwald SE, Menahem N. Effects of beta-aninoproprienonitrile on the static elastic properties and blood pressure of spontaneously hypertensive rats. Cardiovasc. Res. 15:373-381, 1981

Bevan JA, Joyce EHN, Wellman GC. Flow dependent dilation in a resistance artery still occurs after endothelium removal. Circ. Res. 63:980-985, 1988

Bevan JC, Joyce EH. Flow-induced resistance artery tone balance between constrictor 
and dilator mechanisms. Am. J. Physiol. 258:H663-H668, 1990

Bevan RD. Effects of sympathetic denervation on smooth muscle cell proliferation in the growing rabbit ear artery. Circ. Res. 37:14-19 1975

Bevan D. Trophic effects of peripheral adrenergic nerves on vascular structure. Hypertension 6 (suppl III):III19-III26, 1984

Bevan RD, Tsuru H. Functional and structural changes in the rabbit ear artery after sympathetic denervation. Circ. Res. 49: 478-485, 1985

Birk DE and FH Silver Collagen fibrillogenesis in vitro: comparison of types I, II and III. Arch. Biochem. Biophys. 235:178-185, 1984

Bohlen HG. Arteriolar closure mediated by hyperresponsiveness to norepinephrine in hypertensive rats. Am. J. Physiol. 236: H157-H164, 1979

Bolton TB. Mechanisms of action of transmitters and other substances on smooth muscle. Physiol Rev. 59:606-718, 1979

Boonen H.C.M., M.J.A.P. Daemen, P.E. Eerdmans, G.E. Fazzi, E. Van Kleef, P.M.H. Schiffers, J.G.R. De Mey. Mesenteric small artery changes following vasoconstrictor infusion in young rats. J. Cardiovasc. Pharmacol. 22:388-395, 1993

Bouthier JA, Safar ME, Curien ND, London GM, Levenson JA, Simon AC. Effect of cadralazine on brachial artery hemodynamics and forearm venous tone in essential hypertension. Clin. Pharmacol. Ther. 39:82-88, 1986a

Bouthier JD, Safar ME, Benetos A, Simon AC, Levenson JA, Hugues CM. Haemodynamic effects of vasodilating drugs on the common carotid and brachial circulations of patients with essential hypertension. Br. J. Clin. Pharmac. 21:137-142, 1986b

Bramwell JC, Hill AV. The velocity of the pulse wave in man. Proc. Royal Soc. London 93B: 298-306, 1992

Brouwers-Ceiler BL, Nelissen-Vrancken HJMG, Smits JFM, De Mey JGR. The influence of angiotensin II-induced increase in aortic wall mass on compliance in rats in vivo. Cardiovasc. Res. 33:478-484, 1997

Brownlee M, Cerami A, Vlassara H. Advanced glycosylation end products in tissue and the biochemical basis of diabetic complications. $N$. Eng. J. Med. 318:13151321. 1988

Brozovich FV, Yamakawa M. Agonist activation modulates cross-bridge states in single vascular smooth muscle cells. Am J. Physiol. 264:C103-C108, 1993

Bruno L, Azar S, Wellr D. Absence of a prehypertensive stage in post-natal Kyoto hypertensive rats. Jap. Heart J. 20 (Suppl 1): 90,1979

Buga GM, Gold ME, Fukuto JM, Ignarro LJ. Shear stress-induced release of nitric oxide from endothelial cells grown on beads. Hypertension 17:187-193, 1991

Burnstock G, Griffith SG, Sneddon P. Autonomic nerves in the precapillary vessel wall. J. Cardiovasc. Pharmacol. 6 (Suppl.2): S344-S353, 1984

Burton AC, Stinson RH. The measurement of tension in vascular smooth muscle. $J$. Physiol. 153:290-305, 1960

Busby DE, Burton AC. The effect of age on the elasticity of the major brain arteries. Can J. Biochem. Physiol. 43:185-202, 1965

Campbell-Bosswell M., Robertson A.L.. Effects of angiotensin II and vasopressin on human smooth muscle cells in vitro. Exp. Mol. Pathol. 35:265-276, 1981.

Cooke JP, Rossitch E, Andon NA, Loscalzo J, Dzau VJ. Flow activates an endothelium potassium channel to release an endogenous nitrovasodilator. J. Clin. Invest. 88:1663-1671, 1991

Cox RH, Hones AW, Gischer GM. Carotid artery mechanics, connective tissue, and electrolyte changes in puppies. Am. J. Physiol. 227:563, 1974

Cox RH, Jones AW, Swain ML. Mechanics and electrolyte composition of arteries smooth muscle in developing dogs. Am. J. Physiol.231:77-83, 1976a

Cox RH. Effects of norepinephrine on mechanics of arteries in vitro. Am. J. Physiol. 231:420-425, 1976b

Cox RH. Effects of age on the mechanical poperties of rat carotid artery. Am. J. Physiol. 233:H256-H263, 1977a 
Cox RH. Carotid artery mechanics and composition in renal and DOCA hypertension in the rat.

Cardiovasc. Med. 2:761-766, 1977b

Cox RH. Comparison of carotid artery mechanics in the rat, rabbit, and dog. $\mathrm{Am}$. J. Physiol. 234:H280-H288, 1978

Cox RH. Comparison of arterial wall mechanics in normotensive and spontaneously hypertensive rats. Am. J. Physiol. 237:H159-H167, 1979a

Cox RH. Alterations in active and passive mechanics of rat carotid artery with experimental hypertension. Am. J. Physiol. 237:H597-H605, 1979b

Cox RH. Basis for the altered arterial wall mechanics in the spontaneously hypertensive rat. Hypertension 3:485-495, 1981

Cox RH, Bashy R, Jimenez S. Effects of chronic beta-aminoproprionitrile treatment on rat carotid artery. Blood Vessels 25:53-62, 1988

Cox R.H., Mechanical properties of arteries in hypertension. In: Blood vessel changes in hypertension: structure and function. Volume 1, chapter 4. CRC Press Inc., Boca raton, Florida, 65-95, 1989

Daemen MJAP, Lombardi DM, Bosman FT, Schwartz SM. Angiotensin II induces smooth muscle cell proliferation in the normal and injured rat arterial wall. Circ. Res. 68:450-456, 1991.

Daemen MJAP, De Mey JGR. Regional heterogeneity of arterial structural changes. Hypertension 25:464-473, 1995

Davies PF. Flow-mediated endothelial mechanotransduction Physiol. Rev. 75:519-560, 1995

Delacretaz E, Hayoz D, Osterfeld MC, Genton CY, Brunner HR, Waeber B. Long-term Nitric Oxide synthase inhibition and distensibility of carotid artery in intact rats. Hypertension 23:967-970, 1994

Delacretaz E, Zanchỉ A, Nussberger J, Hayoz D, Aubert JF, Brunner HR, Waeber B. Chronic nitric oxide synthase inhibition and carotid artery distensibility in renal hypertensive rats. Hypertension 26:332336, 1995

De Mey JGR, Vanhoutte PM. Heterogeneous behavior of the canine arterial and venous wall. Importance of the endothelium. Circ. Res. 51:439-447, 1982

Dimitriadou V, Aubineau P, Taxi J, Seylaz J. Ultrastructural changes in the cerebral artery wall induced by long-term sympathetic denervation. Blood vessels 25:122-143, 1988

Dobrin PB, Rovick AA. Influence of vascular smooth muscle on contractile mechanics and elasticity of arteries. Am. J. Physiol. 217:1644-1652, 1969

Dobrin PB. Mechanical properties of arteries. Physiol. Rev. 58:397-498, 1978

Dobrin Vascular mechanics. In: Shepherd JT, Abboud FM, eds. Handbook of physiology, Section 2: The Cardiovascular System, Volume III: Peripheral Circulation and Organ Blood Flow. Baltimore, Md.: American Physiology Society; pp65-102, 1980

Dzau VJ. Implications of local angiotensin producton in cardiovascular physiology and pharmacology. Am. J. Cardiol. 59:59A-65A, 1987a

Dzau VJ, Gibbons GH. Autocrine-paracrine mechanisms of vascular myocytes in hypertension. Am. J. Cardiol. 60:991-997, 1987b

Dzau VJ, Safar ME. Large arteries in hypertension: role of the vascular reninangiotensin system. Circulation 77:947954, 1988a

Dzau VJ, Gibbons GH. Cell biology of vascular hypertrophy in systemic hypertension. Am. J. Cardiol. 62:30G35G, 1988b

Evenwel RT, Kasbergen CM, Struijker Boudier HAJ. Central and regional hemodynamics and plasma volume distribution during the development of spontaneous hypertension in rats. Clin. Exp. Hyper. Theor. Pract. A5:1511-1536, 1983

Fananapazir L, Tracy CM, Leon MB, Winkler JB, Cannon III RO, Bonow RO, Maron BJ, Epstain SE. Electrophysiologic abnormalities in patients with hypertrophic cardiomyopathy. Circulation 80:1259-1268, 1989

Fernandez PG, Snedden W, Idikio $\mathrm{H}$, Fernandez D, Kim BK, Triggle CR. The reversal of left ventricular hypertrophy with control of blood pressure in 
experimental hypertension. Scand. $U$. Clin. Lab. Invest. 44:711-716, 1984

Fisher GM, Llaurado JG. Collagen and elastin content in canine arteries selected from functionally different vascular beds. Circ. Res. 19:394-399, 1966

Fisher GM. Effects of spontaneous hypertension and age on arterial connective tissue in the rat. Exp. Gerontol. 11:209, 1976

Fitchett DH. Forearm arterial compliance: a new measure of arterial compliance? Cardiovasc. Res. 18:651-656, 1984

Fleg JL. Alterations in cardiovascular structure and function with advancing age. Am. J. Cardiol. 57:33C-44C, 1986

Folkow B, Hallback M, Lundrun Y, Sivertson $\mathrm{R}$, Weiss $\mathrm{L}$. Importance of adaptive changes in vascular design for establishment of primary hypertension, studied in man and in spontaneously hypertensive rats. Circ. Res. 32-33 (Suppl I): $2-16,1973$

Forieri C, Quaglino D, Mori G. Role of the extracellular matrix in age-related modification of the rat aorta: Ultrastructural, morphometric and enzymatic evaluations. Arterioscler. Thromb. 12:1008-1016, 1992

Frangos JA, Eskin SG, McIntyre LV, Ives CL. Flow effects on prostacyclin production by cultured human endothelial cells. Science 227:1477-1479, 1985

Freslon Jl, Guidicelli JF. Compared myocardial and vascular effects of captopril and dihydralazine during hypertension development in spontaneously hypertensive rats. $\mathrm{Br} . \mathrm{J}$. Pharmacol. 80:533-543, 1983

Froneck K, Bloor CM, Amiel C, Chvapil M. Effects of long term sympathectomy on the arterial wall in rabbits and rats. Exp. Mol. Pathol. 28:279-289, 1978

Froneck K. Trophic effects of the sympathetic nervous system on vascular smooth muscle. Ann. Biomed. Eng. 11:607-615, 1983

Furchgott RF, Zawadzki JV. The obligatory role of endothelial cell in the relaxation of arterial smooth muscle by acetylcholine. Nature 288:373-376, 1980

Geisterfer AAT, Owens GK. Hyperthophic response of cultured vascular smooth muscle cells to angiotensin II (abstract). Fed. Proc. 45:584, 1986

Geisterfer AA, Peach MJ, Owens GK. Angiotensin II induces hypertrophy, but not hyperplasia, of cultured rat aortic smooth muscle cells. Circ. Res. 62:749756,1988

Glaser E, Lacolley P, Boutouyrie P, Sacunha R, Lucet B, Safar ME, Laurent S. Dynamic versus static compliance of the carotic artery in living Wistar Kyoto rats. J. Vasc. Res. 32:254-265, 1995

Gourgon R, Cohen-Solal A. Arterial system, ventricular structure and function. Kluwer Academic Publishers. Chapter 10 ed. ME Safar and MF O'Rourke pp155-179, 1994

Gray S.D. Spontaneous hypertension in the neonatal rat. A review. Clin. exp. Hyper.A6:755-781, 1984

Greenwald SE, Berry CL. Static mechanical properties and chemical composition of the aorta of spontaneously hypertensive rats: a comparison with the effects of induced hypertension. Cardiovasc. Res. 12:364-372, 1978

Gribbin B, Pickering TG, Sleight P. Arterial distensibility in normal and hypertensive man. Clin. Sci. 56:413-417, 1979

Griffin S.A., W.B.C. Brown, F. MacPherson, J.C. McGrath, V.G. Wilson, N. Korsgaard, M.J. Mulvany, A.F. Lever. Angiotensin II causes vascular hypertrophy in part by a non-pressor mechanism. Hypertension 17:626-635, 1991

Guyton AC. Text book of medical physiology. $8^{\text {th }}$ ed. WB Saunders company, Harcourt Brace Jovanovich, Inc. Philidelphia. unit IV, pp 149-167, 1991

Handler CE, Child A, Light ND, Dorrance DE. Mitral valve prolapse, aortic compliance, and skin collagen in joint hypermobility syndrome. Br. Heart J. 54:501-508, 1985

Hansen F, Mangell P, Sonesson B, Lann T. Diameter and compliance in the human common carotid artery - variations with age and sex. Ultrasound Med. Biol. 21:19, 1995

Hansen TR, Abrams GD, Bohr DF. Role of pressure in structural and functional changes in arteries of hypertensive rats. Circ. Res. 34 \& 35 (suppl I): 101, 1974 
Harrap SB, Mitchell GA, Casley DJ, Mirakian C, Doyle AE. Angiotensin II, sodium, and cardiovascular hypertrophy in spontaneously hypertensive rats. Hypertension 21:50-55, 1993

Hayoz D, Rutschmann B, Perret F, Niederberger M, Tardy $\mathrm{Y}$, Mooser V, Nussberger B, Brunner HR. Conduit artery compliance and distensibility are not necessarily reduced in hypertension. Hypertension 20:1-6, 1992

Hayoz D, Rutschmann B, Genton CY, Niederberger M, Brunner HR, Waeber B. Elastic behavior of the carotid artery in intact spontaneously hypertensive rats. Eur. Heart J. 14(Suppl C):10-13, 1993

Head R.J. Hypernoradrenergic innervation: its relationship to functional and hyperplastic changes in the vasculature of spontaneously hypertensive rat. Blood vessels 26:1-20, 1986

Hoeks APG, Samijo SK, Brands P, Reneman RS. Noninvasive determination of shearrate distribution across the arterial lumen. Hypertension 26:26-33, 1995

Huijberts MSP, Wolffenbuttel BHR, Struijker Boudier HAJ, Crijns FRL, Nieuwenhuijzen Kruseman, Poitevin P, Levy BI. Aminoguanidine treatment increaes elasticity and decreases fluid filtration of large arteries from diabetic rats. J. Clin. Invest. 92:1407-1411, 1993

Iriuchijima J. Regional blood flow in conscious spontaneously hypertensive rats. Jpn. J. Physiol. 33:41-50, 1983

Ito $\mathrm{H}$, Vascular connective tissue changes in hypertension. In: Blood vessel changes in hypertension: structure and function. Volume 1, chapter 5. CRC Press Inc., Boca raton, Florida, pp99-122, 1989

Iwatsuki K, Cardinale GJ, Spector S, Udenfriend S. Reduction of blood pressure and vascular collagen in hypertensive rats by betaaminoproprionirtile. Proc. Natl. Acad. Sci. USA 74:360-362, 1977

Judy W.V., Q.M. Watanabe, D.B. Henry, H.R. Besch, W.R. Murphy, G.M. Hockel. Sympathetic nerve activity: role of blood pressure in the spontaneously hypertensive rat. Circ. Res. 38(Suppl. II):21-29, 1976
Kalath S, Tsipouras P, Silver F. Increased aortic root stiffness associated with osteogenesis imperfecta. Ann. Biomed. Eng. 15:91-99, 1987

Kamiya A, Togawa T. Adaptive regulaion of wall shear stress to flow change in the canine carotid artery. Am. J. Physiol. 239:H14-H21, 1980

Kato H, Suzuki H, Taiima S, Ogata Y, Tominaga T, Sato A, Saruta T. Angiotensin II stimulates collagen synthesis in cultured vascular smooth muscle cells. J. Hypertens. 9:17-22, 1991

Kawasaki H, Cline WH Jr., Su C. Involvement of the vascular renin-angiotensin system in beta adrenergic receptor mediated facilitation of vascular neurotransmission in spontaneously hypertensive rats. $J$. Pharmacol. Exp. Ther. 231:23-30, 1984

Kawasaki T, Sasayama S Yagi S, Asakawa T, Hiria T. Non-invasive assessment of the age related changes in stiffness of major branches of the human arteries. Cardiovasc. Res. 21:678-687, 1987

Keeley FW, Elmoselhi A, Leenen FHH. Enalapril suppresses normal accumulation of elastin and collagen in cardiovascular tissues of growing rats. Am. J. Physiol. 26:H1013-H1021, 1992

Kelly RP, Daley JE, Avolio AP, O'Rourke MF. Arterial dilation and reduced wave reflection : Benefit of dilevalol over atenolol in essential hypertension. Hypertension 14:14-21, 1989

Kelly RP, Gibbs HH, O'Rourke MF, Daley JE, Mang K, Morgan JJ, Avolio AP. Nitroglycerine has more favourable effects on left ventricular afterload than from measurement of pressure in a peripheral artery. Eur. Heart J. 11:138144,1990

Kohn RR. Heart and cardiovascular system. In: Finch CE, Hyflick L (eds.). Handbook of biology and aging. New York: Van Nostrand Reinhold 281-317, 1977

Koller A, Kaley G,. Prostaglandins mediates arteriolar dilation to increased blood flow velocity in skeletal muscle microcirculation. Circ. Res. 67:529-534, 1990

Kong JQ, Taylor DA, Fleming WW. Mesenteric vascular responses of young 
spontaneously hypertensive rats. $J$. Pharmacol. Exp. Ther. 258:13-17, 1991

Lacolley P, Glaser E, Challande P, Boutouyrie P, Mignot JP, Duriez M, Levy BI, Safar ME, Laurent S. Structural changes and in situ aortic pressure-diameter relationship in long-term chemical-sympathectomized rats. Am. J. Physiol. 269:H407-H416, 1995

Lais LT, Rios LL, Boutelle S, Dibona GF, Brody MJ. Arterial pressure development in neonatal and young spontaneously hypertensive rats. Blood vessels 14:277284, 1977.

Lakatta EG. Do hypertension and aging have similar effect on the myocardium? Circulation. 75 (suppl.I):I69-I77, 1987

Langille BL, O'Donnel F. Reductions in arterial diameter produced by chronic decreases in blood flow are endotheliumdependent. Science 231:405-407, 1986

Laurent S, Lacolley PM, Cuche JL, Safar ME. Influence of diuretics on brachial artery diameter and distensibility in hypertensive patients. Fundam. Clin. Pharmacol. 4:685-693, 1990

Laurent S, Arcaro G, Benetos A, Lafleche A, Hoeks A, Safar M Mechanism of nitrateinduced improvement on arterial compliance depends on vascular territory. J. Cardiovasc. Pharmacol. 19:641-649, 1992

Laurent S. Arterial system in hypertension. Kluwer Academic Publishers. Chapter 1 ed ME Safar and MF O'Rourke pp 5-26, 1993

Laurent S, Caviezel B, Beck L, Girerd X, Billaud E, Boutouyrie P, Hoeks A, Safar M. Carotid artery distensibility and distending pressure in hypertensive humans. Hypertension 23:878-883, 1994a

Laurent S, Girerd X, Mourad JJ, Lacolley P, Beck L, Boutouyrie P, Mignot JP, Safar ME. Elastic modulus of the radial artery wall material is not increased in patients with essential hypertension. Arterioscler. Thromb. 14:1223-1231, 1994b

Learoyd BM, Taylor MG. Alterations with age in the viscoelastic properties of human arterial walls. Circ. Res. 18:278-292, 1966

Lee RMKW, Coughlin MD, Cheung DWT. Relationship between sympathetic innervation, vascular changes and hypertension in spontaneously hypertensive rats. $J$ Hypertension 4(suppl):81-83, 1986

Lee RMKW, Borokowski KR, Leenen FHH, Tsoporis J, Coughlin M. Combined effect of neonatal sympathectomy and adrenal demedullation on blood pressure and vascular changes in spontaneously hypertensive rats. Circ. Res. 69:714-721, 1991

Lehmann ED, Hopkins KD, Gosling RG. Aortic compliance measurements using Doppler ultrasound: in vivo biochemical correlates. Ultrasound Med. Biol. 19:683710, 1993

Leung DYM, Glagov S, Mathews MB. Cyclic stretching stimulates synthesis of matrix components by arterial smooth muscle cells in vitro. Science 191:475-477, 1976

Leung DYM, Glagov S, Mathews MB. Elastin and collagen accumulation in rabbit ascending aorta and pulmonary trunk during postnatal growth. Circ. Res. 41:316-323, 1977

Levenson JA, Safar ME, Simon AX, Boutier JA, Griener L. Systemic and arterial hemodynamics effects of nifedipine (20 $\mathrm{mg}$ ) in mild-to-moderate hypertension. Hypertension 5 (Suppl V):V57-V60, 1983

Levenson J, Simon AX, Bouthier J, Maasek BC, Safar ME. The effect of acute and chronic nicardipine therapy on forearm arterial haemodynamics in essential hypertension. Br. J. Clin. Pharmac. 20:107S-113S, 1985

Levenson J, Te Quang Sang KH, Devynck MA, Gitel R, Simon A. The role of antihypertensive drugs in counteracting adverse influence on large arteries. Am. Heart J. 114(Suppl. 4): 992-997, 1987

Levy BI, Benessiano, Poitevin P, Lukin L, Safar ME. Systemic arterial compliance in normotensive and hypertensive rats. $J$. Cardiovasc. Pharmacol. 7:S28-S32, 1985

Levy BI, Michel JB, Salzmann JL, Poitevin P, Safar ME, Camilleri JP. Effects of chronic inhibition of converting enzyme on mechanical and structural properties of arteries in rat renovascular hypertension. Circ. Res. 63:227-239, 1988a

Levy BI, Babalis D, Lacolly P, Poitevin, Safar ME. Cardiac hypertrophy and 
characteristic impedance in spontaneaously hypertensive rats. $J$. Hypertens. 6 (suppl N):5110-5111, 1988b Levy BI, Benessiano J, Poitevin PP, Safar ME.

Endothelium-dependent mechanical properties of the carotid artery in WistarKyoto and Spontaneously hypertensive rats. J. Hypertens. 7:S116-S119, 1989

Levy BI, Benessiano J, Poitevin P, Safar M. Endothelium-dependent mechanical properties of carotid artery in WKY and SHR. Role of angiotensin converting enzyme inhibition. Circ. Res. 66:321-328, 1990

Levy BI, Michel JB, Salzmann JL, Poitevin P, Devissaguet M, Scalbert E, Safar ME. Long-term effects of angiotensinconverting enzyme inhibition on the arterial wall of adult spontaneously hypertensive rats. Am. J. Cardiol. 71:8E16E, 1993

Levy BI, Duriez M, Phillipe M, Poitevin P, Michel JB. Effects of chronic dihydropyridine (isradipine) on the large arterial wall of spontaneously hypertensive rats. Circulation 90:30243033, 1994

L'Italien GJ, Chandrasekar NR, Lamuraglia GM, Pevec WC, Dhara S, Warnock DF, Abbott WM. Biaxial elastic properties of rat arteris in vivo: influence of vascular wall cells on anisotrophy. Am. J. Physiol. 267:H574-H579, 1994

Lodwick D, Kaiser MA, Harris J, Cumin F, Vincent M, Samani NJ. Analysis of the role of angiotensinogen in spontaneously hypertensive rats. Hypertension 25:12451251,1995

Lundin SA, Halback-Nordlander M. Background of hyperkinetic circulatory state in young spontaneously hypertensive rats. Cardiovasc. Res. 14:561-567, 1980

Maarek BL, Bouthier JA; Simon AC, Levenson JA, Safar ME. Comparative effects of propranolol and pindolol on small and large arteries and veins of the forearm circulation in hypertensive man. J. Cardiovasc. Pharmacol. 8(Suppl. 4):S61-S66, 1986

Masaki H, Imaizumi T, Ando S, Hirooka Y, Harada S, Momohara M, Nagano M, Takeshita A. Production of chronic congestive heart failure by rapid ventricular pacing in the rabbit. Cardiovasc. Res. 27:828-831, 1993

McCarty R, Kopin IJ. Alterations in plasma catecholamines and behavior during acute stress in spontaneously hypertensive and Wistar Kyoto normotensive rats. Life Sci. 22:997-1005, 1978

McGiff JW, Quilley PC. The rat with spontaneous genetic hypertension is not a suitable model of human essential hypertension. Circ. Res. 48:455-464, 1981

Mecham RP, Stenmark KR, Parks WC. Connective tissue production by vascular smooth musle in development and disease. Chest 99:S43-S47, 1991

Megerman J, Hasson JE, Warnock DF, L'Italien GJ, Abbott W. Noninvasive measurements of nonlinear arterial elasticity. Am. J. Physiol. 250 (Heart Circ. Physiol. 19):H181-H188, 1986

Meiss RA. Dynamic stiffness of rabbit mesotubarium smooth muscle: effect of isometric length. Am.J. Physiol. 234: C14-C26, 1978,

Meiss RA. Potentiation of smooth muscle contractillity after rapid changes in icotonic force. Am. J. Physiol. 271:C511C523, 1996

Merillon JP, Neukirch F, Motte G, Aumont MC, Curien ND, Prasquier R, Gourgon R. The left ventricular end-systolic pressure volume tario: studies during changes in load and inotropism in the human. Eur. Heart J. 2:41-48, 1981

Merillon JP, Fontenier GJ, Lerallut JF,Jaffrin MY, Motte GA, Genain CP, Gourgon RR. Aortic input impedance in normal man and arterial hyperttension: its modification during changes in aortic pressure. Cardiovasc Res. 16:646-656, 1982a

Merillon J.P., Motte G, Masquet C, Azancot I, Guiomard A, Gourgon R. Relationship between physical properties of the arterial system and left ventricular performance in the course of aging and arterial hypertension. Eur. Heart J. 3 (suppl A): $95-102,1982 b$

Michel JB,, Heudes D, Michel O, Poitevin PP, Scalbert E, Corman B, Levy BI. Effect of chronic ANGI-converting enzyme inhibition on aging processes. II. Large 
arteries. Am. J. Physiol. 267:R124-R135, 1994

Milnor WR. Arterial impedance as ventricular afterload. Circ. Res. 36:565-570, 1975

Monnier VM, Kohn RR, Cerami A. Accelerated age-related browning of human collagen in diabetes mellitus. Medical Sciences 81:583-587, 1984

Mourlon legrand MC, Benessiano J, Levy BI. Endothelium, mechanical compliance, and cGMP content in the carotid artery from spontaneously hypertensive rats. $J$. Cardiovasc. Pharmacol. 21 (Suppl. 1):S26-S30, 1993

Mozersky DJ, Summer DS, Hokanson DE, Strandness DE Jr. Transcutaneous measurement of the elastic properties of the human femoral artery. Circulation 46:948-955, 1972

Mullins MM, Kleinman LI, Russell PT, Srivastava LS. Plasma aldosterone concentrations in neonatal spontaneously hypertensive rats. Life Sci. 31:2751-2755, 1982

Mulvany MJ, Aalkjaer C, Christensen J. Changes in noradrenaline sensitivity and morphology of arterial resistance vessels during development of high blood pressure in spontaneously hypertensive rats. Hypertension 2:664-671, 1980a

Mulvany M.J., C. Aalkjaer, J. Christensen. Changes in noradrenaline sensitivity and morphology of arterial resistance vessels during development of high blood pressure in spontaneously hypertensive rats. Br. J. Pharmacol. 71:585-596, 1980b

Mulvany MJ. Contractile properies of resistance vessels related to cellular function. In: Blood vessel changes in hypertension: structure and function. Volume 1, chapter 1. CRC Press Inc., Boca raton, Florida, ppl-24, 1989

Neil-Dwyer G, Child AH, Dorrance DE, Pope FM, Barleti J. Aortic compliance in patients with ruptured intracranial aneurysms. [Letter]. Lancet 23::939-940, 1983

Niederberger M, Hayoz D, Rutschman B, Tardy Y, Nussberger J, Waeber B, et al. Neither hydralazine nor captopril significantly shifts carotid artery distensibility-pressure curves detemined in intact spontaneously hypertensive rats.
J. Hypertens. 9 (suppl 6):S404-S404, 1991

Nishiyama K, Nishiyama A, Frohlich ED. Regional blood flow in normotensive and spontaneously hypertensive rats. Am. J. Physiol. 230:691-698, 1976

Okamoto K, Aoki K. Development of a strain of spontaneously hypertensive rats. Jpn. Circ. J. 27:282-293, 1963

Olensen SP, Clapham DE, Davies PF. Hemodynamic shear stress activates a $\mathrm{K}+$ current in vascular endothelial cells. Nature 331:168-170, 1988

Olivetti G., M. Melissari, G. Marchetti, P. Anversa. Quantitative structural changes of the rat thoracic aorta in early spontaneous hypertension. Tissue composition, and hypertrophy and hyperplasia of the smooth muscle. Circ. Res. 51:19-26, 1982

Ooshima A, Midorikawa O. Increased lysyl oxidase acitvity in blood vessels of hypertensive rats and effect of betaaminoproprionitrile on arteriosclerosis. Jap. Circul. J. 41:1337-1340, 1977

Opsahl W, H Zeronian, M Ellison, D Lewis, RB Rucker, RS Higgins. Role of copper in cross-linking and its influence on selected mechanical properties of chick bone and tendon. J. Nutr. 112:708-716, 1982

O'Rourke MF, Taylor MG. Input impedance of the systemic circulation. Circ. Res. 20:365-380, 1967

O'Rourke MF, Blazek JV, Morreels CL Jr., Krovetz LJ. Pressure wave transmission along the human aorta. Changes with age and in arterial degenerative dieases. Circ. Res. 23:567-579, 1968

O'Rourke MF. Arterial function in health and disease. Edinburgh, London, Melbourne and New York: ChurchillLivingstone pp 3-32, 53-93, 170-224, 1982

O'Rourke M. Coupling between the left ventricle and arterial system in hypertension. Eur. Heart J. 11 (Supplement G):24-28, 1990a

O'Rourke M. Arterial stiffness, systolic blood pressure, and logical treatment of arterial hypertension. Hypertension 15:339-347, 1990b

Osborne Pellegrin MJ, Parjanel J, Horneback W. Role of elastase and lysyl oxidase 
activity in spontaneous rupture of internal elastic lamina in rats. Arteriosclerosis 10:1136-1146, 1990

Owens GK. Influence of blood pressure on development of aortic medial smooth muscle hypertrophy in spontaneously hypertensive rats. Hypertension 9:178187,1978

Owens GK. Differential effects of antihypertensive drug therapy on vascular smooth muscle cell hypertrophy, hyperploidy and hyperplasia in the spontaneously hypertensive rat. Circ. Res. 56:525-536, 1985

Pagani M, Mirsky I, Baig H, Manders WT, Kerkhof P, vatner SF. Effects of age on aortic pressure-diameter and elastic stiffness-stress relationship in unanesthetized sheep. Circ. Res. 44:420429,1979

Pannier BM, London GM, Cuche JL, Girerd $\mathrm{X}$, Safar ME. Physical properties of the aorta and cardiac hypertrophy in essential hypertension. Eur. Heart J. 11 (Suppl G):17-23, 1990

Patel DJ, Fry DL. Longitudinal tethering of arteries in dogs. Circ. Res. 19:1011-1021, 1966

Perret F, Mooser V, Hayoz D, Meister J Etienne J, Farine P marazzi A, Burnier M, Nussberger J, Waeber B, Brunner HR. Evaluation of arterial compliancepressure curves. Effect of antihypertensive drugs. Hypertension 18(II):II77-II83, 1991

Peterson LH, Jensen RE, Parnell J. Mechanical properties of arteries in vivo. Circ. Res. 8:622-639, 1960

Pfeffer M.A., J.M. Pfeffer, E. Frohlich. Hemodynamic correlates of naturally developing left ventricular hypertrophy and spontaneously hypertensive rats (abstr.) International Study Group for Research in Cardiac Metabolism. Winnipeg, Canada, 1972

Pfeffer M.A., E. Frohlich, J.M. Pfeffer. Disparity in autonomic control of cardiac performance in SHR (abstr). Circulation 48(suppl IV):IV-45, 1973

Pfeffer MA, Pfeffer JM. Left ventricular hypertrophy and pressure generating capacity in aging genetically hypertensive rats. J. Cardiovasc Pharmacol. 7:S41S45, 1985

Pithois-Merli I, Levenson J, Filitti V, Simon A, . Comparative long-term vasoactive effects of atenolol and carteolol on the properties of the small and large arteries of the upper extremities in human essential hypertension. Clin. Pharmacol. Ther. 46:686-692, 1989

Pohl U, Holtz J, Busse R, Bassenge E. Crucial role of endothelium in the vasodilator response to increased flow in vivo. Hypertension 8:43-44, 1986

Pourageaud F, De Mey JGR. Structural properties of rat resenteric small arteris after 4 weeks exposure to elevated or reduced blood flow. Am. J. Physiol. 273 (Heart Circ. Physiol 42):H1699-H1709, 1997

Pourageaud F, De Mey JGR. Vasomotor responses in chronically hyperprefused and hyperfused rat mesentric arteries. $\mathrm{Am}$. J. Physiol. 274 (Heart Circ. Physiol 43):H1301-H1307, 1998

Pyeritz RE, McKusick VA. The marfan syndrom: diagnosis and management. $N$. Engl. J. Med. 300:772-777, 1979

Quaglino D Jr., Kennedy R, Fornieri C, Nanney LB, Pasquali Ronchetti I, Davidson JM. Matrix gene expression during the aging process revealed by in situ hybridization. J. Histochem. Cytochem. 37 (abstr.):933, 1989

Rayton JK, DH Harris. Induction of lysyl oxidase with copper. J. Biol. Chem. 254:621-626, 1979

Reneman RS, Van Merode T, Hick P, Hoeks APG. Flow velocity patterns in and distensibility of the carotid artery bulb in subjects of various ages. Circulation 71:500-509, 1985

Reneman RS, Van Merode T, Hick P, Muytjens AMM, Hoeks APG. Agerelated changes in carotid artery wall properties in men. Ultrasound Med. Biol. 12:465-471, 1986

Reneman RS, Hoeks APG, Westerhof N. Noninvasive assessment of artery wall properties in humans; methods and interpretation. J. Vascular Investigation 2:53-64, 1996

Rickstein SE, Yao T, Thoren P. Peripheral and central vascular compliances in conscious 
normotensive and spontaneously hypertensive rats. Acta Physiol. Scand. 112:169-177, 1981

Riley WA, Barnes RW, Evans GW, Burke GL. Ultrasounic measurement of the elastic modulus of the common carotid artery. The atherosclerotic risk in communities (ARIC) study. Stroke 23:952-956, 1992

Rizzoni D, Castellano M, Porteri E, Bettoni G, Muiesan ML, Agabiti Rosei E. Vascular structural and functional alterations before and after the development of hypertension in SHR. Am. J. Hypertens. 7:193-200, 1994

Roach MR, Burton AC. The reason for the shape of the distensibility curves of arteries. Can. J. Biochem. Physiol. 35:681-690, 1957

Robert L, Jacob MP, Frances C, Godeua G, Horneback W. Interaction between elastin and elastase and its role in the ageing of the arterial wall, skin and connective tissue. A review. Mech. Ageing Dev. 28:155-166, 1984

Roman MJ, Saba PS, Pini R, Spitzer M, Pickering TG, Rosen S, Alderman M Devereux R. Parallel cardiac and vascular adaptation in hypertension. Circulation 86:1909-1918, 1992

Roman MJ, Pickering TG, Pini R, Schwartz JE, Devereux RB. Prevalence and determintants of cardiac and vascular hypertrophy in hypertension. Hypertension 26:369-373, 1995

Rubanyi GM, Romero JC, Vanhoutte PM. Flow-induced release of endotheliumderived relaxing factor. Am. J. Physiol. 250:H1145-H1149, 1986

Rubanyi GM, Freay AD, Kauser K, Johns A, Harder DR. Mechanoreception by the endothelium: Mediators and mechanism of pressure- and flow induced vascular responses. Blood vessels 27:246-257, 1990

Rusterholz DB, Mueller SM. Sympathetic nerves exert a chronic influence on the intact vasculature that is age related. Ann. Neurol. 11:365-371, 1972

Saavedra JM, Correa FMA, Seltzer A, Pinto JEB, Viglione P, Tsutsumi K. Enhanced angiotensin converting enzyme binding in arteries from spontaneously hypertensive rats. J. Hypertens. 10:1353-1359, 1992
Saba PS, Roman MJ, Pini R, Spitzer M, Ganau A, Devereux RB. Relation of arterial pressure waveform to left ventricular and carotid anatomy in normotensive subjects. J. Am. Coll. Cardiol. 22:1873-1880, 1993

Safar ME, Simon AC, Levenson JA. Structural changes of large arteries in sustained essential hypertension. Hypertension 6(suppl.III):III117-III121, 1984

Safar ME, Laurent S, Bouthier JA, London GM. Comparative effects of captopril and isosorbide dinitrate on the arterial wall of hypertensive human brachial arteries. $J$. Cardiovasc. Pharmacol. 8:1257-1261, 1986

Safar ME, Toto-Moukouo JJ, Bouthier MD, Asmar RE, Levenson JA, Simon AC, London GM. Arterial dynamics, cardiac hypertrophy, and antihypertensive treatment. Circulation 75(suppl I):I156I162, 1987a

Safar ME, London GM, Bouthier JA, Levenson JA, Laurent S. Brachial artery cross-sectional area and distensibility before and after arteriolar vasodilatation in men with sustained essential hypertension. J Cardiovasc. Pharmacol. 9:734-742, 1987b

Safar ME. Pulse pressure in essential hypertension:clinical and therapeutical implications. Editorial review. $J$. Hypertens. 7:769-776, 1989a

Safar ME, Bons J, Georges D, Gournot A, Duchier J. Calcium blocker lacidipine and carotid arteriolar vasodilation in healty volunteers. Clin. Pharmacol. Ther. 46:9498, 1989b

Safar ME. Ageing and its effect on cardiovascular system. Drugs 39(suppl. 1):1-8, 1990

Safar ME, London GM, Laurent S. Hypertension and the arterial wall. High Blood Press. 2 (Suppl.1):32-40, 1993

Safar M, Van Bortel L, Struijker Boudier H. Resistance and conduit arteries following converting enzyme inhibition in hypertension. J. Vasc. Res. 34:67-81, 1997

Schelling P., Fisher H, Ganten D. Angiotensin and cell growth: a link to cardiovascular hypertrophy? [Editorial]. J. Hypertens. 9:3-15, 1991 
Schiffers PMH, Van der Heijden HAMD, Fazzi GE, Struijker Boudier HAJ, De Mey JGR. Tonic tone in arteries exposed continuously to angiotensin II in vitro. $J$. Pharmacol. Exp. Ther. 266:1520-1527, 1993

Schramm LP, Barton GN. Diminished sympathetic silent period in spontaneously hypertensive rats. Am J. Physiol. 236:R147-R152, 1979

Sen S, Smeby RR, Bumpus FM. Renin in rats with spontanous hypertension Circ. Res. 31:876-880, 1972

Shibata S Kurahashi K, Kuchii M. A possible etiology of contractility impairment of vascular smooth muscle from spontaneously hypertensive rats. $J$. Pharmacol. Exp. Ther. 185:406-417, 1973

Simon AC, Levenson JA, Levy BI, Bouthier JE, Petoneau PP, Safar ME. Effects of nitroglycerin on peripheral arteries in hypertension. Br. J. Clin. Pharmac. 14:241-246. 1982

Simon A, Laurent S, Levenson JA, Bouthier JE, Safar ME. Estimation of forearm arterial compliance in normal and hypertensive man from simultaneous pressure and flow measurements in the brachial artery, using a pulsed Doppler device and a first-order arterial model during diastole. Cardiovasc. Res. 17:331338,1983

Simon AC, Levenson J, Bouthier JD, Safar ME. Effects of chronic administration of enalepril and propranolol on the large arteries in essential hypertension. $J$. Cardiovasc. Pharmacol. 7:856-861, 1985

Simpson P., Mcgrath A, Savion S. Myocyte hypertrophy in neonatal rat heart cultures and its regulation by serum and by catecholamines. Circ. Res. 51:787-801, 1982

Sinaiko A, Mirkin BL. Ontogenesis of the renin-angiotensin system in spontaneously hypertensive and normal wistar rats. Circ. Res. 34:693-696, 1974

Singer HA, Kamm KE, Murphy RA. Estimates of activation in arterial smooth muscle. Am. J. Physiol. 251:C465-C473, 1986

Singer HA, Murphy RA. Maximal rates of activation in electrically stimulated swine carotid media. Circ. Res. 60:438-445, 1987

Smeda J.S., Lee RM, Forrest JB. Structural and reactivity alterations of the renal vasculature of spontaneously hypertensive rats prior to and during established hypertension. Circ. Res. 63:518-533, 1988

Smiesko V, Kokik J, Dolezel S. Role of endothelium in the control of arterial diameter by blood flow. Blood vessels 22:247-251, 1985

Smith TL, Hutchins PM. Central hemodynamics in the developmental stage of spontaneously hypertension in unanesthetized rat. Hypertension 1:508517,1979

Sonesson B Vernersson E, Hansen F, Länne T. Influence of sympathetic stimulation on the mechanical properties of the aorta in humans. Acta Physiol. Scand. 159:139145,1997

Story DR, Ziogas J. Interaction of angiotensin with noradrenergic neuroeffector transmission. TiPS 8:269-271, 1987

Stryer L. Biochemistry, third edition, WH Freeman and company, New York, 1988

Sumitani M, Michelini LC, Krieger EM. Long-term analysis of dynamics in growing conscious rats. Hypertension 8: suppl I:I200-I204, 1986

Sumitani M, Cabral AMS, Michelini LC, Krieger EM. In vivo adaptive responses of the aorta to hypertension and aging. Am. J. Physiol. 273:H96-H103, 1997

Sunagawa K, Maughan WL, Burkhoff D, Sagawa K. Left vnetricular interaction with arteial load studied in isolated canine ventricle. Am. J. Physiol. 245:H773H780, 1983

Tarazi R. The role of the heart in hypertension. Clin. Sci. 63:347s-358, 1982

Tatchum-Talom R, Niederhoffer N, Amin F, Makki T, Tankosic P, Atkinson J. Aortic stiffness and left ventricular mass in a rat model of isolated systolic hypertension. Hypertension 26:963-970, 1995

Ting CT, Brin KP, Lin SJ, Wang MS, Chiang $\mathrm{BN}$, Yin FC. Arterial. hemodynamics in human hypertension. J. Clin. Invest. 78:1462-1471, 1986

Todd ME, Gowen B. Arterial wall and smooth muscle cell development in young Wistar 
rats and the effect of surgical denervation. Circ. Res. 69:438-446, 1991

Trippodo NC, Frohlich ED. Similarities of genetic (spontaneous) hypertension. Man and rat. Circ. Res. 48:309-319, 1981

Vadlamudi RK, RJ McCormick, DM Medeiros, J Vossoughi, ML Failla. Copper deficiency alters collagen types and covalent cross-linking in swine myocardium and cardiac valves. Am. J. Physiol. 264:H2154-H2161, 1993

Van Bortel LMAB, Van Merode T, Smeets FAM, Reneman RS, Mooij JMV, Struijker Boudier HAJ. Nebivolol improves the vessel wall properties of the common carotid artery. Drug invest. 3 (Suppl 1):61-63, 1991

VanDijk A,Wieringa PA, van der Meer M, Laird JD. Mechanics of resting isolated single vascular smooth muscle cells from bovine coronary artery. Am. J. Physiol. 246:C277-C287, 1984

VanHoutte PM, Verbeuren TJ, Webb RC. Local modulation of adrenergic neuroeffector interaction in the blood vessel wall. Physiol. Rev. 61:151-215, 1981

VanHoutte PM. The endothelium-dependent modulation of vascular smooth muscle tone. N. Eng. J. Med. 319:512-513, 1988

Van Merode T., P.J. Hick, A.P.G. Hoeks, K.H. Rahn, R.S. Reneman. Carotid artery wall properties in normotensive and borderline hypertensive subjects of various ages. Ultrasound Med. Biol. 14:563-569, 1988

Van Merode T, Van Bortel LM, Smeets F, Reneman RS, Bohm R, Rahn. Verapamil and nebivolol improve carotid artery distensibility and cross-sectional compliance in hypertensive patients. $J$. Cardiovasc. Pharmacol. 15:109-113, 1990

Van Merode T., Brands PJ, Hoeks APG, Reneman RS. Faster ageing of the carotid artery bifurcation in borderline hypertensive subjects. $J$ Hypertens. 11:171-176, 1993

Van Merode T, Brands PJ, Hoeks APG, Reneman RS. Different effects of ageing on elastic and muscular bifurcations in men. J. Vasc. Res. 33:47-52, 1996

Vater CA, Mainardi CL, Harris ED Jr., Siegel RC. Native crosslinks in collagen fibrils induce resistance to human synovial collagenase. Biochem. J. 181:639-645, 1979

Ventura H., F.H. Messerli, W. Oigman, D.H. Suarez, G.R. Dreslinski, F.G. Dunn, et al. Impaired systemic arterial compliance in borderline hypertension. Am. Heart J. 108:132-136, 1984

Wanstall JC, O"Donnell SR. Inhibition of norrepinephrine contractions by diltiazem on aorta and pulmonary artery from young and aged rats: influence of alphaadrenoceptor reserve. J. Pharmacol. Exp. Ther. 245:1016-1020, 1988

Waeber B, Hayoz D, Evequoz D, Brunner HR. Arterial compliance and distensibility in spontaneously hypertensive rats. $J$. Hypertens. 10 (suppl 6) S79-S81, 1992

Wang DH, Prewitt RL. Captopril reduces aortic and microvascular growth in hypertensive and normotensive rats. Hypertension 15:68-77, 1990

Warshaw DM, Rees DD, Fay FS. Characterization of cross-bridge elasticity and kinetics of cross-bridge cycling during force development in single smooth muscle cells. J. Gen. Physiol. 91:761-779, 1988

Weber KT, JS Janicki, R Pick, C Abrahams, SG Schroff RI Bashey, RM Chen. Collagen in the hypertrophied pressureoverloaded myocardium. Circulation $\mathbf{7 5}$ (suppl I):140-147, 1987

Weber KT, Briila CG. Pathological hypertrophy and cardiac interstitium. Circ. Res. 83:1849-1865, 1991

Westling H, Jansson L, Jonson B, Nilsen R. Vasoactive drugs and elastic properties of human arteries in vivo, with special reference to the action of nitroglycerine. Eur. Heart J. 5:609-616, 1984

Westerhof N., Huisman RM. Arterial haemodynamics of hypertension. Clin. Sci. 72:391-398. 1987

Wong PC, Bernard R, Timmermans PBMWM. Effect of blocking angiotensin II receptor subtype on rat sympathetic nerve function. Hypertension. 19:663-667, 1992

Wolinsky H, Glagov S. Structural basis for the static mechanical properies of the aortic media. Circ. Res. 14:400-413, 1964 
Wolinsky H. Response of the rat aortic media to hypertension. Circ. Res. 26:507-522, 1970

Wolinsky H. Long-term effects of hypertension on the rat aortic wall and their relation to concurrent aging changes. Circ. Res. 30:301-309, 1972

Wolinsky H, Goldfischer S, Daly MM, Kasak LE, Coltoff Schiller B. Arterial lysosomes and connective tissue in primate atherosclerosis and hypertension. Circ. Res. 36:553-561, 1975

Yamauchi M, Woodley DT, Mechanic GL. Ageing and cross-linking of skin collagen. Biochem. Biophys. Res. Commun. 152:898-903, 1988

Yano M, Kumada T, Matsuzaki M, Kohno M, Hiro T, Kohtoku S, Miura T, Katamama K, Ozaki M, Kusukawa R. Effect of diltiazem on aortic pressure-diameter relationship in dogs. Am. J. Physiol. 256:H1580-H1587, 1989

Zanchi A, Wiesel P, Aubert JF, Brunner H, Hayoz D. Time course changes of the mechanical properties of the carotid artery in renal hypertensive rats. Hypertension 29:1199-1203, 1997

Zarins CK, Zatina MA, Giddens DP, Ku DN. Glagov S. Shear stress regulation of artery lumen diameter in experimental atherogenesis. J. Vasc. Surg. 5:413-420, 1987

Zarins CK. Adaptive responses of arteries. $J$. Vasc. Surg. 9:382-389, 1989

Zimmerman BG, Sybertz EJ, Wong PC. Interaction between sympathetic and renin-angiotensin system. J. Hypertens. 2:581-587, 1984 


\section{CHAPTER}

\section{A TECHNIQUE TO ASSESS AORTIC DISTENSIBILITY AND COMPLIANCE IN ANESTHETIZED AND AWAKE RATS}

Am. J. Physiol. 267:H780-H786, 1996

Ad W.van Gorp

Dorette S. van Ingen Schenau

Jean Willigers

Arnold P.G. Hoeks

Jo G. R. De Mey

Harry A.J. Struijker Boudier

Robert S. Reneman 


\section{ABSTRACT}

A non-invasive ultrasonic technique, based upon tracking arterial wall displacements with a vessel wall tracking device attached to a conventional Bmode imager, to assess end-diastolic aortic diameter (d) and aortic diameter changes during the cardiac cycle $(\Delta \mathrm{d})$ in anesthetized and awake rats is presented. From these parameters and invasively measured aortic pulse pressure $(\Delta \mathrm{P})$, aortic distensibility and compliance, the relative and absolute increase in lumen crosssectional area for a given increase in $\mathrm{P}$, respectively, can be calculated. $\mathrm{d}, \Delta \mathrm{d}$ and $\Delta \mathrm{P}$ could be determined with good intra-session (variations per day) and intersession (variations between days) coefficients of variation (CV). The CV's for $\Delta d$ were smaller in awake (4.6-6.0\%) than in anesthetized rats $(7.9-11.0 \%)$, probably due to variations $\Delta \mathrm{P}$ during anesthesia (CV's: 9.0-12.3\%). The CV's for d in awake (3.3-6.5\%) and anesthetized rats (2.6-5.0\%) were comparable. In awake rats the CV for $\Delta \mathrm{d}$, but not for $\mathrm{d}$, increased after implantation of the aortic catheter. It is concluded that $\mathrm{d}, \Delta \mathrm{d}$ and $\Delta \mathrm{P}$ of the aorta can be reliably measured non-invasively in anesthetized and awake rats, allowing the in vivo assessment of aortic distensibility and compliance. The technique is sensitive enough to detect effects of agents on aortic wall properties.

\section{INTRODUCTION}

Arteries lose their elasticity with increasing age (Reneman RS et al.,1986) and in diseases such as atherosclerosis (Van Merode T et al ,1989) and hypertension (Safar ME et al.,1981; Simon AC et al.,1983; Van Merode T et al.,1988; Van Merode T et al.,1993; Laurent S et al.,1994). In hypertension the stiffening of the wall occurs mainly in elastic arteries; muscular arteries, like the radial artery, are not necessarily affected (Laurent S et al ,1994). In most of these studies, performed in humans, the dynamic properties of the artery wall were determined by assessing non-invasively distensibility and compliance by means of ultrasound techniques (Hoeks APG et al.,1990; Hayoz D et al.,1992: Hoeks APG et al.,1993).

Although valuable information has been obtained in these human studies, there is a need for methods to determine arterial distensibility and compliance in intact animals to study under pathological conditions the relationship between geometrical, cellular and molecular changes in the artery wall on the one hand and changes in functional properties of the artery wall on the other. The non- invasive as-sessment of artery wall dynamics in intact animals is preferred over the determination of artery wall properties in vitro, because arteries show a stiffer behavior in vitro than in vivo (Dobrin PB et al.,1978; Gow BS et al.,1979). Besides, the assessment of artery wall properties in vivo is required to study the interplay between changes in these properties and cardiac function.

In the present study we describe a technique to assess aortic distensibility and compliance in anesthetized and awake rats, which is basically a modification of the technique previously described by our group to assess these mechanical entities in humans (Hoeks APG et al.,1990). One of the modifications concerns the signal processing. In the present system radio frequency (RF) signal processing is employed, while the original version made use of Doppler-signal processing. The reliability of this newly developed technique in rats was determined by assessing intra- and inter-session variability, intra-session variations being the differences between measurements on one day and inter-session variations being the differences between measurements on 
consecutive days. Since arterial blood pressure is measured intra-arterially in these experiments, we also investigated whether implantation of the catheter affected the reliability of the technique. Rats were chosen as experimental model because inbred strains of this species provide good models of cardiovascular disease (for example, spontaneously hypertensive rats) and transgenic rats are becoming available.

\section{MATERIALS AND METHODS}

Assessment of aortic distensibility and compliance

Distensibility and compliance of an artery can be defined as the relative $(\Delta \mathrm{V} / \mathrm{V})$ and absolute $(\Delta \mathrm{V})$ increases in arterial volume for a given increase in pressure $(\Delta \mathrm{P})$ during the systolic phase of the cardiac cycle, respectively. Since it is practically impossible to accurately determine volume and volume changes noninvasively in vivo, distensibility and compliance are generally determined by assessing changes in lumen cross-sectional area $(\Delta A / A$ and $\Delta A$, respectively). This simplification is allowed because in unimpeded arteries the increase in volume during the cardiac cycle is caused by an increase in lumen cross-sectional area rather than by lengthening of the artery (Reneman RS et al.,1986). A and $\Delta \mathrm{A}$ can be derived from the end-diastolic diameter (d) and the changes in diameter of the artery during the cardiac cycle $(\Delta \mathrm{d})$, as assessed by means of ultrasound assuming the vessel lumen to be circular in crosssection.
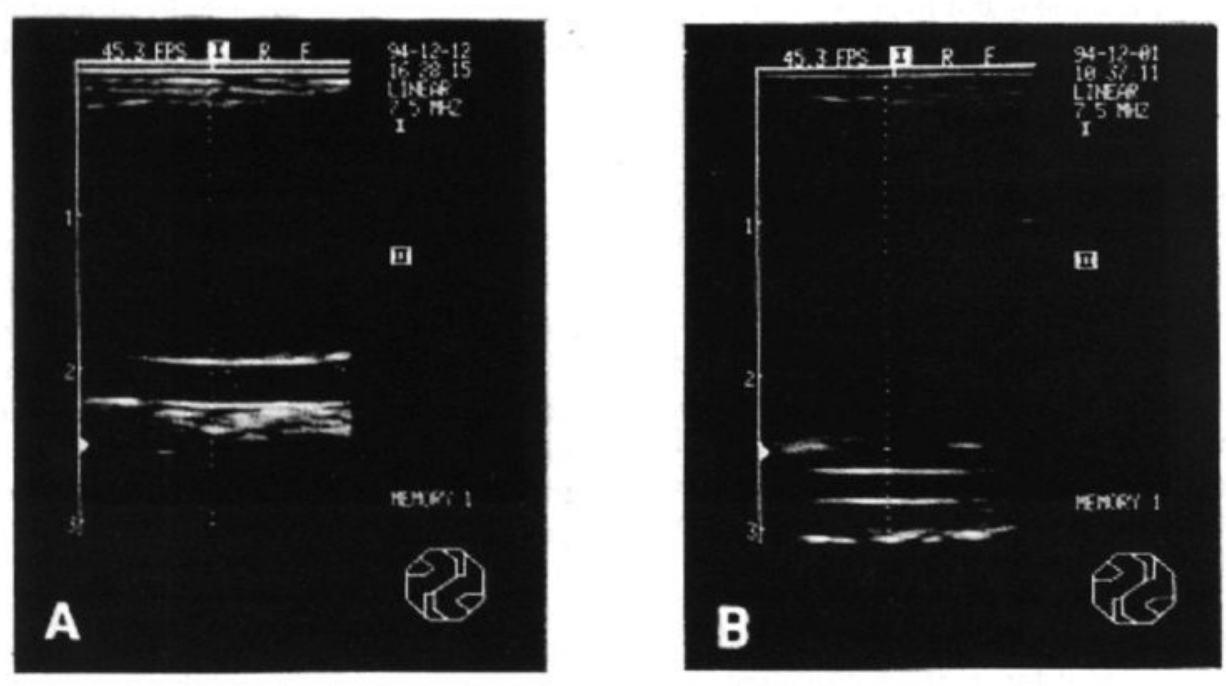

Fig. 2.1 B-mode images of the thoracic aorta in an anesthetized (A) and an awake rat (B). The dotted line perpendicular to the vessel represents the direction of the M-line. 
Description of the ultrasound technique to assess $d$ and $\Delta d$ of the thoracic aorta in rats

The ultrasound device described to assess $\mathrm{d}$ and $\Delta \mathrm{d}$ of the aorta consists of a vessel wall tracking system (WTS, see below) combined with a conventional B-mode ultrasound system (Pie480, 7.5 MHz linear array, Pie Medical, Maastricht, the Netherlands). The rats are shaved at the site of measurement and the ultrasound probe is placed on the thorax slightly to the left of the sternum, ultrasonic gel being applied between probe and skin. The thoracic aorta is then visualized in Bmode (B: brightness; Fig. 2.1) approximately $10 \mathrm{~mm}$ proximal to the diaphragm and the probe is positioned so that the $\mathrm{M}$-line is perpendicular to the vessel wall. Then the ultrasound system is switched to M-mode (M: motion), and ultrasound is emitted and received along the selected line of sight at a programmable emission trigger frequency.

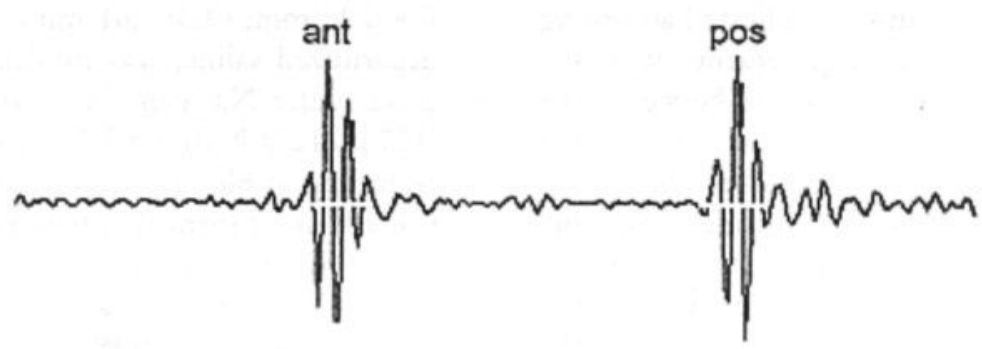

Fig. 2.2: The RF signal of the first acquired M-line as displayed on the PC monitor. The markers (open rectangles), representing the position of the sample windows, are positioned at the $\mathrm{RF}$ signals from the anterior (ant) and posterior (pos) wall.

The WTS is based on a data acquisition system, capable of capturing the received and amplified radio frequency (RF) signals synchronously with the emission trigger at a programmable sample frequency of up to $30 \mathrm{MHz}$ and with a dynamic range of $48 \mathrm{~dB}$ ( 8 bits). The position and width of the range of interest are programmable (on the average 20 and $10 \mathrm{~mm}$, respectively, in the present study). The size of the internal data memory is 1 Mbyte, allowing for the temporary storage of, for example, 512 RF lines of 2000 data points each. At an emission trigger frequency of $250 \mathrm{~Hz}$ the memory will then hold $2.5 \mathrm{sec}$ of data corresponding to at least 10 cardiac cycles and 3 respiration cycles. Because of the higher heart rates, in the awake rats the sampling frequency was doubled, resulting in a data collection for $1.2 \mathrm{sec}$. The WTS is also equipped with an acquisition system for reference signals, such as blood pressure, which are sampled synchronously with the emission trigger activating the capture of an RF line.

After completion of the data acquisition the data are transferred to a PC (486Dx2/66). The first line acquired is graphically presented on a display, allowing manual identification of the anterior and posterior wall boundaries by placing two markers, representing the sample windows for data processing (Fig. 2.2). Once the walls are identified the remaining data are transferred and processed on the fly (in about $5 \mathrm{sec}$ ). To extract the change in position of either 
the anterior or posterior wall, averaged over a few RF lines, the approach based on the cross-correlation model (CCM) for corresponding segments of subsequent RF lines is applied (Hoeks APG et al.,1993). This method has a low noise sensitivity and is insensitive to the actual RF carrier frequency. The estimates for the crosscorrelation coefficients are based on a running average over a programmable number of RF lines (data window in time) to enhance stability of the estimate for the mean displacement. To ensure that always the signals returned by the same structure are considered, the position of the sample windows is adjusted according to the observed displacements (tracking window). The difference between the displacement signals of the anterior and posterior walls yields the change in diameter as a function of time, that is the distension waveform. From the initial distance between the sample windows and the observed distension waveform, the end-diastolic diameter, the peak-to-peak change in diameter, and the length of the cardiac cycle ( $\mathrm{R}-\mathrm{R}$ interval) can be extracted for each cardiac cycle. The displacements of the anterior and posterior walls and the changes in arterial diameter (distension) during consecutive cardiac cycles, as recorded in an anesthetized and an awake rat, are presented in Fig. 2.3. Aortic pressure (see below) and distension waveforms as a function of time are shown in Fig. 2.4.

\section{Reliability assessment.}

Because previous in vitro experiments have shown that this type of ultrasound system can resolve displacements of a few micrometers (Hoeks APG et al.,1990), in the present reliability study we have limited ourselves to the determination of intraand inter-session variability in the assessment of $\Delta \mathrm{d}, \mathrm{d}$ and the R-R interval in both anesthetized (Group I) and awake (Group II) rats. Where applicable (see below) this variability was also determined for the aortic blood pressure measurements. Group I consisted of 10 and Group II of $6 \mathrm{Wistar}$ Kyoto rats (WKY's). The animals were housed in individual cages, maintained on a 12 -hour light, 12-hour dark cycle, fed ad libitum (Hope Farms, Woerden, the Netherlands) and had free access to tap water. The experimental protocols were approved by the Institutional Animal Care and Use Committee of the University of Limburg.

In the WKY's of Group I (mean weight at 10 weeks of age: $242 \mathrm{~g}$; range 223-259 g) a polyethylene catheter (PE 10; ID: $0.28 \mathrm{~mm}$; OD: $0.61 \mathrm{~mm})$, filled with heparinized saline, was implanted in the aorta under $\mathrm{Na}$ - pentobarbital anesthesia $(100 \mu \mathrm{l} / 100 \mathrm{~g}$ body wt; $60 \mathrm{mg} / \mathrm{ml})$ for the recording of blood pressure. The catheter was advanced through a femoral artery to just below the bifurcation of the left renal artery. The catheter advanced through was guided underneath the skin and exteriorized at the base of the skull. Aortic pressure was measured with an external pressure transducer (CP-01, Century Technology, Inglewood, CA, USA). The delay in the pressure measuring system was $12 \mathrm{msec}$, indicating a frequency response beyond $50 \mathrm{~Hz}$. Two days later the reliability studies were started. Measurements of $\mathrm{d}, \Delta \mathrm{d}$, the R-R interval, diastolic aortic pressure $\left(\mathrm{P}_{\mathrm{dia}}\right)$, and $\Delta \mathrm{P}$ were performed on 3 consecutive experimental days (sessions). During the measurements the rats were anesthetized with ketamin/xylazine (10: $50 \mathrm{~g} / \mathrm{ml} ; 100$ $1 / 100 \mathrm{~g}$ body weight) and body temperature was controlled by a rectal temperature probe and maintained at $38^{\circ} \mathrm{C}$ with an infrared heating lamp. On each day these parameters were measured four times at short intervals during at least 5 heart beats. Measurements were started after aortic blood pressure had stabilized following the induction of anesthesia (after about $20 \mathrm{~min}$ ). The 
ultrasound probe was removed from the body in between the measurements. On each day the coefficient of variation (CV) between the 4 measurements was determined per rat and was defined as the intra-session variablility. The intra-session CV's presented per day are the mean values $( \pm \mathrm{SD})$ of the 10 rats. To determine the inter-session variability (variations between days) the average value of the 4 measurements was assessed per rat per day and the $\mathrm{CV}$ between these values on consecutive experimental days was calculated. The inter-session CV's presented are the mean values of the 10 rats. This approach in determining intersession variability was taken, because in intervention studies animals are generally used as their own controls. We have limited ourselves to the assessment of intra- and inter-session variability because in pilot experiments no differences in variability could be observed between investigators.

A $\mathrm{mm}$

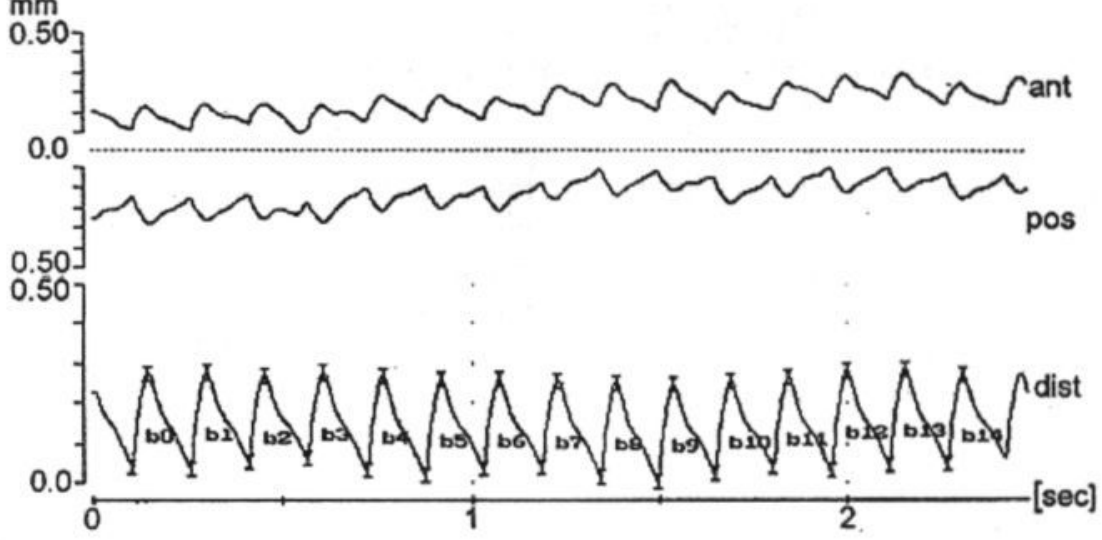

B

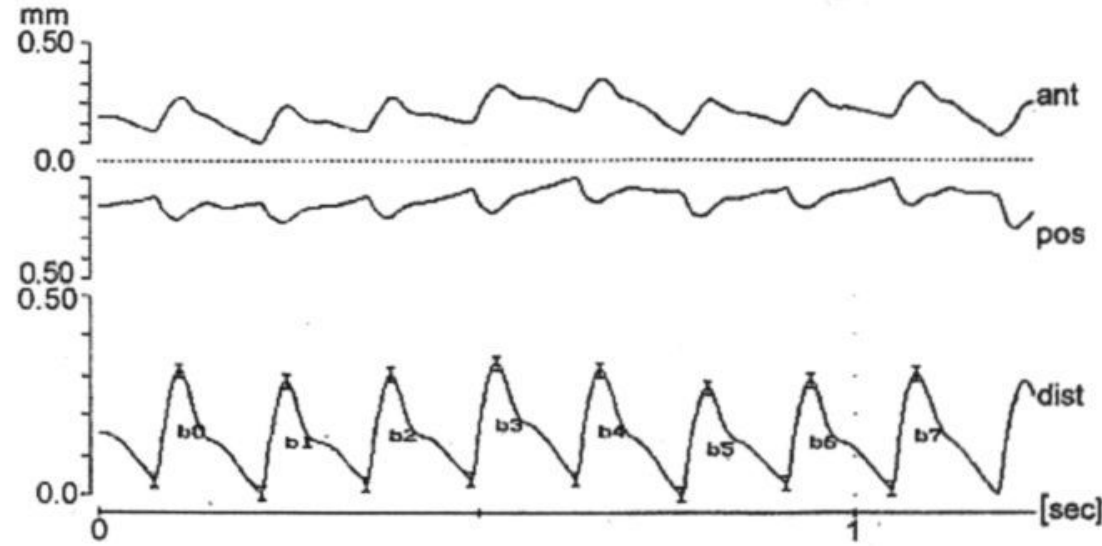

Fig. 2.3: Recordings of the displacement of the anterior (ant) and posterior (pos) walls of the aorta as a function of time during consecutive cardiac cycles, and the difference between both, reflecting the changes in aortic diameter during the heart cycle as a function of time (distension; dist) in an anesthetized (A) and an awake rat (B). b refers to heart beat. The signs on the distension tracings refer to detected end-diastole and peak systole, respectively. 


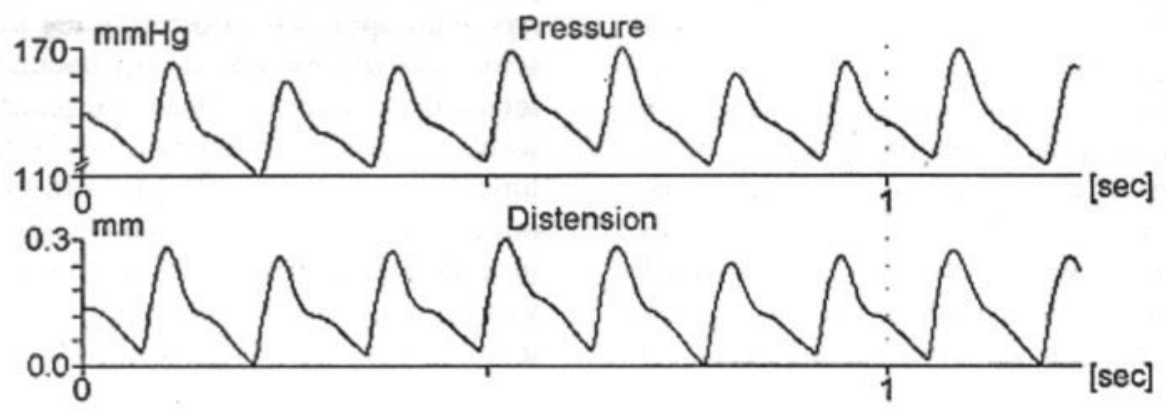

Fig. 2.4: Aortic pressure and distension wave forms as a function of time recorded in an awake rat.

The rats in Group II (mean weight at 12 weeks of age: $299 \mathrm{~g}$; range $275-344 \mathrm{~g}$ ) were trained for 5 weeks (from 7 weeks of age) to get adapted to the cages in which they were restrained during the measurements. They were placed in the restrainers for 2 hours during 5 days a week. The last 2 weeks they were also trained to get used to the application of gel and probe. The restrainers were built in our institute and are especially suited for ultrasound measurements. The restrainers have an opening on the ventral side for the positioning of the probe and are equipped with a stand for their hind feet to rest on (Fig. 2.5). After the training period measurements were performed on 3 consecutive experimental days (sessions) and intra- and inter-session variability for $\mathrm{d}, \Delta \mathrm{d}$ and the R-R interval were determined as described above, albeit that the data presented refer to 6 rats. To obtain insight into the effect of implantation of the intra-aortic catheter (see above) on the measurements, if any, the same procedure was repeated, starting 2 days after implantation of the catheter. After implantation of the catheter $\mathrm{P}_{\mathrm{dia}}$ and $\Delta \mathrm{P}$ were measured as well. The intra- and inter-session variability for the variables measured were determined again. The inter-session variations in the measurements before and after implantation of the catheter were tested for significance with the use of the F-test. Differences between the absolute values of the variables determined before and after implantation of the catheter were evaluated for statistical significance using the paired Student-t test. To this end the values averaged over 3 days per rat before catheter implantation were compared with those after implantation.

In an additional group of 12 week old male WKY's $(n=6)$, we evaluated whether drug effects on aortic wall properties could be detected with the ultrasound technique. These rats were equipped with an intra-aortic catheter for pressure registration as described above and with a catheter in the vena cava for intravenous drug infusion with a motor driven syringe. Two days later the rats were anesthetized with ketamine/xylazine under the experimental conditions as described above. After $30 \mathrm{~min}$ of equilibration, during which blood pressure and heart rate stabilized, intravenous infusion of the $\alpha_{1}$-adrenoceptor agonist methoxamine (Sigma Chemical, Saint Louis Mo USA; dissolved in $0.9 \%$ saline) was started. 
Infusion volume was maintained constant at $100 \mathrm{l} / \mathrm{min}$, but the dose of the agonist was increased every $10 \mathrm{~min}$, from 0 via $0.2,1.0$ and 5 to $25 \mu \mathrm{g} / \mathrm{min}$. Near the end of each infusion period, two ultrasound recordings of the thoracic aorta were performed during $2.3 \mathrm{sec}$ each. Observations made during each cardiac cycle comprised in these two recordings were averaged.

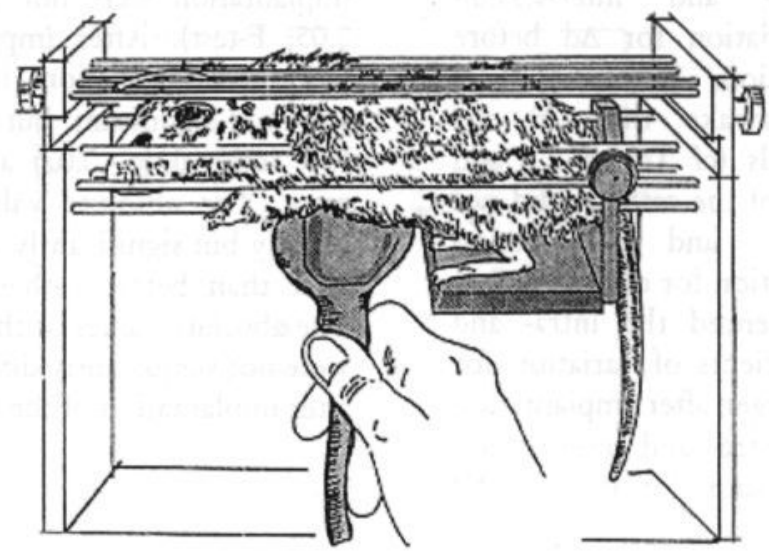

Fig. 2.5: Illustration of the restrainer for the measurements on awake rats.

Table 2.1: Intra-session and inter-session coefficients of variation for diameter and distension in anesthetized rats.

\begin{tabular}{|c|c|c|c|c|}
\hline \multirow[b]{3}{*}{ Intra-session } & \multicolumn{2}{|c|}{$\mathrm{d}$} & \multicolumn{2}{|c|}{$\Delta \mathrm{d}$} \\
\hline & mean, $\mu \mathrm{m}$ & $\mathrm{CV}, \%$ & mean, $\mu \mathrm{m}$ & $\mathrm{CV}, \%$ \\
\hline & & & & \\
\hline Day 1 & $1,918 \pm 69$ & $3.3 \pm 1.4$ & $254.8 \pm 23.5$ & $7.9 \pm 3.8$ \\
\hline Day 2 & $2,003 \pm 81$ & $3.9 \pm 1.4$ & $240.0 \pm 29.1$ & $11.0 \pm 5.3$ \\
\hline Day 3 & $1,936 \pm 131$ & $6.5 \pm 2.7$ & $282.8 \pm 26.5$ & $8.7 \pm 5.4$ \\
\hline Inter-session & $1,952 \pm 97$ & $4.6 \pm 0.9$ & $259.3 \pm 26.9$ & $9.2 \pm 3.0$ \\
\hline
\end{tabular}

Values are means $\pm \mathrm{SD} ; \mathrm{n}=10$ rats. Intra-session (variations/day; 4 measurements per rat per day) coefficients of vaiation (CV) on 3 consecutive days and inter-session (variations among days) CVs for diameter (d) in anesthetized rats. Mean values of $d$ and $\Delta d$ per day and values of these variables averaged over 3 days (inter-session) are presented as well.

\section{RESULTS}

The intra- and inter-session coefficients of variation in the anesthetized rats (Group I) for $\mathrm{d}$ and $\Delta \mathrm{d}$ as well as the absolute values of these variables are presented in Table 2.1. The intra- and inter-session coefficients of variation were smaller for $\mathrm{d}$ than for $\Delta \mathrm{d}$. The intra- and inter-session coefficients of variation were smaller for the $\mathrm{R}-\mathrm{R}$ interval and $\mathrm{P}_{\mathrm{dia}}$ than for $\Delta \mathrm{P}$ (Table 2.2). The absolute values of these variables are also presented in this table.

The intra- and inter-session coefficients of variation in the trained, awake rats (Group II) for $\mathrm{d}, \Delta \mathrm{d}$ and the R-R interval 
before and after catheter implantation are presented in Table 2.3. Before implantation the intra- and inter-session coefficients of variation for $\mathrm{d}$ and the R-R interval were similar in the awake and anesthetized rats (see Tables 2.1, 2.2 and 2.3). The intra- and inter-session coefficients of variation for $\Delta \mathrm{d}$ before catheter implantation, however, were smaller in the awake than in the anesthetized animals (cf Tables 2.1 and 2.3). Implantation of the catheter did not affect the intra- and inter-session coefficients of variation for $\mathrm{d}$ and the R-R interval, but influenced the intra- and inter-session coefficients of variation for $\Delta \mathrm{d}$, which were larger after implantation (Table 2.3). The intra- and inter-session coefficients of variation for $\mathrm{P}_{\text {dia }}$ and $\Delta \mathrm{P}$ were larger in anesthetized than in awake rats (cf Tables 2.2 and 2.4). The absolute values of the variables measured in awake rats are presented in the tables 2.3 and 2.4 as well. The inter-session variations in d, $\Delta \mathrm{d}$ and $\mathrm{R}-\mathrm{R}$ interval before catheter implantation were not significant $(p>$ 0.05; F-test). After implantation of the catheter the variations in $\mathrm{d}, \Delta \mathrm{d}$ and $\Delta \mathrm{P}$ were not significant, but the variations in $R-R$ interval $(p=0.02)$ and $P_{\text {dia }}(p=0.03)$ were. The absolute values of $\Delta \mathrm{d}$ were slightly but significantly lower $(p<0.05)$ after than before catheter implantation. The absolute values of the other variables were not significantly different before and after implantation of the catheter.

Table 2.2: Intra-session and inter-session CVs for R-R interval, diastolic aortic pressure, and pulse pressure in anesthetized rats.

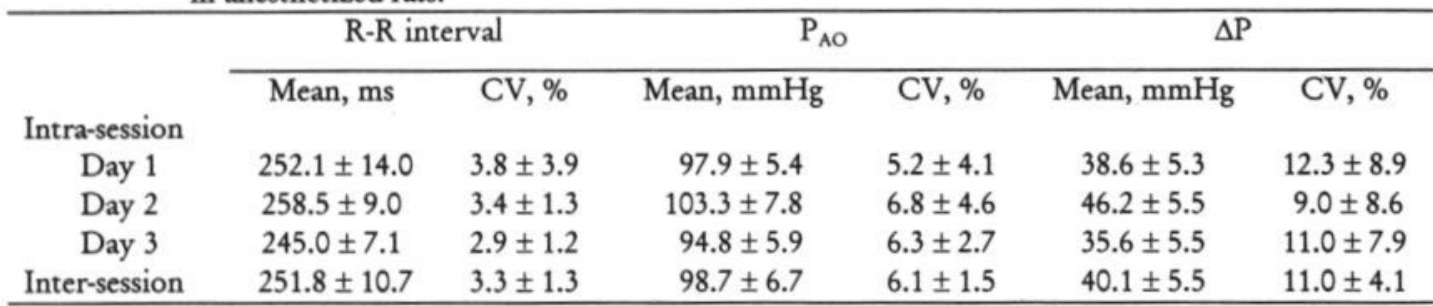

Values are means $\pm S D ; n=10$ rats. Intra-session (4 measurements per rat per day) CVs on 3 consecutive days and inter-session Cvs for $R-R$ interval, diastolic aortic pressure $\left(P_{A O}\right)$, and pulse pressure $(\Delta P)$ in anesthetized rats. Mean values of $R-R$ interval, $P_{A O}$, and $\Delta P$ per day and the values of these variables averaged over 3 days (inter-session) are presented as well.

Fig. 2.6 summarizes the observations during administration of the $\alpha_{1}$ adrenoceptor agonist methoxamine in anesthetized 12 week old WKY's. Intravenous infusion of the agonist $(0.2$ to $25 \mathrm{~g} / \mathrm{min}$ ) caused a dose-dependent increase of diastolic blood pressure. During infusion of the lowest dose of methoxamine $(0.2 \mu \mathrm{g} / \mathrm{min})$ a small, but significant $(\mathrm{P}<0.05$; two way analysis of variance), reduction of the end-diastolic diameter of the thoracic aortic was observed, despite elevation of intra-aortic diastolic pressure. This apparent aortic vasoconstriction was not accompanied by a significant alteration of absolute distension of the vessel. With higher doses of methoxamine, the local vasoconstrictor action of the agonist was progressively overruled by the pressor action of the 
compound. Especially at the highest dose, the end-diastolic diameter of the thoracic aorta was markedly increased and the absolute distension was drastically reduced.
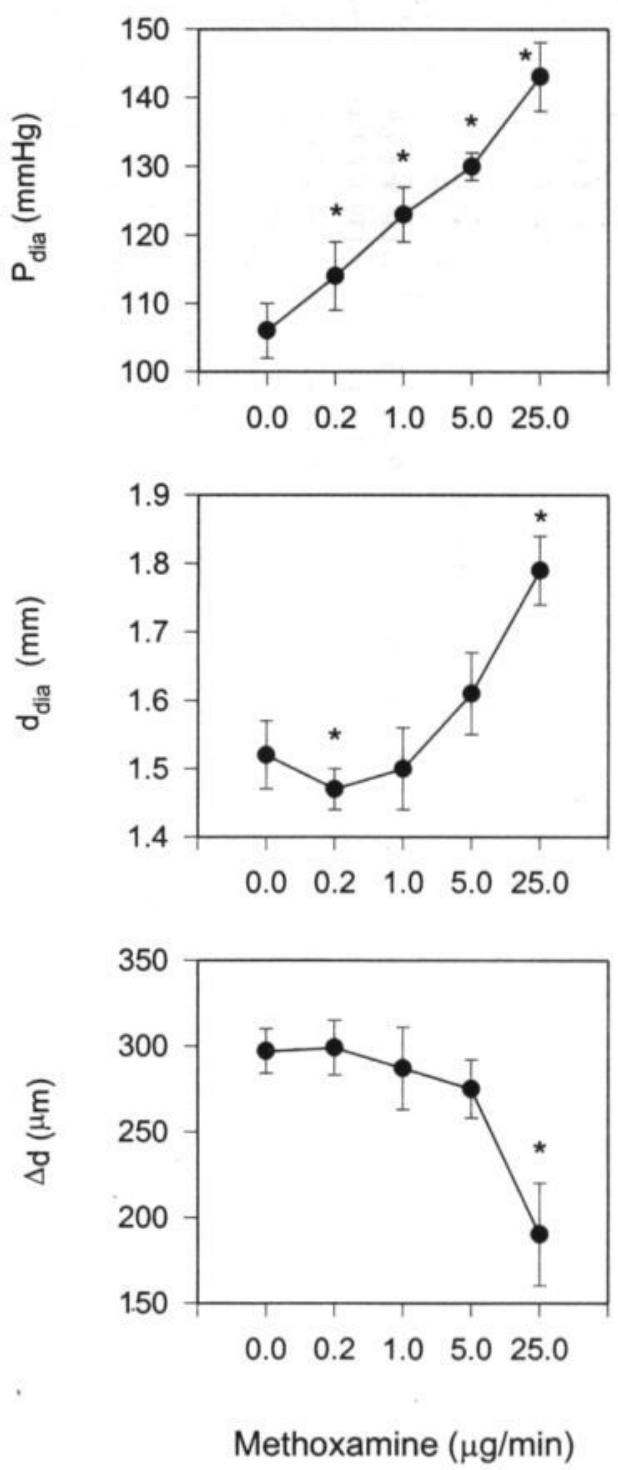

Fig. 2.6: Dose-response curves of methoxamine for diastolic blood pressure $\left(\mathrm{P}_{\mathrm{dia}}\right)$, end-diastolic diameter $\left(\mathrm{d}_{\mathrm{dia}}\right)$ and absolute distension $(\Delta \mathrm{d})$ as obtained in 6 anesthetized rats. Mean values and SEM are presented. Asterisks indicate significantly different from control. 


\begin{tabular}{|c|c|c|c|c|c|c|}
\hline & \multicolumn{2}{|c|}{$\mathrm{R}-\mathrm{R}$ interval } & \multicolumn{2}{|c|}{$\mathrm{P}_{\mathrm{AO}}$} & \multicolumn{2}{|c|}{$\Delta \mathrm{P}$} \\
\hline & Mean, ms & $\mathrm{CV}, \%$ & Mean, $\mathrm{mmHg}$ & $\mathrm{CV}, \%$ & Mean, $\mathrm{mmHg}$ & $\mathrm{CV}, \%$ \\
\hline & \multicolumn{6}{|c|}{ Before implantation } \\
\hline \multicolumn{7}{|l|}{ Intra-session } \\
\hline Day 1 & $1,830 \pm 49$ & $2.6 \pm 1.1$ & $291.5 \pm 16.0$ & $4.6 \pm 2.2$ & $143.8 \pm 6.3$ & $4.1 \pm 2.3$ \\
\hline Day 2 & $1,840 \pm 73$ & $3.5 \pm 1.9$ & $285.8 \pm 16.0$ & $4.6 \pm 3.9$ & $148.0 \pm 9.1$ & $5.5 \pm 2.6$ \\
\hline Day 3 & $1,860 \pm 97$ & $5.0 \pm 1.6$ & $290.3 \pm 19.5$ & $5.2 \pm 3.9$ & $145.4 \pm 9.5$ & $5.3 \pm 3.8$ \\
\hline Inter-session & $1,843 \pm 76$ & $3.7 \pm 1.7$ & $288.0 \pm 19.1$ & $5.3 \pm 2.7$ & $145.7 \pm 8.4$ & $5.0 \pm 2.1$ \\
\hline \multirow{2}{*}{\multicolumn{7}{|c|}{ Intra-session }} \\
\hline & & & & & & \\
\hline Day 1 & $1,870 \pm 57$ & $3.0 \pm 1.3$ & $264.7 \pm 28.3$ & $9.0 \pm 7.5$ & $147.9 \pm 9.9$ & $5.2 \pm 5.1$ \\
\hline Day 2 & $1,910 \pm 85$ & $4.1 \pm 1.3$ & $256.2 \pm 17.7$ & $6.4 \pm 4.5$ & $139.6 \pm 7.4$ & $4.9 \pm 2.8$ \\
\hline Day 3 & $1,870 \pm 81$ & $3.8 \pm 3.1$ & $286.3 \pm 30.7$ & $9.9 \pm 4.0$ & $144.0 \pm 6.1$ & $3.7 \pm 2.5$ \\
\hline Inter-session & $1,883 \pm 77$ & $3.6 \pm 2.2$ & $269.0 \pm 26.2^{*}$ & $8.4 \pm 4.5$ & $143.8 \pm 8.0$ & $4.6 \pm 3.3$ \\
\hline
\end{tabular}


Table 2.4: Intra-session and inter-session $C V s$ for $\mathrm{P}_{\mathrm{AO}}$ and $\Delta \mathrm{P}$ after implantation of intra-aortic pressure catheter in trained, awake rats.

\begin{tabular}{rcccc}
\hline & \multicolumn{2}{c}{$\mathrm{P}_{\mathrm{AO}}$} & \multicolumn{2}{c}{$\Delta \mathrm{P}$} \\
\cline { 2 - 5 } & Mean, mmHg & $\mathrm{CV}, \%$ & Mean, mmHg & $\mathrm{CV}, \%$ \\
Intra-session & $121.5 \pm 5.2$ & $3.9 \pm 1.9$ & $39.7 \pm 2.4$ & $4.8 \pm 3.0$ \\
Day 1 & $126.1 \pm 3.6$ & $2.6 \pm 1.2$ & $47.3 \pm 2.6$ & $5.3 \pm 2.1$ \\
Day 2 & $116.6 \pm 2.8$ & $2.1 \pm 1.0$ & $46.2 \pm 2.2$ & $4.5 \pm 4.2$ \\
Day 3 & $121.4 \pm 4.0$ & $2.9 \pm 1.6$ & $44.4 \pm 2.4$ & $4.9 \pm 3.3$ \\
Inter-session & & & & \\
\hline
\end{tabular}

Values are means $\pm \mathrm{SD} ; \mathrm{n}=6$. Intra-session (4 measurements per rat per day) CVs on 3 consecutive days and inter-session $\mathrm{CVs}$ for $\mathrm{P}_{\mathrm{AO}}$ and $\triangle \mathrm{P}$ in trained, awake rats after implanation of intra-aortic pressure catheter. Measurements began 2 days after implantation. Mean values of $\mathrm{P}_{\mathrm{AO}}$ and $\Delta \mathrm{P}$ per day and averaged over 3 days (inter-session)are presented as well.

\section{DISCUSSION}

The findings in the present study show that the basic parameters, like aortic diameter, the change in aortic diameter during the cardiac cycle and aortic pulse pressure, required to calculate aortic distensibility and compliance, can be determined reliably in both anesthetized and awake rats by means of an ultrasonic vessel wall tracking system attached to a conventional B-mode imager and an implanted pressure catheter. To the best of our knowledge this is the first time that these parameters have been measured in conscious rats. This offers the possibility to study non-invasively aortic wall properties in small animal models of, for example, hypertension and diabetes, and to investigate in these models the relationship between changes in these properties on the one hand and cellular and molecular changes in the aortic wall on the other, if any. Besides, the technique is enough sensitive to obtain information regarding the effects of pharmacological agents on aortic wall properties.

In the past decades several techniques have been developed to measure artery wall displacement. One of the first techniques made use of amplitude tracking, i.e. tracking of the crossing of the leading edge of the received wall signals in A-mode (Arndt JO et al.,1968). In this approach both the internal artery diameter and the change in artery diameter during the cardiac cycle are overestimated, mainly because the echogenicity depends on the distance between transducer and artery wall, which varies with the phase of this cycle. An alternative approach uses zerocrossing tracking combined with detection of the phase of the RF signal (Hokanson DE et al.,1972; Mozersky DJ et al.,1972). Later developments along this line aimed at improvements in the detection and processing methods (Groves DH et al.,1982; Imura TK et al.,1986). The zerocrossing method is far more accurate than amplitude tracking, but is sensitive to changes in the position of the artery relative to the probe due to local RF phase interference. In the method presented here a 2D-echo system in combination with displacement estimation, using cross-correlation of RF signals, is employed for the simultaneous detection of artery diameter and artery wall displacement. In an early development (Hoeks APG et al.,1985) both sample volumes coinciding with the walls were fixed in depth and size, preventing adequate tracking of the walls. In later systems these sample volumes were allowed to track the moving position of the wall. Initially Doppler tracking was 
used (Hoeks APG et al.,1990), but in the present study we employ RF correlation tracking. This type of tracking is insensitive to phase interference by RF signals returned from closely spaced reflectors. An additional advantage is that the output of the RF correlator is presented in a fraction of sample points rather than a fraction of an RF period, as with the Doppler method, so that the sample frequency can be chosen freely provided that it is higher than twice the maximum frequency of the RF signal. Moreover, the result is independent of the actual carrier frequency allowing the emission of short bursts (wide bandwith) to obatin a high axial resolution.

Good intra- and inter-session coefficients of variation were obtained in an- esthetized and awake rats. It is interesting to note that before implantation of the catheter to measure intra-aortic blood pressure, the intra- and inter-session coefficients of variation for the diameter changes of the aorta during the cardiac cycle $(\Delta d)$ are better in the awake (intra: $4.6-6.0 \%$; inter: $5.3 \%$ ) than in the anesthetized animals with an implanted catheter (intra: 7.9-11.0\%; inter: $9.2 \%$ ). For the assessment of the aortic diameter the intra- and inter-session coefficients of variation are comparable under these circumstances (awake, intra: 2.6-5.0\%; inter: $3.7 \%$; anesthetized, intra: $3.3-6.5 \%$, inter: $4.6 \%$ ). No clear-cut explanation can be given for the difference in the coefficients of variation for the assessment of the changes in aortic diameter during the cardiac cycle between the awake and anesthetized rats because no aortic blood pressure data are availabe in the awake animals before implantation of the catheter. Nevertheless it is tempting to speculate that the larger coefficient of variation in the anesthetized rats results from the relatively large variability in aortic pulse pressure $(\Delta \mathrm{P})$ in these animals (intra: 9.0-12.3\%; inter:
$11.0 \%), \Delta \mathrm{P} \quad$ being an important determinant of $\Delta \mathrm{d}$. The variations in pulse pressure are likely to be caused by the anesthesia. Although we aimed at performing the measurements of aortic diameters and the aortic diameter changes during the cardiac cycle when blood pressure had stabilized after induction of anesthesia, differences in pulse pressure between measurements had to be appreciated.

It cannot be excluded that the intraaortic catheter affects the reliability of the determination of the aortic diameter changes during the cardiac cycle, because in the awake rats the coefficients of variation for this parameter increased after implantation of the catheter (Table 2.3), despite the fact that the variations in pulse pressure were small. After implantation, like before implantation, the variations in the changes in aortic diameter during the cardiac cycle, however, were not significant. One could argue that implantation of the catheter, which is large in outer diameter relative to the aortic lumen, induces reflections overestimating the change in aortic diameter during the cardiac cycle. This change in diameter, however, appeared to be slightly but significantly smaller after than before implantation of the catheter so that the influence of reflections can likely be ignored.

Diastolic aortic blood pressure is an important determinant of diastolic aortic diameter. Therefore, the small coefficients of variation for the latter parameter can be explained by the small variations in the former one, at least in the experiments where aortic blood pressure was measured (Group I and Group II after implantation of the catheter).

Although the technique presented allows the assessment of the basic parameters for the determination of distensibility and compliance in conscious rats, one should realize that the animals 
are likely to be stressed in their restrainers as indicated by the relatively high diastolic aortic pressures (cf Tables 2.2 and 2.4) and heart rates (cf Tables 2.2 and 2.3) under these circumstances. The pulse pressures of the awake and anesthetized rats, however, were comparable (cf Tables 2.2 and 2.4).

It may be concluded that aortic distensibility and compliance can be calculated reliably in awake and anesthetized rats by measuring aortic pulse pressure through an implanted catheter, and aortic diameter and the aortic diameter changes during the cardiac cycle by means of an ultrasonic vessel wall tracking system combined with a conventional B-mode imager. The measurements may also be considered to be accurate, because in vitro this system has been shown to be able to resolve displacements of a few micrometers (Hoeks APG et al.,1993). 


\section{REFERENCES}

Arndt, J.O., J. Klauske, and F. Mersch. The diameter of the intact carotid artery in man and its change with pulse pressure. Eur. J. Physiol. (Pflügers Arch.) 301: 230240, 1968.

Dobrin, P.B. Mechanical properties of arteries. Physiol. Rev. 58: 397-460, 1978.

Gow, B.S., and C.D. Hadfield. The elasticity of canine and human coronary arteries with reference to postmortem changes. Circ. Res. 45: 588-594, 1979.

Groves, D.H., T. Powalowski, and D.N. White. A digital technique for tracking movies interfaces. Ultrasound Med. Biol. 8: 185-190, 1982

Hayoz, D., Y. Tardy, F. Perret, B. Waeber, J.-J. Meister, and H.R. Brunner. Noninvasive determination of arterial diameter and distensibility by echotracking techniques in hypertension. $J$. Hypertens. 10: S95-S100, 1992.

Hoeks, A.P.G. Non-invasive study of the local mechanical arterial characteristics in humans. In: The arterial system in bypertension. Eds. M.E. Safar and M.F. O'Rourke, Kluwer Academic Publ.: 119. 134, 1993.

Hoeks, A.P.G., T.G.J. Arts, P.J. Brands, and R.S. Reneman. Comparison of the performance of the RF cross-correlation and Doppler autocorrelation technique to estimate the mean velocity of simulated ultrasound signals. Ultrasound Med. Biol. 19: 727-740, 1993.

Hoeks, A.P.G., P.J. Brands, F.A.M. Smeets, and R.S. Reneman. Assessment of the distensibility of superficial arteries. Ultrasound Med. Biol. 16: 121-128, 1990.

Hoeks, A.P.G., C.J. Ruissen, P. Hick, and R.S. Reneman. Transcutaneous detection of relative changes in artery diameter. Ultrasound Med. Biol. 11: 51-59, 1985.

Hokanson, D.E., D.J. Mozersky, D.S. Sumner, and D.E. Strandness. A phase locked echo-tracking system for recording arterial diameter changes in vivo. J. Appl. Phys. 32: 728-733, 1972.

Imura, T., K. Yamamoto, K. Kanamori, T. Mikami, and H. Yasuda. Non-invasive ultrasonic measurement of the elastic properties of the human abdominal aorta. Cardiovasc. Res. 20: 208-214, 1986.

Laurent, S., B. Caviezel, L. Beck, X. Girerd, E. Billaud, P. Boutouyrie, A. Hoeks, and M. Safar. Carotid artery distensibility and distending pressure in hypertensive humans. Hypertension 23: 878-883, 1994.

Laurent, S., X. Girerd, J.-J. Mourad, P. Lacolley, L. Beck, P. Boutouyrie, J.-P. Mignot, and M. Safar. Elastic modulus of the radial artery wall material is not increased in patients with essential hypertension. Arterioscler. Thromb. 14: 1223-1231, 1994.

Mozersky, D.J., D.S. Sumner, D.E. Hokanson, and D.E. Strandness. Transcutaneous measurement of the elastic properties of the human femoral artery. Circulation 46: 948-955, 1972.

Reneman, R.S., T. Van Merode, P. Hick, A.M.M. Muytjens, and A.P.G. Hoeks. Age-related changes in carotid artery wall properties in men. Ultrasound Med. Biol. 12: 465-471, 1986.

Safar, M.E., P.A. Peronneau, J.A. Levenson, J.A. Toto-Moukouo, and A. Ch. Simon. Pulsed Doppler: diameter, blood flow velocity and volumic flow of the brachial artery in sustained essential hypertension. Circulation 63: 393-400, 1981.

Simon, A.Ch., A. Laurent, J.A. Levenson, J.E. Bouthier, and M.E. Safar. Estimation of forearm arterial compliance in normal and hypertensive men. Cardiovasc. Res. 17: 331-338, 1983.

Van Merode, T., P.J. Brands, A.P.G. Hoeks, and R.S. Reneman. Faster ageing of the carotid artery bifurcation in borderline hypertensive subjects. J. Hypertens. 11: 171-176, 1993.

Van Merode, T., P.J.J. Hick, A.P.G. Hoeks, K.H. Rahn, and R.S. Reneman. Carotid artery wall properties in normotensive and borderline hypertensive subjects of various ages. Ultrasound Med. Biol. 14: 563-569, 1988.

Van Merode, T., J. Lodder, F Smeets, A Hoeks, and R. Reneman. Accurate noninvasive method to diagnose minor atherosclerotic lesions in carotid artery bulb. Stroke 20: 1336-1340, 1989. 


\section{CHAPTER}

EFFECTS OF SMOOTH MUSCLE TONE ON AORTIC COMPLIANCE IN CONSCIOUS NORMOTENSIVE AND SPONTANEOUSLY HYPERTENSIVE RATS
A.W. van Gorp
D.S. van Ingen Schenau
A.P.G. Hoeks
H.A.J. Struijker Boudier
R.S. Reneman
J.G.R. De Mey 


\section{ABSTRACT}

We evaluated whether smooth muscle modulates elastic properties of the aorta in conscious rats. We therefore applied ultrasound wall tracking at the level of the thoracic aorta in conscious restrained normotensive Wistar Kyoto (WKY) and spontaneously hypertensive rats (SHR) during intravenous administration of vasoactive agents. In WKY, the $\alpha_{1}$-adrenoceptor antagonist prazosin $(0.2$ to 5.0 $\mu \mathrm{g} / \mathrm{kg}$.min $)$ significantly increased the diastolic lumen area of the aorta $\left(\mathrm{A}_{\text {dia }}+20 \%\right.$ at the highest dose), but did not modify the compliance (CC) or distensibility (DC) of the vessel. Similarly, the $\mathrm{AT}_{1}$-receptor antagonist losartan $(30 \mu \mathrm{g} / \mathrm{kg}$.min) increased $\mathrm{A}_{\text {dia }}(+19 \%)$ but did not modify CC or DC. Low doses of the $\alpha_{1}$-adrenoceptor agonist phenylephrine ( 0.08 to $2.0 \mu \mathrm{g} / \mathrm{kg}$.min) did not modify blood pressure $(\mathrm{P})$ nor the $\mathrm{A}_{\text {dia }}$, CC or DC of the aorta. At higher doses of phenylephrine $(10 \mu \mathrm{g} / \mathrm{kg} \cdot \mathrm{min})$, both P and $\mathrm{A}_{\text {dia }}(+36 \%)$ were increased and CC and DC were reduced. Similar effects were observed with angiotensin II (4 to $100 \mathrm{ng} / \mathrm{kg}$.min). In SHR the vasopressor agonists induced qualitatively similar effects: low doses were without effect on the aorta while high doses caused increases in $\mathrm{P}$ and $\mathrm{A}_{\mathrm{DIA}}$ and decreases in CC and DC. Losartan (30 $\mu \mathrm{g} / \mathrm{kg} . \mathrm{min})$ did not elicit significant responses in SHR while prazosin $(5.0 \mu \mathrm{g} / \mathrm{kg} \cdot \mathrm{min})$ induced a marked reduction of $\mathrm{P}$ that was accompanied by a fall of $\mathrm{A}_{\text {dia }}$ and a significant increase in CC. Prazosin abolished the difference in blood pressure between WKY and SHR, while phenylephrine and angiotensin II raised P in WKY to the level seen in SHR. In each of these isobaric conditions, $A_{\text {dia }}$ and CC were significantly smaller in SHR than in WKY, while the elastic modulus was comparable in both strains. These results suggest that in conscious restrained rats, the thoracic aorta is in a state of active vasoconstriction and that this activity of the aortic smooth muscle does not influence the pulsatile mechanics of the vessel. The results furthermore confirm that the compliance of the rat aorta is primarily dependent upon blood pressure and that pressure-independent differences between WKY and SHR are largely due to the smaller aortic lumen in the hypertensive rats.

\section{INTRODUCTION}

Systemic arterial compliance and resistance influence the afterload on the left ventricle. The former is located primarily in the aorta. The latter is offered predominantly by the small muscular arteries and arterioles (Westerhof $\mathrm{N}$ et al.,1969; Folkow B,1982). In the distal parts of the arterial tree, the arterial smooth muscle clearly mediates the influences of autonomic nerves, hormones and endothelium-derived factors on resistance. Influences of aortic smooth muscle on arterial compliance are less well established. In recent experiments using intravascular ultrasound in man (Bank AJ et al.,1995) and locally applied recording devices in dogs (Barra JG et al.,1993), it could be demonstrated that intra-aortic application of vasoactive agents altered the pulsatile mechanical properties of the vessel. It remains to be established whether in conditions of activated neurohumoral mechanisms, as in hypertension and congestive heart failure, these subtle local influences on the aorta are not overruled by pressure changes resulting from the stimulation of the distal muscular arteries. Moreover, the situation is not clear in rats, a species in which several experimental models for various cardiovascular diseases have been developed. Previous experiments in rats involved vessel isolation, extensive surgery or anesthesia, which are known to influence smooth muscle cell reactivity and vessel wall mechanics (Dobrin PB et al.,1969; Gow BS et al.,1979; Pagani M et al.,1979). In hypertensive rats, influences of smooth muscle tone on aorta compliance may be pronounced as a result of (a) smooth muscle hypertrophy, 
(b) increased supply and sensitivity to vasoconstrictor stimuli, and (c) impaired endothelium-dependent vasodilatation.

In the present study we used a recently developed ultrasound/arterial wall tracking system to record changes in aortic lumen caliber in relation to changes in aortic pressure in conscious rats (Van Gorp et al.,1996). Recordings were made in the same animals during systemic administration of stimuli and antagonists of $\alpha_{1}$-adrenoceptors and angiotensin II receptors, which have been proposed to be activated in essential hypertension and heart failure (Head RJ et al.,1989; Dzau VJ et al.,1994). Furthermore, measurements were performed during ketamine/xylazine anesthesia, which is accompanied by marked inhibition of vasomotor centers in the central nervous system (Van Zwieten P.A et al.,1983). Both normotensive WKY rats and spontaneously hypertensive rats (SHR) were used.

\section{MATERIALS AND METHODS}

\section{Study design}

The experimental procedures were performed according to institutional guidelines and approved by the Ethical Committee for the Use of Experimental Animals of the Universiteit Maastricht (The Netherlands). Experiments were performed in male Wistar Kyoto (WKY) and spontaneously hypertensive rats (SHR) (local inbred strains, Universiteit Maastricht). To familiarize them with the experimental conditions, they were placed in a restrainer for 2 hours during 5 days a week from 6 to 10 weeks of age. Then sham aortic wall tracking (see below) was added to the training program for another week. From this stage on, a total of 11 recording sessions were performed in each individual at 2 to 4 days interval. All recordings were performed by the same observer. Each session consisted of at least
4 recordings during $1.3 \mathrm{~s}$ (approximately 7 cardiac cycles and 2 to 3 respiration cycles). During the first 6 sessions, the reproducibility of the ultrasound aortic wall tracking technique was evaluated. This is described in detail elsewhere (Van Gorp A. et al.,1996). Then the rats were anesthetized with Na-pentobarbital and equipped with an intra-aortic and an intravena-cava catheter filled with heparinized saline. These catheters were advanced from the femoral artery and vein, guided under the dorsal skin and exteriorized at the back of the head. The arterial catheter was used for intra-aortic pressure measurements with an external low volume displacement pressure transducer (CP-01, Century Technology, Inglewood, CA, USA). Its tip was positioned just below the renal arteries.

From the 7th recording session onwards, antagonists and agonists were infused through the intravenous cannula to evaluate influences of neurohumoral mechanisms.

The order of drug testing was as follows: session 7 , prazosin ( 0.2 to 5.0 $\mu \mathrm{g} / \mathrm{kg}$.min); session 8 , phenylephrine ( 0.08 to $10.0 \mu \mathrm{g} / \mathrm{kg} \cdot \mathrm{min})$; session 9 , losartan (DUP753, $30 \mu \mathrm{g} / \mathrm{kg}$.min during $60 \mathrm{~min}$ ) with addition of prazosin $(5.0 \mu \mathrm{g} / \mathrm{kg} \cdot \mathrm{min})$ during the last $15 \mathrm{~min}$; session 10 , angiotensin II ( 0.004 to $0.1 \mu \mathrm{g} / \mathrm{kg}$.min $)$ followed by the administration of prazosin $(5.0 \mu \mathrm{g} / \mathrm{kg}$.min) during continuous infusion of the highest dose of the vasopressor peptide. Between drug administrations, separated by 2-3 days, all variables returned to their basal values. The drugs were obtained from Sigma Chemicals (Saint Louis, MO, USA).

At the initiation of the 7th recording session, a 1-ml arterial blood sample was obtained to determine plasma catecholamine levels by HPLC and fluorescent detection (Van der Hoorn et al, 1989). Between session 8 and 9, basal values of blood pressure $(\mathrm{P})$ and pulse 
interval (PI) and plasma norepinephrine (NE) and epinephrine (E) levels were determined while the animals were undisturbed and freely moving in their individual cages.

During the last recording session, the animals were anesthetized with ketamine/xylazine $\quad(10: 50 \mu \mathrm{g} / \mathrm{ml} ; 100$ $\mu \mathrm{l} / 100 \mathrm{~g}$ body weight). After recording of blood pressure and aorta mechanics, a blood sample was obtained and the animals were exsanguinated through the arterial cannula. The thoracic aorta was isolated, fixed, cross-sectioned and stained with Lawson's solution after which the crosssectional area of the tunica media (CSA) was determined (Boonen H.C.M. et al.,1993). The CSA was corrected for the recoil that occurred during vessel isolation (Van Gorp $\mathrm{AW}$ et al.,1995). It was assumed that media CSA did not change significantly during the experimental period.

\section{Ultrasound assessment of aorta diameter and distension}

The ultrasound device described to assess diameter (d) and diameter changes $(\Delta d)$ of the aorta consists of a vessel wall-tracking system (WTS) combined with a conventional B-mode (B, brightness) ultrasound system (Pie 480, 7.5 Mhz. Linear array, Pie Medical, Maastricht, The Netherlands). The rats were shaved at the site of measurement, and the ultrasound probe was placed on the thorax slightly to the left of the sternum; ultrasonic gel is applied between probe and skin. The thoracic aorta was then visualized in Bmode $10 \mathrm{~mm}$ proximal to the diaphragm, and the probe was positioned so that the $\mathrm{M}$-line (M, motion) was perpendicular to the vessel wall. Then the ultrasound system was switched to M-mode, and ultrasound was emitted and received along the selected line of sight at a programmable emission trigger frequency.
The WTS is based on a data acquisition system, capable of capturing the received and amplified radio frequency signals synchronously with the emission trigger at a programmable sample frequency of up to $30 \mathrm{Mhz}$. The position and width of the range of interest are programmable (on the average 20 and 10 $\mathrm{mm}$, respectively, in the present study). Reference signals, such as blood pressure, are likewise synchronously sampled with the emission trigger. At an emission frequency of $1653 \mathrm{~Hz}$., the $1 \mathrm{MB}$. Internal memory will hold $2.5 \mathrm{~s}$. of data, corresponding to approximately 16 cardiac and 4 respiration cycles under the current experimental conditions. Because of the higher heart rate in the awake rats, sampling frequency was doubled, resulting in data collection for $1.2 \mathrm{~s}$.

After completion of the data acquisition, the data were transferred to a PC (486 DX2/66). The first line acquired was graphically presented on a display, allowing manual identification of the anterior and posterior wall bounderies by placing two markers, representing the sample windows for data processing. Once the walls are identified, the remaining data are transferred and processed on the fly.

\section{Relationship between aortic diameter and pressure}

Diastolic diameter $\left(\mathrm{d}_{\text {dia }}\right)$ and diameter changes during the cardiac cycle $(\Delta d)$ were converted to lumen area $\left(\mathrm{A}_{\text {dia }}\right)$ and changes thereof $(\Delta \mathrm{A})$, assuming a circular crosssection of the vessel $\left(\mathrm{A}_{\mathrm{dia}}=\pi \cdot\left(\mathrm{d}_{\mathrm{dia}} / 2\right)^{2}\right)$. With the additional assumption that the length of the vessel remains constant, a reasonable assumption (Reneman R.S. et al.,1996), the absolute and relative change in lumen area per unit of pressure represent the compliance and distensibility of the vessel, respectively. Pressure measurements and recordings of aorta diameter were performed at different 
locations (below the renal arteries and above the diaphragm, respectively). Furthermore, both transducer systems are likely to differ in terms of their timeresponse relationship. We therefore limited the data analysis to the situation at enddiastole and to the maximal changes occurring during the cardiac cycle. $\Delta \mathrm{A} / \Delta \mathrm{P}$ and $\left(\Delta \mathrm{A} / \mathrm{A}_{\mathrm{dia}}\right) / \Delta \mathrm{P}$ will be referred to as the compliance coefficient (CC) and the distensibility coefficient (DC), respectively. $\mathrm{D}_{\text {dia }}$ and $\mathrm{DC}$ were further used for the calculation of the incremental elastic modulus or Young's modulus $\left(\mathrm{E}_{\text {inc }}\right)$ according to the formula:

$$
\mathrm{E}_{\text {inc }}=\mathrm{D}_{\text {dia }} /(\text { h.DC })
$$

in which $\mathrm{h}$ represents the media thickness, which was calculated from the media cross-sectional area (CSA) and $\mathrm{D}_{\text {dia }}$ according to the following formula:

$$
\mathrm{h}=-\left(\mathrm{d}_{\mathrm{dia}} / 2\right)+\left\{\left(\mathrm{d}_{\mathrm{dia}} / 2\right)^{2}+\mathrm{CSA} / \pi\right\}^{1 / 2}
$$

\section{Statistics}

Observations obtained during the $1.3 \mathrm{~s}$ recordings were averaged. Two recordings were obtained in each animal under each condition of drug and dose and these were averaged. Observations during drug administration were compared to those under basal conditions during the same session, using ANOVA followed by Bonferroni's t-test. Representative basal values were obtained by averaging all findings prior to drug administration in all 5 experimental sessions. The data are shown as mean \pm SEM.

Table 3.1: Effects of restraining and anesthesia on blood pressure, heart rate and plasma catecholanimes in ratsa.

\begin{tabular}{lcccccc}
\hline & \multicolumn{3}{c}{ Wistar Kyoto rats } & \multicolumn{3}{c}{ Spontaneously Hypertensive rats } \\
condition & $\begin{array}{l}\text { Conscious } \\
\text { free }\end{array}$ & restrained & anesthetized & $\begin{array}{l}\text { Conscious } \\
\text { free }\end{array}$ & restrained & anesthetized \\
$\mathrm{P}_{\text {dia }}(\mathrm{mmHg})$ & $91 \pm 3$ & $124 \pm 4^{*}$ & $93 \pm 4^{*}$ & $145 \pm 5$ & $156 \pm 5^{*}$ & $98 \pm 5^{*}$ \\
$\Delta \mathrm{P}(\mathrm{mmHg})$ & $46 \pm 3$ & $41 \pm 5$ & $30 \pm 3^{*}$ & $57 \pm 4$ & $62 \pm 4$ & $49 \pm 5$ \\
$\mathrm{HR}(\mathrm{b} / \mathrm{min})$ & $352 \pm 19$ & $469 \pm 12^{*}$ & $271 \pm 15^{*}$ & $412 \pm 20$ & $495 \pm 25^{*}$ & $265 \pm 17^{*}$ \\
{$[\mathrm{NE}](\mathrm{pg} / \mathrm{ml})$} & $143 \pm 39$ & $283 \pm 43^{*}$ & $20 \pm 4^{*}$ & $397 \pm 84$ & $797 \pm 169 *$ & $25 \pm 6^{*}$ \\
{$[\mathrm{E}](\mathrm{pg} / \mathrm{ml})$} & $103 \pm 32$ & $95 \pm 28$ & $<3^{*}$ & $393 \pm 83$ & $349 \pm 73$ & $10 \pm 6^{*}$ \\
\hline
\end{tabular}

${ }^{a}$ Diastolic blood pressure $\left(\mathrm{P}_{\text {dia }}\right)$, pulse pressure $(\Delta \mathrm{P})$, heart rate $(\mathrm{HR})$, are shown along with arterial plasma levels of norepinephrine $([N E])$ and epinephrine $([E])$ as means \pm SEM $(n=10)$

* The difference from conscious/free is statistically significant $(\mathrm{p}<0.05)$ 

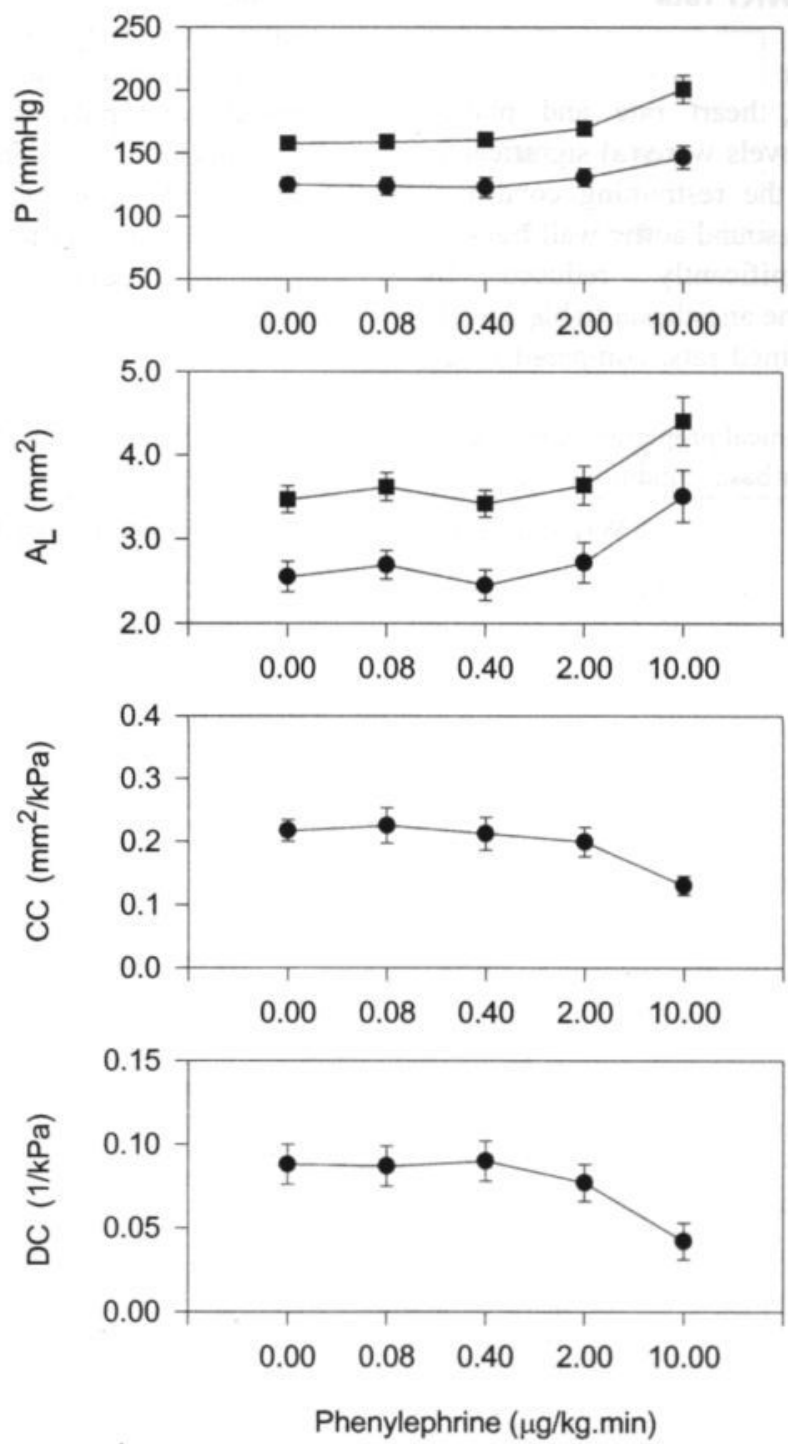

Figure 3.1 Effects of increasing doses of phenylephrine $(0.08$ to $10.0 \mu \mathrm{g} / \mathrm{kg}$.min $)$ on pressure $(P)$, aortic lumen area $\left(A_{L}\right)$, compliance $(C C)$ and distensibility $(D C)$ in conscious rats. $A_{L}$ and $P$ are shown for both end-diastole (circles) and peak systole (squares). Means $\pm \operatorname{SEM}(n=7)$. 


\section{RESULTS}

\section{Normotensive WKY rats}

\section{Basal conditions}

Blood pressure, heart rate and plasma catecholamine levels were (a) significantly elevated under the restraining conditions required for ultrasound aortic wall tracking and (b) significantly reduced by ketamine/xylazine anesthesia (table 3.1). In conscious restrained rats, compared to the same animals under anesthesia, the lumen area of the aorta at end-diastole $\left(\mathrm{A}_{\text {dia }}\right)$ and the distension of the vessel during the cardiac cycle $(\Delta \mathrm{A})$ were significantly smaller despite the elevated diastolic pressure and pulse pressure (table 3.2). Consequently, the compliance (CC) and distensibility (DC) of the aorta were smaller and the elastic modulus $\left(\mathrm{E}_{\text {inc }}\right)$ was larger in conscious than in anesthetized WKY (table 3.2).

Table 3.2: Mechanical properties of the thoracic aorta in consious restrained and in anesthetized rats under basal conditions ${ }^{\mathrm{a}}$.

\begin{tabular}{lcccc}
\hline & \multicolumn{2}{c}{ Wistar Kyoto rats } & \multicolumn{2}{c}{ Spontaneoulsy hypertenisve rats } \\
& $\begin{array}{l}\text { Conscious/ } \\
\text { restrained }\end{array}$ & Anesthetized & $\begin{array}{l}\text { Conscious/ } \\
\text { restrained }\end{array}$ & Anesthetized \\
$\mathrm{P}_{\text {dia }}(\mathrm{mmHg})$ & $124 \pm 4$ & $93 \pm 4^{\mathrm{s}}$ & $153 \pm 4^{+}$ & $98 \pm 5^{\mathrm{s}}$ \\
$\Delta \mathrm{P}(\mathrm{mmHg})$ & $41 \pm 5$ & $30 \pm 3^{\mathrm{s}}$ & $53 \pm 4$ & $49 \pm 5^{+}$ \\
$\mathrm{A}_{\text {dia }}\left(\mathrm{mm}^{2}\right)$ & $2.61 \pm 0.21$ & $2.82 \pm 0.16^{\mathrm{s}}$ & $2.72 \pm 0.15$ & $2.60 \pm 0.10^{\mathrm{s+}}$ \\
$\Delta \mathrm{A}\left(\mathrm{mm}^{2}\right)$ & $0.84 \pm 0.08$ & $1.17 \pm 0.11^{\mathrm{s}}$ & $0.58 \pm 0.04^{+}$ & $0.83 \pm 0.10^{\mathrm{s}}$ \\
$\mathrm{CC}\left(\mathrm{mm}^{2} / \mathrm{kPa}\right)$ & $0.165 \pm 0.020$ & $0.313 \pm 0.038^{\mathrm{s}}$ & $0.087 \pm 0.009^{+}$ & $0.135 \pm 0.013^{\mathrm{s+}}$ \\
$\mathrm{DC}(1 / \mathrm{kPa})$ & $0.064 \pm 0.007$ & $0.113 \pm 0.011^{\mathrm{s}}$ & $0.032 \pm 0.003^{+}$ & $0.053 \pm 0.091^{\mathrm{s+}}$ \\
$\mathrm{E}_{\text {inc }}(\mathrm{kPa})$ & $322 \pm 44$ & $208 \pm 32^{\mathrm{s}}$ & $665 \pm 83^{+}$ & $396 \pm 61^{\mathrm{s+}}$ \\
\hline
\end{tabular}

${ }^{a}$ Diastolic blood pressure $\left(\mathrm{P}_{\text {dia }}\right)$, pulse pressure $(\Delta \mathrm{P})$, aortic lumen aera at end-diastole $\left(\mathrm{A}_{\text {dia }}\right)$, aortic distension during the cardia cycle $(\triangle \mathrm{A})$, compliance $(\mathrm{CC})$, distensibility $(\mathrm{DC})$ and incremental elastic modulus $\left(E_{\text {inc }}\right)$ are shown as mean $\pm \operatorname{SEM}(n=10)$.

s the differnce from conscious is statistically significant $(p<0.05)$.

${ }^{+}$the difference from WKY is statistically significant $(\mathrm{p}<0.05)$.

Effects of $\alpha_{1}$-adrenoceptor stimulation and blockade

Intravenous infusion of increasing doses of phenylephrine in restrained conscious WKY ultimately increased arterial blood pressure (Fig. 3.1). Low subpressor doses of the agonist $(0.08$ and $0.4 \mu \mathrm{g} / \mathrm{kg}$.min $)$ did not significantly alter the lumen area, distension or mechanical properties of the aorta (Fig. 3.1). At a high vasopressor dose (10 $\mu \mathrm{g} / \mathrm{kg} \cdot \mathrm{min})$, both $\mathrm{P}_{\text {dia }}$ and $\Delta \mathrm{P}$ were elevated. This was accompanied by an increase in $\mathrm{A}_{\text {dia }}$ and a reduction of $\mathrm{CC}$ and
DC. As a consequence, $\mathrm{E}_{\text {inc }}$, was increased under this condition (Fig. 3.1, table 3.3).

At 1.0 and $5.0 \mu \mathrm{g} / \mathrm{kg} \cdot \mathrm{min}$, prazosin lowered $\mathrm{P}_{\text {dia }}$ simultaneously with a significant dilatation of the thoracic aorta (Fig. 3.2). Mechanical properties of the vessel, such as CC, DC, and $\mathrm{E}_{\text {ine }}$, were not significantly modified during prazosininduced blood pressure lowering and dilatation (Fig. 3.2, table 3.3). 

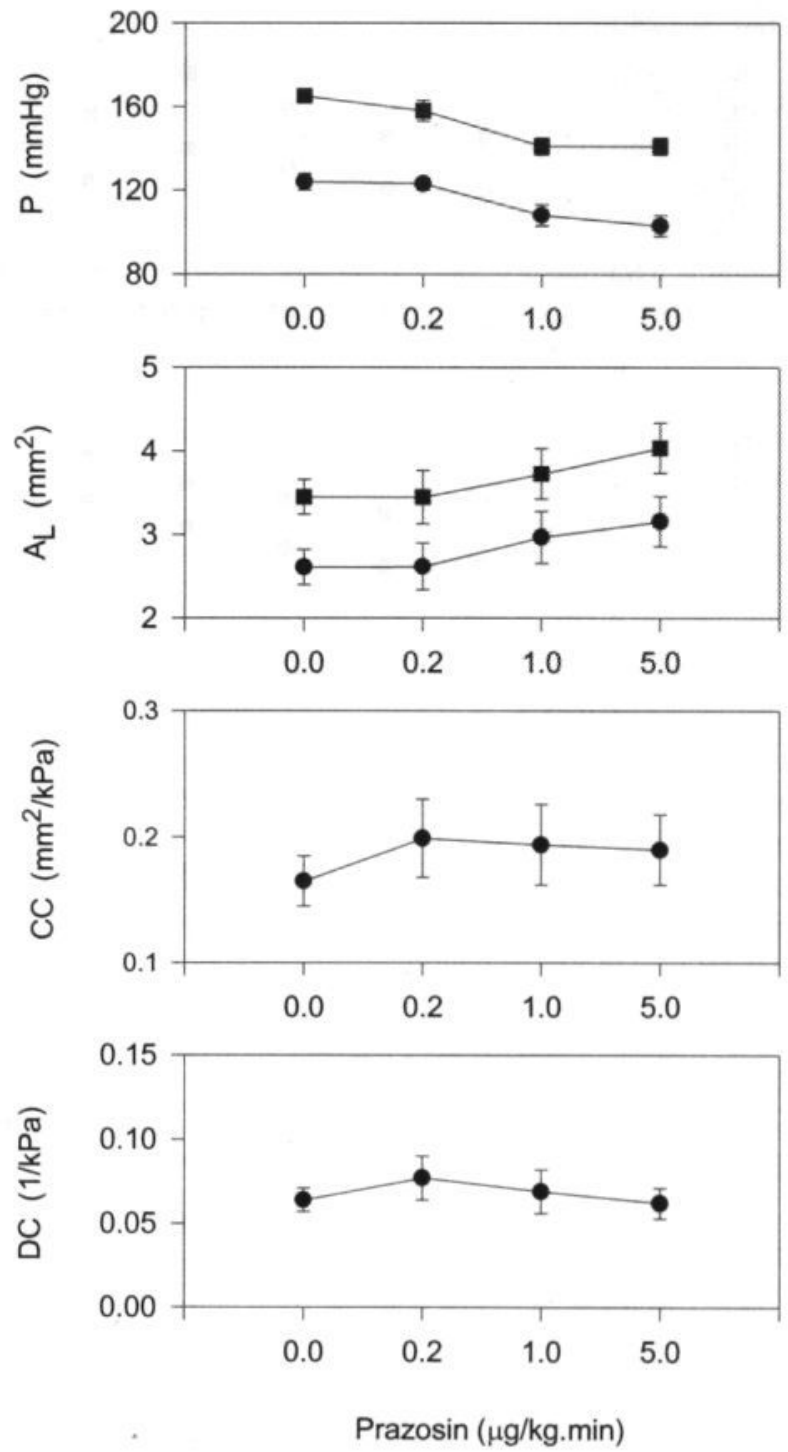

Figure 3.2 Effects of increasing doses of prazosin $(0.2$ to $5.0 \mathrm{Fg} / \mathrm{kg}$.min) on pressure (P), aortic lumen area $\left(A_{L}\right)$ compliance $(C C)$ and distensibility $(D C)$ in conscious rats. $A_{L}$ and $P$ are shown for both end-diastole (circles) and peak systole (squares). Means \pm SEM $(\mathrm{n}=7)$. 

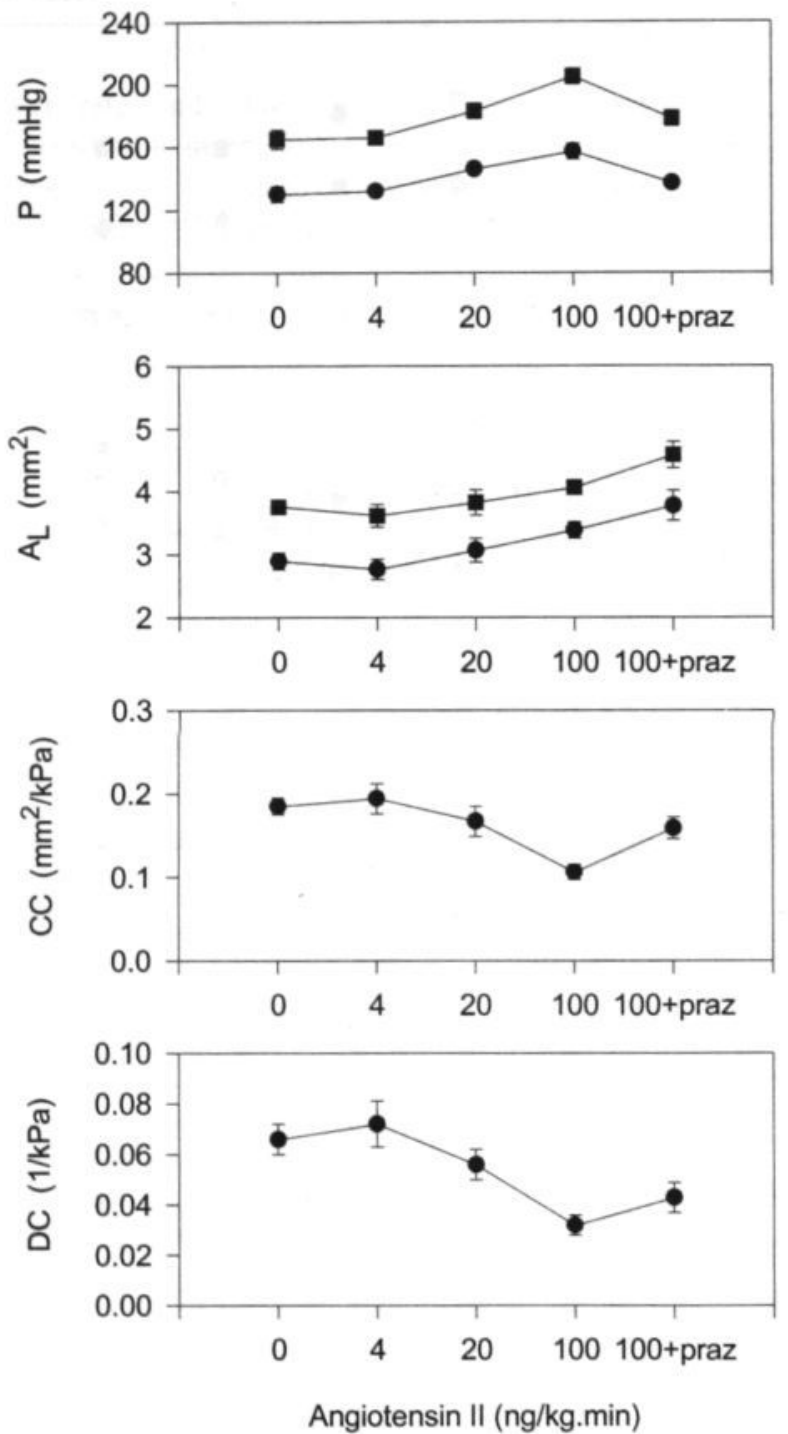

Figure $3.3 \quad$ Effects of increasing doses of angiotensin II (4 to $100 \mathrm{ng} / \mathrm{kg}$.min) on pressure (P), aortic lumen area $\left(A_{L}\right)$, compliance $(C C)$ and distensibility $(D C)$ in conscious rats. $\mathrm{A}_{\mathrm{L}}$ and $\mathrm{P}$ are shown for both end-diastole (circles) and peak systole (squares). During administration of the highest dose of the peptide, prazosin (PRAZ, $5 \mu \mathrm{g} / \mathrm{kg}$.min) was included in the infusate. Means $\pm \operatorname{SEM}(\mathrm{n}=7)$.

Effects of angiotensin II and losartan

Intravenous infusion of increasing doses of angiotensin II ultimately increased blood pressure in conscious WKY. A low subpressor dose of the peptide (4 $\mathrm{ng} / \mathrm{kg}$.min) did not significantly modify the 
lumen area and mechanical properties of the aorta (Fig. 3.3). At a high pressor dose (100 ng/kg.min), $P_{\text {dia }}$ and $A_{\text {dia }}$ were increased, while CC and DC were reduced (Fig. 3.3). This was accompanied by a marked increase of $\mathrm{E}_{\text {inc }}$ (table 3.3).

Administration of prazosin $\mu \mathrm{g} / \mathrm{kg}$.min) partly reversed the pressor effect of angiotensin II (100 ng/ kg.min) but induced an additional dilatation of the aorta (Fig. 3.3). This was accompanied by partial normalization of CC (Fig. 3.3). Yet, DC remained significantly reduced and $E_{\text {inc }}$ remained significantly enhanced, possibly due to the dependence of these parameters on the aortic lumen area.

During 45 minutes of administration of losartan $(30 \mu \mathrm{g} / \mathrm{kg} \cdot \mathrm{min}), \mathrm{P}_{\text {dia }}$ and $\Delta \mathrm{P}$ were not significantly modified. At 30 minutes after exposure to the $\mathrm{AT}_{1}$-receptor antagonist, $\mathrm{A}_{\mathrm{dia}}$ was significantly elevated $\left(3.03 \pm 0.26\right.$ versus $\left.2.60 \pm 0.22 \mathrm{~mm}^{2}\right)$, but $\mathrm{CC}, \mathrm{DC}$, or $\mathrm{E}_{\text {inc }}$ were not modified (Fig. 3.4 , table 3.3).

The effects of prazosin, losartan, phenylephrine, and angiotensin II on pressure (P), lumen caliber (A) and compliance (the slope of the relation between $\mathrm{A}$ and $\mathrm{P}$ ) are summarized in Fig. 3.5. An increase in lumen caliber was accompanied by reduced compliance only when blood pressure was increased.

\section{Spontaneously hypertensive rats}

\section{Basal conditions}

In SHR, as in WKY, restraining increased and ketamine/xylazine anesthesia decreased (a) blood pressure, (b) heart rate, and (c) plasma norepinephrine levels (table
3.1). In $S H R$, anesthesia lowered $P_{\text {dia }}$ to the level seen in WKY. Under this isobaric condition, pulse pressure remained significantly larger and both aorta lumen caliber and compliance were significantly smaller in SHR than in WKY (table 3.2).

Although of lesser maximal amplitude, the effects of the vasopressor agonists phenylephrine and angiotensin II were qualitative similar in SHR and WKY (table 3.3). Also in SHR aorta, the agonistinduced pressure elevation was accompanied by (a) an increase in lumen caliber, (b) a decrease in CC and DC, and (c) an increase in $\mathrm{E}_{\text {inc }}$ of the aorta.

Effects of $\alpha_{1}$-blockade were more pronounced in SHR than in WKY (table 3.3). Prazosin led to a marked fall in pressure that entailed a reduction of $\mathrm{A}_{\mathrm{dia}}$ and an elevation of CC.

Finally, it may be worth considering observations in SHR and WKY under "near" isobaric conditions: (a) prazosintreated SHR versus prazosin-treated WKY, (b) phenylephrine-treated WKY versus SHR and (c) angiotensin II-treated WKY versus SHR. As was the case during ketamine/xylazine anesthesia (table 3.2), both lumen caliber and compliance were significantly smaller in SHR than in WKY under each of these isobaric conditions (table 3.3). $\mathrm{E}_{\text {inc }}$ did, however, not differ between the strains when differences in blood pressure were abolished by acute pharmacological intervention. Media CSA was not yet significantly elevated in the 3month old SHR that we investigated $\left(0.585 \pm 0.013 \mathrm{~mm}^{2}\right.$ versus $0.565 \pm 0.011$ $\mathrm{mm}^{2}$ ), but in view of their smaller lumen diameter, wall thickness was increased. 

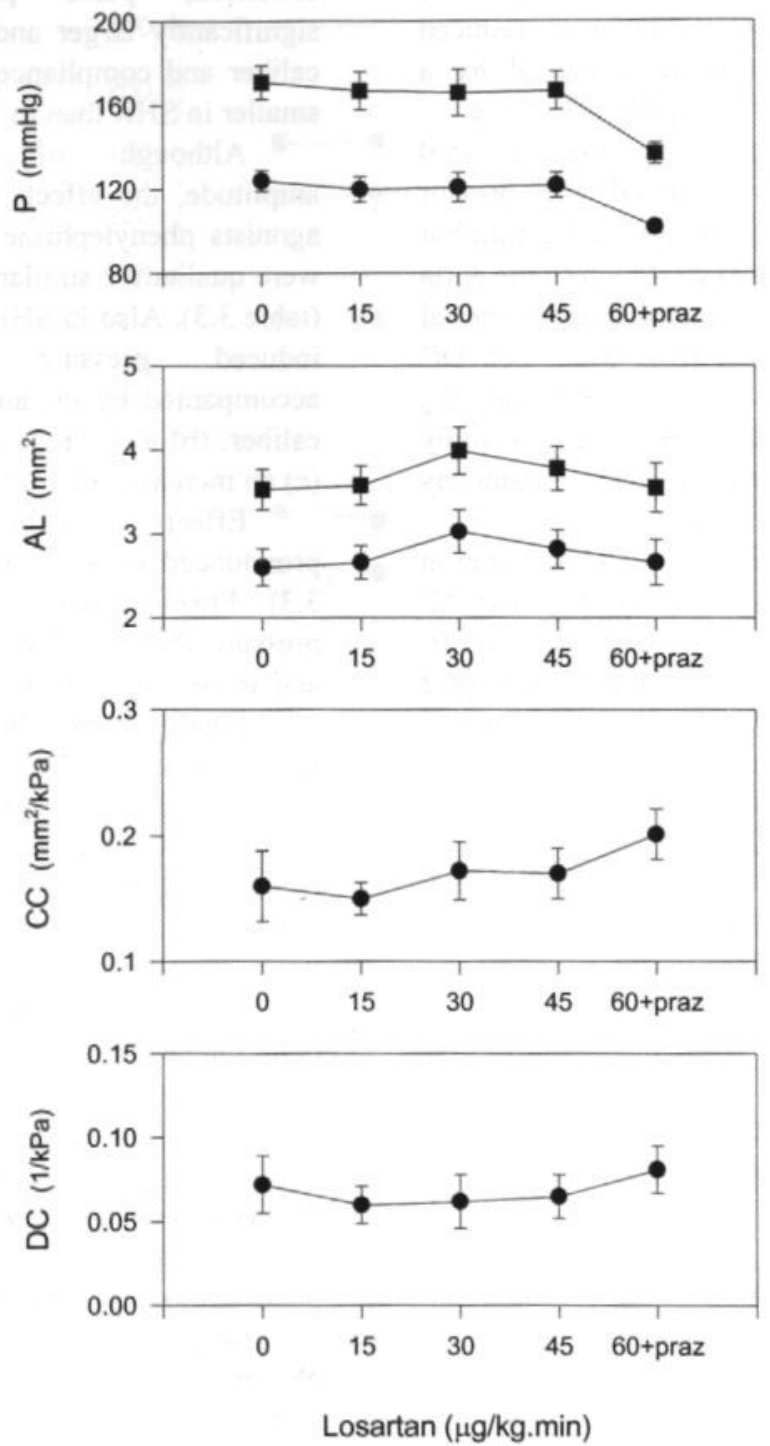

Figure 3.4 Effects of intravenous administration of losartan $(30 \mu \mathrm{g} / \mathrm{kg} \cdot \mathrm{min})$ on pressure (P), aortic lumen area $\left(A_{L}\right)$, compliance $(C C)$ and distensibility (DC) in conscious rats. $A_{L}$. and $\mathrm{P}$ are shown for both end-diastole (circles) and peak systole (squares). During the last $15 \mathrm{~min}$ period, prazosin (PRAZ, $5 \mu \mathrm{g} / \mathrm{kg} \cdot \mathrm{min}$ ) was included in the infusate. Means $\pm \operatorname{SEM}(n=7)$. 

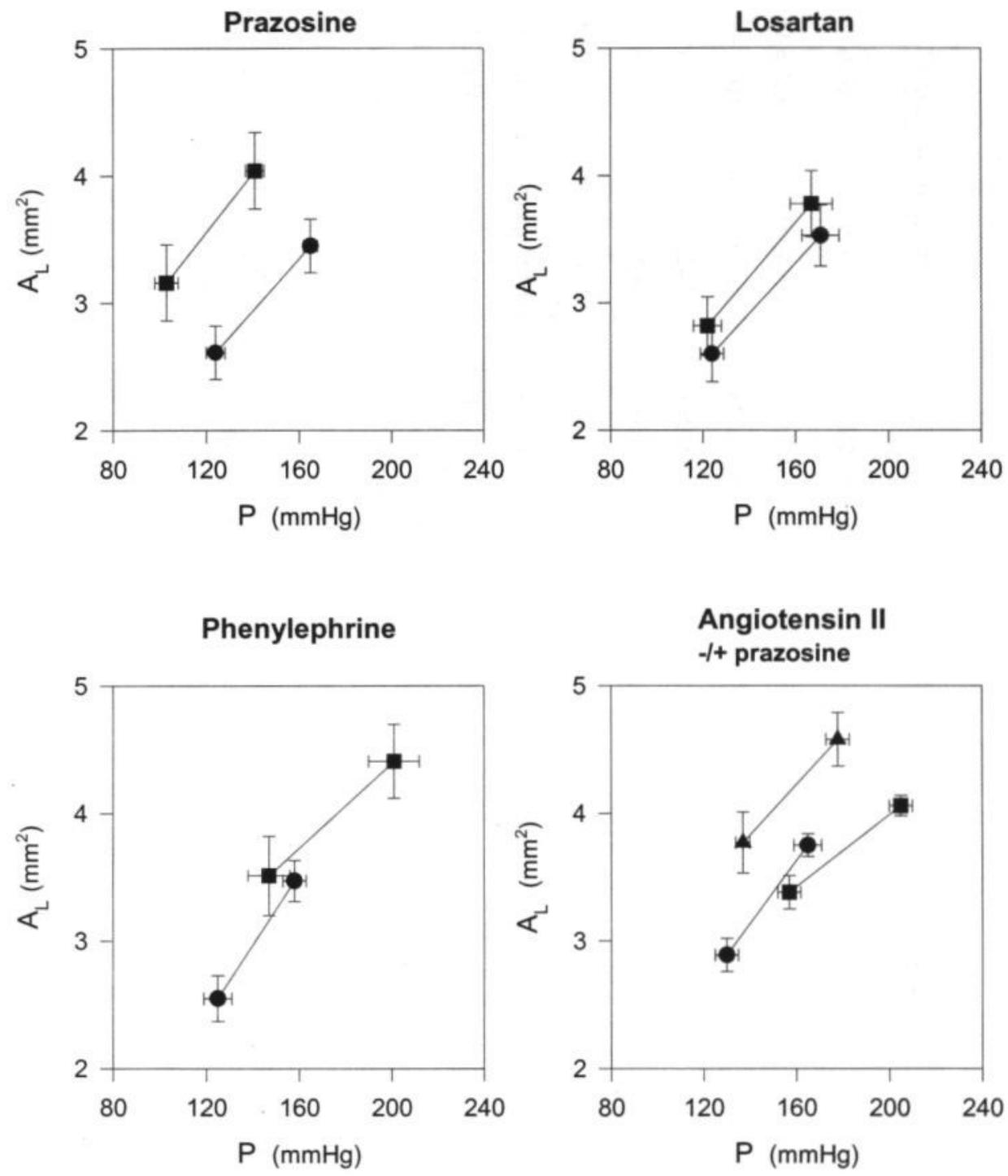

Figure 3.5 Drug effects on the relationship between pressure $(\mathrm{P})$ and aortic lumen area $\left(\mathrm{A}_{\mathrm{L}}\right)$ at end-diastole and peak systole in conscious rats. Besides observations under basal conditions (filled circles), findings during administration of the following drugs are shown (squares): prazosin, top left ( $5 \mu \mathrm{g} / \mathrm{kg} \cdot \mathrm{min})$, losartan, top right (30 $\mu \mathrm{g} / \mathrm{kg} \cdot \mathrm{min})$, phenylephrine, bottom left (10 $\mu \mathrm{g} / \mathrm{kg}$.min), angiotensin II, bottom right (100 $\mathrm{ng} / \mathrm{kg}$.min) before and after (triangle) additional administration of prazosin. Means \pm SEM. 
Table 3.3: Effects of blockade and stimulation of $\alpha$-adrenoceptors on the mechanical properties of the thoracic aorta in conscious rats ${ }^{2}$

\begin{tabular}{lccccccc}
\hline & $\begin{array}{c}\mathrm{P}_{\text {dia }} \\
(\mathrm{mmHg})\end{array}$ & $\begin{array}{c}\Delta \mathrm{P} \\
(\mathrm{mmHg})\end{array}$ & $\begin{array}{c}\mathrm{A}_{\text {dia }} \\
\left(\mathrm{mm}^{2}\right)\end{array}$ & $\begin{array}{c}\Delta \mathrm{A} \\
\left(\mathrm{mm}^{2}\right)\end{array}$ & $\begin{array}{c}\mathrm{CC} \\
\left(\mathrm{mm}^{2} / \mathrm{kPa}\right)\end{array}$ & $\begin{array}{c}\mathrm{DC} \\
(1 / \mathrm{kPa})\end{array}$ & $\begin{array}{c}\mathrm{E}_{\text {inc }} \\
(\mathrm{kPa})\end{array}$ \\
WKY & $124 \pm 4$ & $41 \pm 5$ & $2.57 \pm 0.21$ & $0.062 \pm 0.013$ & $0.165 \pm 0.020$ & $0.064 \pm 0.007$ & $322 \pm 44$ \\
WKY+PRAZ & $103 \pm 5$ & $37 \pm 4$ & $3.11 \pm 0.30$ & $0.053 \pm 0.006$ & $0.189 \pm 0.028$ & $0.062 \pm 0.009$ & $416 \pm 67$ \\
WKY+PHE & $147 \pm 8$ & $54 \pm 3$ & $3.47 \pm 0.31$ & $0.053 \pm 0.007$ & $0.130 \pm 0.015$ & $0.042 \pm 0.011$ & $778 \pm 132$ \\
WKY+LOS & $121 \pm 7$ & $44 \pm 5$ & $2.99 \pm 0.27$ & $0.066 \pm .0 .003$ & $0.172 \pm 0.023$ & $0.062 \pm 0.015$ & $441 \pm 83$ \\
WKY+ANG II & $157 \pm 5$ & $48 \pm 2$ & $3.37 \pm 0.19$ & $0.031 \pm 0.006$ & $0.106 \pm 0.008$ & $0.032 \pm 0.004$ & $850 \pm 124$ \\
SHR & $153 \pm 4$ & $53 \pm 4$ & $2.72 \pm 0.06$ & $0.028 \pm 0.003$ & $0.087 \pm 0.009$ & $0.032 \pm .0 .003$ & $665 \pm 83$ \\
SHR+PRAZ & $108 \pm 4$ & $46 \pm 3$ & $2.57 \pm 0.12$ & $0.042 \pm 0.011$ & $0.117 \pm 0.011$ & $0.045 \pm 0.003$ & $424 \pm 33$ \\
SHR+PHE & $167 \pm 4$ & $66 \pm 7$ & $2.93 \pm 0.09$ & $0.057 \pm 0.006$ & $0.065 \pm 0.007$ & $0.022 \pm 0.003$ & $1069 \pm 163$ \\
SHR+LOS & $150 \pm 6$ & $65 \pm 7$ & $2.81 \pm 0.12$ & $0.026 \pm 0.011$ & $0.067 \pm 0.005$ & $0.024 \pm 0.001$ & $853 \pm 66$ \\
SHR+ANG II & $176 \pm 7$ & $69 \pm 5$ & $3.14 \pm 0.10$ & $0.038 \pm 0.008$ & $0.056 \pm 0.004$ & $0.018 \pm 0.002$ & $1383 \pm 147$ \\
\hline
\end{tabular}

${ }^{a}$ Diastolic blood pressure $\left(\mathrm{P}_{\text {dia }}\right)$, pulse pressue $(\Delta \mathrm{P})$, aortic lumen area at end-diastole $\left(\mathrm{A}_{\text {dia }}\right)$, aortic distension during the cardiac cycle $(\Delta \mathrm{A})$, compliance (CC), distensibility (DC), and incremental elastic modulus ( $\mathrm{E}_{\text {inc }}$ )are shown in WKY and SHR under basal conditions and during administration of proazosin (PRAZ, $5 \mu \mathrm{g} / \mathrm{kg} \cdot \mathrm{min}$ ), phenylephrine (PHE, $10 \mu \mathrm{g} / \mathrm{kg} \cdot \mathrm{min}$ ), losartan (LOS, $30 \mu \mathrm{g} / \mathrm{kg} \cdot \mathrm{min})$ or angiotensin II (ANG II, $100 \mathrm{ng} / \mathrm{kg} \cdot \min )$. Means \pm SEM $(n=10)$. 


\section{DISCUSSION}

The results of this study indicate that in conscious rats local aortic smooth muscle tone: (a) may affect lumen diameter, (b) does not significantly influence compliance and (c) does not contribute to the difference in aorta mechanics between SHR and WKY rats. Rather, aortic compliance seems to be governed by blood pressure, vessel geometry and vessel wall composition.

\section{Technical considerations}

Previously we showed that a B-mode ultrasound and wall tracking system can be used to accurately and reproducibly measure the diameter of the thoracic aorta and its distension during the cardiac cycle in intact anesthetized and awake rats (Van Gorp A et al.,1996). This approach was combined with invasive pressure measurements to describe aortic mechanical properties in terms of compliance and distensibility of the wall and of the elasticity of the wall material.

Despite extensive training prior to data acquisition, blood pressure, heart rate and the circulating levels of norepinephrine were elevated during the recording sessions in the conscious rats. Most likely, the restraining conditions and the placement of the ultrasound probe on the thorax remained stressful. We therefore included measurements during anesthesia with ketamine/xylazine, which, among others, is characterized by a marked inhibition of sympathetic vasomotor activity (Vanhoutte P.M et al.,1981; Van Zwieten et al.,1983; and this study).

\section{Effects of vasoactive compounds}

We used intravenous administration of drugs to evaluate whether activity of the aortic smooth muscle influences the mechanical properties of the vessel in situ. Local drug application may be preferred for this purpose but the systemic approach allows to assess aortic responses in relation to cardiac and resistance artery function. The choice of the drugs was based on anatomical and pharmacological considerations. Unlike major parts of the resistance vasculature, the rat thoracic aorta is not equipped with sympathetic nerves (Stassen FRM et al.,1998) and is thus not exposed to neurogenic norepinephrine. Exogenously supplied adrenergic agonists and antagonists may thus be anticipated to more readily gain access to their binding sites in the aorta. Angiotensin II was included because the peptide is not only known to directly cause vasoconstriction, but also to potentiate vascular effects of low levels of $\alpha_{1}$-adrenergic stimulation (Duckles SP,1981; Story DF et al.,1987; Henegar JR et al.,1995).

We previously reported that in anesthetized rats, low doses of the $\alpha_{1}$ agonist methoxamine caused a constriction of the aorta that was not accompanied by an alteration of the compliance of the vessel (Van Gorp A et al.,1996). In the present investigation in conscious rats, subpressor doses of the $\alpha_{1}$-agonist phenylephrine did not modify diameter or mechanical properties of the aorta. On the other hand, the $\alpha_{1}$-antagonist prazosin caused significant dilatation despite lowering of blood pressure. In view of this, we suggest that the elevated circulating levels of catecholamines in conscious restrained rats maintain the aorta in a constricted state. Because also the $\mathrm{AT}_{1}$-antagonist losartan caused a significant isobaric vasodilatation, the aortic constriction may be due to synergism between catecholamines and angiotensin II. This interaction is also suggested by the observation that prazosin, administered in the presence of a high dose of angiotensin II, caused additional widening of the aorta despite reducing the pressor effect of the peptide.

Drug-induced dilatation of the aorta was not accompanied by a modification of 
the compliance of the vessel. On the other hand, widening of he aorta in response to elevated blood pressure, as seen in the presence of a high dose of phenylephrine or angiotensin II resulted in a reduction of compliance. This is in line with a model suggested by Benetos et al (Benetos A et al.,1993). In this view, the contractile filaments are arranged in series with the elastic elements (Fig. 3.6). Stimulation of contractility by endogenous mediators shortens the contractile elements and reduces the internal circumference of the vessel. This would not affect the length of the elastic elements and their behavior during the rapid cardiac cycle. Elevation of pressure, on the other hand, stretches the elastic components resulting in a recruitment of collagen fibers and a reduction of compliance. An alternative overall explanation may be that the capacity of the rat aorta to constrict and dilate is too small to result in detectable mechanical consequences. Recently also Chang (Chang KC,1998) concluded that aortic smooth muscle tone does not modify the pulsatile mechanics of the aorta in rats. In his study, effects of a single dose of methoxamine on aortic characteristic impedance were evaluated with an exponentially tapered T-tube model. The added value of our study is that we used intact conscious animals and a range of doses of various vasoconstrictor agonists and antagonists.
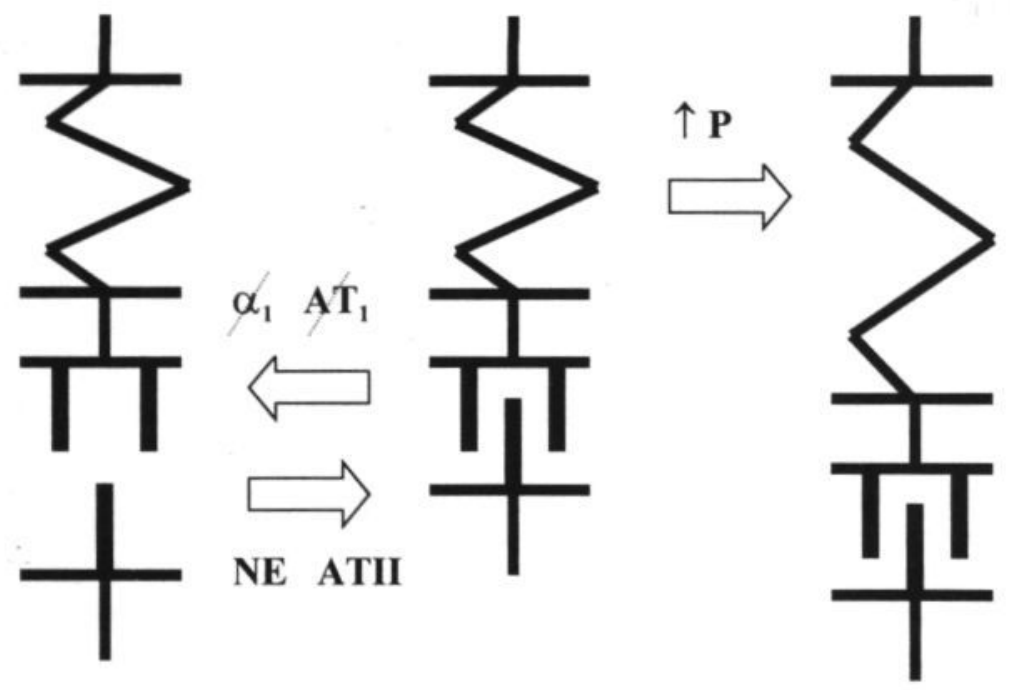

Figure 3.6 Schematic representation of the series organization of elastic components (top) and contractile elements (bottom) in rat thoracic aorta as suggested by observations in intact conscious animals. Basal levels of endogenous norepinephrine (NE) and angiotensin II (ATII) interact to cause a local isobaric shortening of the contractile elements without modification of the stiffness of the vessel. The constriction can be reversed by blockade of $\alpha_{1}$ adrenergic receptors or $\mathrm{AT}_{1}$-receptors. Elevation of pressure ( $\left.\uparrow P\right)$, on the other hand, stretches primarily the elastic elements and thereby increases the stiffness of the tissue. 
Our findings contrast with those in muscular and small resistance arteries of man and rats where conditions that increase or decrease sympathetic stimulation were observed to reduce or enhance distensibility, respectively (Baumbach GL et al.,1994; Boutouyrie P et al.,1994). This discrepancy may find its origin in regional differences in density, differentiation and organization of the arterial smooth muscle cells along the vascular tree. At first site, our suggestion also contrasts with the recent observation that chemical sympathectomy increases the distensibility of the elastic rat common carotid artery (Mangoni et al.,1997). This vessel however, is not equipped with sympathetic nerves in intact rats (Stassen et al.,1998). Therefore, effects of chronic systemic sympathectomy on the mechanics of large arteries most likely result from adaptations to altered local pressure and blood flow rather than from removal of vasomotor tone.

\section{Observations in spontaneously}

hypertensive rats

SHR are characterized by a hyperactive sympathetic nervous system and by enhanced vascular sensitivity to angiotensin II (Head RJ.et al.,1989; Lee RM et al.,1991a; Lee RM et al.,1991b; Dzau VJ et al.,1994). In line with this, we observed a marked pressure lowering effect of prazosin and ketamine/xylazine anesthesia. Losartan, however, did not lower pressure, which could be due to the marked sympathetic stimulation during restraining. Unlike in WKY, we could not detect significant aortic vasodilatation in SHR. Yet, the presence of aortic vasomotor tone is suggested by the lack of changes in diameter during the marked blood pressure lowering elicited by $\alpha_{1}$-blockade. If at all, the influence of this tone on the pulsatile mechanics of SHR aorta was limited as was the case for the normotensive rats. Under basal conditions the aortic compliance was markedly lower in SHR than WKY. Because aortic smooth muscle tone does not seem to be a major determinant of compliance, this inter-strain difference cannot be attributed to contractile reactivity. It cannot solely be attributed to differences in operating pressure either. We noted before (van Gorp AW et al.,1995) that sympathetic nerve inhibition with ketamine/xylazine normalized pressure but not aortic compliance. We confirmed and expanded this observation. Also prazosin normalized pressure, but not compliance. Furthermore, in normotensive rats, rendered acutely hypertensive by infusion of phenylephrine or angiotensin II, aortic compliance remained significantly higher than in SHR. Structural changes are likely candidates for mechanical alterations that cannot be attributed to pressure or tone. Media hypertrophy is not significant in young SHR (van Gorp AW et al.,1995; and this study) and has been found not to reduce aortic compliance in another setting (BrouwersCeiler DL et al.,1997). The material properties of the aortic wall as assessed by the incremental elastic or Young's modulus, did not differ significantly between SHR and WKY when assessed under isobaric conditions. For several reasons, including the series design suggested above, this parameter must, however, be treated with caution (van Gorp AW et al.,1995).

The most prominent structural difference between the aorta in both strains is lumen diameter. Under all isobaric conditions encountered, the aortic lumen was narrower in SHR than WKY. We have not addressed whether this represents an adaptive response to high blood pressure or a developmental defect that may or may not be causally related to hypertension. The results of our study, however, force us to suggest that the structural diameter of a blood vessel is a prominent determinant of its pulsatile mechanical characteristics. 


\section{Conclusion}

Although the thoracic aorta can dilate significantly in conscious rats, the effects of aortic smooth muscle on the in situ pulsatile mechanics of the vessel are limited. This may be due to a series organization of contractile and elastic components. Dynamic mechanical properties of the rat aorta seem to be governed by blood pressure and especially by as yet unidentified determinants of the structural caliber of the vessel. 
REFERENCES

Bank AJ, Wilson RF, Kubo SH, Holte JE, Dresing TJ, Wang H. Direct effects of smooth muscle relaxation and contraction on in vivo human brachial artery elastic properties. Circ. Res. 77:1008-1016, 1995

Barra JG, Armentano RL, Levenson J, Cabrera Fisher EI, Pichel RH, Simon A. Assessment of smooth muscle contribution to descending thoracic aortic elastic mechanics in consious dogs. Circ. Res. 73:1040-1050, 1993

Baumbach GL, Heistad DD. Remodeling of cerebral arteriols in chronic hypertension. Hypertension 13:968-972, 1989

Benetos A, Pannier B, Brahimi M, Safar ME, Levy BI. Dose-related changes in the mechanical properties of the carotid artery in WKY rats and SHR following relaxation of arterial smooth muscle. $J$. Vasc. Res. 30:23-29, 1993

Boonen HCM, Daemen MJAP, Eerdmans PE, Fazzi GE, Van Kleef E, Schiffers PMH, De Mey JGR. Mesenteric small artery changes following vasoconstrictor infusion in young rats. J. Cardiovasc. Pharmacol. 22:388-395, 1993

Boutouyrie P, Lacolley P, Girerd X, Beck L, Safar M, Laurent S. Sympathetic activation decreases medium sized arterial compliance in humans. $\mathrm{Am} \mathrm{J}$ Physiol 267:H1368-H1377, 1994

Brouwers-Ceiler DL, Nelissen Vrancken HJMG, Smits JFM, De Mey JGR. The influence of angiotensin II-induced increase in aortic wall mass on compliance in rats in vivo. J. Vasc. Res. 33:478-484, 1997

Chang KC. Hypertensive effects of methoxamine on arterial mechanics in rats: analysis based on exponentially tapered T-tube model. Eur. J. Pharmacol. 350:195-202, 1998

Dobrin PB, Rovick AA. Influence of vascular smooth muscle on contractile mechaniscs and elasticity of arteries. Am. J. Physiol. 217; 1644-1652, 1969

Duckles SP. Angiotensin II potentiates responses of of the rabbit basiliar artery to adrenergic nerve stimulation. Life Sci. 28:635-640, 1981

Dzau VJ, Pratt RE, Gibbons GH. Angiotensin as local modulating factor in ventricular dysfunction and failure due to coronary artery disease. Drugs 47(suppl 4):1-13, 1994

Folkow B. Physiological aspects of primary hypertension. Physiol. Rev. 62:347-504, 1982

Gow BS, Hadfield CD. The elasticity of canine and human coronary arteries with reference to postmortem changes. Circ. Res. 45:588-594, 1979

Grassi G, Giannattasio C, Falia M, Pesenti A, Peretti G, Marinori E, Fraschini N, Vailati S, Mancia G. Sympathetic modulation of radial artery compliance in congestive heart failure. Hypertension 26:348-354, 1995

Head RJ. Hypernoradrenergic innervation :its relationship to functional and hyperplastic changes in the vasculature of the spontaneously hypertensive rat. Blood Vessels 26:1-20, 1989

Henegar JR, Brower GL, Kabour A, Janicki JS. Catecholamines response to chronic ANG II infusion and its role in nyocyte and coronary vascular damage. Am. J. Physiol. 269:H1564-H1569, 1995

Lee RM, Berecek KH, Tsoporis J, McKenzie $\mathrm{R}$, Triggle $\mathrm{CR}$. Prevention of hypertension and vascular changes by captopril treatment. Hypertension 17:141$150,1991 \mathrm{a}$

Lee RM, Borokowski KR, Leenen $\mathrm{FHH}$, Tsoporis J, Coughlin M. Combined effect of neonatal sympathectomy and adrenal demedullation on blood pressure and vascular changes in spontaneously hypertensive rats. Circ. Res. 69:714-721, 1991b

Mangoni AA, Mircoli L, Giannattasio C, Mancia G, Ferrari AU. Effect of sympathectomy on mechanical properties of common carotid and femoral arteries. Hypertension 30:1085-1088, 1997

Pagani M, Mirsky I, Biag H, Manders WT, Kerkhof P, Vatner SF. Effects of age on aortic pressure-diameter and elastic stiffness -stress relationship in 
unasthetized sheep. Circ. Res. 44:420429, 1979

Reneman RS, Hoeks APG, Westerhof N. Noninvasive assessment of artery wall properties in humans; methods and interpretation. J. Vascular Investigation 2:53-64, 1996

Stassen FRM, Maas RGHT, Schiffers PMH, Janssen GMJ, De Mey JGR. A positive and reversible relastionship between adrenergic nerves and alpha-la adrenochptors in rat arteries. $J$. Pharmacol. Exp. Therap. 284:399-405, 1998

Story DF, Ziogas J. Ineractions of angiotensin with naradrenergic neuroeffector transmission. TIPS 8:269-271, 1987

Van der Hoorn FAJ, Boomsma F, Man in 't Veld AJ, Schalekamp MADH. Determination of catecholamines in human plasma by high-performance liquid chromatography: comparison between a new method with fluorescence detection and an established method with electrochemical detection. J. Chrom. 487: 17-28, 1989
Van Gorp AW, Van Ingen Schenau D, Hoeks APG, Struijker Boudier HAJ, Reneman RS, De Mey JGR. Aortic wall properties in normotensive and hypertensive rats of various ages in vivo. Hypertension 26:363-368, 1995

Van Gorp A., Van Ingen Schenau DS, Willegers J, Hoeks APG, De Mey JGR, Struijker Boudier HAJ, Reneman RS. A technique to assess aortic distensibility and compliance in anesthetized and awake rats. Am. J. Physiol. 270:H780H786, 1996

Vanhoutte P.M., T.J. Verbeuren, R.C. Webb. Local modulation of adrenergic neuroeffector interactions in the blood vessel wall. Physiol. Rev. 61:151-218, 1981

Van Zwieten PA, Thoolen MJMC, Timmermans PBMWM. The pharmacology of centrally acting antihypertensive drugs. $\mathrm{Br}$. J. Clin. Pharmacol. 15(Suppl):455-462, 1983

Westerhof N, Bosman F, De Vries CJ, Noordergraaf A. Analog studies of the human systemic arterial tree. $J$. Biomechanics 2:121-143, 1969 


\section{CHAPTER 4}

IN SPONTANEOUSLY HYPERTENSIVE RATS ALTERATIONS IN AORTIC WALL PROPERTIES PRECEDE THE DEVELOPMENT OF HYPERTENSION

Ad W. Van Gorp

Dorette S. van Ingen Schenau

Arnold P.G. Hoeks

Harry A.J. Struijker Boudier

Jo G.R. De Mey

Robert S. Reneman 


\section{ABSTRACT}

In hypertension arterial wall properties do not necessarily depend on increased blood pressure alone. The present study investigates the relationship between the development of hypertension and thoracic aortic wall properties in 1.5, 3 and 6 month old spontaneously hypertensive (SHR) and Wistar Kyoto rats (WKY). During ketamine/xylazine anesthesia, compliance and distensibility were assessed by means of a noninvasive ultrasound technique combined with invasive blood pressure measurements. Morphometric measurements provided in vivo media cross-sectional area and thickness, allowing the calculation of the incremental elastic modulus. Extracellular matrix protein contents were determined as well. At the age of 1.5 month blood pressure was not significantly different in SHR and WKY, but compliance and distensibility were significantly lower in SHR. Incremental elastic modulus was not significantly different between SHR and WKY at this age. Media thickness was significantly larger in SHR than in WKY, but there was no significant difference in collagen density and content. The findings in this study show that in SHR alterations in mechanical aortic wall properties precede the development of hypertension. The decrease in compliance and distensibility at young age most likely results from an increase in media thickness rather than a change in intrinsic elastic properties.

\section{INTRODUCTION}

Compliance and distensibility of the elastic arteries are reduced in established (Cox R.H.,1981; Safar M.E. et al., 1984) as well as in borderline (Van Merode T.et al.,1988; Ventura H.et al.,1984) hypertension. These changes in arterial wall properties do not necessarily result from increased blood pressure alone, because in hypertension structural changes of the arterial walls have been observed (Cox R.H.,1979; Levy B.I.et al.; 1988; Levy B.I.et al.,1990; Mulvany J.M.J.et al.,1990). Moreover, in relatively young borderline hypertensive patients distensibility and compliance of the carotid artery are significantly reduced, as compared to age-matched control subjects, while the difference in blood pressure between these patients and control subjects is only small (Van Merode T et al.,1993; Van Merode T et al.,1988). In addition, in these patients different parts of the carotid artery bifurcation are differently affected, as far as the reduction of distensibility is concerned, while these parts are subjected to the same mean blood pressure (Van
Merode T et al.,1993). Especially the latter observation indicates that in hypertension changes in artery wall properties may occur independent of blood pressure.

In the present study we investigated whether there is a relationship between the development of hypertension and aortic wall properties in spontaneously hypertensive rats (SHR). To this end, arterial blood pressure, arterial wall distensibility and compliance, the incremental elastic modulus and the media cross-sectional area were determined in 1.5, 3 and 6 months old SHR. Agematched Wistar Kyoto rats (WKY) served as controls. This study was performed in SHR, because this genetically hypertensive rat strain has been regarded as model for primary hypertension in humans (Struijker Boudier HAJ.,1997) and in this strain hypertension develops gradually during the first weeks of life (Okamoto K et al.,1963). In addition, a number of extracellular matrix (ECM) components were determined, which have previously been shown to play a key role in the elastic properties of the vessel wall (Berry CL et al.,1976; Cox RH,1981; Cox RH,1979; Dobrin PB,1978; Greenwald SE $e t$ 
al.,1978). We hypothesized that part of the pressure-independent changes in vessel wall properties may be due to alterations in ECM components.

\section{METHODS}

\section{Study Design.}

The experiments were performed in 1.5, 3 and 6 month old male WKY and SHR of the Okamoto-Aoki strain (local inbred strains; Central Animal Facilities, Maastricht University, Maastricht, the Netherlands). Each group consisted of 12 animals. The rats were housed in individual cages, maintained on a 12-hour light, 12-hour dark cycle, fed at libitum (Hope Farms, Woerden, the Netherlands) and they had free access to tap water. The experimental protocols were approved by the local Institutional Animal Care and Use Committee.

For the measurement of arterial blood pressure an intra-aortic catheter filled with heparinized saline was implanted under ether anesthesia. The outer diameter of the intra-aortic catheter was $0.5 \mathrm{~mm}$. The catheter was advanced from a femoral artery to just below the bifurcation of the left renal artery. The catheter was guided under the skin and exteriorized at the base of the skull. Two days later, blood pressure was measured in the freely moving conscious animal by means of an external low volume displacement pressure transducer (CP-01, Century Technology $\mathrm{Co}$, Inglewood $\mathrm{Ca}$, USA). The delay in time between the tip of the catheter and the pressure transducer was $12 \mathrm{~ms}$ and, hence, garanteed a pressure signal frequency up to $50 \mathrm{~Hz}$.

Elastic properties of arteries are, among others, dependent on the operating blood pressure. To obtain comparable blood presssure conditions the animals were anesthetized with ketamine/xylazine
(10:50 $\mathrm{mg} / \mathrm{ml} ; 100 \mathrm{ml} / 100 \mathrm{~g}$ body weight) which lowered the diastolic blood pressure in SHR to the level in WKY, the blood pressure of which was only marginally affected by the anesthetic cocktail (see results). Blood pressure was measured simultaneously with the diameter of the thoracic aorta and the displacement of its walls during the cardiac cycle, using an ultrasonic wall tracking device (see below). Experiments were terminated by exsanguination of the anesthetized animals, after which the thoracic aorta was isolated for subsequent histological examination.

\section{Ultrasound Assessment of Aorta Diameter and Wall Displacement.}

The aortic diameter and the diameter changes during the cardiac cycle were measured by means of a conventional Bmode ultrasound system ( $\mathrm{B}=$ brightness) (Pie 480, 7.5 MHz linear array) attached to a vessel wall tracking system (WTS, Pie Medical, Maastricht, the Netherlands) as described in detail before (Van Gorp A et al.,1996). The probe was positioned on the left side of the sternum, $10 \mathrm{~mm}$ above the diaphragm. The B-mode was used to visualize the thoracic aorta whereafter an M-line $(\mathrm{M}=$ motion $)$ was selected. The ultrasound system was switched to Mmode and ultrasound was emitted and received along the selected line.

The recieved Radio Frequency (RF) signals were amplified and captured and temporarily stored by a data acquisition system. The internal memory capacity of the WTS limited the available measuring time. The emission trigger frequency was set at $1653 \mathrm{~Hz}$, and each analog RF-signal was converted digitally in 256 points. This in combination with an internal memory of 1 megabyte provides a measuring time of $2.5 \mathrm{~s}$, allowing the 
recording of approximately 10 cardiac and 3 respiratory cycles.

The RF signals were transferred to a PC. The first RF-signal captured was visualized on the monitor screen to identify manually the anterior and posterior walls by means of two markers. Subsequently, the position of these markers was used by the tracking system to follow the position of the anterior and posterior walls and to calculate with a response time of $10 \mathrm{~ms}$ the displacements of these walls over time. The difference in the displacements between these walls reflects the change in diameter (distension). The minimal distance between the markers provides the enddiastolic diameter $\left(\mathrm{d}_{\text {dia }}\right)$. The WTS allows assessment of artery wall displacements with a resolution of a few micrometers (Hoeks APG et al.,1990). For the thoracic aorta of rats the intra-session variability for $\mathrm{d}_{\text {dia }}$ varies between 3.3 and $6.5 \%$ and the inter-session variability for this parameter is $4.6 \%$. For the distension, $\Delta d$, intrasession variability varies between 7.9 and $11 \%$ and the inter-session variability is 9.2 $\%$. There is no difference between observers (Van Gorp A et al.,1996).

The WTS was also equipped with an acquisition system to sample blood pressure signals synchronously with the emission trigger. Under anesthesia, measurements were started after blood pressure and heart rate had stabilized (average $20 \mathrm{~min}$ ). In each animal two observers performed three recordings of $2.5 \mathrm{~s}$. The data obtained during these sessions were averaged.

\section{Relationship between Lumen Diameter and Pressure.}

Since the WTS and the intra-aortic catheter exhibit different frequency characteristics, we limited the analysis of the relationship between aorta lumen caliber and intraaortic pressure to the situation at end- diastole ( $\mathrm{D}_{\text {dia }}$ and $\mathrm{P}_{\text {dia }}$ ) and to the maximal changes in pressure $(\Delta \mathrm{P})$ and diameter $(\Delta d)$ during the cardiac cycle. The values attained for $\mathrm{d}_{\text {dia }}$ and $\Delta \mathrm{d}$ were converted to lumen area's and changes thereof $\left(\mathrm{A}_{\text {dia }}\right.$ and $\left.\Delta \mathrm{A}\right)$, assuming a circular cross-section of the vessel. With the additional reasonable assumption that vessel segment length remains constant during the cardiac cycle (Reneman RS et al.,1996), the absolute and the relative change in aortic lumen area during the cardiac cycle were calculated and expressed per unit of pressure, providing information about the cross-sectional compliance and distensibility of the vessel, respectively (Hoeks APG et al.,1990;.Hoeks APG et al.,1993; Hoeks APG, 1993; Reneman RS et al.,1986). Below $\Delta \mathrm{A} / \Delta \mathrm{P}$ and $(\Delta \mathrm{A} / \mathrm{A}) / \Delta \mathrm{P}$ will be referred to as the compliance coefficient (CC) and the distensibility coefficient (DC), respectively.

\section{Aortic Wall Structure.}

A segment of $10 \mathrm{~mm}\left(\mathrm{~L}_{\mathrm{i}}\right)$, halfway the heart and diaphragm, was marked on the aorta and subsequently removed from the animal and cleaned of adhering fat and connective tissue after which the ex vivo length of the segment $\left(\mathrm{L}_{\mathrm{e}}\right)$ was measured under a stereo-microscope with a precision of $\pm 5 \mu \mathrm{m}$. The segment was fixed in $4 \%$ neutral buffered formaldehyde and embedded in paraffin after which $4 \mathrm{~mm}$ thick cross-sections were obtained. These sections were stained with Lawson's solution, which highlights elastic laminae, and the cross-sectional area of the media was determined using an axioplan microscope (Zeiss) equipped with a standard CCD camera (Stemmer, Germany) (Boonen HCM et al.,1993). Digitized images were analyzed with commercial software (JAVA, Jandell Scientific, Corte Madera $\mathrm{Ca}$, USA). The area enclosed by the external and internal elastic lamina was considered to represent 
the ex vivo cross-sectional area of the media $\left(\mathrm{CSA}_{\mathrm{e}}\right)$. This was converted to in vivo media cross-sectional area $\left(\mathrm{CSA}_{i}\right)$ by the following formula:

$$
\mathrm{CSA}_{\mathrm{i}}=\left(\mathrm{Le}_{\mathrm{e}} / \mathrm{L}_{\mathrm{i}}\right) \cdot \mathrm{CSA}_{\mathrm{e}}
$$

in which it was assumed that aortic wall volume remains constant after isolation and fixation and in which $\mathrm{L}_{\mathrm{i}}$ and $\mathrm{L}_{\mathrm{e}}$ refer to the length of the thoracic aorta before and after isolation, respectively.

Media thickness (Mt) in diastole was calculated from diastolic diameter $\left(\mathrm{d}_{\text {dia }}\right)$ and from $\mathrm{CSA}_{\mathrm{i}}$, using the formula:

$\mathrm{CSA}_{\mathrm{i}}=\pi\left(\mathrm{d}_{\mathrm{dia}} / 2+\mathrm{Mt}\right)^{2}-\pi\left(\mathrm{d}_{\mathrm{dia}} / 2\right)^{2}$

which can be rewritten as:

$$
\mathrm{Mt}=-\left(\mathrm{d}_{\mathrm{dia}} / 2\right)+\left\{\left(\mathrm{d}_{\mathrm{dia}} / 2\right)^{2}+\mathrm{CSA}_{\mathrm{i}} / \pi\right\}^{1 / 2}
$$

In these calculations it is assumed that the cross-section of the aorta is circular in situ. Measurements of mechanical properties and dimensions were combined to calculate the incremental elastic modulus or Young's modulus (Einc):

$E_{\text {inc }}=d_{\text {dia }} /(M t \cdot D C)$

\section{Collagen content}

Paraffin embedded, $4 \mu \mathrm{m}$ thick crosssections, were also used to determine collagen area. The sections were stained with Sirius Red solution, which highlights collagen (James J et al.,1990). The collagen occupied area, enclosed by the external and internal elastic laminae, representing the media collagen area, was determined as described above. The data are presented as media collagen density, i.e., the collagen volume as percentage of the total tissue volume in the section.
Biochemical determination of collagen content of the adventitia and media was performed as described by Chiariellio et al. (Chiariellio M et al.,1986). To facilitate separation of adventitia and media, aorta's were incubated for $24 \mathrm{~h}$ in phosphate buffered saline (PBS) at $4{ }^{\circ} \mathrm{C}$. The media and adventitia were mechanically separated from each other under a dissection microscope. The media was dried under vacuum and the dry weight was measured. Afterwards, the media was incubated in a $1 \%$ Sodium Dodecyl Sulfate (SDS) solution in PBS for $24 \mathrm{~h}$ at $4{ }^{\circ} \mathrm{C}$. Incubation in $1 \%$ SDS extracts the non-cross-linked collagen from the aorta. The supernatant was collected and stored at $-70{ }^{\circ} \mathrm{C}$ and the pellet was incubated in a Cyanogen Bromide Solution in $70 \%$ formic acid for $24 \mathrm{~h}$ at room temperature. Cyanogen Bromide cleaves proteins at methionine sites. Since elastin does not and collagen does contain methionine, cross-linked collagen can be extracted from the aortic media by Cyanogen Bromide. The pellet, containing elastin, and both supernatants, containing non-cross-linked and crosslinked collagen, respectively, were dried under vacuum and hydrolyzed in $6 \mathrm{~N} \mathrm{HCL}$ at $120{ }^{\circ} \mathrm{C}$. The collagen content was determined by the amount of hydroxyproline residues. The hydroxyproline residues were oxidized with choramine $T$, which reacts with $\mathrm{p}$ dimethylamino-benzaldehyde. In the different fractions the colored compound produced was measured photospectometrically at $558 \mathrm{~nm}$. Hydroxyproline represents between 10.5 and $11.5 \%$ of the aminoacid residues in collagen (Chiariellio M et al.,1986). The data are presented as $\mathrm{mg}$ hydroxyproline per $\mathrm{g}$ dry weight normalized for the crosssectional area of the media. 


\section{Statistics}

In each animal 6 consecutive $2.5 \mathrm{~s}$ simultaneous recordings of pressure, internal lumen diameter and distension were obtained and characteristics were calculated for each individual cardiac cycle. Mean values were calculated for each recording session, then these values were averaged for each individual animal and eventually a group mean was obtained for each strain-age group.

The data are presented as means \pm SD. Comparisons between age groups were performed with a two way ANOVA extented with a Tukey test for multiple comparison. Comparison between strains was performed with the unpaired Student's t-test. $\mathrm{P}<0.05$ was considered to denote statistically significant differences.
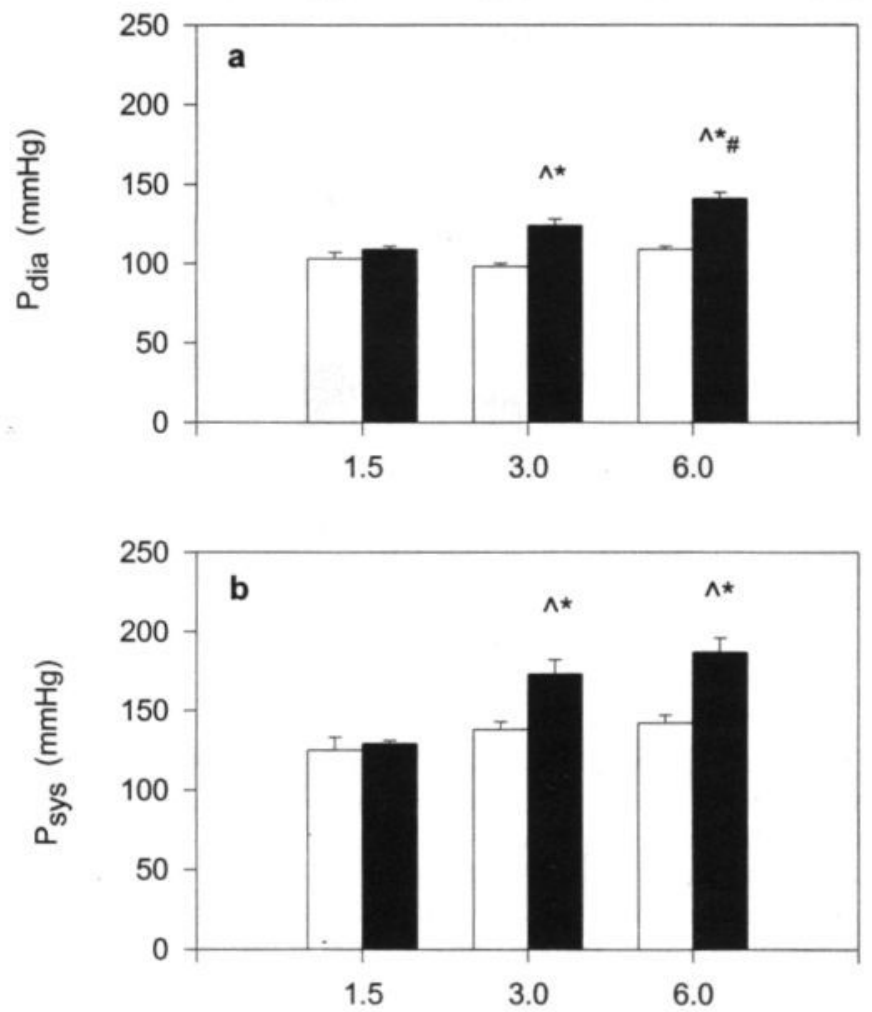

Age in months

Fig. 4.1. Diastolic (a) and systolic (b) blood pressure ( $\mathrm{mmHg}$ ) in conscious Wistar Kyoto rats (WKY; open bars) and conscious spontaneously hypertensive rats (SHR; closed bars). Mean \pm SD $(\mathrm{n}=12)$.

* significantly different between WKY and SHR.

^ significantly different from 1.5 month old WKY or SHR.

\# significantly different between 3 and 6 month old WKY or SHR. 

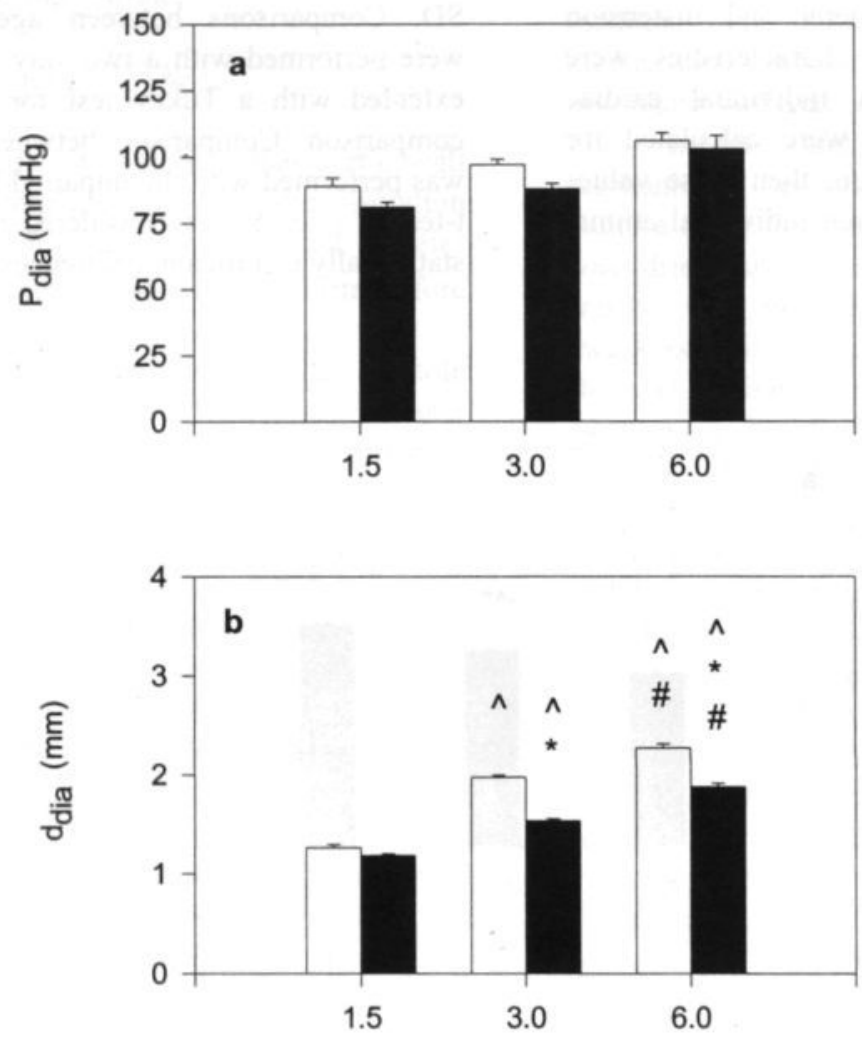

Age in months

Fig. 4.2. Diastolic blood pressure (a) ( $\mathrm{mmHg}$ ) and diastolic aortic diameter (b) (mm) after anesthesia with ketamine/xylazine in Wistar Kyoto rats (WKY; open bars) and spontaneously hypertensive rats (SHR; closed bars). Mean $\pm S D(n=12)$.

* significantly different between WKY and SHR.

^ significantly different from 1.5 month old WKY or SHR.

\# significantly different between 3 and 6 month old WKY or SHR.

\section{RESULTS}

Between 1.5, 3 and 6 months of age, body weight increased in both strains (data not shown), while blood pressure, determined under conscious freely moving conditions, increased only in SHR (Fig. 4.1). At 1.5 months of age, body weight and blood pressure were not significantly different between WKY and SHR, whereas in both other age groups body weights were significantly lower and blood pressure significantly higher (Fig. 4.1) in SHR than in WKY.

Anesthesia with ketamine/xylazine significantly lowered diastolic blood 
significantly higher (Fig. 4.1) in SHR than in WKY.

Anesthesia with ketamine/xylazine significantly lowered diastolic blood pressure in 1.5 month old WKY as well as in 1.5, 3 and 6 month old SHR (Fig. 4.2). In 3 and 6 month old WKY, diastolic blood pressure was not affected by this type of anesthesia. During anesthesia the original differences in diastolic blood pressure between SHR and WKY at 3 and
6 months of age were abolished (Fig. 4.2), as was the difference in pulse pressure at 3 months of age (data not shown). Heart rate decreased between 1.5 and 3 months of age and was not significantly different between 3 and 6 months of age in both strains. At 1.5, 3 and 6 months of age, there was no significant difference in heart rate between SHR and WKY (data not shown).
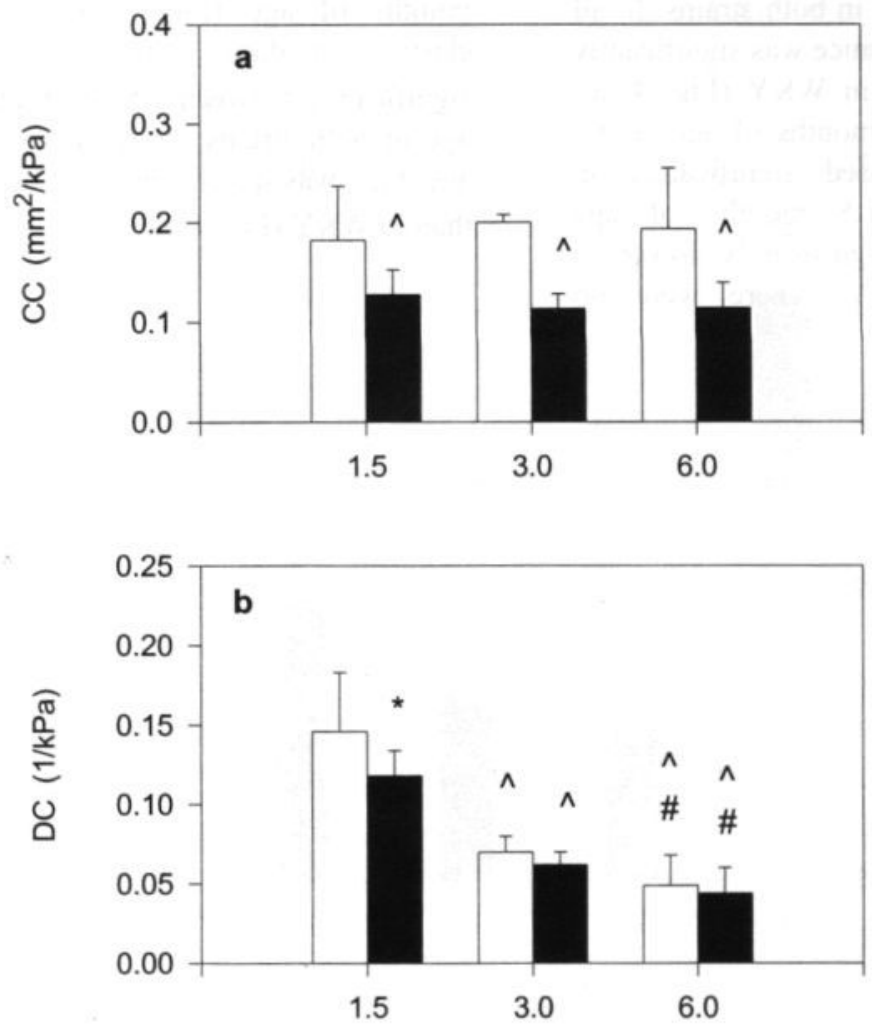

Age in months

Fig. 4.3. Compliance coefficient (a) $\left(\mathrm{mm}^{2} / \mathrm{kPa}\right)$ and distensibility coefficient (b) $(1 / \mathrm{kPa})$ after anesthesia with ketamine/xylazine in Wistar Kyoto rats (WKY; open bars) and spontaneously hypertensive rats (SHR; closed bars). Mean $\pm \mathrm{SD}(\mathrm{n}=12)$.

* significantly different between WKY and SHR.

^ significantly different from 1.5 month old WKY or SHR.

\# significantly different between 3 and 6 month old WKY or SHR. 
In both SHR and WKY, D dia increased between 1.5 and 6 months of age. At 1.5 months of age there was no significant difference in ddia between SHR and WKY. At 3 and 6 months of age, however, ddia measured at comparable $\mathrm{P}_{\text {dia }}$ was significantly smaller in SHR than in WKY (Fig. 4.2).

Aortic wall properties determined under comparable blood pressure conditions in 1.5, 3 and 6 month old WKY and SHR are presented in figure 3 through 5. Compliance did not change between 1.5 and 6 months of age in both strains. In all 3 age groups, compliance was significantly lower in SHR than in WKY (Fig. 4.3a). Between 1.5 and 3 months of age, aortic distensibility decreased significantly in both strains. At 1.5 months of age distensibility was significantly lower in SHR than in WKY. There were no significant differences in distensibility between SHR and WKY at 3 and 6 months of age (Fig. 4.3b).

Between 1.5 and 6 months of age, in vivo media cross-sectional area $\left(\mathrm{CSA}_{\mathrm{i}}\right)$ increased in both strains. There were no significant differences in $\mathrm{CSA}_{\mathrm{i}}$ between SHR and WKY at 1.5, 3 and 6 months of age (Fig. 4.4). Media thickness (Mt) did not significantly change between 1.5 and 6 months of age in both strains. At 1.5 and 3 months of age Mt was significantly larger in SHR as compared to WKY, but not at 6 months of age (Fig. 4.5). Incremental elastic modulus ( $\left.E_{i n c}\right)$ increased significantly between 1.5 and 6 months of age in both strains. Only at 3 months of age, $E_{\text {inc }}$ was significantly smaller in SHR than in WKY (Fig. 4.5).

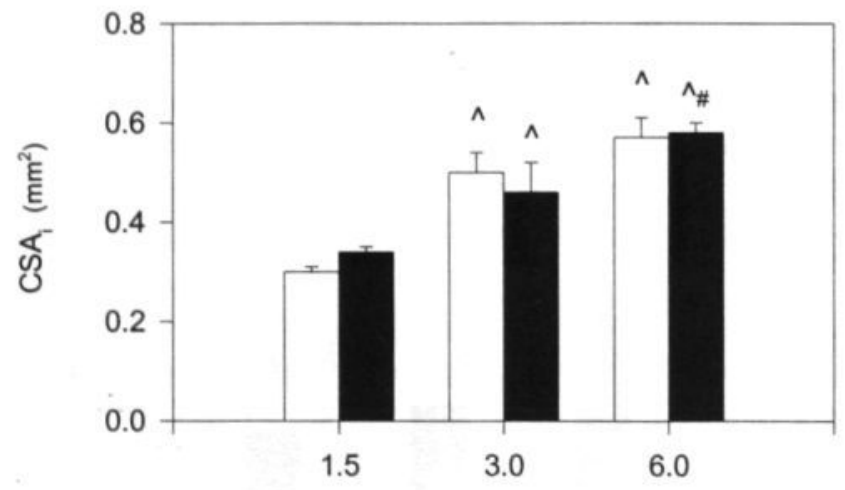

Age in months

Fig. 4.4. In vivo media cross-sectional area $\left(\mathrm{mm}^{2}\right)$ in Wistar Kyoto rats (WKY; open bars) and spontaneously hypertensive rats (SHR; closed bars). Mean \pm SD $(n=12)$.

^ significantly different from 1.5 month old WKY or SHR.

\# significantly different between 3 and 6 month old WKY or SHR. 

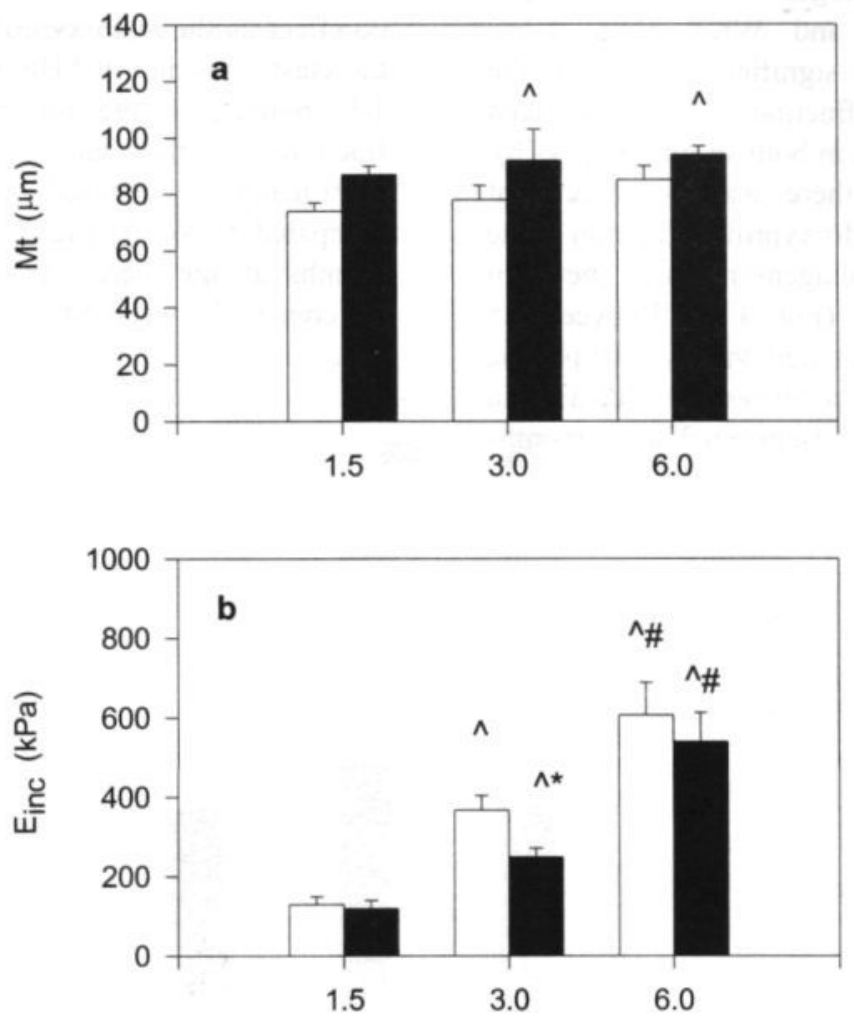

Age in months

Fig. 4.5. Media thickness (a) $(\mu \mathrm{m})$ and incremental elastic modulus (b) (kPa) in Wistar Kyoto rats (WKY; open bars) and spontaneously hypertensive rats (SHR; closed bars). Mean \pm SD $(\mathrm{n}=12)$,

* significantly different between WKY and SHR.

^ significantly different from 1.5 month old WKY or SHR.

\# significantly different between 3 and 6 month old WKY or SHR.

There were no significant changes in media collagen density as determined with morphometry on Sirius Red stained sections between 1.5 and 6 month of age in both strains (Fig. 4.6). The collagen densities did not differ significantly between SHR and WKY at $1.5,3$ or 6 months of age (Fig. 4.6). In the media there were no significant changes in hydroxyproline fraction in the non-cross- linked collagen residue between 1.5 and 6 month old SHR (Fig. 4.7a). At 1.5 months of age hydroxyproline fraction of the noncross-linked collagen residue was significantly larger as compared to 3 and 6 month old WKY (Fig. 4.7a). At 1.5 months of age hydroxyproline fraction of the non-cross-linked collagen residue was significantly higher in WKY as compared to SHR (Fig. 4.7a). At 3 and 6 months of 
age in the media no significant difference in hydroxyproline fraction in the noncross-linked collagen residues was found between SHR and WKY (Fig. 4.7a). Ageing had no significant effect on the hydroxyproline fraction in the cross-linked collagen residue in both strains (Fig. 4.7b). In the media there was no significant difference in hydroxyproline fraction in the cross-linked collagen residues between SHR and WKY (Fig. 4.7b). Between 1.5 and 3 months of age the hydroxyproline fraction in the elastin residue increased in WKY (Fig. 4.7c). Between 3 and 6 months of age there was no significant change in hydroxyproline fraction in the elastin residue in WKY (Fig. 4.7c). Ageing had no effect on the hydroxyproline fraction of the elastin residue in SHR (Fig. 4.7c). At 1.5 months of age the hydroxyproline fraction in the elastin residue was significantly increased in SHR as compared to WKY (fig 7c). At 3 and 6 months of age there were no significant differences between SHR and WKY (fig 7c).

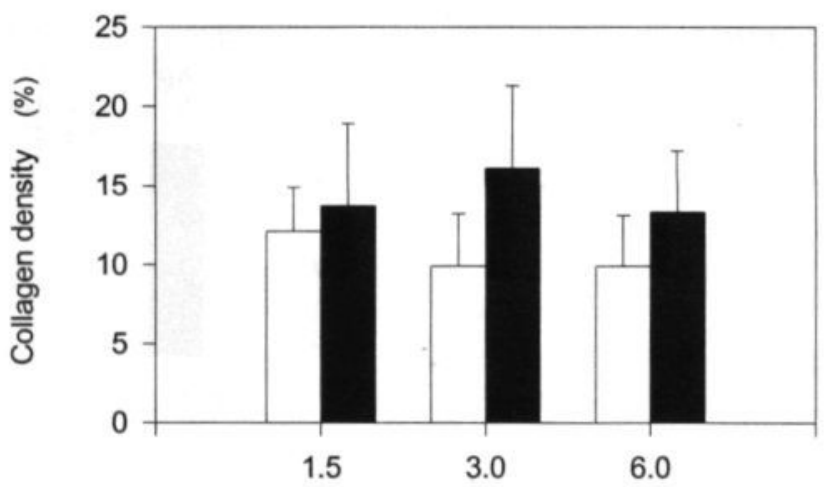

Age in months

Fig. 4.6. Media collagen density , i.e., the collagen volume as percentage (\%) of the total tissue volume in the section measured by morphometry in Wistar Kyoto rats (WKY; open bars) and spontaneously hypertensive rats (SHR; closed bars). Mean \pm SD $(n=12)$

\section{Discussion}

The findings in the present study show that in SHR alterations in aortic wall properties precede the development of hypertension. At the age of 1.5 months distensibility and compliance of the thoracic aorta are lower in SHR than in WKY, while systolic and diastolic blood pressures are not significantly different between these strains. The reduced distensibility and compliance most likely results from an increase in media thickness rather than a change in intrinsic elastic properties. This conclusion is based upon the findings that at the age of 1.5 month the incremental elastic modulus, a measure of elasticity that characterizes intrinsic elastic properties (Reneman RS et al.,1996), is not significantly different between SHR and 
WKY, while the media is significantly thicker in SHR. This assumption is supported by the finding that cross-linked collagen content, an important determinant of artery wall elasticity (Cox RH,1989), is not significantly different between SHR and WKY.
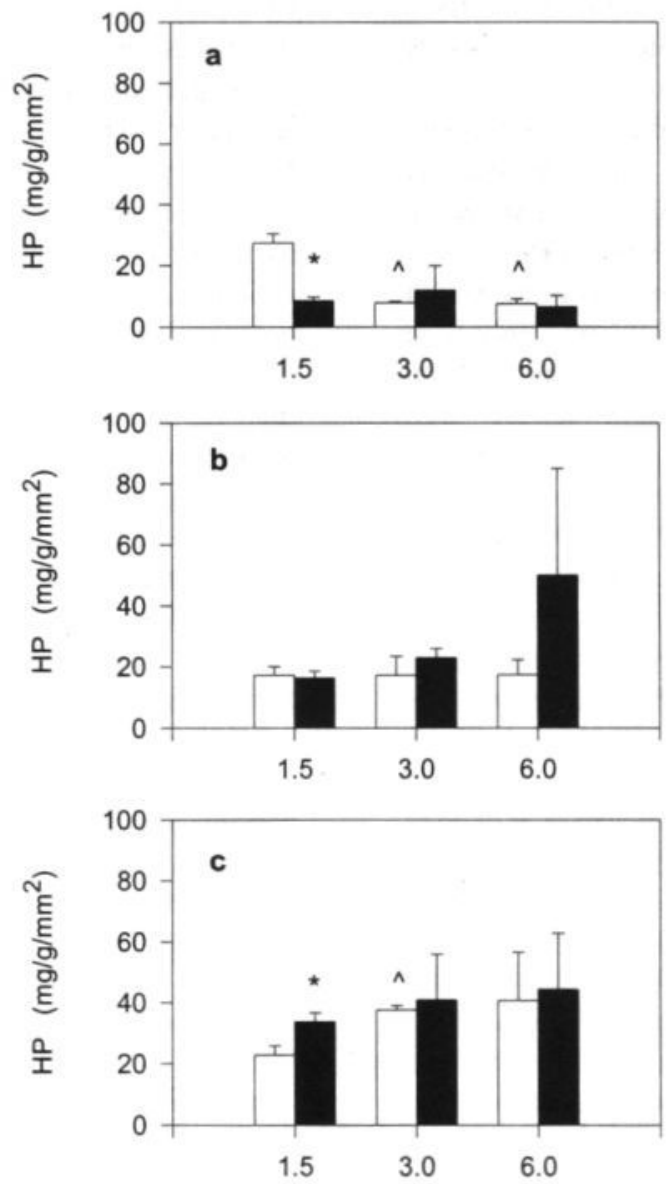

Age in months

Fig. 4.7. Non-cross-linked (a) and cross-linked (b) collagen and elastin fraction (c) in the media as assessed by the amount of hydroxyproline residues $\left(\mathrm{mg} /\left(\mathrm{g} / \mathrm{mm}^{2}\right)\right)$. Wistar Kyoto Rats (WKY; open bars) and spontaneously hypertensive rats (SHR; closed bars). Mean \pm SD $(\mathrm{n}=12)$.

* significantly different between WKY and SHR.

^ significantly different from 1.5 month old WKY or SHR. 
We deliberately performed the experiments during ketamine/xylazine anesthesia to be able to assess dynamic arterial wall properties under conditions. Xylazine is well known for its $\alpha_{2}$ adrenergic agonistic properties. The compound thereby (i) inhibits the activity of the vasomotor center in the central nervous system (Van Zwieten PA et al.,1983), (ii) reduces peripheral adrenergic neurotransmission by a prejunctional inhibitory action (Vanhoutte PM et al, T.J.1981) and (iii) dilates the aorta through a local endothelium-dependent mechanism (Vanhoutte PM et al.,1989). Following administration of ketamine/xylazine circulating catecholamine levels were reduced by 80 to $90 \%$ and, unlike in conscious restrained WKY, prazosin and Na-nitroprusside failed to dilate the aorta in vivo (unpublished results). That the blood pressure lowering effect of ketamine/xylazine was far more marked in SHR than WKY is compatible with the hyperactivity of the sympathetic nervous system in SHR (Daemen MJAP et al.,1995; Grobecker $\mathrm{H}$ et al.,1975; Lee RMKW et al.,1986; Smith TL et al.,1979). The finding in the present study that in SHR hypertension does not develop in the first 6 weeks of life is in agreement with the study of $\mathrm{KL}$ Christensen et al. (Christensen KL et al.,1989), but at variance with the studies of others (Gray S.D.,1982; Lais LT et al.,1977; Smith PG et al.,1983). These differences in the onset of hypertension development could be explained by intra-strain differences in SHR used by the various investigators and by different methods of blood pressure measurement. In their early work Okamoto and Aoki (Okamoto K et al.,1963) referred to 3 general stages in spontaneous hypertension in the rat. The first stage was referred to as "prehypertensive" period, encompassing the first 40-50 days of life. At this stage blood pressure is not or only slightly increased, as compared to WKY, but left ventricular mass is already significantly increased (Folkow B,1972; Gray S.D,1984; Pfeffer MA et al.,1972; Pfeffer MA et al.,1973). Also observed at this stage of life is hypertrophy throughout the whole vascular tree, on both the arterial and the venous side, including the thoracic aorta (Gray S.D,1984). These data and the data in the present study suggest that in SHR the early changes in arterial wall properties are not necessarily related to an increase in blood pressure. In other studies, however, left ventricular hypertrophy was found to follow an increase in blood pressure (Harrap SB et al.,1993) and arterial wall hypertrophy was found to occur concomitantly with the rise in blood pressure (Olivetti G et al, 1982).

The mechanism responsible for the increase in media mass in SHR is as yet unknown. A possible cause of the increase in media thickness could be the enhanced activity of the sympathetic nervous system, which is known to be present before the onset of blood pressure elevation (Judy WV et al.,1976). Moreover, in SHR sympathetic innervation density of the vasculature is increased (Head RJ et al.1986), while the response to norepinephrine is enhanced already during the prehypertensive phase (Kong JQ et al.,1991; Mulvany MJ et al.,1980; Mulvany MJ et al.,1980; Rizzoni D et al.,1994; Smeda JS et $a l ., 1988)$. This overall increase in activation of and sensitivity to the sympathetic nervous system could induce hypertrophy of smooth muscle cells by its growth promoting effect (Bevan D,1984; Daemen MJAP et al.,1995; Simpson P et al..,1982). A possible role for the renin-angiotensin system can not be excluded because Saavedra et al. (Saavedra JM et al.,1992) described an increase in angiotensin converting enzyme in the aorta of prehypertensive SHR as compared to WKY. Angiotensin II has a growth inducing activity on vascular smooth muscle cells in cell cultures (CampbellBosswell M et al.,1981; Geisterfer AA et al.,1988) and on large and small arteries even at subpressor doses (Boonen HCM et al.,1993; Brouwers-Ceiler DL et al.,1997; Daemen MJAP et al.,1991; Griffin SA et al.,1991). Inhibition of this system is associated with a reduction 
in medial thickness (Schelling P et al.,1991; Wang DH et al.,1990). There is increasing evidence that the vascular hypertrophic effects of the sympathetic system and of the renine angiotensin system may be intimately related (Daemen MJAP et al.,1991; Stassen FRM et al.,1997).

During the state of elevated blood pressure (3 and 6 months of age) the compliance of the thoracic aorta at comparable blood pressure was significantly lower in SHR than in WKY, but no significant difference in media cross-sectional area and distensibility of the thoracic aorta could be observed between the two strains at 3 and 6 months of age. Therefore, differences in compliance are most likely caused by the significantly smaller diastolic diameters at comparable blood pressure in SHR than in WKY. The observation that crosssectional compliance does not change significantly with age in both SHR and WKY, despite a significant decrease in distensibility and loss of elasticity as indicated by the increase in incremental elastic modulus, indicates that crosssectional compliance is the regulated parameter. It has been proposed that compliance is kept constant as possible with age by an increase in diameter (Laurent S,1995; Reneman RS et al.,1986).

At the age of 1.5 months, the reduced distensibility and compliance of the thoracic aorta in SHR, as compared to WKY, has to be attributed to an increase in wall thickness due to an increase in muscle mass rather than a difference in wall structure and composition. The latter is indicated by the absence of a difference in total and cross-linked collagen content of the thoracic aorta. Cross-linked collagen is an important determinant of artery wall properties (Cox RH,1989). The finding at the age of 1.5 months that the non-cross-linked collagen content of the thoracic aortic wall is lower in SHR than in WKY indicates that the rate of collagen turnover is lower in SHR. The non-crosslinked collagen molecules do not have tight interactions with the existing extracellular matrix and, hence, are not able to possess tensile strength. Therefore, the non-cross-linked collagen fraction will have very little or no influence on the mechanical properties of the aortic wall (Vadlamudi RK et al.,1993). The finding also suggests that the total elastin content, which at the age of 1.5 month was found to be higher in SHR than in WKY, does not significantly affect artery wall properties.

The loss of distensibility and elastic properties of the thoracic aorta, as indicated by the increase in elastic modules, with age also has to be ascribed to an increase in muscle mass, because the increase in media cross-sectional area with age, due to a combined increase in wall thickness and diameter, is not associated with a change in total and cross-linked collagen content of the aortic wall. The higher total elastin content of the thoracic aortic wall in WKY at the age of 3 months than at the age of 1.5 months again indicates that this content does not influence aortic wall properties.

The finding in the present study that the total collagen content of the thoracic aortic wall is not increased in SHR is at variance with the observations of other investigators (Levy BI et al.,1994). This discrepancy could be explained by the significantly higher blood pressure levels in their than in our study (Ito $H, 1989$ ). It can not be excluded that the tremendous variation in the individual collagen values (Fig. 4.6) contributes to this discrepancy.

In conclusion, the findings in the present study show that in SHR alterations in properties of the thoracic aortic wall precede the development of hypertension. The reduction of distensibility and compliance before blood pressure increases most likely results from an increase in media thickness rather than a change in intrinsic elastic properties and the composition of the wall. 
REFERENCES

Bevan D. Trophic effects of peripheral adrenergic nerves on vascular structure. Hypertension 6 (suppl III):III19-III26, 1984.

Berry CL, Greenwald SE. Effects of hypertension on the static mechanical properties and chemical composition of the rat aorta. Cardiovas. Res. 10:437$451,1976$.

Boonen HCM, Daemen MJAP, Eerdmans PE, Fazzi GE, Van Kleef E, Schiffers PMH, De Mey JGR. Mesenteric small artery changes following vasoconstrictor infusion in young rats. J. Cardiovasc. Pharmacol. 22:388-395, 1993.

Brouwers-Ceiler DL, Nelissen-Vrancken JIJMG, Smits JFM, De Mey JGR. The influence of angiotensin II induced hypertrophy on aortic compliance in rats in vivo. Cardiovasc. Res. 33:478-484, 1997.

Campbell-Bosswell M., Robertson AL. Effects of angiotensin II and vasopressin on human smooth muscle cells in vitro. Exp. Mol. Pathol. 35:265-276, 1981.

Chiariellio M., Ambrosio G, Cappelli-Bigazzi M, Perrone-Filardi P, Brigante F, Sifola C. A biochemical method for the quantification of myocardial scarring after experimental coronary artery occlusion. J.Mol. Cell. Cardiol. 18:283290, 1986.

Christensen KL, Jespersen LT, Mulvany MJ. Development of blood pressure in spontaneously hypertensive rats after withdrawal of long-term treatment related to vascular structure. $J$. Hypertens. 7:83-90, 1989.

Cox RH. Basis for the altered arterial wall mechanics in the spontaneously hypertensive rat. Hypertension 3:485495, 1981.

Cox RH. Mechanical properties of arteries in hypertension. In: Blood vessel changes in hypertension: structure and function. Volume 1, chapter 4. CRC Press Inc., Boca raton, Florida, pp65-95, 1989.

Cox RH. Comparison of arterial wall mechanics in normotensive and spontaneously hypertensive rats. Am. J. Physiol. 6:H159-H167, 1979.
Daemen MJAP, De Mey JGR. Regional heterogeneity of arterial structural changes. Hypertension 25:464-473, 1995

Daemen MJAP. Lombardi DM, Bosman FT, Schwartz SM. Angiotensin II induces smooth muscle cell proliferation in the normal and injured rat arterial wall. Circ. Res. 68:450-456, 1991.

Dobrin PB. Mechanical properties of arteries. Physiol. Rev. 58:397-460, 1978.

Folkow B. Hemodynamic consequences of adaptive structural changes of the resistance vessels in hypertension. Clin. Sci. 40:1-12, 1972.

Geisterfer AA, Peach MJ, Owens GK. Angiotensin II induces hypertrophy, but not hyperplasia, of cultured rat aortic smooth muscle cells. Circ. Res. 62:749$756,1988$.

Gray SD. Spontaneous hypertension in the neonatal rat. A review. Clin. exp. Hyper. A. 6:755-781, 1984.

Gray SD. Early postnatal differences between WKY and SHR in anatomical and physiological parameters. Fed. Proc. 41:1589, 1982.

Greenwald SE, Berry CL. Static mechanical properties and chemical composition of the aorta of spontaneously hypertensive rats: a comparison with the effects of induced hypertension. Cardiovas. Res. 12:364-372, 1978.

Griffin SA, Brown WBC, MacPherson F, McGrath JC, Wilson VG, Korsgaard N, Mulvany MJ, Lever AF. Angiotensin II causes vascular hypertrophy in part by a non-pressor mechanism. Hypertension 17:626-635, 1991.

Grobecker H, Roizen MF, Veise V, Saavedra JM, Kopin IJ. Sympathoadrenal medullary activity in young spontaneously hypertensive rats. Nature 258:267-268, 1975.

Harrap SB, Mitchell GA, Casley DJ, Mirakian C, Doyle AE. Angiotensin II, sodium, and cardiovascular hypertrophy in spontaneously hypertensive rats. Hypertension 21:50-55, 1993.

Head RJ. Hypernoradrenergic innervation: its relationship to functional and hyperplastic changes in the vasculature of spontaneously hypertensive rat. Blood vessels 26:1-20, 1986.

Hoeks APG, Brands PJ, Smeets FAM, Reneman RS. Assessment of the 
distensibility of superficial arteries. Ultrasound Med. Biol. 16:121-128, 1990.

Hoeks APG, Arts TGJ, Brands PJ, Reneman RS. Comparison of the performance of the rf cross correlation and Doppler autocorrelation technique to estimate the mean velocity of simulated ultrasound signals. Ultrasound Med. Biol. 19:727740, 1993.

Hoeks APG. The arterial system in hypertension. Kluwer Academic Publishers. chapter 8 ed M.E. Safar and M.F.O'Rourke pp119-134, 1993.

Ito $\mathrm{H}$. Vascular connective tissue changes in hypertension. In: Blood vessel changes in hypertension: structure and function. Volume 1, chapter 5. CRC Press Inc., Boca raton, Florida, pp99-122, 1989.

James JJ, Bosch KS, Aronson DC, Houtkooper JM. Sirius red histophotometry and spectrophotometry of sections in the assessment of the collagen content of liver tissue and its application in growing rat liver. Liver 10:1-5, 1990

Judy WV, Watanabe QM, Henry DB, Besch HR, Murphy WR, Hockel GM. Sympathetic nerve activity: role of blood pressure in the spontaneously hyertensive rat. Circ. Res. 38(Suppl. II):21-29, 1976.

Kong JQ, Taylor DA, Fleming WW. Mesenteric vascular responses of young spontaneously hypertensive rats. $J$. Pharmacol. Exp. Ther. 258:13-17, 1991.

Lais LT, Rios LL, Boutelle S, Dibona GF, Brody MJ. Arterial pressure development in neonatal and young spontaneously hypertensive rats. Blood vessels 14:277284, 1977.

Laurent S. Arterial wall hypertrophy and stiffness in essential hypertensive patients. Hypertension 26:355-362, 1995.

Lee RMKW, Coughlin MD, Cheung DWT. Relationship between sympathetic innervation, vascular changes and hypertension in spontaneously hypertensive rats. $J$ Hypertension 4(suppl):81-83, 1986.

Levy BI, Michel JB, Salzman JL, Azizi M, Poitevin P, Safar M, Camilleri JP. Effects of chronic inhibition of converting enzyme on mechanical and structural properties of arteries in rat renovascular hypertension. Circ. Res. 63:227-229, 1988.

Levy BI, Benessiano J, Poitevin P, Safar ME. Endothelium dependent mechanical properties of the carotid artery in WKY and SHR. Role of angiotensin converting enzyme inhibition. Circ. Res. 66:321328, 1990.

Levy BI, Duriez M, Phillipe M, Poitevin P, Michel JB. Effects of chronic dihydropydidine (Isradipine) on the large arterial walls of spontaneoulsy hypertensive rats. Circulation 90;30243033, 1994.

Mulvany MJ, Aalkjaer C, Christensen J. Changes in noradrenaline sensitivity and morphology of arterial resistance vessels during development of high blood pressure in spontaneously hypertensive rats. Br. J. Pharmacol. 71:585-596, 1980.

Mulvany MJ, Nyborg N. An increased calcium sensitivity of mesenteric resistance vessels in young and adult spontaneously hypertensive rats. Hypertension 2:664-671, 1980.

Mulvany J.M.J., Aalkjaer C. Structure and function of small arteries. Physiol. Rev. 70: 921-961, 1990.

Okamoto K, Aoki K. Development of a strain of spontaneously hypertensive rats. Jap. Circ. J. 27:202-293, 1963.

Olivetti G, Melissari M, Marchetti G, Anversa P. Quantitative structural changes of the rat thoracic aorta in early spontaneous hypertension. Tissue composition, and hypertrophy and hyperplasia of the smooth muscle. Circ. Res. 51:19-26, 1982.

Pfeffer MA, Pfeffer JM, Frohlich E. Hemodynamic correlates of naturally developing left ventricular hypertrophy and spontaneously hypertensive rats (abstr.) International Study Group for Research in Cardiac Metabolism. Winnipeg, Canada, 1972.

Pfeffer MA, Frohlich E. Pfeffer JM. Disparity in autonomic control of cardiac performance in SHR (abstr). Circulation 48(suppl IV):IV-45, 1973.

Reneman RS, Van Merode T, Hick P, Muytjens AMM, Hoeks APG. Agerelated changes in carotid artery wall properties in men. Ultrasound Med. Biol. 12:465-471, 1986. 
Reneman RS, Hoeks APG, Westerhof N. Non-invasive assessment of artery wall properties in humans; methods and interpretation. J. Vascular Investigation 2:53-64, 1996.

Rizzoni D, Castellano M, Porteri E, Bettoni G, Muiesan ML, Agabiti Rosei E. Vascular structural and functional alterations before and after the development of hypertension in SHR. Am. J. Hypertens. 7:193-200, 1994.

Saavedra JM, Correa FMA, Seltzer A, Pinto JEB, Viglione P, Tsutsumi K. Enhanced angiotensin converting enzyme binding in arteries from spontaneously hypertensive rats. J. Hypertens. 10:13531359, 1992.

Safar ME, Simon AC, Levenson JA. Structural changes in large arteries in sustained essential hypertension. Hypertension. 6(Suppl III):III117-III121, 1984.

Schelling P, Fisher H, Ganten D. Angiotensin and cell growth: a link to cardiovascular hypertrophy? [Editorial]. J. Hypertens. 9:3-15, 1991.

Simpson P, Mcgrath A, Savion S. Myocyte hypertrophy in neonatal rat heart cultures and its regulation by serum and by catecholamines. Circ. Res. 51:787-801, 1982.

Smeda JS, Lee RM, Forrest JB. Structural and reactivity alterations of the renal vasculature of spontaneously hypertensive rats prior to and during established hypertension. Circ. Res. 63:518-533, 1988.

Smith PG, Poston CW, Mills E.. Contribution of noradrenergic reactivity and sympathetic nervous system (SNS) activity to blood pressure in neonatal and adult spontaneously hypertensive rats. Fed. Proc. 42:895, 1983.

Smith TL, Hutchins PM. Central hemodynamics in the developmental stages of spontaneous hypertension in the unanesthetized rat. Hypertension 1:508$517,1979$.

Struijker Boudier HAJ. Pathophysiology of hypertension. In: Handbook of Hypertension. Chapter 5, Volume 17. ed. A. Zanchetti and G. Mancia. pp170-212, 1997.
Stassen FRM, Brouwers-Ceiler DL, Raat H, Fazzi GE, Smits JFM, De Mey JGR. Angiotensin II induces media hypertrophy and hyperreactivity in mesenteric but not superior epigastric small arteries of the rat. J. Vasc. Res. 34: 289-297, 1997.

Vadlamudi RK, McCormick RJ, Medeiros DM, Vossoughi J, Failla ML. Copper deficiency alters collagen types and covalent cross-linking in swine myocardium and cardiac valves. Am. J. Physiol. 264:H2154-H2161, 1993.

Van Gorp AW, Van Ingen Schenau DS, Willegers J, Hoeks APG, De Mey JGR, Struijker Boudier HAJ, Reneman RS. A technique to assess aortic distensibility and compliance in anesthetized and awake rats. Am. J. Physiol. 270:H780H786, 1996.

Vanhoutte PM, Verbeuren TJ, Webb RC. Local modulation of adrenergic neuroeffector interactions in the blood vessel wall. Physiol. Rev. 61:151-218, 1981.

Vanhoutte PM, Miller VM. Alpha-2 adrenoceptors and endothelium-derived relaxing factor. Am. J. Med. 87(Suppl):15,1989 .

Van Merode T, Hick PJ, Hoeks AP, Rahn KH, Reneman RS. Carotid artery wall properties in normotensive and borderline hypertensive subjects of various ages. Ultrasound Med. Biol. 14:563-569, 1988.

Van Merode T, Brands PJ, Hoeks APG, Reneman RS. Faster ageing of the carotid artery bifurcation in borderline hypertensive subjects. $J$ Hypertension 11:171-176, 1993.

Van Zwieten PA, Thoolen MJMC, Timmermans PBMWM. The pharmacology of centrally acting antihypertensive drugs. $\mathrm{Br}$. J. Clin. Pharmacol. 15(Suppl):455-462, 1983.

Ventura H, Messerli FH, Oigman W, Suarez DH, Dreslinski GR, Dunn FG, et al. Impaired systemic arterial compliance in borderline hypertension. Am. Heart J. 108:132-136, 1984.

Wang DH, Prewitt RL. Captopril reduces aortic and microvascular growth in hypertensive and normotensive rats. Hypertension 15:68-77, 1990. 


\section{CHAPTER}

\section{AORTIC WALL PROPERTIES IN NORMOTENSIVE AND HYPERTENSIVE RATS OF VARIOUS AGES IN VIVO.}

(Hypertension 26:363-368, 1995)

Ad W van Gorp

Dorette $S$ van Ingen Schenau

Arnold P G Hoeks

Harry A J Struijker Boudier

Robert S Reneman

Jo G R De Mey 


\section{ABSTRACT}

The distensibility of the arterial system, which is partly determined by arterial wall structure, smooth muscle tone, and actual pressure level, decreases with ageing and hypertension. Our aim was to compare aortic wall properties in 3-and 6- moth old normotensive Wistar Kyoto rats (WKY) and spontaneously hypertensive rats (SHR) at comparable blood pressures in vivo. During ketamine/xylazine anesthesia in rats we performed ultrasound arterial wall tracking and invasive pressure measurements to determine, at the level of the thoracic aorta, diastolic pressure, diastolic lumen area, changes in pressure and lumen area during the cardiac cycle, and indexes of compliance and distensibility. These observations were combined with histological measurements for determination of media cross-sectional area and thickness and the imcremental elastic modulus under conditions as expected in situ. Anesthesia abolished the difference in diastolic pressure between SHR and WKY. Between 3 and 6 months of age in WKY, diastolic area and incremental elastic modulus increased significantly, distensibility decreased, and all other recorded variables were not modified. Between 3 and 6 months of age in SHR, diastolic area and incremental elastic modulus increased, distensibility of the aortic wall decreased, and all other mechanical and structural properties did not change significantly. At both ages, diastolic area and compliance were significantly smaller in SHR than WKY. The other mechanical and structural properties measured or calculated at comparable pressure did not differ between strains. Differences between the aorta of 3 and 6 month old rats and between strains observed in vivo at comparable pressures can largely be attributed to differences in lumen caliber. These may represent the first findings concerning remodeling of the aorta in intact rats.

\section{INTRODUCTION}

Arterial distensibility decreases with ageing and hypertension (Carlson RG et al.,1970; Merillon JP et al.,1982; Reneman RS et al.,1986; Van Merode $\mathrm{T}$ et al.,1993). This increases aortic input impedance and decreases systemic arterial compliance and thus may adversely affect cardiac function in the long run by elevating cardiac afterload and reducing the energetic efficiency of the myocardium (Merillon JP et al.,1982; Nichols WW et al.,1990; Nichols WW et al.,1985; Kelly RP et al.,1992). Arterial distensibility is determined by the composition and organization of the arterial wall, the contractile tone of arterial smooth muscle cells, and the actual pressure level (Dobrin PB,1978). The precise mechanism responsible for the alterations in distensibility with ageing and hypertension is still largely unknown.

The aim of the present study was to determine the distensibility, compliance and structure of the thoracic aorta in two age groups of normotensive and hypertensive rats at identical pressures in vivo. Distensibility and compliance were determined by ultrasound arterial wall tracking and invasive pressure measurements in 3 and 6 month old Wistar Kyoto rats (WKY) and spontaneously hypertensive rats (SHR) anesthetized with ketamine/xylazine. The structure was assessed by morphometry of cross sections.

\section{METHODS}

\section{Study design}

Experiments were performed in 3 and 6 month old male WKY and SHR of the Okamoto Aoki strain (Okamoto et al., 1963) (local inbred strains; Central Animal Facilities, University of Limburg, Maastricht, Netherlands); each group contained 12 rats. The rats were housed in individual cages, maintained on a 12 hour light/dark cycle, fed ad libitum (Hope Farms), and had free access to tap water. Experimental protocols were approved by the local Institutional Animal Care and Use Committee. 
For measurement of arterial blood pressure the rats were equipped under ether anesthesia with an intra-aortic catheter filled with heparinized saline. The catheter was advanced from a femoral artery to just below the bifurcation of the left renal artery. The catheter was guided under the skin and exteriorized at the base of the skull. Two days later blood pressure was measured in the freely moving conscious rats through an external low volume displacement pressure transducer (CP-01, Century Technology Co.). The time delay of the catheter and pressure transducer was 12 milliseconds and hence guaranteed a sample frequency grater than $50 \mathrm{~Hz}$. The rats were subsequently anesthetized with ketamine/xylazine (10:50 $\mu \mathrm{g} / \mathrm{ml} ; 100 \mu \mathrm{L} .100 \mathrm{~g}$ body wt), and blood pressure measurements were performed along with ultrasound wall tracking of the thoracic aorta. Experiments were terminated by exsanguination of the rats, after which the thoracic aorta was isolated for subsequent histological examination.

\section{Ultrasound Assessment of Aortic Diameter and Wall Movement}

The diameter and change in diameter during the cardiac cycle were assessed as a continuous function of time with the use of a vessel wall tracking system (see below) attached to a conventional B-mode ultrasound system (Pie480, 7.5 MHz. Linear array, Pie Medical). With this ultrasonic technique we measured the internal diameter of the aorta (Hoeks APG et al., 1990). The ultrasound probe was placed on the thorax slightly to the left of the sternum. The thoracic aorta was then visualized in B-mode ( $\mathrm{B}$, brightness), and an $\mathrm{M}$-line was positioned perpendicular to the vessel walls approximately $10 \mathrm{~mm}$ cranially from the diaphragm. Thereafter the ultrasound system was switched to Mmode (M, motion), and ultrasound was emitted and received along the selected line of sight at a programmable emission trigger frequency.
The concept of the wall tracking system has been described in detail before (Hoeks APG et al., 1990). It is based on a data-acquisition system capable of capturing the received and amplified radio frequency (RF) signals synchronously with the emission trigger at a programmable sample frequency of up to $30 \mathrm{MHz}$. And with a dynamic range of 48 $\mathrm{dB}$ ( 8 bits). The position and width of the range of interest are programmable (on average, 20 and $1-\mathrm{mm}$, respectively, in the present study). The size of the internal data memory is 1 megabyte, allowing for the temporary storage of, for example, 512 RF lines of 2000 data points each. At an emission frequency of $250 \mathrm{~Hz}$. The memory will then hold 2.5 seconds of data, corresponding to approximately 10 cardiac cycles (and three respiration cycles) under the present experimental conditions (Fig. 5.1). The wall tracking system is also equipped with an acquisition system for reference signals such as blood pressure, which are sampled synchronously with the emission trigger, activating the capture of an RF line (Fig. 5.2).

After data acquisition is complete the data are transferred to a personal computer. The first line acquired is graphically presented and displayed, allowing manual identification of the anterior and posterior wall boundaries by placement of two markers representing the sample windows for data processing. Once the walls are identified the remaining data are transferred and processed on the fly ( $<10$ seconds). To extract the change in position of either the anterior or posterior wall, averaged over a few RF lines, the approach based on the cross-correlation model for corresponding segments of subsequent RF lines was applied (Hoeks APG et al.,1993). This method has a low noise sensitivity and is insensitive to the RF carrier frequency. The estimates for the cross-correlation coefficients are based on a running average over a programmable number of RF lines (data window in time) 
to enhance the stability of the estimate for the mean displacement. To ensure that the signals were always returned by the same structure, we adjusted the position of the sample windows according to the observed displacements (tracking window). The difference between the displacement signal of the posterior and anterior walls yields the change in diameter as a function of time. From the observed distension waveform, in combination with the initial distance between the sample windows, the internal end-diastolic diameter, the peak to peak change in internal diameter, and the length of the cardiac cycle can be extracted for each cardiac cycle.

Measurements were started after blood pressure and heart rate had stabilized with rats under anesthesia (20 minutes). In each rat two observers performed three 2.5 second recordings. The data obtained during these sessions were averaged. The ultrasound system used is very accurate and can resolve displacements of only a few micrometers (Hoeks APG et al., 1990). The reliability in anesthetized rats is also good. The variabilities between four consecutive measurements as performed on 1 day by one investigator expressed as coefficients of variation varied between $3.2 \%$ and 6.5 $\%$ for the aortic diameter $\left(\mathrm{d}_{\text {dia }}\right)$ and between $7.9 \%$ and $11.0 \%$ for the change in aortic diameter during the cardiac cycle $(\Delta d)$. The variabilities between successive experimental days, also expressed as coefficients of variance, were $4.6 \%$ for $\mathrm{d}_{\text {dia }}$ and $9.2 \%$ for $\Delta \mathrm{d}$. These values are comparable to the ones recently reported for human carotid and femoral arteries (Kool MJF et al.,1994).

\section{Relationship Between Lumen Diameter and Pressure}

Since the wall tracking system and the intra-aortic catheter display different time responses, we limited the analysis of the relationship between aorta lumen caliber and intra-aortic pressure to the situation at end diastole and to the maximal changes in pressure and diameter that occurred during the cardiac cycle. Diameters and diameter changes were converted to lumen areas and changes ( $\mathrm{A}$ and $\Delta \mathrm{A}$ ), assuming a perfect circular cross section of the vessel. With the additional assumption that the vessel segment length remains constant, the absolute and relative changes in aortic lumen area noted during the cardiac cycle and expressed per unit of pressure provide information about the compliance and distensibility of the vessel, respectively (Hoeks APG et al., 1990; Hoeks APG et al.,1993; Kool MJF et al.,1994).

\section{Aortic Wall Structure}

A $10 \mathrm{~mm}$ supradiaphragmatic segment of the thoracic aorta was isolated, fixed in $4 \%$ neutral buffered formaldehyde, and embedded in paraffin, after which $4 \mu \mathrm{m}$ thick sections were obtained. These were stained with Lawson's solution, which highlights elastic laminae, and the crosssectional area of the media was determined with an axioplan microscope (zeiss) equipped with a standard CCD camera (Stemmer) (Boonen HCM et al.,1991; Boonen HCM et al.,1993). digitized images were analyzed with commercial software (JAVA, Jandel Scientific). The area enclosed by the external and crosssectional area of the media $\left(\mathrm{CSA}_{e}\right)$. This was converted to in vivo media crosssectional $\left(\mathrm{CSA}_{i}\right)$ by the formula $\mathrm{CSA}_{1}=\left(\mathrm{L}_{e} / \mathrm{L}_{\mathrm{i}}\right) \cdot \mathrm{CSA}_{\mathrm{e}}$, in which it was assumed that aortic wall volume remains constatn after isolation and fixation and in which $\mathrm{L}_{\mathrm{i}}$ and $\mathrm{L}_{\mathrm{e}}$ refer to the lenght of the thoracic aorta before and after isolation, respectiviely. To this end, a segment of 10 $\mathrm{mm}\left(\mathrm{L}_{\mathrm{e}}\right)$ was again measured under a stereomicroscope with a precision of \pm 5 $\mu \mathrm{m} . \mathrm{L}_{\mathrm{e}} / \mathrm{L}_{\mathrm{i}}$ averaged $0.75 \pm 0.02$ and $0.75 \pm$ 0.01 in 3 and 6 month old WKY and 0.72 \pm 0.01 and $0.79 \pm 0.01$ in 3 and 6 month old SHR, respectively. Media thickness $\left(M_{1}\right)$ in diastole was calculated from the ultrasound measurement of diameter $\left(\mathrm{d}_{\text {dia }}\right)$ and from $\mathrm{CSA}_{\mathrm{i}}$ using the formula 


$$
\mathrm{CSA}_{\mathrm{i}}=\left(\mathrm{Le}_{\mathrm{e}} / \mathrm{L}_{\mathrm{i}}\right) \cdot \mathrm{CSA}_{\mathrm{e}}
$$

in which it was assumed that aortic wall volume remains constant after isolation and fixation and in which $\mathrm{L}_{\mathrm{i}}$ and $\mathrm{L}_{\mathrm{e}}$ refer to the length of the thoracic aorta before and after isolation, respectively.

Media thickness (Mt) in diastole was calculated from diastolic diameter ( $\mathrm{d}_{\mathrm{dia}}$ ) and from $\mathrm{CSA}_{\mathrm{i}}$, using the formula:

$\mathrm{CSA}_{\mathrm{i}}=\pi\left(\mathrm{d}_{\mathrm{dia}} / 2+\mathrm{Mt}\right)^{2}-\pi\left(\mathrm{d}_{\mathrm{dia}} / 2\right)^{2}$

which can be rewritten as:

$$
\mathrm{Mt}=-\left(\mathrm{d}_{\mathrm{dia}} / 2\right)+\left\{\left(\mathrm{d}_{\mathrm{dia}} / 2\right)^{2}+\mathrm{CSA}_{\mathrm{i}} / \pi\right\}^{1 / 2}
$$

In these calculations it is assumed that the cross section of the aorta was circular in situ.

Measuroments of mechanical properties and dimensions were combined to calculate the incremental elastic modulus or Young's modulus $\left(\mathrm{E}_{\text {inc }}\right)$ :

$E_{\text {inc }}=d_{d i a} /(M t . D C)$

where DC is the distensibility coefficient.

\section{Statistics}

Table 5.1: General characteristics in conscious 3 and 6 month old WKY and SHR.

\begin{tabular}{lcccc}
\hline Parameter & WKY & WKY & SHR & SHR \\
Age (months) & 3 & 6 & 3 & 6 \\
Body weight $(\mathrm{g})$ & $314 \pm 9$ & $435 \pm 5^{*}$ & $276 \pm 7^{\wedge}$ & $385 \pm 6^{* \wedge}$ \\
$\mathrm{P}_{\text {dia }}(\mathrm{mmHg})$ & $98 \pm 2$ & $109 \pm 2^{*}$ & $124 \pm 4^{\wedge}$ & $141 \pm 3^{* \wedge}$ \\
$\mathrm{P}_{\text {dia }}(\mathrm{kPa})$ & $12.9 \pm 0.2$ & $14.5 \pm 0.03^{*}$ & $16.4 \pm 0.6^{\wedge}$ & $18.7^{*} \pm 0.5^{* \wedge}$ \\
\hline
\end{tabular}

$\mathrm{P}_{\mathrm{dia}}$ indicates diastolic blood pressure. Values are mean $\pm \mathrm{SEM} ; \mathrm{n}=12$

* significantly different from 3 months of age

^ significantly different from WKY 

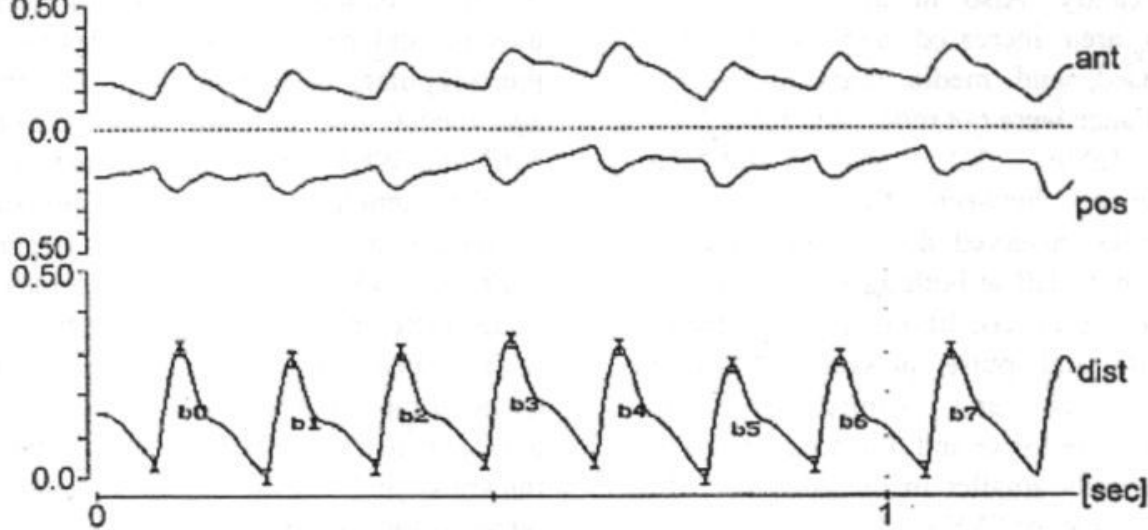

Fig. 5.1 Typical tracings show displacement of the anterior (ANT) and posterior (POS) thoracic aortic wall recorded as a function of time in an anesthetized 6 month old spontaneously hypertensive rat. The difference between these displacements, representing the change in aortic diameter, is represented in the bottom trace (DIST).

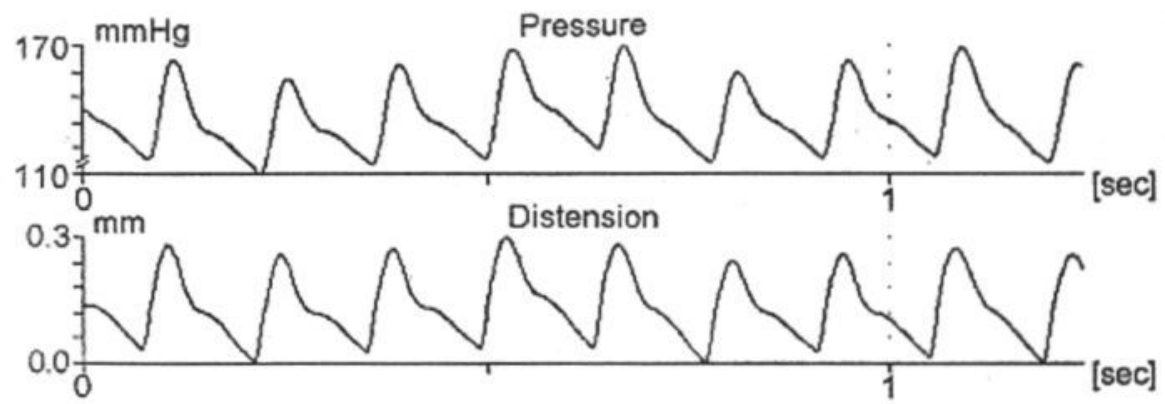

Fig. 5.2 Tracings show relation between pressure (top) and the change in aortic diameter (bottom) as a function of time. Data were obtained in the same recording session as that shown in Fig. 5.1.

Anesthesia with ketamine/xylazine hardly affected diastolic pressure in 3 or 6 month old WKY (Table 5.2). In SHR on the other hand anesthesia hardly lowered blood pressure. During anesthesia the original difference in diastolic pressure between SHR and WKY was abolished, as was the difference in pulse pressure at 3 months of age (Table 5.2). Pulse pressure remained significantly elevated in 6 month old anesthetized SHR.

Table 5.2 summerizes findings with respect to aortic wall properties in anesthetized 3 and 6 month old WKY and SHR. In WKY between 3 and 6 months of age diastolic pressure, pulse pressure, and heart rate as well as media cross-sectional area, media thickness, and aortic compliance were not modified. However, aortic lumen area at diastole was increased, and distensibility of the aortic wall was reduced (Table 5.2). The increase in lumen area and decrease in distensibility resulted in a significant elevation of the elastic modulus. In SHR, comparable changes were observed 
between 3 and 6 months of age, except for the pulse pressure, which rose significantly. Also in this strain aortic lumen area increased and distensibility decreased, and media mass and aortic compliance were not modified (Table 5.2).

Table 5.2 also illustrates differences between the aortic wall properties observed during anesthesia in WKY and SHR at both ages. At 3 months of age under conditions of comparable diastolic and pulse pressures, diastolic lumen area and compliance were significantly lower and the elastic modulus significantly smaller in the aorta of SHR than in that of WKY. These differences can be appreciated from the relationships between intra-aortic pressure and aortic lumen area shown in Fig. 5.3. The slope of the line connecting observations during diastole and peak systole corresponds to the compliance coefficient. At 3 month of age media area did not differ between SHR and WKY. However, in view of the smaller lumen at comparable pressure, media thickness was significantly larger in SHR than WKY (Table 5.2). At 6 months of age differences between SHR and WKY with respect to aortic lumen area and aortic compliance persisted (table 2, Fig. 5.3). Differences in terms of media thickness and elastic modulus, however, were no longer significant at 6 months of age (Table 5.2).

Table 5.2: Aortic wall properties in ketamine/xylazine anesthetized 3 and 6 month old WKY and SHR

\begin{tabular}{lcccc}
\hline Strain & WKY & WKY & SHR & SHR \\
Age $(m o n t h s)$ & 3 & 6 & 3 & 6 \\
$P_{\text {dia }}(\mathrm{kPa})$ & $12.7 \pm 0.3$ & $14.0 \pm 0.3$ & $11.7 \pm 0.3$ & $13.6 \pm 0.7^{* \wedge}$ \\
$\mathrm{PP}(\mathrm{kPa})$ & $4.6 \pm 0.2$ & $5.6 \pm 0.4$ & $5.5 \pm 0.2$ & $8.0 \pm 0.3^{* \wedge}$ \\
$\mathrm{PI}(\mathrm{ms})$ & $252 \pm 5$ & $245 \pm 7$ & $256 \pm 7$ & $250 \pm 9$ \\
$\mathrm{~d}_{\text {dia }}(\mathrm{mm})$ & $1.97 \pm 0.02$ & $2.27 \pm 0.04^{*}$ & $1.53 \pm 0.02^{\wedge}$ & $1.87 \pm 0.04^{* \wedge}$ \\
$\mathrm{A}_{\text {dia }}\left(\mathrm{mm}^{2}\right)$ & $3.00 \pm 0.11$ & $4.08 \pm 0.13$ & $1.80 \pm 0.05^{\wedge}$ & $2.79 \pm 0.13^{* \wedge}$ \\
$\mathrm{CC}\left(\mathrm{mm}^{2} / \mathrm{kPa}\right)$ & $0.200 \pm 0.008$ & $0.193 \pm 0.017$ & $0.113 \pm 0.004^{\wedge}$ & $0.114^{\wedge} \pm 0.007^{\wedge}$ \\
$\mathrm{DC}\left(1 / \mathrm{kPa}^{*}\right.$ & $0.070 \pm 0.003$ & $0.049 \pm 0.005^{*}$ & $0.062 \pm 0.002$ & $0.044 \pm 0.004^{*}$ \\
$\mathrm{CSA}\left(\mathrm{mm}^{2}\right)$ & $0.50 \pm 0.04$ & $0.57 \pm 0.04$ & $0.46 \pm 0.06$ & $0.58 \pm 0.02^{2}$ \\
$\mathrm{M}_{\mathrm{t}}(\mathrm{mm})$ & $78 \pm 5$ & $85 \pm 5$ & $92 \pm 1 \wedge^{\wedge}$ & $94 \pm 3$ \\
$\mathrm{E}_{\text {inc }}(\mathrm{kPa})$ & $368 \pm 36$ & $607 \pm 82^{*}$ & $250 \pm 22^{\wedge}$ & $540 \pm 73^{*}$ \\
\hline
\end{tabular}

Definitions are as in Table 5.1 and PP, pulse pressure; PI, pulse interval; $\mathrm{d}_{\text {dia }}$, diastolic lumen diameter; $\mathrm{A}_{\text {dia }}$, diastolic lumen area; CC, compliance; DC, distensibility coefficient; CSA, cross sectional area of the aortic media at in situ vessel lenght; $\mathrm{M}_{t}$, aortic media thickness at $\mathrm{d}_{\text {dia }}$; and $\mathrm{E}_{\text {ine }}$, incremental elastic (or Young's) modulus. Values are mean $\pm \mathrm{SEM} ; \mathrm{n}=12$

*significantly different from 3 month old animals, $\mathrm{p}<0.05$

^ significantly different from WKY, $\mathrm{p}<0.05$ 

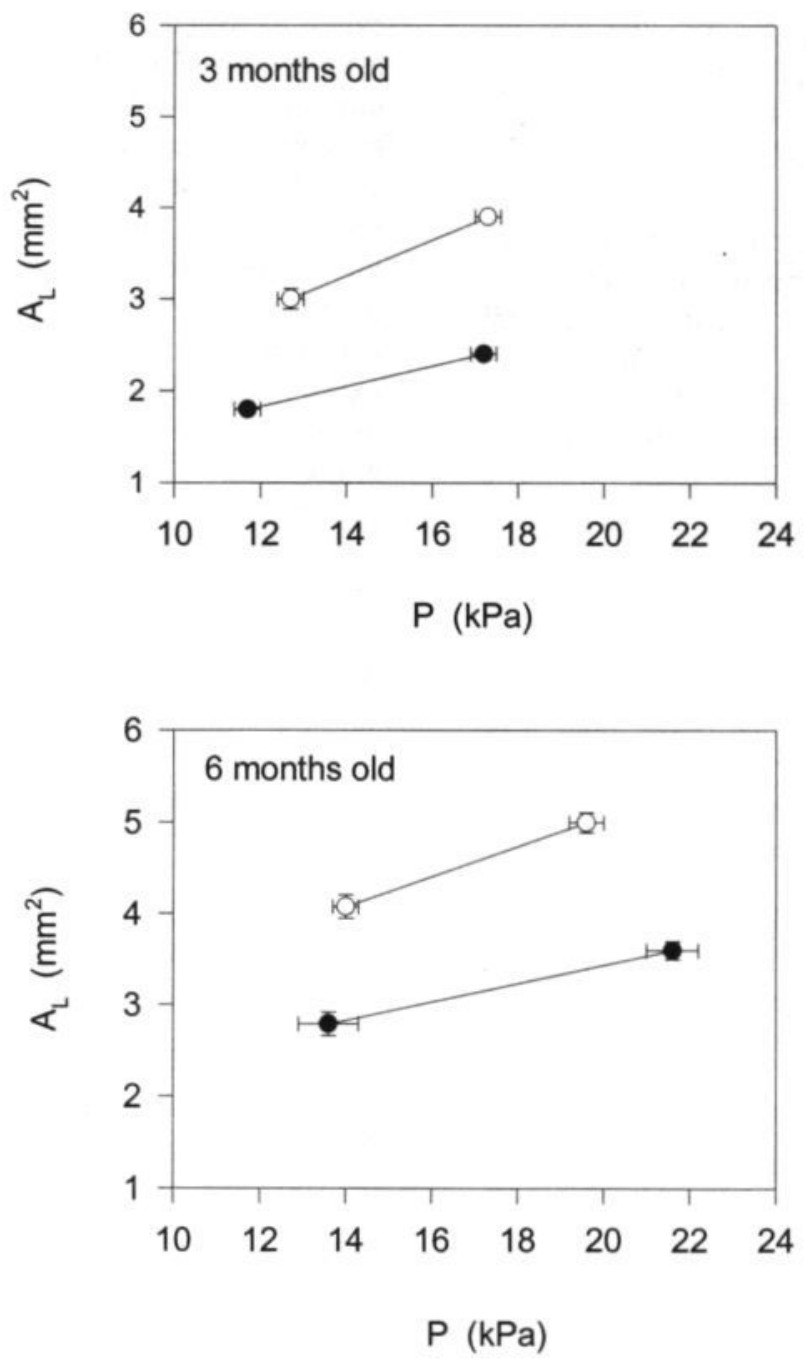

Fig. 5.3. Line graphs show relationships between intra-aortic pressure $(P)$ and aortic lumen area $\left(A_{L}\right)$ at diastole and systole in 3 month old (top) and 6 month old (bottom) anesthetized Wistar Kyoto rats $(\mathrm{O})$ and spontaneously hypertensive rats $(\bullet)$. The slope of lines connecting minimal and maximal values refers to the compliance coefficient discussed in the text and shown table 5.2. Mean $\pm \mathrm{SEM} ; \mathrm{n}=12$. 


\section{DISCUSSION}

We determined in vivo aortic wall properties by ultrasound techniques at comparable pressures in 3 and 6 month old SHR and WKY. The main change with aging and hypertension consisted of an alteration of the lumen caliber of the vessel. Cross-sectional compliance was reduced in SHR compared with WKY.

Mechanical and structural properties of arteries and their interactions have been studied extensively with respect to the development and treatment of hypertension. In recent years primarily small resistance sized arteries were addressed in this respect, in view of the elevated total peripheral vascular resistance that characterizes essential hypertension (Folkow B et al.,1982; Mulvany M et al.,1990). At this level both wall hypertrophy and a reduction of lumen diameter (remodelling) may be involved (Mulvany MJ et al.,1990; Heagerty AM et al.,1993). The situation is less clear in more proximal parts of the circulation such as the aorta. Reduction of the distensibility of this vessel can adversely affect cardiac function in the long run and thus promote the development of various cardiac diorders (Carlson RG, et al.,1970; Merillon JP et al.,1982; Nichols WW et al.,1985; Reneman RS et al.,1986; Nichols WW et al.,1990; Kelly RP et al.,1992; Van Merode T et al.,1993). In this respect hypertension may accelerate the changes that occur during normal aging (Van Merode T et al.,1993). However, the exact nature of the changes in the aortic distensibility and compliance with aging and hypertension remains largely unknown. In general, the mechanical properties of a vessel such as the aorta are determined by its structure, the activity of its smooth muscle, and the actual pressure level (Dobrin PD,1978). Studies of arterial wall mechanics in hypertension have been performed in both humans and animals with the use of in vivo and in vitro methods. Many of these studies addressed static rather than dynamic mechanical properties. In general, these studies have resulted in the conclusion that an increase in stiffness or elastic modulus of arteries exists in hypertension (for review see Cox RH,1989 and Mulvany MJ et al.,1990). Using an ultrasound system connected to a wall tracking system, Hayoz et al. (Hayoz D et al.,1992) measured in vivo the crosssectional compliance and distensibility of the carotid artery of SHR and found an increase in both. These results are contradictory to our findings. No clear cut explanation can be given for this discrepancy. It is possible that the carotid artery behaves differently from the aorta (our study) under these circumstances.

In the present investigation we attempted to study aortic wall properties in vivo in two age groups of normotensive and hypertensive rats. We used ultrasound techniques to record internal minimal (diastolic) lumen diameter and diameter changes during the cardiac cycle. Combined with invasive blood pressure measurements this allowed us to estimate wall distensibility and compliance. The analysis was restricted to maximal changes in diameter and pressure because aortic wall displacement and pressure were not determined at identical locations. Consequently, we could not dissociate between the contributions of elastic and viscous wall properties to the observed aortic wall displacement. For obvious reasons the measurements could not be obtained in freely moving, conscious rats. We deliberately performed the experiments during ketamine/xylazine anesthesia in an attempt to compare findings under comparable hemodynamic conditions. Xylazine is well known for its $\alpha_{2}$-derenergic agonistic properties. The compound thereby (1) inhibits the activity of the vasomotor center in the central nervous system (Van Zwieten et al.,1983), (2) reduces peripheral adrenergic neurotransmission by a prejunctional inhibitory action (Vanhoutte PM et al.,1981), and (3) dilates the aorta through a local endothelium dependent mechanism 
(VanHoutte PM et al.,1989). The low heart rates and unpublished observations are in line with this scenario. After administration of ketamin/xylazine, circulating catecholamine levels were reduced by $80 \%$ to $90 \%$, and unlike in conscious, restrained WKY, prazosin and nitroprusside failed to dilate the aorta in vivo (unpublished results). That the blood pressure lowering effect of ketamin/xylazine was far more marked in SHR than WKY is compatible with other evidence that indicates hyperactivity of the sympathetic nervous system in SHR (Grobecker H et al.,1975; Smith TL et al.,1979; Lee RMKW et al.,1986; Daemen MJAP et al.,1995). The anesthesia used abolished the difference in diastolic pressure between both strains and reduced interstrain differences in pulse pressure.

To analyze the contribution of structural wall properties to the mechanical properties observed by ultrasound wall tracking, we corrected histological findings with respect to media cross-sectional area for the changes that occurred during vessel isolation, and we tok into account the in vivo measurements of diastolic lumen diameter to calculate media thickness. Thus, the experimental approaches used allowed us to compare aortic wall properties in two age groups of WKY and SHR under dynamic in vivo conditions at comparable levels of (diastolic) blood pressure and possibly during relaxation of the aortic smooth muscle.

Between 3 and 6 months of age, aortic lumen caliber at diastole increased in both WKY and SHR. This change may account for the significant reduction of the distensibility and for the significant increase of the elastic modulus with aging. Other variables, such as the area and thickness of the media, tended to increase, but these changes did not reach statistical significance. Compliance did not change either with increasing age in both SHR and WKY. The loss of distensibility is apparently compensated for so that increases in systolic pressure, an independent risk factor (Menotti A et al.,1989; Saige A et al.,1993), are limited. The mechanism by which aortic caliber increased between 3 and 6 months of age cannot be deduced from our findings. However, it may be of interest that the rats gained more than $30 \%$ body weight and are known to exhibit a significant increase in cardiac output during this time interval (Smith TL et al.,1979). it has been reported that chronic increases in flow increase arterial lumen diameter (Langille BL et al.,1986; Langille BL et al.,1990).

At both 3 and 6 months of age aortic lumen diameter at diastole was considerably smaller in SHR than WKY. This together with the unaltered distensibility may account for the significantly lower compliance of the aorta of SHR than that of WKY. At 3 months of age the smaller lumen caliber and increased wall thickness culminate in a significantly lower elastic modulus in SHR. Surprisingly, the encroachment of the aortic wall on the lumen in SHR was not due to increased media mass. This lack of aortic wall hypertrophy in SHR contrasts with several earlier reports (for review see Owens GK et al.,1989 and Daemen MJAP et al.,1995). This may be due to our attempts to estimate aortic wall structure at the pressure, lumen diameter, and vessel segment length corresponding to the conditions during the recording of wall elasticity in vivo. The structural narrowing of the SHR aorta at comparable pressure is analogous to ovwervations in resistance sized arteris from SHR, renin-angiotensin transgenic rats, and essential hypertensive patients (Heagerty AM et al.,1988; Baumbach GL et al.,1989; Heagerty AM et al.,1993; Thybo NK et al.,1992; Korsgaard N et al.,1993). This suggests that what is now generally referred to as vascular remodeling in hypertension (Heagerty AM et al.,1993) is not restricted to distal small arteries.

It is of interest to note that in SHR aorta, compared with WKY aorta, the incremental elastic modulus or Young's 
modulus was reduced (suggesting increased distensibility) despite the lower compliance and comparable distensibility measured. This was statistically significant at 3 months of age and showed an insignificant trend at 6 months of age. It has previously been reported that in human radial artery the incremental elastic modulus is not increased with hypertension (Laurent S et al.,1994). however, the validity of Young's modulus to estimate elastic properties under these circumstances may be questioned. It treats the arterial wall as a homogeneous and mere elastic structure. We based its calculation on media thickness rather than wall thickness because of the poor delineation of the outer vessel wall boundary. However, the relative contributions of media and adventitia to vessel wall mechanics in situ are poorly understood. Furthermore, both layers are composed of diverse components including cells, collagen, elastin, and other extracellular matrix components. The relative importance of each of these and their interactions require further investigation.

In conclusion, in the present study we were able to evaluate mechanical and structural properties of the thoracic aorta in two age groups of normotensive and hypertensive rats under dynamic in vivo conditions and at comparable diastolic pressures. We observed an increase in lumen diameter between 3 and 6 moths of age in both strains. Differences between SHR and WKY included at both ages a reduction of aortic lumen diameter. This is compatible with earlier findings in resistance sized arteries that have been attributed to remodeling of the arterial wall. Future analysis of underlying mechanisms will require detailed analysis of arterial wall components. 


\section{REFERENCES}

Baumbach GL, Heistad DD. Remodeling of cerebral arterioles in chronic hypertension. Hypertension 13:968-972, 1989

Boonen HCM, Schiffers PMH, Fazzi GE, Jansen GMJ, Daemen MJAP, De Mey JGR. DNA synthesis in isolated arteries; kinetics and structural consequences. $\mathrm{Am}$. J. Physiol. 260:H210-H217, 1991

Boonen HCM, Daemen MJAP, Eerdmans PE, Fazzi GE, Van Kleef E, Schiffers PMH, De Mey JGR. Mesenteric small artery changes following vasoconstrictor infusion in young rats. J. Cardiovasc. Pharmacol. 22:388-395, 1993

Carlson RG, Lillehei CW, Edwards J. Cystic medial necrosis of the ascending aorta in relation to age and hypertension. Am. J. Cardiol. 25:411-415, 1970

Cox RH. Mechanical properties of arteries in hypertension. In: Blood vessel changes in hypertension: structure and function. Boca Raton. Fla. CRC Press Inc. 1:65-95, 1989

Daemen MJAP, DE Mey JGR. Regional heterogeneity of arterial structural changes. Hypertension 25:464-473, 1995

Dobrin PB. Mechanical properties of arteries. Physiol. Res. 58:397-460, 1978

Folkow B. Physiological aspects of primary hypertension. Physiol. Rev. 62:347-504, 1982

Grobecker H Roizen MF, Veise V, Saavedra JM, Kopin IJ. Sympathoadrenal medullary activity in young spontaneously hypertensive rats. Nature 258:267-268, 1975

Hayoz D, Rutschmann B, Perret F, Niederger M, Tardy Y, Mooser V, Nussberger J, Qaeber B, Brunner HR. Conduit artery compliance and distensibility are not necessarily reduced in hypertension. Hypertension 20:1-6, 1992

Heagerty AM, Aalkjaer C, Bund SJ. Effects of drug treatment on human resistance arteriole morphology: direct evidence for structural remodeling of resistance vessels. Lancet 26:1209-1212, 1988

Heagerty AM, Aalkjaer C, Bund SJ, Korsgaard N, Mulvany MJ. Small arteries structure in hypertension: dual processes of remodeling and growth. Hypertension 21:391-397, 1993
Hoeks APG, Brands PJ, Smeets FAM, Reneman RS. Assessment of the distensibility of superficial arteries. Ultrasound Med. Biol. 16:121-128, 1990

Hoeks APG, Arts TGJ, Brands PJ, Reneman RS. Comparison of the performance of the rf cross correlation and Doppler autocorrelation technique to estimate the mean velocity of simulated ultrasound signals. Ultrasound Med. Biol. 19:727740,1993

Kelly RP, Tanin R, Kass DA. Effect of reduced aortic compliance on cardiac efficiency and contractile function of in situ canine left ventricle. Circ. Res .71:490-502, 1992

Kool MJF, Van Merode T, Reneman RS, Hoeks APG, Struijker Boudier HAJ, Van Bortel LMAB. Evaluation of reproducibility of a vessel wall movement detector system for assessment of large artery properties. Cardiovasc. Res. 28:610-614, 1994

Korsgaard N, Aalkjaer C, Heagerty AM, Izzard AS, Mulvany MJ. Histology of small arteries from patients with essential hypertension. Hypertension 22:523-526, 1993

Langille BL, O'Donnel F. Reduction in arterial diameter produced by chronic decreases in blood flow are endothelium dependent. Science 231:405-407, 1986

Langille BL, Brownlee RD, Adamson SL. Perinatal aortic growth in lambs: relation to blood flow changes at birth. Am. J. Physiol. 259:H1247-H1253, 1990

Laurent S, Girerd X, Mourad JJ, Lacolley P, Beck L, Boutouyrie P, Mignot JP, Safar M. Elastic modulus of the radial artery wall material is not increased in patients with essential hypertension. Arterioscler. Thromb. 14:1223-1231, 1994

Lee RMKW, Couglhlin MD, Cheung DWT. Relationship between sympathetic innervation, vascular changes and hypertension in spontaneously hypertensive rats. J. Hypertens. 4 (suppl):81-83, 1984

Menotti A, Seccareccia F, Giampaoij S, Guili B. The predictive role of systolic, diastolic and mean blood pressue on cardiavascular and all causes of death. $J$. Hypertens. 7:595-599, 1989

Merillon JP, Matte G, Masquet C, Azancot I, Guiomard A, Gourgon R. Relationship 
between physical properties of the arterial system and left ventricular performance in the course of ageing and hypertension. Eur. Heart J. 3:95-102, 1982

Mulvany MJ, Aalkjaer C. Structure a function of small arteries. Physiol. Rev. 70:921961,1990

Nichols WW, O'Rourke MF, Avolio AP, Yaginuma T, Murgo JP, Pepine CJ, Conti CR. Effects of age in ventricular/vascular coupling. Am J. Cardiol.55:1179-1184, 1985

Nichols WW, O'Rourke MF. Ageing, high blood pressure and disease in humans. In: McDonald's blood flow in arteries. 3rd ed. Baltimore, Md: Edward Arnold Publishers Ltd; 398-420, 1990

Okamoto K, Aoki K. Development of a strain of spontaneously hypertensive rats. Jpn. Circ. J. 27:202-293, 1963

Owens GK. Control of hypertrophic versus hyperplastic growth of vascular smooth muscle cells. Am. J. Physiol. 257:H1755H1765, 1989

Reneman RS, Van Merode T, Hick P, Muytjens AMM, Hoeks APG. Age related changes in carotid artery wall properties in men. Ultrasound Med. Biol. 12:464-471, 1986

Saige A, Larson MG, Levy D. The natural history of borderline isolated systolic hypertension. N. Eng. J. Med. 329:19121917, 1993

Smith TL, Hutchins PM. Central hemodynamics in the developmental stage of spontaneous hypertension in the unanesthetized rat. Hypertension 1:508517,1979

Thybo NK, Korsgaard N, Mulvany MJ. Morphology and function of mesenteric resistance arteries in transgenic rats with low-renin hypertension. J. Hypertens. 10:1191-1196, 1992

Vanhoutte PM, Verbeuren TJ, Webb RC. Local modulation of adrenergic neuroeffector interactions in the blood vessel wall. Physiol. Rev. 61:151-218, 1981

VanHoutte PM, Miller VM,. Alpha-2 adrenoceptors and endothelium derived relaxing factor. Am. J. Med. 87 (suppl): 15, 1989

Van Merode T, Brands PJ, Hoeks APG, Reneman RS. Faster ageing of the carotid artery bifurcation in borderline hypertensive subjects. J. Hypertens. 11:171-176, 1993

Van Zwieten PA, Thoolen MJMC, Timmermans PBMWM. The pharmacology of centrally acting antihypertensive drugs. $\mathrm{Br} . \mathrm{J}$. Clin. Pharmacol. 15 (suppl):455-462, 1983

Wallenstein S, Zucker CL, Fleiss JL. Some statistical methods useful in circulation research. Circ. Res. 47:1-7, 1980 


\section{CHAPTER $\mathbf{6}$}

HYPERTENSION DOES NOT AGGRAVATE THE CHANGES IN ARTERY WALL PROPERTIES AND STRUCTURE WITH ADVANCING AGE IN OLDER RATS.

Ad W. Van Gorp

Dorette S. Van Ingen Schenau

Arnold P.G. Hoeks

Jo G.R.De Mey

Harry A.J. Struijker Boudier

Robert S. Reneman 
Compliance and distensibility of the elastic arteries decrease with age in humans. It has been proposed that hypertension has an accelerating effect on the decline of elasticity of arteries and on the structural changes as seen with ageing. The present study investigates the effect of hypertension on artery wall properties in ageing spontaneously hypertensive rats (SHR) and age matched Wistar Kyoto rats (WKY) as controls ( 9 through 18 months of age). During ketamine/xylazine anesthesia, compliance and distensibility were assessed by means of a noninvasive ultrasound technique combined with invasive blood pressure measurements. Morphometric measurements provided in vivo media cross-sectional area and thickness, allowing the calculation of the incremental elastic modulus. Extracellular matrix protein contents were determined as well. The findings in this study show that the compliance of the thoracic aorta is lower in aged than in the adult WKY, due to a decrease in distensibility, but that in SHR the compliance does not change with age, despite a decrease in distensibility of the thoracic aorta. In SHR the decrease in compliance seems to be compensated for by an increase in diameter. A similar progressive increase in media mass, as indicated by the larger media crosssectional area and thickness, is found in both strains, but is more pronounced in SHR than in WKY. The elastic properties of the thoracic aorta do not change with increasing age in both strains, as indicated by the absence of significant differences in the incremental elastic modulus between age categories. Altogether these observations indicate that hypertension does not aggravate the changes in artery wall properties and structure as occurring with increasing age. The collagen content and density do not change with increasing age in both strains. Therefore, collagen can not be held responsible for the changes in wall properties and structure as observed with age. A change in elastin content can probably not be held responsible for the changes in wall properties either, because in both strains its content increases with age.

\section{INTRODUCTION}

\section{Compliance and distensibility of the} elastic arteries are reduced in borderline (Ventura H et al.,1984; Van Merode T et al.,1988; Van Merode et al.,1993) as well as in established hypertension (Safar M,1990) as compared to age-matched control subjects. These changes in arterial wall properties do not necessarily result from increased blood pressure alone, because in hypertension structural changes of the arterial walls have been observed (Mulvany MJ. et al.,1980; Levy BI. et al.,1988; Cox R,1989; Levy BI. et al.,1990).

Compliance and distensibility of the elastic arteries also decrease with age (Reneman RS et al.,1986; Cox RH,1989; Michel JB et al.,1994; Sonesson B et al.,1997). Ageing is associated with characteristic changes in arterial morphology and structure. In different species, ageing has been shown to be associated with an increased diameter of the aorta and other large arteries (Learoyd BM et al.,1966; Bader H.,1967; Pagani M et al.,1979; Reneman RS et al.,1985; Sumitani M et al.,1986; Safar M.,1990; Hansen F et al.,1995) and an increase in thickness of the media and intima of the aorta (Learoyd BM et al.,1966; Bader H.,1967; Wolinsky H.,1972; Berry CL et al.,1975; Sumitani M et al.,1986; Benetos A et al,,1993). Increased collagen content is a consistent finding in senescent vessels (Kohn RR.,1977; Benetos A et al.,1993). In aged rats, Fornieri et al.. (Forieri $\mathrm{C}$ et al.,1992) observed an increase in the volume density of collagen, but a reduction of the total amount per crosssectional area.

It has been proposed that hypertension has an accelerating effect on the decline of elasticity of arteries and on the structural changes as seen with ageing (Lakatta EG,1987; Michel JB et al, 1994), but the results obtained in previous studies are conflicting (Benetos A et al.,1992; Sumitani M 
et al.,1997; Zanchi A et al.,1997) and do not allow straightforeward conclusions regarding the accelerating effect of hypertension on the reduction of arterial compliance and elasticity and the deterioration of arterial wall structure in aged rats. In a previous study on young adult WKY and SHR ( 1.5 to 6 month old) we have shown that hypertension does not affect the elastic and structural properties of the thoracic aorta with advancing age (Van Gorp AW et al.,1995). Therefore, in the present study we assessed the dynamic mechanical properties, including the incremental elastic modulus, of the thoracic aorta in vivo in 9 to 18 month old WKY and SHR. In addition, the collagen and elastin contents of the aortic wall were determined.

\section{METHODS}

\section{Study Design.}

Fourty-eight WKY and 48 SHR were randomly divided into four groups. The experiments were performed on 9, 12, 15 and 18 month old male WKY and SHR of the Okamoto-Aoki strain (local inbred strains; Central Animal Facilities, Maastricht University, Maastricht, the Netherlands). Each group consisted of 12 animals. The rats were housed in individual cages, maintained on a 12-hour light, 12-hour dark cycle, fed at libitum (Hope Farms, Woerden, the Netherlands) and they had free access to tap water. The experimental protocols were approved by the local Institutional Animal Care and Use Committee.

For the measurement of arterial blood pressure an intra-aortic catheter filled with heparinized saline was implanted under ether anesthesia. The outer diameter of the intra-aortic catheter was $0.5 \mathrm{~mm}$. The catheter was advanced from a femoral artery to just below the bifurcation of the left renal artery. The catheter was guided under the skin and exteriorized at the base of the skull. Two days later, blood pressure was measured in the freely moving conscious animal by means of an external low volume displacement pressure transducer (CP-01, Century Technology $\mathrm{Co}$, Inglewood $\mathrm{Ca}$, USA). The delay in time between the tip of the catheter and the pressure transducer was $12 \mathrm{~ms}$ and, hence, guaranteed a pressure signal frequency up to $50 \mathrm{~Hz}$.

Elastic properties of arteries are, among other factors, dependent on the operating blood pressure. To be able to compare the elastic properties of hypertensive and normotensive rats, arterial diameter and artery wall displacements have to be measured at near equal diastolic blood pressures. To this end the animals were anesthetized with ketamine/xylazine $(10: 50 \mathrm{mg} / \mathrm{ml} ; 100$ $\mathrm{ml} / 100 \mathrm{~g}$ body weight) which lowered the diastolic blood pressure in SHR to the level in WKY (see results). Blood pressure was measured simultaneously with the diameter of the thoracic aorta and the displacement of its walls during the cardiac cycle, using an ultrasonic wall tracking device (see below). Experiments were terminated by exsanguination of the anesthetized animals, after which the thoracic aorta was isolated for subsequent histological examination.

Ultrasound Assessment of Aorta Diameter and Wall Displacement.

The aortic diameter and the diameter changes during the cardiac cycle were measured by means of a conventional Bmode ultrasound system (B = brightness)(Pie480, 7.5 MHz linear array) attached to a vessel wall tracking system (WTS, Pie Medical, Maastricht, the Netherlands) as described in detail before (Van Gorp A et al.,1996). The probe was positioned on the left side of the sternum, $10 \mathrm{~mm}$ above the diaphragm. The B-mode was used to visualize the thoracic aorta whereafter an $\mathrm{M}$-line $(\mathrm{M}=$ motion) was selected. The ultrasound system was 
switched to M-mode and ultrasound was emitted and received along the selected line.

The received Radio Frequency (RF) signals were amplified and captured and temporarily stored by a data acquisition system. The internal capacity of the WTS limited the available measuring time. The emission trigger frequency was set at $1653 \mathrm{~Hz}$ and each analog RF-signal was converted digitally in 256 points at a rate of $21 \mathrm{MHz}$. The emission trigger frequency of $1653 \mathrm{~Hz}$ in combination with an internal memory of 1 megabyte provides a measuring time of $2.5 \mathrm{~s}$, allowing the recording of 10 cardiac and 3 respiratory cycles.

The RF signals were transferred to a PC. The first RF-signal captured was visualized on the monitor screen to identify manually the anterior and posterior walls by means of two markers. Subsequently, the position of these markers was used by the tracking system to follow the position of the anterior and posterior walls and to assess the displacement of these walls during the cardiac cycle. The difference in the displacements between these walls reflects the change in diameter (distension) during this cycle. The minimal distance between the markers provides the end-diastolic diameter $\left(\mathrm{d}_{\text {dia }}\right)$. The WTS allows assessment of artery wall displacements with a resolution of a few micrometers (Hoeks A et al.,1990). For the thoracic aorta of rats the intra-session variability for $\mathrm{d}_{\text {dia }}$ varied between 3.3 and $6.5 \%$ and the inter-session variability for this parameter was $4.6 \%$. For the distension, $\Delta d$, intrasession variability varied between 7.9 and $11 \%$ and the inter-session variability was $9.2 \%$. There was no difference between observers (Van Gorp A et al., 1996).

The WTS was also equipped with an acquisition system for reference data to sample blood pressure signals synchronously with the emission trigger. Under anesthesia, measurements were started after blood pressure and heart rate had stabilized (average $20 \mathrm{~min}$ ). In each animal two observers performed three recordings of $2.5 \mathrm{~s}$. The data obtained during these sessions were averaged.

\section{Relationship between Lumen Diameter and Pressure.}

Since the WTS and the intra-aortic catheter exhibit different time-responses, and the selected M-line did not always coincide with the tip of the pressure catheter, we limited the analysis to (1) the relationship between aorta lumen caliber and intra-aortic pressure at end-diastole $\left(\mathrm{d}_{\text {dia }}\right.$ and $\left.\mathrm{P}_{\text {dia }}\right)$ and $(2)$ the maximal changes in pressure $(\Delta \mathrm{P})$ and diameter $(\Delta \mathrm{d})$ during the cardiac cycle. $d_{\text {dia }}$ and $\Delta d$ were converted to lumen area's and changes thereof ( $A_{\text {dia }}$ and $\left.\Delta \mathrm{A}\right)$, assuming a circular cross-section of the vessel. With the additional assumption that vessel segment length remains constant during the cardiac cycle (Reneman R et al.,1996), the absolute and the relative change in aortic lumen area during the cardiac cycle provides information about the cross-sectional compliance and distensibility of the vessel, respectively (Reneman R et al, 1990; Hoeks A et al,1993a; Hoeks A,1993b). $\Delta \mathrm{A} / \Delta \mathrm{P}$ and $(\triangle \mathrm{A} / \mathrm{A}) / \Delta \mathrm{P}$ will be referred to as the compliance coefficient (CC) and the distensibility coefficient (DC), respectively.

\section{Aortic Wall Structure.}

A segment of $10 \mathrm{~mm}\left(\mathrm{~L}_{i}\right)$, halfway between the heart and diaphragm, was marked on the aorta and subsequently removed from the animal and cleaned of adhering fat and connective tissue after which the ex vivo length of the segment (Le) was measured under a stereomicroscope with a precision of $\pm 5 \mu \mathrm{m}$. The segment of the thoracic aorta was isolated, fixed in $4 \%$ neutral buffered formaldehyde and embedded in paraffin after which $4 \mu \mathrm{m}$ thick sections were obtained. These sections were stained with 
Lawson's solution, which highlights elastic laminae, and the cross-sectional area of the media was determined using an axioplan microscope (Zeiss) equipped with a standard CCD camera (Stemmer, Germany) (Boonen H et al..,1993). Digitized images were analyzed with commercial software (JAVA, Jandell Scientific, Corte Madera $\mathrm{Ca}, \mathrm{USA}$ ). The area enclosed by the external and internal elastic lamina was considered to represent the ex vivo cross-sectional area of the media $\left(\mathrm{CSA}_{\mathrm{e}}\right)$. This was converted to in vivo media crosssectional area $\left(\mathrm{CSA}_{i}\right)$ using the following formula:

$$
\mathrm{CSA}_{\mathrm{i}}=\left(\mathrm{L}_{\mathrm{e}} / \mathrm{L}_{\mathrm{i}}\right) \cdot \mathrm{CSA} \mathrm{A}_{\mathrm{e}}
$$

in which it was assumed that aortic wall volume remains constant after isolation and fixation and in which $\mathrm{L}_{\mathrm{i}}$ and $\mathrm{L}_{\mathrm{e}}$ refers to the length of the thoracic aorta before and after isolation, respectively.

Media thickness (Mt) in diastole was calculated from diastolic diameter $\left(\mathrm{d}_{\text {dia }}\right)$ and from CSA, using the formula:

$\mathrm{CSA}_{\mathrm{i}}=\pi\left(\mathrm{d}_{\mathrm{dia}} / 2+\mathrm{Mt}\right)^{2}-\pi\left(\mathrm{d}_{\mathrm{dia}} / 2\right)^{2}$

which can be rewritten as:

$\mathrm{Mt}=-\left(\mathrm{d}_{\mathrm{dia}} / 2\right)+\left\{\left(\mathrm{d}_{\mathrm{dia}} / 2\right)^{2}+\mathrm{CSA}_{\mathrm{i}} / \pi\right\}^{1 / 2}$

In these calculations it is assumed that the cross-section of the aorta is circular in situ.

Measurements of mechanical properties and dimensions were combined to calculate the incremental elastic modulus or Young's modulus $\left(\mathrm{E}_{\mathrm{inc}}\right)$ :

$\mathrm{E}_{\mathrm{inc}}=\mathrm{d}_{\mathrm{dia}} /(\mathrm{Mt} . \mathrm{DC})$

\section{Collagen content.}

Four $\mu \mathrm{m}$ thick Paraffin sections were also used to determine collagen area. The sections were stained with Sirius red solution, which highlights collagen (James J et al.,1990). The collagen occupied area, enclosed by the external and internal elastic lamina, was determined as described above. The data are presented as media collagen density, i.e., the collagen area as percentage of the total media area in the section.

Biochemical determination of collagen content of the media of the remaining part of the thoracic aorta was performed essentially as described by Chiariellio et al.. (Chiariellio M et al.,1986). To facilitate the separation of the adventitia and media, aortas were incubated for 24 hours (h) in phosphate buffered saline (PBS, $\mathrm{pH}=7.0$ ) at $4{ }^{\circ} \mathrm{C}$. The media and adventitia were separated from each other mechanically under a dissection microscope. The media was dried under vacuum and the dry weight was measured. Afterwards, the media was incubated in a $1 \%$ Sodium Dodecyl Sulphate (SDS) solution in PBS for $24 \mathrm{~h}$ at $4{ }^{\circ} \mathrm{C}$. Incubation in $1 \%$ SDS extracts the non-cross-linked collagen from the aorta. The supernatant was collected and stored at $-70^{\circ} \mathrm{C}$ and the pellet was incubated in a Cyanate Bromide Solution in $70 \%$ formic acid for $24 \mathrm{~h}$ at room temperature. Cyanate Bromide cleaves proteins at methionine sites. Since elastin does not and collagen does contain methionine, cross-linked collagen can be extracted from the aortic media by Cyanogen Bromide. The pellet, containing elastin, and both supernatants, containing non-cross-linked and crosslinked collagen, respectively, were dried under vacuum and hydrolyzed in $6 \mathrm{~N} \mathrm{HCl}$ at $120{ }^{\circ} \mathrm{C}$. The collagen content was determined by the amount of hydroxyproline residues. The hydroxyproline residues were oxidized with chloramine $T$, which reacts with $\mathrm{p}$ demethylamino-benzaldehyde. In the different fractions the colored compound produced was measured photospectometrically at $558 \mathrm{~nm}$. Hydroxyproline represents between 10.5 and $11.5 \%$ of the aminoacid residues in 
collagen (Chiariellio M et al,1986). The data are presented as mg hydroxyproline per $\mathrm{g}$ dry weight normalized for the crosssectional area of the media.

\section{Statistics.}

In each animal 6 consecutive $2.5 \mathrm{~s}$ simultaneous recordings of pressure, internal lumen diameter and distension were obtained and the various parameters were calculated for each individual cardiac cycle. Mean values were determined for each recording session, then these values were averaged for each individual animal and eventually a group mean was obtained for each different age group. The data are presented as means $\pm \mathrm{SD}$. Comparisons between age groups and strains were performed with the two way ANOVA extended with a post-hoc test (Tukey) for multiple comparison. $\mathrm{P}<0.05$ was considered to denote statistically significant differences.

All animals in the 18 month old WKY group survived, but before the onset of the measurements, only 7 out of 12 SHR had survived the advancing age to 18 months. Therefore, 18 month old SHR have to be considered as a selected group and from a statistical point of view it is not allowed to compare these animals with the 18 month old WKY and with SHR from the other age groups in a trend analysis.

Table 6.1: Body weight and anesthetized heart rate of aged WKY and SHR $($ mean \pm SD) $n=12$

\begin{tabular}{|lccc|c|}
\hline \multicolumn{4}{c}{ Months of age } \\
\hline parameter & 9 & 12 & 15 & 18 \\
\hline body weight $(\mathrm{g})$ & & & \\
WKY & & & \\
SHR & $467 \pm 35$ & $514 \pm 34$ & $495 \pm 19$ & $512 \pm 26$ \\
& $397 \pm 30^{*}$ & $443 \pm 19^{* \prime \prime}$ & $439 \pm 40^{* \prime \prime}$ & $427 \pm 19$ \\
heart rate $\left(\mathrm{min}^{-1}\right)$ & & & & \\
WKY & $217 \pm 28$ & $266 \pm 22^{\prime \prime}$ & $265 \pm 34^{* \prime}$ & $263 \pm 19^{\prime \prime}$ \\
SHR & $221 \pm 18$ & $265 \pm 18^{*}$ & $267 \pm 29^{*}$ & $270 \pm 15^{\prime \prime}$ \\
\hline
\end{tabular}

"significantly different compared to 9 months of age, $p<0.05$

$s$ significantly different compared to 12 months of age, $p<0.05$

^ significantly different compared to 15 months of age, $\mathrm{p}<0.05$

* significantly different between WKY and SHR, $p<0.05$

\section{RESULTS}

Body weight was significantly higher in WKY as compared to SHR in all age groups and did not change with increasing age in WKY. In SHR of 9 months body weight was lower than in the other age groups (Table 6.1). Diastolic blood pressure, determined under conscious freely moving conditions, was significantly higher in SHR than in WKY in all age groups and did not change significantly with age in both strains (Fig. 6.1a). In SHR, conscious pulse pressure was higher at 12 and 15 months as compared with 9 months of age (Fig. 6.1b). In WKY, conscious pulse pressure did not change significantly with age (Fig. 6.1b), except for an increase at 15 months of age (Fig. 6.1b). At the age of 12 and 15 months, pulse pressure was higher in SHR than in WKY (Fig. 6.1b). 

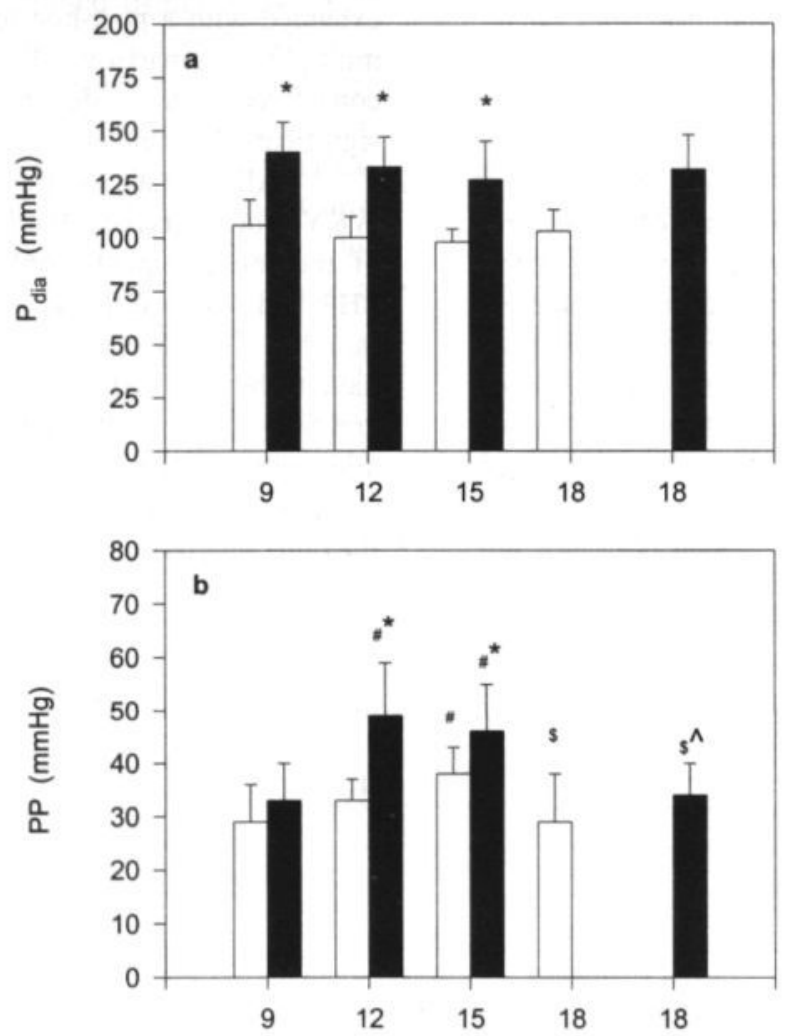

Age in months

Fig. 6.1 Diastolic blood pressure (a) $(\mathrm{mmHg})$ and pulse pressure (b) $(\mathrm{mmHg})$ in conscious Wistar Kyoto rats (WKY; open bars) and conscious spontaneously hypertensive rats (SHR; closed bars) of varying ages. Mean $\pm \mathrm{SD}(\mathrm{n}=12)$.

* significantly different between WKY and SHR.

\# significantly different from 9 month old WKY or SHR.

s significantly different from 12 month old WKY or SHR.

^ significantly different from 15 month old WKY or SHR.

Anesthesia with ketamine/xylazine significantly lowered diastolic blood pressure in SHR and WKY (Fig. 6.1a and 6.2a). During anesthesia the original differences in diastolic blood pressure between SHR and WKY disappeared in all age categories, but was higher at 12 and 15 months than at 9 months of age in both strains (Fig. 6.1a and 6.2a). Under anesthesia no consistent significant difference in pulse pressure (Fig. 6.2) and heart rate (Table 6.1) could be detected between both strains in all age categories. During anesthesia heart rate was significantly higher at 12 and 15 months than at 9 months of age in both strains, but no consistent significant differences in pulse pressure could be detected between the age categories in both strains (Fig. $6.2)$. 

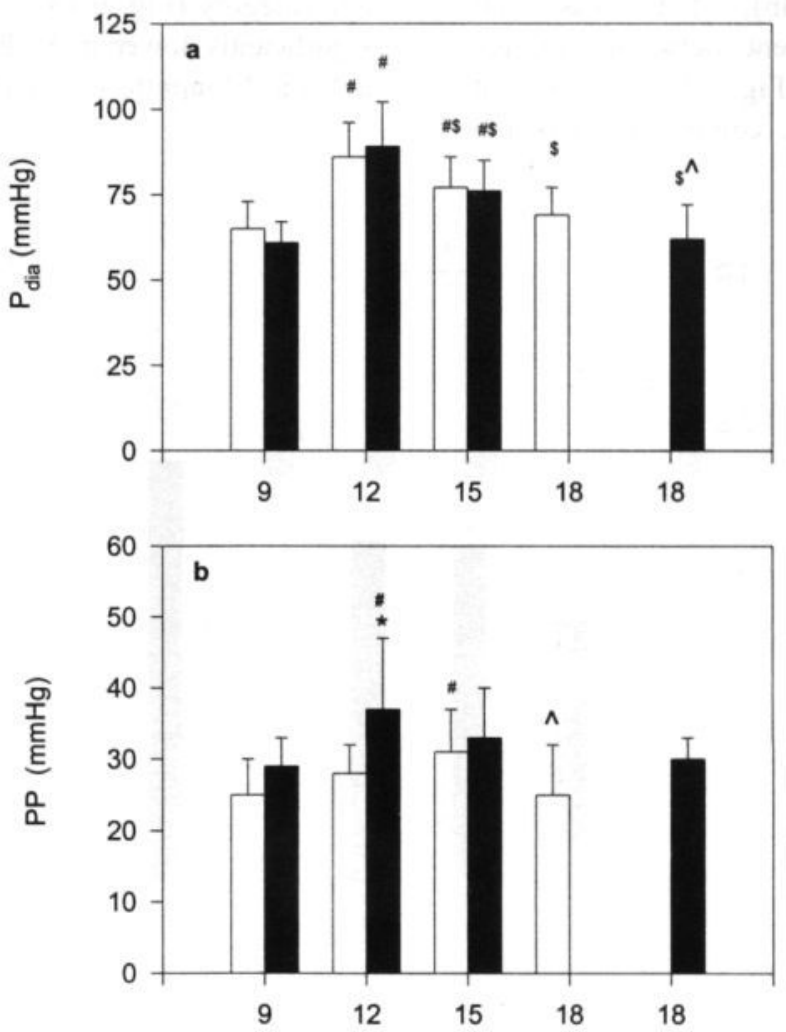

Age in months

Fig. 6.2. Diastolic blood pressure (a) $(\mathrm{mmHg})$ and pulse pressure (b) $(\mathrm{mm})$ during anesthesia with ketamine/xylazine in Wistar Kyoto rats (WKY; open bars) and spontaneously hypertensive rats (SHR; closed bars) of varying ages. Mean $\pm S D(n=12)$.

* significantly different between WKY and SHR.

\# significantly different from 9 month old WKY or SHR.

s significantly different from 12 month old WKY or SHR.

^ significantly different from 15 month old WKY or SHR.

Diastolic diameter of the thoracic aorta determined under anesthesia, did not change significantly with age in WKY (Fig. 6.3), but increased with age in SHR. At 9 and 12 months of age, diastolic diameter was significantly smaller in SHR as compared with WKY (Fig. 6.3), this difference disappeared at older age (Fig. $6.3)$.
In both strains, aortic distensibility was lower at 12 and 15 months than at 9 months of age (Fig. 6.4a). In WKY, distensibility was higher in 18 months as compared with 15 months of age and was not significantly different from the 9 and 12 month old groups (Fig. 6.4a). Distensibility was lower in SHR than in WKY at 9 and 12 months of age (Fig. 6.4a). Compliance was significantly lower 
at 15 months than at 9 months of age in WKY (Fig. 6.4b), but was not significantly different between the age categories in SHR (Fig. 6.4b). In WKY, at 18 months of age, compliance was not significantly different from the 9 month age category (Fig. 6.4b). Compliance was significantly lower in SHR than in WKY at 9 and 12 months of age (Fig. 6.4b).

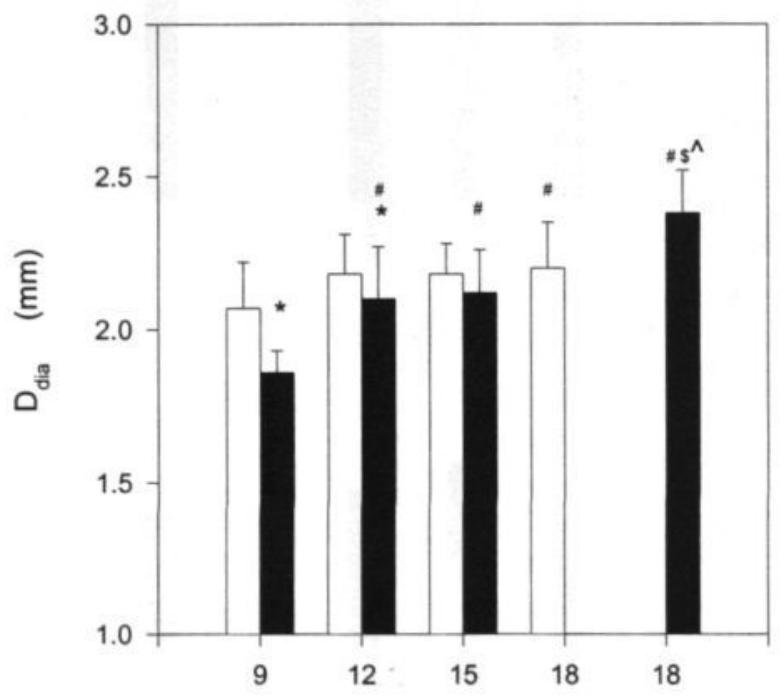

Age in months

Fig. 6.3. Diastolic aortic diameter ( $\mathrm{mm})$ during anesthesia with ketamine/xylazine in Wistar Kyoto rats (WKY; open bars) and spontaneously hypertensive rats (SHR; closed bars) of varying ages. Mean $\pm S D(n=12)$.

* significantly different between WKY and SHR.

\# significantly different from 9 month old WKY or SHR.

s significantly different from 12 month old WKY or SHR.

^ significantly different from 15 month old WKY or SHR.

Media cross-sectional area $\left(\mathrm{CSA}_{i}\right)$ increased significantly with age in SHR and WKY (Fig. 6.5a). In all age groups $\mathrm{CSA}_{\mathrm{i}}$ was larger in SHR than in WKY (Fig. 6.5a). Similar changes and differences were observed in media thickness (Mt) (Fig. 6.5b). The Mt to diastolic diameter ratio was slightly, but significantly larger in the older age groups in WKY (15 and 18 months), but was not significantly different between the age groups in SHR (Fig. 6.6a). This ratio was significantly larger in SHR than in WKY in all age categories (Fig. 6.6a).

In both strains the incremental elastic modulus $\left(\mathrm{E}_{\text {inc }}\right)$ was not significantly different between age groups (Fig. 6.6b). At 9 months of age $E_{\text {ine }}$ was significantly smaller in SHR than in WKY (Fig. 6.6b). 

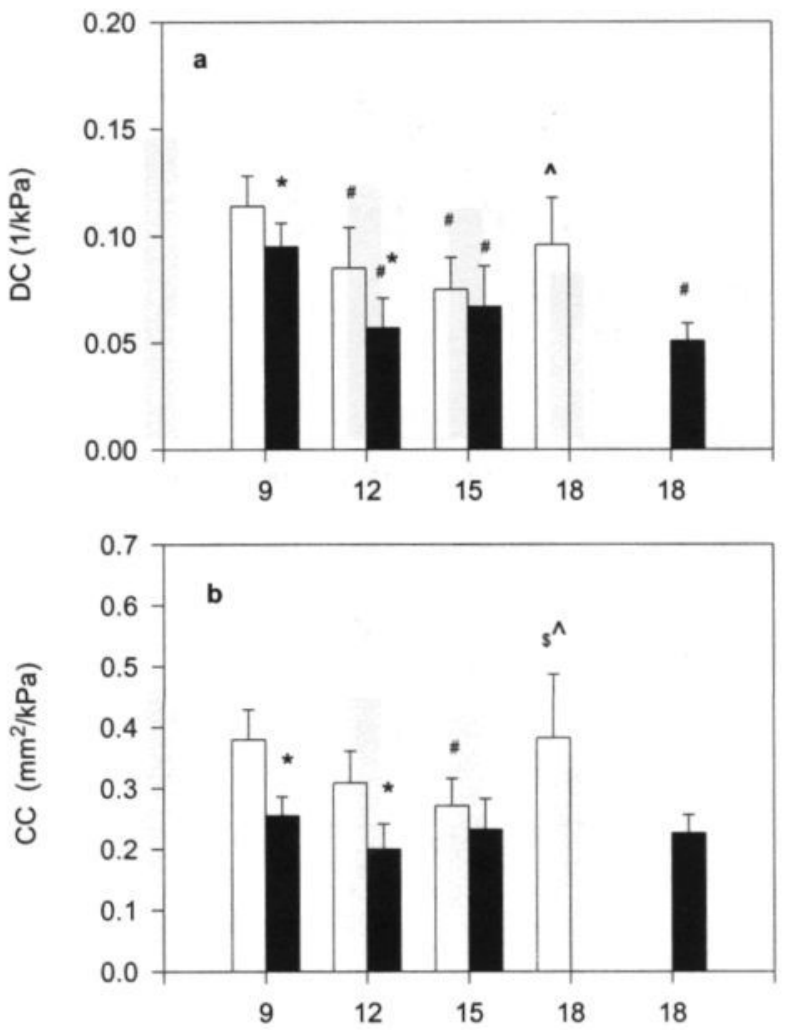

Age in months

Fig. 6.4. Distensibility coefficient (a) $(1 / \mathrm{kPa})$ and compliance coefficient (b) $\left(\mathrm{mm}^{2} / \mathrm{kPa}\right)$ during anesthesia with ketamine/xylazine in Wistar Kyoto rats (WKY; open bars) and spontaneously hypertensive rats (SHR; closed bars) of varying ages. Mean $\pm \operatorname{SD}(n=12)$.

* significantly different between WKY and SHR.

\# significantly different from 9 month old WKY or SHR.

s significantly different from 12 month old WKY or SHR.

^ significantly different from 15 month old WKY or SHR. 

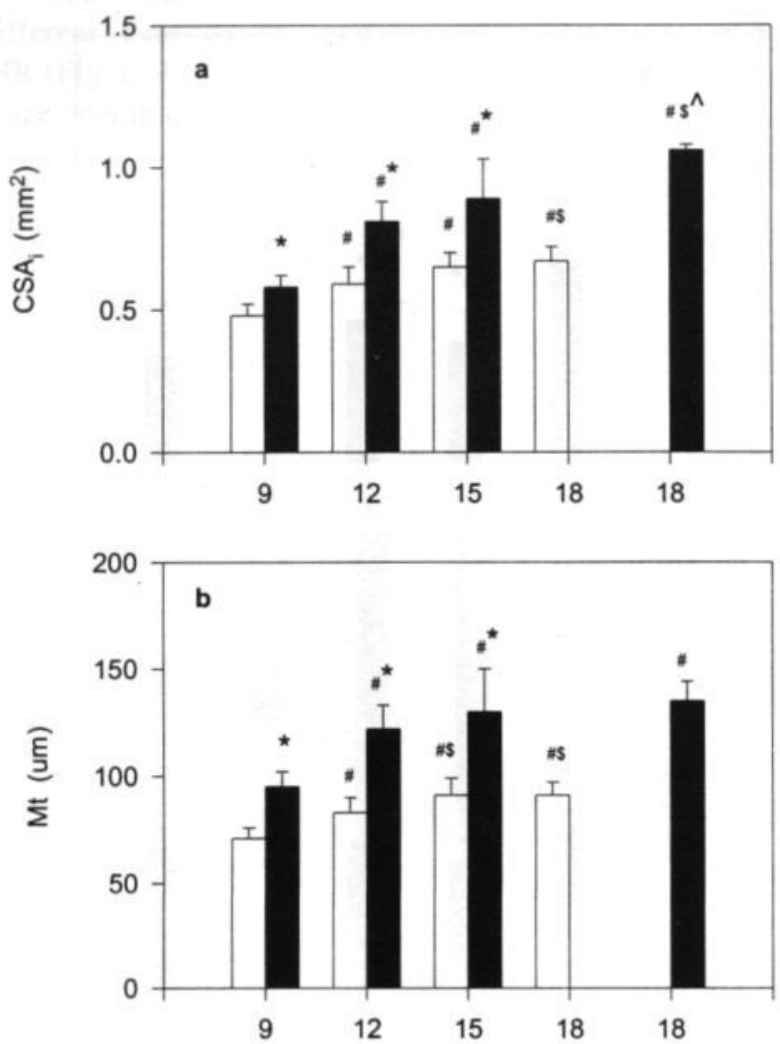

Age in months

Fig. 6.5. In vivo media cross-sectional area (a) $\left(\mathrm{mm}^{2}\right)$ and media thickness (b) ( $\left.\mu \mathrm{m}\right)$ in Wistar Kyoto rats (WKY; open bars) and spontaneously hypertensive rats (SHR; closed bars) of varying ages. Mean $\pm \mathrm{SD}(\mathrm{n}=12)$.

* significantly different between WKY and SHR.

\# significantly different from 9 month old WKY or SHR.

s significantly different from 12 month old WKY or SHR.

^ significantly different from 15 month old WKY or SHR.

In both strains no significant differences in media collagen density, as determined with morphometry on sirius red stained sections, could be detected between the different age groups and between SHR and WKY (Table 6.2). Collagen density obtained with morphometry showed a large variability. In both SHR and WKY, the non-cross-linked collagen content was lower in 9 month old animals than in the older ones (Table 6.2). At 9 and 12 months of age this content was lower in SHR than in WKY (Table 6.2). The cross-linked collagen content was higher in the 9 months old group than in the older groups, in both WKY and SHR and was significantly lower in SHR than in WKY at the age of 9 months (Table 6.2). In both strains the elastin content was lower in the animals of 9 months old than in the older 
Table 6.2: Collagen density and $\mathrm{mg} / \mathrm{g}$ dryweight of collagen and elastin content normalized to in vivo media cross-sectional area of aged WKY and SHR

$(\mathrm{x} \pm \mathrm{SD}) \mathrm{n}=12$

\begin{tabular}{|c|c|c|c|c|}
\hline \multirow[b]{2}{*}{ parameter } & \multicolumn{4}{|c|}{ Months of age } \\
\hline & 9 & 12 & 15 & 18 \\
\hline \multicolumn{5}{|c|}{ collagen density $(\%)$} \\
\hline WKY & $18.0 \pm 5.0$ & $17.5 \pm 5.2$ & $20.8 \pm 5.0$ & $14.8 \pm 4.2$ \\
\hline SHR & $17.0 \pm 4.0$ & $13.7 \pm 6.6$ & $15.7 \pm 5.8$ & $16.8 \pm 5.0$ \\
\hline \multicolumn{5}{|c|}{ Non-cross-linked collagen $\left(\mathrm{mg} / \mathrm{g} / \mathrm{mm}^{2}\right)$} \\
\hline WKY & $5.2 \pm 1.3$ & $7.9 \pm 0.8^{\prime \prime}$ & $6.3 \pm 0.5^{\prime \prime}$ & $6.4 \pm 0.5^{\prime \prime}$ \\
\hline SHR & $2.2 \pm 0.2^{*}$ & $5.8 \pm 0.4^{* *}$ & $6.2 \pm 1.5^{\prime \prime}$ & $6.0 \pm 1.7^{\prime \prime}$ \\
\hline \multicolumn{5}{|c|}{ Cross-linked collagen $\left(\mathrm{mg} / \mathrm{g} / \mathrm{mm}^{2}\right)$} \\
\hline WKY & $28.3 \pm 3.3$ & $13.0 \pm 4.5^{\prime \prime}$ & $18.5 \pm 5.7$ & $23.7 \pm 7.1$ \\
\hline SHR & $22.3 \pm 2.6^{*}$ & $12.6 \pm 3.2^{\prime \prime}$ & $16.8 \pm 6.1$ & $15.7 \pm 6.7$ \\
\hline \multicolumn{5}{|c|}{ Elastin $\left(\mathrm{mg} / \mathrm{g} / \mathrm{mm}^{2}\right)$} \\
\hline WKY & $17.9 \pm 1.1$ & $49.7 \pm 7.2^{\prime \prime}$ & $44.9 \pm 3.0^{\prime \prime}$ & $47.5 \pm 2.6^{\prime \prime}$ \\
\hline SHR & $18.7 \pm 2.1$ & $45.8 \pm 1.4^{\prime \prime}$ & $40.7 \pm 6.7^{\prime \prime}$ & $46.2 \pm 5.5^{\prime \prime}$ \\
\hline
\end{tabular}

" significantly different compared to 9 months of age, $\mathrm{p}<0.05$

s significantly different compared to 12 months of age, $\mathrm{p}<0.05$

^ significantly different compared to 15 months of age, $\mathrm{p}<0.05$

*significantly different between WKY and SHR, $\mathrm{p}<0.05$

Body weight (Table 6.1) and conscious diastolic blood pressure (Fig. 6.1a) were not significantly different between 18 month old and younger SHR. Conscious pulse pressure was significantly lower at 18 month as compared to 12 and 15 month old SHR (Fig. 6.1b). Anesthesia reduced the diastolic blood pressure, but had no effect on pulse pressure in 18 month old SHR (Fig. 6.1a and 6.2a). In 18 months old SHR, the anesthetized heart rate was not significantly different from the 12 and 15 month old rats, but significantly higher as compared with the 9 month animals (Fig. 6.1a and 6.2a). Diastolic diameter was significantly larger in 18 month old SHR than in the other age groups (Fig. 6.2). Distensibility was significantly lower in 18 month than in 9 month old SHR, but was not significantly different from the distensibility in 12 and 15 month old SHR (Fig. 6.3a).There were no significant differences in compliance between 18 month old SHR and the younger animals (Fig. 6.3b). CSA $\mathrm{C}_{\mathrm{i}}$ was significantly larger in 18 month old SHR than in the younger SHR (Fig. 6.4a). Mt was only significantly different between 18 month and 9 month old SHR (Fig. 6.4b). The Mt to diastolic diameter ratio was not significantly different between 18 month old and the younger SHR (Fig. 6.5a). $\mathrm{E}_{\text {inc }}$ was significantly larger in 18 month old than in 9 month old SHR (Fig. 6.5b).

Collagen density was not significantly different between 18 month old SHR and the younger ones (Table 6.2). Non-cross-linked collagen content (Table 6.2) and elastin content (Table 6.2) were significantly larger, and cross-linked 

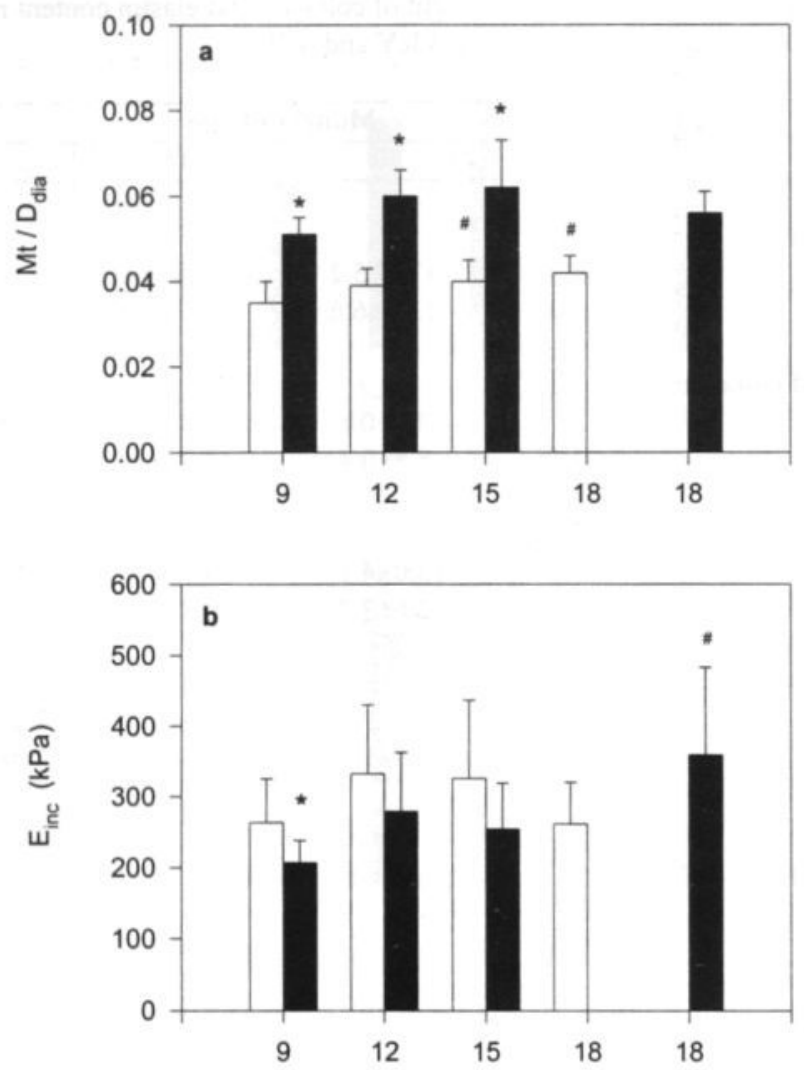

Age in months

Fig. 6.6. Media thickness to diastolic diameter ratio (a) and incremental elastic modulus (b) $(\mathrm{kPa})$ in Wistar Kyoto rats (WKY; open bars) and spontaneously hypertensive rats (SHR; closed bars) of varying ages. Mean $\pm \mathrm{SD}(\mathrm{n}=12)$.

* significantly different between WKY and SHR.

\# significantly different from 9 month old WKY or SHR. 


\section{DISCUSSION}

The findings in this study show that the compliance of the thoracic aorta is lower in aged than in the adult WKY, due to a decrease in distensibility, but that in SHR the compliance does not change with age, despite a decrease in distensibility of the thoracic aorta. In SHR the decrease in compliance seems to be compensated for by an increase in diameter. A similar progressive increase in media mass, as indicated by the larger media crosssectional area and thickness, is found in both strains, but is more pronounced in SHR than in WKY. The small differences in diameter between WKY and SHR combined with the more pronounced media hypertrophy in SHR results in a larger media thickness to diameter ratio in SHR than in WKY. This ratio is not affected by age in both strains. The elastic properties of the thoracic aorta do not change with increasing age in both strains, as indicated by the absence of significant differences in the incremental elastic modulus between age categories. Altogether these observations indicate that hypertension does not aggravate the changes in artery wall properties and structure as occurring with increasing age. Although the content of non-cross-linked collagen was lower in SHR than in WKY at 9 and 12 month of age and the cross-linked collagen content was lower in SHR than WKY, the changes in the content of these collagen subtypes with age are similar in both strains. Because the total collagen content is not different between age categories either, it is unlikely that changes in these matrix proteins can be held responsible for the changes in wall properties and structure as observed with age. A change in elastin content can probably not be held responsible for the changes in wall properties either, because in both strains its content increases with age. This increase may contribute to the increase in wall mass with age as observed in both strains.

One of the main functions of the thoracic aorta is to buffer the pulsatile output from the heart and to provide a continuous flow to the distal vascular beds. This buffering capacity is determined by the diastolic diameter and elastic properties of the artery wall (Reneman RS et al.,1996). It has been proposed that hypertension induces structural changes and has an accelerating effect on the decline of the buffering capacity and the elasticity of arteries as seen with ageing (Lakatta EG,1987; Michel JB et al.,1994). In the present study the compliance and the elastic properties of the thoracic aorta were found to be preserved with increasing age in SHR as a result of the enlargement of the diameter and the absence of an alteration in incremental elastic modulus. The increase in diameter of the aorta with advancing age is in agreement with previous findings (Sumitani M et al.,1997), in this study the increase in diameter with advancing age was believed to be a consequence of the growth of the animals. The findings in the present study, however, do not support this notice, because in SHR body weight only increases between 9 and 12 months of age, while the diastolic thoracic aorta diameter further increases at older age (Fig. 6.3). Besides, at 15 months of age the diastolic diameter is comparable in SHR and WKY, despite a lower body weight in the former species. Blood pressure can not be held responsible for the increase in diastolic diameter either, because in SHR blood pressure does not change significantly with advancing age. Whether the increase in diastolic diameter in SHR may be considered as a compensation mechanism 
to normalize an enhanced shear stress remains to be investigated.

The absence of a change in incremental elastic modulus can be explained by the fact that diastolic diameter and media thickness increase and distensibility decrease with age resulting in a comparable incremental elastic modulus in the different age categories. Similar observations were made in studies on the carotid artery of ageing SHR (Waeber B et $a l ., 1992)$, on the aorta of renal hypertensive rats (Sumitani M et al.,1997; Zanchi A et al.,1997), and on the thoracic aorta of young and adult rats (Van Gorp A et al.,1995). In other studies in SHR, however, the compliance and the elastic properties of the carotid artery were found to be reduced with increasing age (Benetos A et al.,1992). An explanation for this discrepancy could be the level of arterial blood pressure in the SHR strains used. The blood pressure level in the SHR strain employed in the present study was not as high as that in the study by Benetos and colleagues (Benetos $\mathrm{A}$ et al.,1992; Levy BI et al.,1994). The severity of the blood pressure elevation may be important in the induction of structural alteration in the aortic wall (Wolinsky H,1972; Fisher GM,1976).

In the SHR strain used spontaneous mortality strongly increases after 17 months of age (Schoemaker R,1989), which was confirmed in the present study. Therefore, the survivors in the 18 month old SHR group may represent a selection and it was decided to exclude these survivors from the trend analysis. In general, however, the findings in this group of survivors were not significantly different from 12 and 15 month old SHR.

It should be noted that in the present study the functional properties of the thoracic aorta, as compliance and distensibility, are determined considering the entire wall. In the calculation of the incremental elastic modulus, however, only the thickness of the media is taken into account because of the poor delineation of the outer vessel wall boundary. Therefore, changes in the elastic properties of the adventitita and intima, if any, can not be ruled out.

We deliberately performed the experiments during ketamine/xylazine anesthesia to be able to assess dynamic artery wall properties at comparable levels of blood pressure. Xylazine is well known for its $\alpha_{-2}$ adrenergic agonistic properties. The compound thereby (i) inhibits the activity of the vasomotor center in the central nervous system (Van Zwieten PA et $a l, 1983$ ), (ii) reduces peripheral adrenergic neurotransmission by a prejunctional inhibitory action (Vanhoutte PM et al.,1981) and (iii) dilates the aorta through a local endothelium-dependent mechanism (Vanhoutte PM et al.,1989). Following administration of ketamine/xylazine circulating catecholamine levels were reduced by 80 to $90 \%$ and, unlike in conscious restrained WKY, prazosin and Na-nitroprusside failed to dilate the aorta in vivo (unpublished results). The blood pressure lowering effect of ketamine/xylazine was far more marked in SHR than WKY which is compatible with the hyperactivity of the sympathetic nervous system in SHR (Grobecker $\mathrm{H}$ et al,1975; Smith TL et al..,1979; Lee RM et al.,1986; Daemen MP et al.,1995).

The increase in wall mass with age has been ascribed to growth of the animal (Wolinski H,1972; Berry CL et al.,1975; Sumitani ML et al.,1986), but this explanation is less likely for the increase in wall mass observed with increasing age in both strains in the present study. In SHR, body weight only increased significantly between 9 and 12 months of age and was 
not significantly different between age categories in WKY. An increase in blood pressure cannot be held responsible for the increase in wall mass either, because blood pressure did not change with age in both WKY and SHR. The increase in media mass may be induced by an increased activity of the sympathetic nervous and renin angiotensin systems, which have profound effects on smooth muscle cell growth and extracellular matrix protein synthesis, and, therefore, on arterial wall mass (Campbell-Bosswell M. et al.,1981; Dzau VJ,1987; Geisterfer AA et al.,1988; Daemen MJ et al.,1991; Griffin SA et al.,1991; Boonen $\mathrm{H}$ et al.,1993; Schiffers PM et al.,1993; Daemen M et al.,1995).

Collagen and elastin contents are believed to be important determinants of the arterial elastic behavior and collagen content is believed to increase with ageing and in hypertension (Cox RH,1989). In the present study, however, collagen content was not different between SHR and WKY and did not change with age in both strains. Between 9 and 12 months of age, noncross-linked collagen content increased in SHR and WKY, which may indicate that the turn-over of collagen is increased or that collagen cross-linking is reduced. The non-cross-linked collagen molecules do not have tight interactions with the existing extracellular matrix and, hence, are not able to carry tensile strength and will have very little or no contribution to the mechanical properties of the aortic wall (Vadlamudi RK et al.,1993). Between 9 and 12 months of age, cross-linked collagen content decreased and elastin content increased in both SHR and WKY, events believed to increase the elasticity of arteries (Cox RH,1989), which contrasts with the unaltered elasticity of the thoracic aorta in SHR and WKY as observed in the present study. The absence of a change in collagen content with age as well as the changes in cross-linked and non-crosslinked collagen and the increase in elastin content with age indicate that there is no relation between these matrix proteins and the functional and elastic properties of the thoracic aorta wall. Previous studies in different rat models of hypertension, however, described an association between elevated blood pressure and an increase in the synthesis and deposition of collagen in large arteries (Folkow B et al.,1973; Iwatsuki K et al.,1977; Ooshima A et al.,1977; Berry CL et al.,1981; Levy BI et al.,1994). Collagen content appears to increase with the severity of hypertension and with the duration of blood pressure elevation (Wolinsky $\mathrm{H}, 1972$; Fisher GM,1976). The putative increase in collagen as described in these studies, however, can be questioned because in these early studies absolute amounts were considered. If in hypertension the amounts of collagen and elastin are related to the increase of wall mass, a decrease in the density of collagen and elastin is observed (Wolinsky H,1970; Wolinsky H,1972; Wolinsky H et al.,1975; Cox RH,1979a; Cox RH,1979b; Cox RH,1981). In aged rats, Fornieri et al.. (Forieri C et al.,1992) described an increase in the volume density of collagen, but a reduction of the total amount per cross-sectional area. Altogether, these findings are in accordance with the findings in the present study that the relative amount of collagen are not altered with ageing and in hypertension. Collagen and elastin both have a very long half life and, therefore, it is questionable whether the effects of ageing and hypertension on these scleroproteins may be comparable between humans and rats.

In conclusion, the results presented in this study indicate that hypertension does not aggravate the reduction of the in vivo dynamic mechanical and structural properties of the thoracic aorta as occurring with increasing age. 


\section{REFERENCES}

Bader H. Dependence of wall stress in the human thoracic aorta on age and pressure. Circ. Res. 20:354-361, 1967

Benetos A, Bouaziz H, Albaladejo P, Levy BI, Safar ME. Physiological and pharmacological changes in the carotid artery pressure-volume curve in situ in rats. J. Hypertens. 10(Suppl 6):s127S131, 1992

Benetos A, Huguet F, Albaladejo P, Brisac AM, Pappo M, Safar ME, Levy BI. Role of adrenergic tone in mechanical and functional properties of carotid artery during ageing. Am. J. Physiol. 265:H1132-H1138, 1993

Berry CL, Greenwald SE, Rivett JF. Static mechanical properties of the developing and mature rat aorta Cardiovasc. Res. 9:669-678, 1975

Berry CL, Greenwald SE, Menahem N. Effects of beta-aninoproprienonitrile on the static elastic properties and blood pressure of spontaneously hypertensive rats. Cardiovasc. Res. 15:373-381, 1981

Boonen HCM, Daemen MJAP, Eerdmans PE, Fazzi GE, Van Kleef, Schiffers PMH, De Mey JGR. Me E senteric small artery changes following vasoconstrictor infusion in young rats. J. Cardiovasc. Pharmacol. 22:388-395, 1993

Campbell-Bosswell M, Robertson AL. Effects of angiotensin II and vasopressin on human smooth muscle cells in vitro. Exp. Mol. Pathol. 35:265-276, 1981

Chiariellio M, Ambrosio G, Cappelli-Bigazzi M, Perrone-Filardi P, Brigante F, Sifola C. A biochemical method for the quantification of myocardial scarring after experimental coronary artery occlusion. J.Mol. Cell. Cardiol. 18:283290, 1986

Cox RH. Alterations in active and passive mechanics of rat carotid artery with experimental hypertension. Am. J. Physiol. 237:H597-H605, 1979a

Cox RH Comparison of arterial wall mechanics in normotensive and spontaneously hypertensive rats. Am. J. Physiol 237:H159-H167, 1979b

Cox RH. Basis for the altered arterial wall mechanics in the spontaneously hypertensive rats. Hypertension 3:485495, 1981

Cox RH. Mechanical properties of arteries in hypertension. In: Blood vessel changes in hypertension: structure and function. Volume 1, chapter 4. CRC Press Inc., Boca raton, Florida, pp65-95, 1989

Daemen MJAP, Lombardi DM, Bosman FT, Schwartz SM. Angiotensin II induces smooth muscle cell proliferation in the normal and injured rat arterial wall. Circ. Res. 68:450-456, 1991

Daemen MPAJ, De Mey JGR. Regional heterogeneity of arterial structural changes. Hypertension 25:464-473, 1995

Dzau VJ. Implications of local angiotensin production in cardiovascular physiology and pharmacology. Am. J. Cardiol. 59:59A-65A, 1987

Fisher GM. Effects of spontaneous hypertension and age on arterial connective tissue in the rat. Exp. Gerontol. 11:209, 1976

Folkow B, Hallback M, Lundrun Y, Sivertson $\mathrm{R}$, Weiss L. Importance of adaptive changes in vascular design for establishment of primary hypertension, studied in man and in spontaneously hypertensive rats. Circ. Res. 32-33 (Suppl I): $2-16,1973$

Forieri C, Quaglino D, Mori G. Role of the extracellular matrix in age-related modification of the rat aorta: Ultrastructural, morphometric and enzymatic evaluations. Arterioscler. Thromb. 12:1008-1016, 1992

Geisterfer AA, Peach MJ, Owens GK. Angiotensin II induces hypertrophy, but not hyperplasia, of cultured rat aortic smooth muscle cells. Circ. Res. 62:749756,1988

Griffin SA, Brown WBC, MacPherson F, McGrath JC, Wilson VG, Korsgaard N, Mulvany MJ, Lever AF. Angiotensin II causes vascular hypertrophy in part by a 
non-pressor mechanism. Hypertension 17:626-635, 1991

Grobecker H, Roizen MF, Veise V, Saavedra JM, Kopin IJ. Sympathoadrenal medullary activity in young spontaneously hypertensive rats. Nature 258:267-268, 1975.

Hansen F, Mangell P, Sonesson B, Lann T. Diameter and compliance in the human common carotid artery - variations with age and sex. Ultrasound Med Biol 21:1-9, 1995

Hoeks APG, Brands PJ, Smeets FAM, Reneman RS. Assessment of the distensibility of superficial arteries. Ultrasound Med Biol 16:121-128, 1990

Hoeks APG, Arts TGJ, Brands PJ, Reneman RS. Comparison of the performance of the rf cross correlation and Doppler autocorrelation technique to estimate the mean velocity of simulated ultrasound signals. Ultrasound Med Biol 19:727-740, 1993a

Hoeks APG. The arterial system in hypertension Kluwer Academic Publishers chapter 8 ed ME Safar and MF O'Rourke ppl19-134, 1993b

Iwatsuki K, Cardinale GJ, Spector S, Udenfriend $\mathrm{S}$. Reduction of blood pressure and vascular collagen in hypertensive rats by betaaminoproprionitrile. Proc. Natl. Acad. Sci. USA. 74:360-362, 1977

James J, Bosch KS, Aronsen DC, Houtkooper JM. Sirius red histophotometry and spectophotometry of sections in the assessment of the collagen content of liver tissue and its application in growing rat liver. Liver 10:1-5, 1990

Kohn RR. Heart and cardiovascular system. In: Finch CE, Hyflick L (eds.). Handbook of biology and aging. New York: Van Nostrand Reinhold 281-317, 1977

Lakatta EG. Do hypertension and aging have similar effect on the myocardium? Circulation. 75 (suppl.I):I69-I77, 1987

Learoyd BM, Taylor MG. Alterations with age in the viscoelastic properties of human arterial walls. Circ. Res. 18:278-292, 1966

Lee RMKW, Coughlin MD, Cheung DWT. Relationship between sympathetic innervation, vascular changes and hypertension in spontaneously hypertensive rats. $J$ Hypertens. 4(suppl):81-83, 1986

Levy BI, Michel JB, Salzman JL, Azizi M, Poitevin P, Safar M, Camilleri JP. Effects of chronic inhibition of converting enzyme on mechanical and structural properties of arteries in rat renovascular hypertension. Circ. Res. 63:227-229, 1988

Levy BI, Benessiano J, Poitevin P, Safar ME. Endothelium dependent mechanical properties of the carotid artery in WKY and SHR. Role of angiotensin converting enzyme inhibition. Circ. Res 66:321-328, 1990

Levy BI, Duriez M, Phillipe M, Poitevin P, Michel JB. Effects of chronic dihydropyridine (isradipine) on the large arterial wall of spontaneously hypertensive rats. Circulation 90:30243033, 1994

Michel JB, Heudes D, Michel O, Poitevin PP, Scalbert E, Corman B, Levy BI. Effect of chronic ANGI-converting enzyme inhibition on aging processes. II. Large arteries. Am. J. Physiol. 267:R124-R135, 1994

Mulvany MJ, C Aalkjaer, J Christensen. Changes in noradrenaline sensitivity and morphology of arterial resistance vessels during development of high blood pressure in spontaneously hypertensive rats. Br. J. Pharmacol. 71:585-596, 1980

Ooshima A, Midorikawa O. Increased lysyl oxidase activity in blood vessels of hypertensive rats and effect of betaaminoproprionitrile on arteriosclerosis. Jap. Circul. J. 41:1337-1340, 1977

Pagani M, Mirsky I, Baig H, Manders WT, Kerkhof P, vatner SF. Effects of age on aortic pressure-diameter and elastic stiffness-stress relationship in 
unanesthetized sheep. Circ. Res. 44:420429, 1979

Reneman RS, Van Merode T, Hick P, Hoeks APG. Flow velocity patterns in and distensibility of the carotid artery bulb in subjects of various ages. Circulation 71:500-509, 1985

Reneman RS, Van Merode T, Hick P, Muytjens AMM, Hoeks APG. Agerelated changes in carotid artery wall properties in men. Ultrasound Med. Biol. 12:465-471, 1986.

Reneman RS, Hoeks APG, Westerhof N. Noninvasive assessment of artery wall properties in humans: methods and interpretation. J. Vascular Investigation 2:53-64, 1996

Safar M. Ageing and its effect on cardiovascular system. Drugs 39 (suppl. 1):1-8, 1990

Schiffers PMH, Van der Heijden HAMD, Fazzi GE, Struijker Boudier HAJ, De Mey JGR. Tonic tone in arteries exposed continuously to angiotensin II in vitro. $J$. Pharmacol. Exp. Ther. 266:1520-1527, 1993

Schoemaker R. Experimental heart failure in rats, $\mathrm{Ph}$. D.Thesis, Maastricht University, 1989

Smith TL, Hutchins PM. Central hemodynamics in the developmental stage of spontaneously hypertension in unanesthetized rat. Hypertension 1:508517,1979

Sonesson B Vernersson E, Hansen F, Länne T. Influence of sympathetic stimulation on the mechanical properties of the aorta in humans. Acta Physiol. Scand. 159:139145, 1997

Sumitani M, Michelini LC, Krieger EM. Long-term analysis of dynamics in growing conscious rats. Hypertension $\mathbf{8}$ ( suppl I)I200-I204, 1986

Sumitani M, Cabral AMS, Michelini LC, Krieger EM. In vivo adaptive responses of the aorta to hypertension and aging. Am. J. Physiol. 273:H96-H103, 1997

Vadlamudi RK, McCormick RJ, Medeiros DM, Vossoughi J, Failla ML. Copper deficiency alters collagen types and covalent cross-linking in swine myocardium and cardiac valves. Am. J. Physiol. 264:H2154-H2161, 1993

Van Gorp AW, Van Ingen Schenau DS, Hoeks APG, Struijker Boudier HAJ, Reneman RS, De Mey JGR. Aortic wall properties in normotensive and hypertensive rats of various ages in vivo. Hypertension 26:363-368, 1995

Van Gorp AW, Van Ingen Schenau DS, Willegers J, Hoeks APG, De Mey JGR, Struijker Boudier HAJ, Reneman RS. A technique to assess aortic distensibility and compliance in anesthetized and awake rats. Am. J. Physiol. 270:H780H786, 1996.

Vanhoutte PM, Verbeuren TJ, Webb RC. Local modulation of adrenergic neuroeffector interactions in the blood vessel wall. Physiol. Rev. 61:151-218, 1981.

Vanhoutte PM, Miller VM. Alpha-2 adrenoceptors and endothelium-derived relaxing factor. Am. J. Med. 87(Suppl):15, 1989.

Van Merode T, Hick PJ, Hoeks AP, Rahn KH, Reneman RS. Carotid artery wall properties in normotensive and borderline hypertensive subjects of various ages. Ultrasound Med. Biol. 14:563-569, 1988.

Van Merode T, Brands PJ, Hoeks APG, Reneman RS. Faster ageing of the carotid artery bifurcation in borderline hypertensive subjects. $J$ Hypertens. 11:171-176, 1993.

Van Zwieten PA, Thoolen MJMC, Timmermans PBMWM. The pharmacology of centrally acting antihypertensive drugs. $\mathrm{Br} . \mathrm{J}$. Clin. Pharmacol. 15(Suppl):455-462, 1983.

Ventura H, Messerli FH, Oigman W, Suarez DH, Dreslinski GR, Dunn FG, et al.. Impaired systemic arterial compliance in borderline hypertension. Am. Heart J. 108:132-136, 1984.

Waeber B, Hayoz D, Evequoz D, Brunner HR. Arterial compliance and distensibility in 
spontaneously hypertensive rats. $J$. Hypertens. 10 (suppl 6) S79-S81, 1992

Wolinsky H. Response of the rat aortic media to hypertension. Morphological and chemical studies. Circ. Res. 26:507-522, 1970

Wolinsky H. Long-term effects of hypertension on the rat aortic wall and their relation to concurrent aging changes. Circ. Res. 30:301-309, 1972
Wolinsky H, Goldfischer S, Daly MM, Kasak LE, Coltoff Schiller B. Arterial lysosomes and connective tissue in primate atherosclerosis and hypertension. Circ. Res. 36:553-561, 1975

Zanchi A, Wiesel P, Aubert JF, Brunner HR, Hayoz D. Time course of changes of the mechanical properties of the carotid artery in renal hypertensive rats. Hypertension 29:1199-1203, 1997 


\section{CHAPTER 7}

THE INFLUENCE OF ANTIHYPERTENSIVE MEDICATION ON THE CONSCIOUS IN-VIVO DYNAMIC MECHANICAL PROPERTIES OF THE THORACIC AORTA IN SPONTANEOUSLY HYPERTENSIVE RATS

Ad W. van Gorp

Dorette S. van Ingen Schenau

Arnold P.G.Hoeks

Jo G.R. De Mey

Robert S. Reneman

Harry A.J. Struijker Boudier 


\begin{abstract}
The dynamic mechanical properties of large arteries change in hypertensive disease. These changes are related to the pressure increase as such, but could also be caused by pressure-independent factors. One way to test the role of pressureindependent mechanisms is to compare the effects of different regimens of druginduced blood pressure lowering. In this study we investigated the effects of a 6 weeks treatment of young 6 week old spontaneously hypertensive rats (SHR) with the ACE-inhibitor captopril, the calcium entry blocker nifedipine and the arterial vasodilator hydralazine. At the end of the treatment period we measured the diameter of the thoracic aorta and its change during the cardiac cycle using a previously described non-invasive ultrasound technique in conscious animals. Blood pressure was measured via an intra-aortic catheter. These measurements allowed the calculation of aorta compliance and distensibility. After these measurements animals were sacrificed to determine the media cross sectional area of the thoracic aorta. This allowed the calculation of the incremental elastic modulus of the aorta. The results of our measurements show that (i) diastolic diameter of the aorta was not influenced by significantly by any treatment, except for a small reduction following hydralazine; (ii) aortic compliance and distensibility were increased by all antihypertensives; (iii) the antihypertensives did not influence the aorta incremental elastic modulus and (iv) the media crosssectional area of the aorta was reduced to a comparable degree by the various antihypertensives. From these data we conclude that the effects of antihypertensive drugs on dynamic mechanical properties of the aorta of SHR are due to their pressure lowering effect rather than to direct effects on aorta diameter or vascular stiffness.
\end{abstract}

\section{INTRODUCTION}

Large arteries have a conduit and buffering function (O'Rourke M,1982). Because of their distensibility, they are able to buffer the pulsatile output of the ventricle. Indeed, after left ventricular ejection has distended the aorta and its large branches and closure of the aortic valves has been achieved, the elastic aorta and its branches recoil, thereby sustaining the pressure head rendering blood flow to the periphery steadier than it would otherwise. In established hypertension, a number of structural changes occur in large arteries (Safar M,1988; Struijker Boudier H et al.,1995), which comprise smooth muscle hypertrophy and changes in extracellular matrix composition. These structural changes reduce the buffering capacity of the large arteries. Experimental, clinical and epidemiological studies have shown that these vascular abnormalities contribute to hypertension-induced cardiovascular complications (Safar M,1988; Struijker Boudier $\mathrm{H}$ et al.,1995).

Although the elevation of blood pressure as such is an important trigger for large artery structural and functional changes, it has been proposed that these changes due to the activation of different neurohumoral systems occur independently of blood pressure levels (Benetos A et al.,1992). These findings are in agreement with the fact that changes in buffer function precede the increase in blood pressure in spontaneously hypertensive rats (Van Gorp A et al., abstract). A particular role has been suggested for the reninangiotensin system (Benetos A et al.,1992). 
Angiotensin II has multiple effects on aortic wall structure and function independent of any effects mediated through blood pressure elevation. These include effects on vascular smooth muscle cell growth (Campbell-Bosswell M et al.,1981; Geisterfer A et al.,1988; Daemen M et al.,1991; Giffin S et al.,1991) and extracellular matrix formation (Dzau V,1987). In other studies, it has been described that angiotensin converting enzyme (Saavedra $\mathrm{J}$ et al,,1992) and the mRNA of angiotensinogen (Lodwick D et al.,1995) are increased in the aorta's of prehypertensive SHR as compared to WKY.

A potential way to test the role of pressure-independent mechanisms of influencing large artery properties is to compare the effects of different regimens of pharmacological methods of blood pressure reduction. The recently developed technique of aorta diameter and wall movement measurement in intact conscious rats (Van Gorp A et al.,1996) allows such an approach. In this study, we hypothesize that the pressure-independent differences in mechanical properties between spontaneously hypertensive rats and Wistar Kyoto rats are the result of an increased activity of the renin-angiotensin system and these differences can be reversed by early treatment with ACEinhibitors. Therefore, we investigated the effect of treatment with the ACE-inhibitor captopril on the reversion of mechanical and structural alterations of the aortic wall observed already in early stages of spontaneous hypertension. The calciumentry-blocker nifedipine and the arterial vasodilator hydralazine are used as antihypertensive agents that exert their blood pressure lowering effect independently of the renin-angiotensin system.

\section{METHODS}

\section{Animals and treatment}

SHR were obtained from the Central Animal Facilities of the Maastricht University (Maastricht, The Netherlands) or from Iffa Credo (France). Rats were housed individually and maintained on a 12-hour light, 12-hour dark cycle. They were fed ad libitum (Hope Farms, Woerden, The Netherlands) and had free access to tap water. All experimental protocols were approved by the local Institutional Animal Care and Use Committee. Starting at an age of 6 weeks, the animals were trained for a period of 6 weeks in a restrainer which was developed in our institute (Van Gorp A et al.,1996). Their systolic blood pressures were measured (see below) and they were randomized into groups of 10 animals each for the various treatments. Randomization was such that starting systolic blood pressures did not differ significantly for the various treatment groups. Treatments consisted of different antihypertensives: 0.01 $\mathrm{mg} / \mathrm{kg} /$ day nifedipine, $4 \mathrm{mg} / \mathrm{kg} /$ day hydralazine, 2.5 or $12.5 \mathrm{mg} / \mathrm{kg} /$ day captopril. The doses of nifedipine and hydralazine were chosen on the basis of pilot experiments (Eerdmans P et al.,1993) to reach equal degrees of blood pressure reduction as with $12.5 \mathrm{mg} / \mathrm{kg} /$ day captopril. The antihypertensives were administered by the use of osmotic minipumps (Alzet) implanted underneath the skin. Nifedipine was dissolved in a solution of $50 \%(\mathrm{v} / \mathrm{v})$ ethanol and $50 \%$ (v/v) polyethylene glycol. Hydralazine and captopril were dissolved in water. Shamoperated SHR served as controls. 


\section{Blood pressure measurement}

At the age of 6 weeks, systolic blood pressure was measured with the use of a tail cuff plethysmography. At the end of the treatment period of 6 weeks, a polyethylene catheter (PE-10; ID $0.28 \mathrm{~mm}$, OD $0.61 \mathrm{~mm}$ ), filled with heparinized saline, was implanted in the aorta under pentobarbital sodium anesthesia (100 $\mu \mathrm{l} / 100 \mathrm{~g}$ body weight; $60 \mathrm{mg} / \mathrm{ml}$ ) for the recording of blood pressure. The catheter was advanced through a femoral artery to just below the bifurcation of the renal artery. The catheter was guided underneath the skin and exteriorized at the base of the skull. Aortic pressure was measured with an external pressure transducer (CP-01, Century Technology, Inglewood, CA, USA). The delay in the pressure measuring system was $12 \mathrm{~ms}$, indicating a frequency response beyond $50 \mathrm{~Hz}$. After two days, the studies on the mechanical and structural properties of the thoracic aorta were started.

\section{Ultrasound assessment of aorta diameter rand wall movement}

The ultrasound device to assess diameter (d) and diameter changes $(\Delta d)$ of the aorta during the cardiac cycle consists of a vessel wall tracking system (WTS) combined with a conventional B-mode (B, brightness) ultrasound system (Pie 480, 7.5 Mhz linear array, Pie Medical, Maastricht, The Netherlands)(Hoeks A et al.,1990, 1993). The rats were shaved at the site of measurement and the ultrasound probe was placed on the thorax slightly to the left of the sternum; ultrasonic gel was applied between probe and skin. The thoracic aorta was then visualized in B-mode, $10 \mathrm{~mm}$ proximal to the diaphragm, and the probe was positioned so that the M-line (M, motion) was perpendicular to the vessel wall. Then the ultrasound system was switched to M-mode and ultrasound was emitted and received along the selected line of sight at a programmable emission trigger frequency. At an emission frequency of $1653 \mathrm{~Hz}$, the $1 \mathrm{MB}$ memory will hold $2.5 \mathrm{~s}$ of data, corresponding to approximately 12 cardiac and 4 respiration cycles under the current experimental conditions. Because of the higher heart rate in the awake rats, sampling frequency was doubled resulting in data collection for 1.2 s (Van Gorp A et al.,1996).

\section{Protocol}

During the 6-week treatment period, the rats were accustomed to the restrainer for hemodynamic measurements in the conscious state, 5 days per week during approximately 30 minutes per day. Two days following the intra-aortic catheter implantation, rats were placed in the restrainer. After 15 minutes in the restrainer, blood pressure and aortic wall movement measurements were performed.

\section{Calculation of compliance and distensibility}

Arterial compliance is defined as the absolute increase in volume $(\Delta \mathrm{V})$ for a given increase in arterial blood pressure (pulse pressure $=\Delta \mathrm{P}$ ). Distensibility, on the other hand, is the relative increase in volume $(\Delta \mathrm{V} / \mathrm{V})$ for a given $\Delta \mathrm{P}$. Assuming that a volumetric increase is due to radial distension rather than longitudinal elongation (Reneman R et al.,1986, 1996) and that vascular lumen cross-section is perfectly circular, compliance (CC) and distensibility (DC) can be approached as follows: 
$\mathrm{CC}=\Delta \mathrm{V} / \Delta \mathrm{P} \approx \Delta \mathrm{A} / \Delta \mathrm{P}$

$\approx\left(\mathrm{d}_{\mathrm{dia}} \Delta \mathrm{d}\right) /(2 \Delta \mathrm{P})$

$\mathrm{DC}=(\Delta \mathrm{V} / \mathrm{V})) / \Delta \mathrm{P} \approx\left(\Delta \mathrm{A} / \mathrm{A}_{\text {dia }}\right) / \Delta \mathrm{P}$

$\approx\left(2 \Delta \mathrm{d} / \mathrm{d}_{\mathrm{dia}}\right) / \Delta \mathrm{P}$

where $d_{\text {dia }}$ and $A_{\text {dia }}$ stand for the enddiastolic diameter and area, respectively; $\Delta \mathrm{d}$ and $\Delta \mathrm{A}$ represent the changes in diameter and lumen area during the cardiac cycle, respectively.

\section{Structural measurements}

At the end of each experiment, the rats were euthanized and a $10-\mathrm{mm}$ segment of the middle part of the thoracic aorta was excised. The extent of longitudinal retraction upon isolation was assessed by pre $\left(\mathrm{L}_{\mathrm{i}}\right)$ and post $\left(\mathrm{L}_{\mathrm{e}}\right)$ excision measurement of the segment length. The excised vessel was fixed by immersion in $4 \%$ phosphate buffered formalin before being embedded in paraffin.

Media cross-sectional area $\left(\mathrm{CSA}_{\mathrm{e}}\right)$, defined as the area between the internal and external elastic laminae, was determined by semi-automated morphometry (JAVA 1,21 Jandel Scientific, Corte Madera, CA, USA) on 4 $\mu \mathrm{m}$ cross-sections stained with Lawson's solution (a classic elastin stain), using an axioplan microscope (Zeiss) equipped with a standard CCD camera (Stemmer,
Germany) (Boonen $\mathrm{H}$ et al.,1993). This value was converted to the expected in-vivo CSA $\left(\mathrm{CSA}_{i}\right)$, assuming that vascular mass is constant, by accounting for vascular retraction upon isolation, i.e.

$\mathrm{CSA}_{\mathrm{i}}=\mathrm{CSA}_{\mathrm{e}} \cdot \mathrm{L}_{\mathrm{e}} / \mathrm{L}_{\mathrm{i}}$

$\mathrm{CSA}_{\mathrm{i}}$ and $\mathrm{d}_{\text {dia }}$ were used to calculate media thickness (Mt) according to:

$M t=-d_{\text {dia }} / 2+\left[\left(d_{\text {dia }} / 2\right)^{2}+\mathrm{CSA}_{i} /\right]^{1 / 2}$

Furthermore, the incremental elastic modulus $\left(\mathrm{E}_{\text {inc }}\right)$, was calculated as:

$$
\mathrm{E}_{\text {inc }}=\mathrm{d}_{\text {dia }} /(M t . D C)
$$

\section{Statistical analysis}

Each group of SHR consisted of 10 animals. In each animal, 6 consecutive 1.2 $\mathrm{s}$ recordings were made. The recordings of pressure, internal lumen diameter and distension were obtained and mechanical vessel characteristics were calculated for each individual cardiac cycle. Mean values were calculated for each recording session; then these values were averaged for each individual animal and eventually a group mean was obtained for each strain.

The data are presented as means \pm SD. Comparison between different groups was performed with ANOVA followed by a Tukey test for multiple comparison (Wallenstein S et al.,1980). 

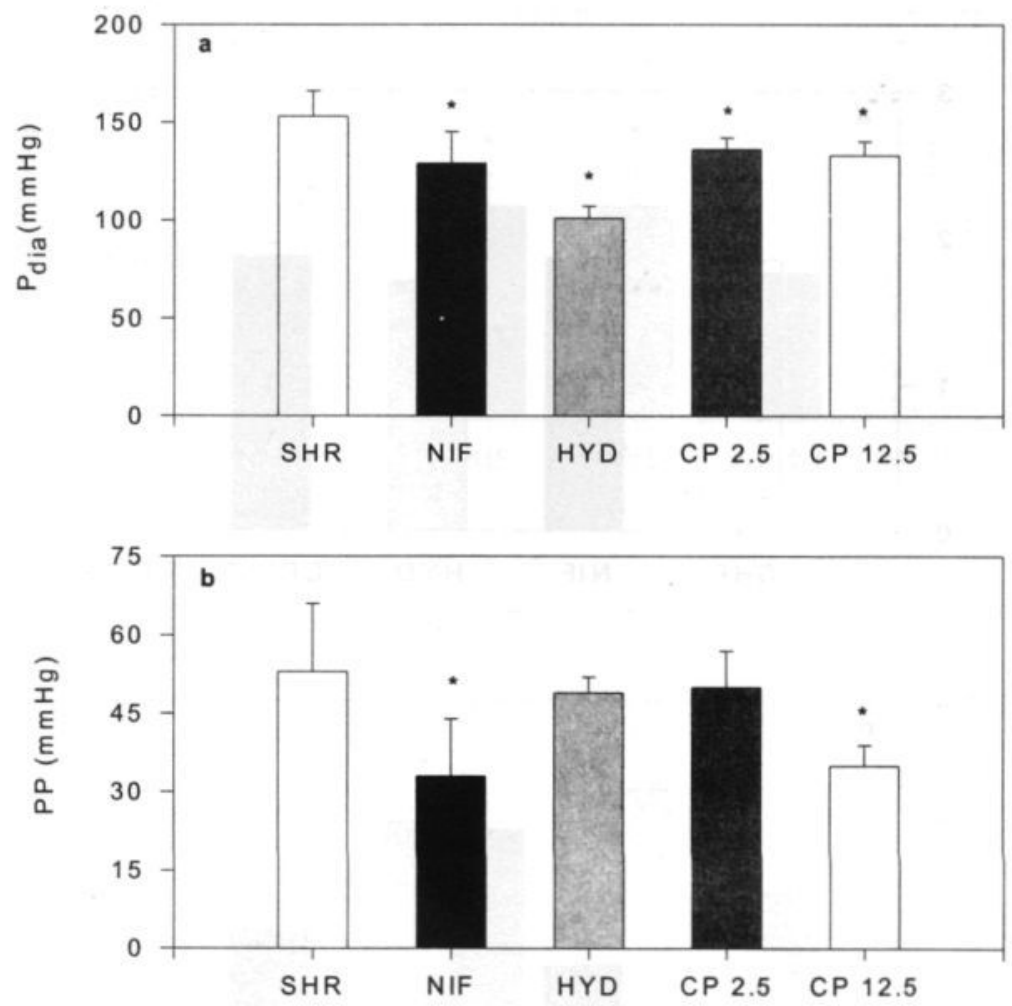

Fig. 7.1. Bar graphs showing diastolic blood pressure (a) and pulse pressure (b) in untreated spontaneously hypertensive rats (SHR, $\mathrm{n}=12$ ), and SHR treated with $0.01 \mathrm{mg} / \mathrm{kg} / \mathrm{day}$ nifedipine (NIF, n=12), $4 \mathrm{mg} / \mathrm{kg} /$ day hydralazine (HYD, n=12), $2.5 \mathrm{mg} / \mathrm{kg} /$ day (CP2.5, $\mathrm{n}=12)$ and 12.5 captopril $\mathrm{mg} / \mathrm{kg} /$ day $(\mathrm{CP} 12.5, \mathrm{n}=12)$. Mean \pm SD.

* significantly different from untreated control SHR $\mathrm{p}<0.05$.

\section{RESULTS}

At the time of the start of the treatment (age: 6 weeks), systolic blood pressures, determined with tail plethysmography) did not differ significantly for the various SHR treatment groups (range: 125 \pm 11 to $143 \pm 14 \mathrm{~mm} \mathrm{Hg}$ ). Following 6 weeks of treatment, blood pressures were measured in restrained conscious animals with an implanted aortic catheter. Figure 7.1 summarizes the values for diastolic pressure and pulse pressure. Diastolic pressure was reduced significantly in all treated SHR groups. The strongest reduction was observed in hydralazine treated SHR, although the diastolic blood pressures observed in that group did not differ significantly from that in the other SHR groups. Pulse pressures were reduced 

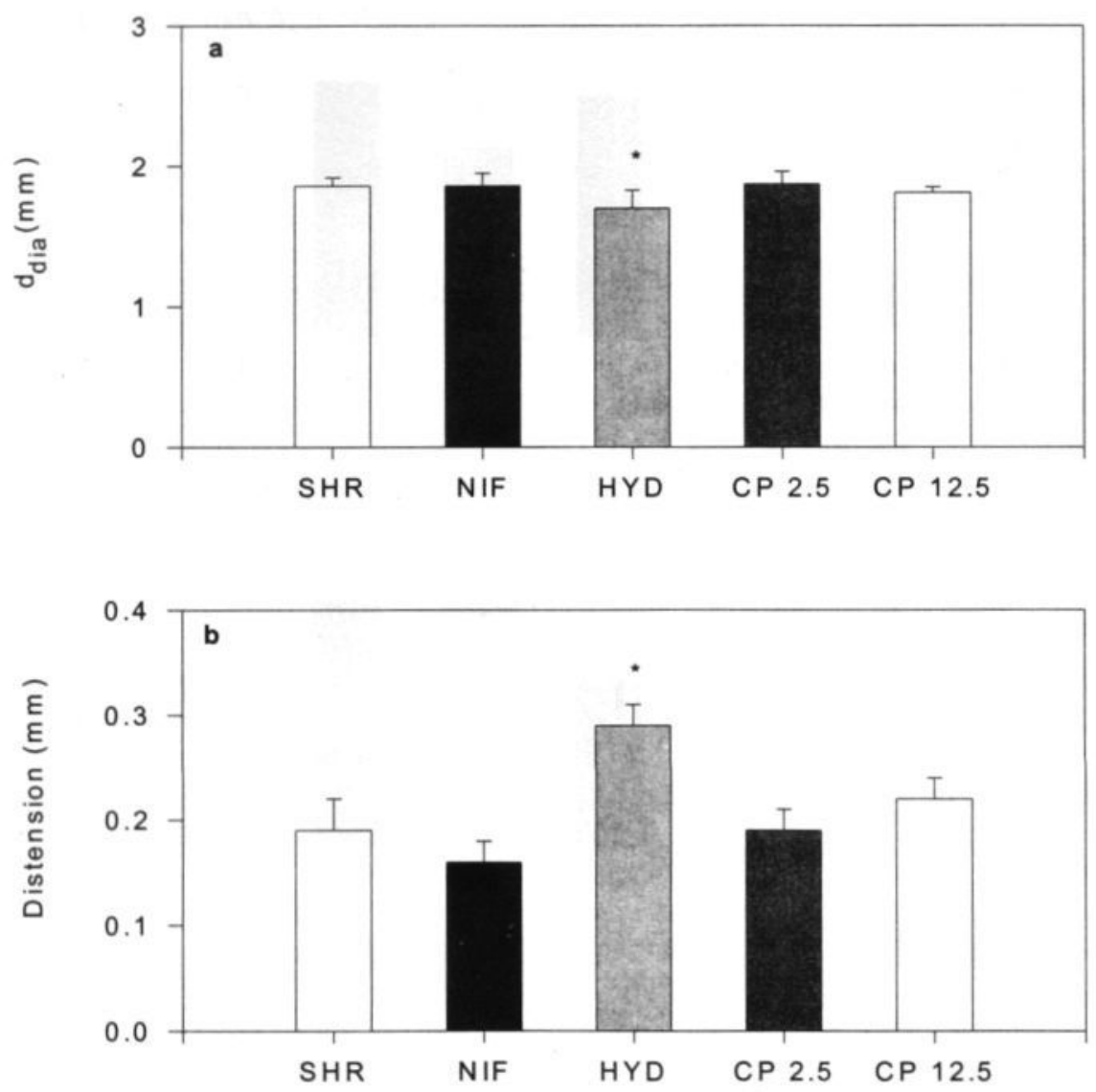

Fig. 7.2. Bar graphs showing diastolic diameter (a) and distension (b) in untreated spontaneously hypertensive rats (SHR, $\mathrm{n}=12$ ), and SHR treated with $0.01 \mathrm{mg} / \mathrm{kg} /$ day nifedipine (NIF, $\mathrm{n}=12), 4 \mathrm{mg} / \mathrm{kg}$ /day hydralazine (HYD, $\mathrm{n}=12), 2.5 \mathrm{mg} / \mathrm{kg} /$ day $(\mathrm{CP} 2.5, \mathrm{n}=12)$ and 12.5 captopril $\mathrm{mg} / \mathrm{kg} /$ day (CP 12.5, $\mathrm{n}=12)$. Mean \pm SD.

* significantly different from untreated control SHR $p<0.05$.

Conscious diastolic aorta diameter was significantly smaller in the hydralazine treated SHR when compared to control SHR. In the other groups diastolic diameter of the aorta did not differ significantly
(Fig. 7.2a). Distension was significantly higher in hydralazine treated SHR when compared to control SHR (Fig. 7.2b). No significant differences were observed for the other treatment groups. 

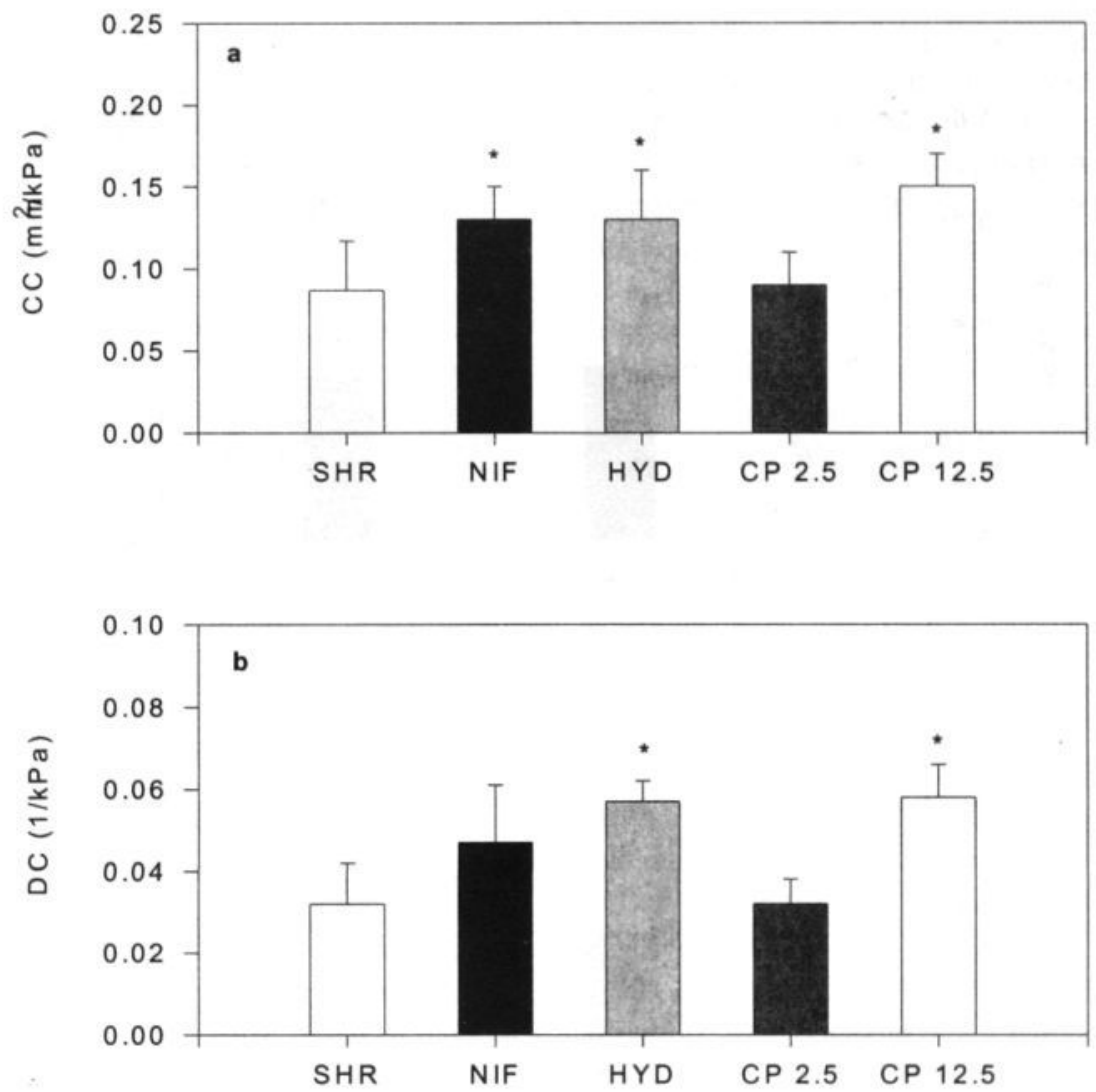

Fig. 7.3. Bar graphs showing compliance coefficient (a) and distensibility coefficient (b) in untreated spontaneously hypertensive rats (SHR, $\mathrm{n}=12$ ), and SHR treated with $0.01 \mathrm{mg} / \mathrm{kg} /$ day nifedipine (NIF, n=12), $4 \mathrm{mg} / \mathrm{kg} /$ day hydralazine (HYD, $\mathrm{n}=12$ ), $2.5 \mathrm{mg} / \mathrm{kg} /$ day (CP2.5, $\mathrm{n}=12)$ and 12.5 captopril $\mathrm{mg} / \mathrm{kg} /$ day $(\mathrm{CP} 12.5, \mathrm{n}=12)$. Mean \pm SD.

${ }^{*}$ significantly different from untreated control SHR $\mathrm{p}<0.05$. 

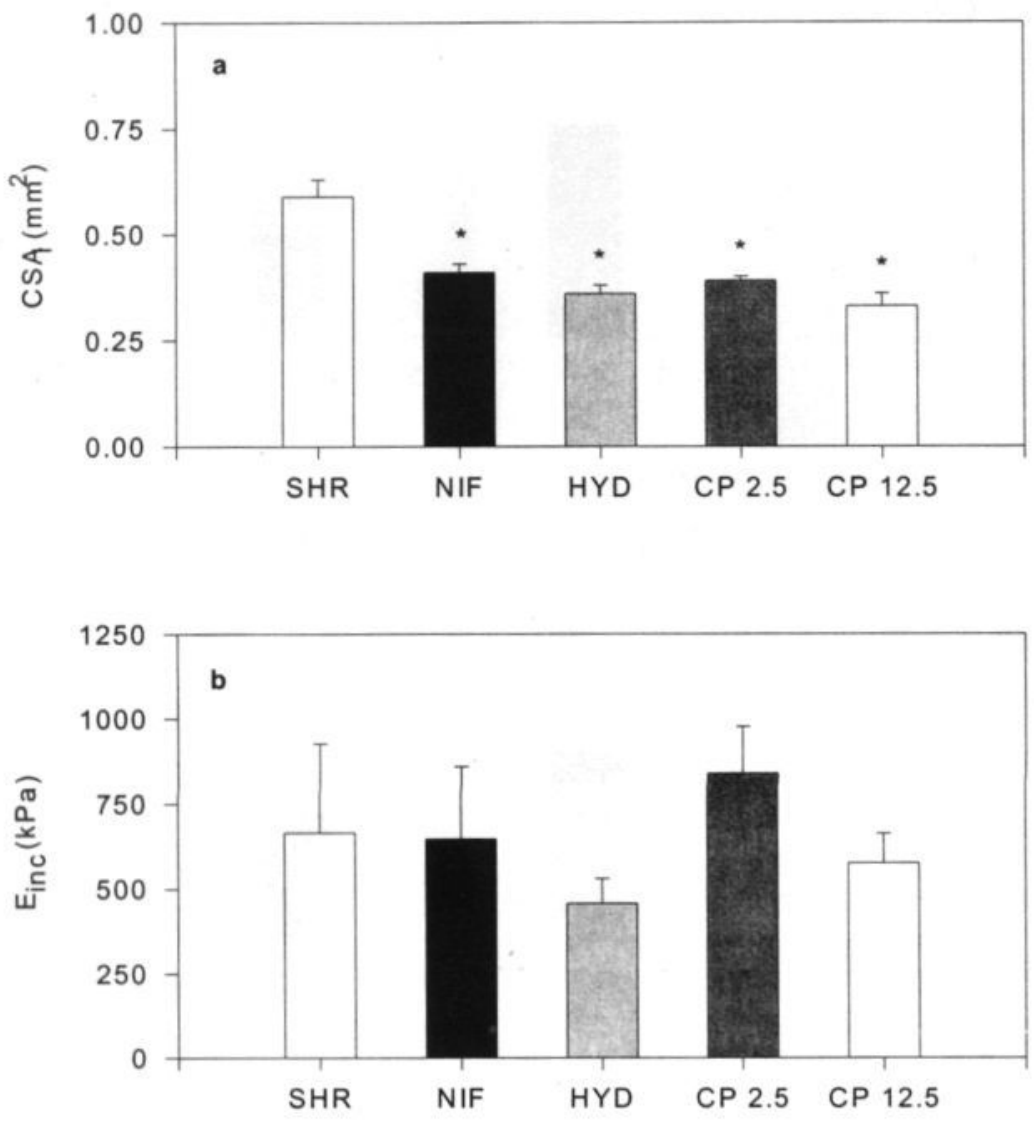

Fig. 7.4. Bar graphs showing media cross-sectional area (a) and incremental elastic modulus (b) in untreated spontaneously hypertensive rats (SHR, $n=12)$, and SHR treated with 0.01 $\mathrm{mg} / \mathrm{kg} /$ day nifedipine (NIF, $\mathrm{n}=12$ ), $4 \mathrm{mg} / \mathrm{kg} /$ day hydralazine $(\mathrm{HYD}, \mathrm{n}=12$ ), $2.5 \mathrm{mg} / \mathrm{kg} /$ day $(\mathrm{CP} 2.5, \mathrm{n}=12)$ and 12.5 captopril $\mathrm{mg} / \mathrm{kg} /$ day $(\mathrm{CP} 12.5, \mathrm{n}=12)$. Mean $\pm \mathrm{SD}$.

* significantly different from untreated control SHR $\mathrm{p}<0.05$. 
In SHR treated with nifedipine, hydralazine and captopril $12.5 \mathrm{mg} / \mathrm{kg} /$ day, aorta compliance and distensibility were increased (Fig. 7.3). The increase was significant with the exception of the change in distensibility following nifedipine. A 6-week treatment with 2.5 $\mathrm{mg} / \mathrm{kg}$ /day captopril failed to augment aorta compliance and distensibility (Fig. 7.3).

The media cross-sectional area of the aorta was reduced significantly by all antihypertensive treatment regimens (Fig. 7.4a). The incremental elastic modulus of the aorta was not different for the various experimental groups (Fig. 7.4b).

\section{DISCUSSION}

In the present study in-vivo dynamic mechanical properties of the thoracic aorta were determined in conscious 3-month old SHR. These rats had been treated with different antihypertensive drugs for 6 weeks during the period in which pressure rises in SHR. Sham-treated SHR served as controls. The antihypertensive treatment regimens were aimed at obtaining comparable diastolic blood pressures. The results show that (i) diastolic diameter of the aorta was not influenced significantly by any treatment, except for a small reduction following hydralazine, (ii) aortic compliance and distensibility were increased by all antihypertensives, except for the low dose of captopril, (iii) the antihypertensives did not influence the aorta incremental elastic modulus and (iv) the media cross-sectional area of the aorta was reduced to a comparable degree by the various antihypertensives.

We used an in vivo non-invasive ultrasound technique to assess local mechanics of the aorta. The simultaneous measurement of distension and pressure at nearly the same site allows the determination of cross-sectional compliance and distensibility of the aorta
(Hoeks A et al.,1990; Reneman R et al.,1996; Van Gorp A et al.,1996). Furthermore, since the cross-sectional area of the aorta was determined we could obtain an index for the material stiffness of the aorta wall, i.e., its incremental elastic modulus. The importance of in vivo determinations of arterial mechanical properties was stressed in a recent paper by Zanchi et al. (Zanchi A et al. 1998). These authors found major differences in the elastic properties of the rat carotid artery during in vivo, in situ and in vitro conditions. Cross-sectional distensibility was dramatically decreased in vitro and even in situ (Zanchi A et al.,1998). This was not related to an increased stiffness of the arterial wall, but rather to a change in geometry of the artery in situ and in vitro. These observations imply that in vitro or in situ measurements cannot automatically be extrapolated to in vivo conditions. On the other hand, a disadvantage of our approach is that we had to restrain rats in order to perform distension measurements in the conscious state. In previous studies we circumvented this potential disadvantage by the use of anesthesia (Van Gorp A et al.,1995,1996). However, anesthesia interferes with blood pressure control. Since the primary goal of the present study was to investigate the effects of various antihypertensive drugs on aorta mechanics, we regarded this form of interference by anesthetics as inappropriate. In stead, we paid particular attention to adequate habituation of the rats to the restraining conditions. We cannot exclude, however, that our rats were exposed to increased sympathetic activity due to the restraining conditions. The impact of a possible raised sympathetic activity on aorta mechanics remains uncertain since conflicting effects have been reported on the influence of sympathetic tone on large artery mechanics (Lacolley P et al.,1995; Mangoni A et al.,1997). 
The data obtained in this study give rise to a few unexpected results. The first is the lack of effect of the various antihypertensives on aorta diameter. All agents used are regarded as vasodilators although with different mechanisms to induce vasodilatation. It is generally accepted that in acute experiments these drugs dilate precontracted vessels, both in vivo and in vitro. In a previous study we showed that the thoracic aorta in intact SHR of an age comparable to that in the present study is in a state of active vasoconstriction (Van Gorp A et al., chapter 3). In spite of this, we do not observe dilatation following long-term treatment with the various vasodilators in this study. One reason for this apparent discrepancy could be that the drugs used primarily dilate arteries and arterioles located more distally in the vascular system. Our previous hemodynamic and microcirculation studies indeed suggest that hydralazine and dihydropyridine calcium antagonists, such as nifedipine, primarily affect small arteries and arterioles (Struijker Boudier H et al.,1984; Nievelstein $\mathrm{H}$ et al.,1986; Messing M et al.,1990). This agrees with the resistance and blood pressure lowering actions of these drugs and suggests a lack of in vivo effects on large arteries, such as the aorta. The situation is more complex for ACEinhibitors. It has been difficult to prove in vivo vasodilatation following ACEinhibitors (Smits J et al.,1984; Messing M et al.,1991) Only few vascular beds are under chronic tonic influence of angiotensin II. The renal circulation is an example of such a vascular bed and indeed ACE-inhibitors preferentially dilate intrarenal small vessels (Smits J et al.,1984; Bergström G et al.,1998).

An alternative explanation for the lack of increase in aorta diameter is that the lowering of blood pressure in treated SHR may have passively caused a decrease of diameter which is counteracted by a drug induced dilatation. The net sum of these two actions could be a lack of diameter change. Hydralazine is the only exception since it actually decreased aorta diameter slightly. It is of interest to note that chronic hydralazine caused a larger degree of blood pressure reduction than the other antihypertensives. This larger blood pressure reduction may have tipped the balance into the direction of a smaller diameter.

A second unexpected finding of our study was that none of the antihypertensives used influenced aorta stiffness, as assessed by the determination of the incremental elastic modulus. Until recently, it was generally accepted that hypertension produces an increase in large artery stiffness (Cox R,1981; Lévy B et al.,1993; Safar and Frohlich E,1995). However, various groups have recently questioned whether arterial stiffness is increased in essential hypertensive patients or in SHR (Laurent S et al.,1993, 1994, 1995; Hayoz D et al.,1992). These authors suggested that the decreased large artery compliance in essential hypertension and SHR is simply due to the elevated blood pressure and consequent shift towards lower compliances on the bell shaped pressure compliance curves (Laurent S et al.,1995). This shift would be part of an adaptive process whereby sustained hypertension is associated with a remodeling of he arterial wall to maintain normal stress distribution in the wall. In a recent study in SHR, Bezie et al. (Bezie Y et al ,1998) showed no abnormal collagen density in SHR aorta, whereas the number of cell surface contacts with the elastic lamellae in SHR aortas was increased compared to that in normotensive rats. The situation in SHR may be different from that in renovascular hypertension (Sosa-Melgerejo J et al.,1996; Zanchi A et al.,1997) or in renin transgenic hypertension in rats (Van Gorp et al., chapter 8). In these two models - both characterized by an elevated vascular renin-angiotensin II activity - vascular stiffness is increased dramatically. 
Angiotensin II thus seems to have a direct, hypertension-independent effect on the vessel wall to increase its stiffness.

Our results are in line with the concept that the pressure level primarily determines aorta dynamic mechanical properties in SHR. All antihypertensives we studied increased compliance and distensibility to a degree comparable to that in normotensive controls (Van Gorp A et al.,1996). The ACE-inhibitor captopril did not have any additional effects. Previous evidence of blood pressure-independent effects of ACE-inhibitors on large artery compliance was primarily obtained in high-renin models of hypertension (Lévy B et al.,1989). Clinical evidence summarized by Benetos et al. (Benetos A et al.,1997) shows that ACE-inhibitors, calcium entry blockers and nitrates increase large artery compliance in hypertensive patients to an equal degree. However, more inconsistent data were obtained with drugs blocking the sympathetic nervous system (Benetos A et al.,1997) or diuretics (Kool M et al.,1994). The reasons for the discrepant results with the latter groups of antihypertensives remain to be established.

The data in this study show that not only the mechanical properties but also the media cross-sectional area are affected to a comparable degree by the different antihypertensive treatments. The chronic reduction in blood pressure apparently triggers a number of adaptations in the aorta wall that lead to a wall structure and function comparable to that in normotensive animals. The mechanical adaptation of the aorta wall does not rule out that other cellular or subcellular components of the vessel wall are affected more irreversibly. Furthermore, we started our drug treatment regimens in a period in which blood pressure was not or only slightly elevated in SHR. It remains to be investigated whether similar results are obtained if treatment is started in a period of more established hypertension.
In conclusion, the present study shows that early onset treatment of SHR with different antihypertensive drugs inhibits the development of hypertension, and normalizes aorta wall mechanics and media hypertrophy. The drugs achieve this effect by their pressure lowering effect and not by a direct effect on aorta diameter or vascular stiffness. 


\section{REFERENCES}

Benetos A, Levy BI, Safar M. Effects of converting enzyme inhibition on carotid artery compliance in spontaneously hypertensive rats. J. Cardiovasc. Pharmacol. 20 (Suppl B):S22-S27, 1992

Benetos A, Laurent S, Asmar RG, Lacolley P. Large artery stiffness in hypertension.

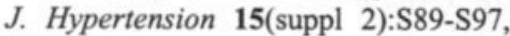
1997

Bergström G, Johansson I, Stevenson KM, Kett MM, Anderson WP. Perindopril treatment affects both preglomerular renal vascular lumen dimensions and in vivo responsiveness to vasoconstrictors in spontaneously hypertensive rats. Hypertension 31:1007-1013, 1998

Bezie Y, Lacolley P, Laurent S, Gabella G. Connection of smooth muscle cells to elastic lamellae in aorta of spontaneously hypertensive rats. Hypertension 32:166-169, 1998

Boonen HCM, Daemen MJAP, Eerdmans PE, Fazzi GE, Van Kleef E, Schiffers PMH, De Mey JGR. Mesenteric small artery changes following vasoconstrictor infusion in young rats. J. Cardiovasc. Pharmacol. 22:388-395, 1993

Campbell-Bosswell M., Robertson A.L. Effects of angiotensin II and vasopressin on human smooth muscle cells in vitro. Exp. Mol. Pathol. 35:265276, 1981

Cox $\mathrm{RH}$. Basis for the altered arterial wall mechanics in the spontaneously hypertensive rat. Hypertension 3:485495, 1981

Daemen MJAP, Lombardi DM, Bosman FT, Schwartz SM. Angiotensin II induces smooth muscle cell proliferation in the normal and injured rat arterial wall. Circ. Res. 68:450-456, 1991

Dzau VJ. Implications of local angiotensin producton in cardiovascular physiology and pharmacology. Am. J. Cardiol. 59:59A-65A, 1987

Eerdmans P, Struijker Boudier H, De Mey J. Contractile reactivity of isolated resistance arteries after 4 weeks of treatment with rilmenidine, clonidine or hydralazine in spontaneously hypertensive rats. $J$. Hypertension 9(suppl 6):S348-S349, 1993

Geisterfer AA, Peach MJ, Owens GK. Angiotensin II induces hypertrophy, but not hyperplasia, of cultured rat aortic smooth muscle cells. Circ. Res. 62:749756,1988

Griffin S.A., W.B.C. Brown, F. MacPherson, J.C. McGrath, V.G. Wilson, N. Korsgaard, M.J. Mulvany, A.F. Lever. Angiotensin II causes vascular hypertrophy in part by a non-pressor mechanism. Hypertension 17:626-635, 1991

Hayoz D, Rutschmann B, Perret F et al... Conduit artery compliance and distensibility are not necessarily reduced in hypertension. Hypertension 20:1-6, 1992

Hoeks APG, Brands PJ, Smeets FAM, Reneman RS. Assessment of the distensibility of superficial arteries. Ultrasound Med. Biol. 16:121-128, 1990

Hoeks APG. The arterial system in hypertension. Kluwer Academic Publishers. chapter 8 ed M.E. Safar and M.F.O'Rourke ppl 19-134, 1993

Kool MJF, Lustermans FA, Breed JG, Struijker Boudier HA, Hoeks AP, Reneman RS, Van Bortel L. The influence of perindopril and diuretic combination

amiloride/hydrochlorothiazide on the vessel wall properties of large arteries in hypertensive patients. J. Hypertens. 13:839-848, 1995

Lacolley P, Glaser E, Challande P, Boutouyrie P, Mignot JP, Duriez M, Levy BI, Safar ME, Laurent S. Structural changes and in situ aortic pressure-diameter relationship in long-term chemicalsympathectomized rats. Am. J. Physiol. 269:H407-H416, 1995

Laurent S, Hayoz D, Trazzi S, Boutouyrie P, Waeber B, Omboni S, Brunner $\mathrm{H}$, Mancia G, Safar M. Isobaric compliance of the radial artery is increased in patients with essential hypertension. J. Hypertens. 11:89-98, 1993

Laurent S, Girerd X, Mourad JJ, Lacolley P, Beck L, Boutouyrie P, Mignot JP, Safar ME. Elastic modulus of the radial artery 
wall material is not increased in patients with essential hypertension. Arterioscler. Thromb. 14:1223-1231, 1994

Laurent S. Arterial wall hypertrophy and stiffness in essential hypertensive patients. Hypertension 26:355-362, 1995

Levy BI, Michel JB, Salzmann JL, Poitevin P, Safar ME, Camilleri JP. Effects of chronic inhibition of converting enzyme on mechanical and structural properties of arteries in rat renovascular hypertension. Circ. Res. 63:227-239, 1988

Levy BI, Michel JB, Salzmann JL et al.... Long-term effects of angiotensinconverting enzyme inhibition on the arterial wall of adult spontaneously hypertensive rats. Am. J. Cardiol. 71:8E-16E, 1993

Lodwick D, Kaiser MA, Harris J, Cumin F, Vincent M, Samani NJ. Analysis of the role of angiotensinogen in spontaneously hypertensive rats. Hypertension 25:1245-1251, 1995

Mangoni AA, Mircoli L, Giannattasio C, Mancia G, Ferrari AU. Effect of sympathectomy on mechanical properties of common carotid and femoral arteries. Hypertension 30:10851088, 1997

Messing MWJ, Van Essen H, Struijker Boudier HAJ. Effects of alpha adrenoceptor antagonists on striated muscle microcirculation of conscious rats. Drugs 40((suppl 4):31-33, 1990

Messing MWJ, Van Essen $\mathrm{H}$, Struijker Boudier HAJ. Angiotensin II does not contribute to the in vivo tone of striated muscle arterioles in conscious SHR. Blood vessels 28:317-,. 1991

Nievelstein HNMW, Tyssen CM, Smits JFM, Struijker Boudier HAJ. Regional hemodynamic effects of the betaadrenoceptor blockers tertatolol and propranolol in conscious, spontaneously hypertensive rats. Arch. Int. Pharmacodyn. 282:118-129, 1986

O'Rourke MF. Arterial function in health and disease. Edinburgh, London, Melbourne and New York: ChurchillLivingstone pp 3-32, 53-93, 170-224, 1982
Reneman RS, Van Merode T, Hick P, Muytjens AMM, Hoeks APG. Agerelated changes in carotid artery wall properties in men. Ultrasound Med. Biol. 12:465-471, 1986

Reneman RS, Hoeks APG, Westerhof N. Non-invasive assessment of artery wall properties in humans; methods and interpretation. J. Vascular Investigation 2:53-64, 1996

Saavedra JM, Correa FMA, Seltzer A, Pinto JEB, Viglione P, Tsutsumi K. Enhanced angiotensin converting enzyme binding in arteries from spontaneously hypertensive rats. J. Hypertension. 10:1353-1359, 1992

Safar M Therapeutic trials and large arteries in hypertension. Am. Heart J. 115:702710,1988

Safar ME, Frohlich ED. The arterial system in hypertension. Hypertension 26:10-14, 1995

Smits JFM, Struijker Boudier HAJ. Systemic and regional hemodynamicsfollowing acute inhibition of angiotensin I converting enzyme in conscious SHR. Progr. Pharmacol. 5:39-49, 1984

Sosa-Melgarejo JA, Berry CL. Cell to stroma contacts in the tunica media of the hypertensive rat thoracic aorta. Arch. Med. Res. 27:123-126, 1996

Struijker Boudier HAJ, Nievelstein HN,Van Essen H, Smits JFM. Calcium antagonists: systemic and regional haemodynamic effects in conscious spontaneously hypertensive rats (SHR). J. Hypertension 2(suppl):S527-S529, 1984

Struijker Boudier HAJ, Smits JF, De Mey JGR. Pharmacology of cardiac and vascular remodeling. Annu. Rev. Pharmacol. Toxicol. 35:509-539, 1995

Van Gorp AW, Van Ingen Schenau DS, Hoeks APG, Struijker Boudier HAJ, Reneman RS, De Mey JGR. Aortic wall properties in normotensive and hypertensive rats of various ages in vivo. Hypertension 26:363-368, 1995

Van Gorp, A., Van Ingen Schenau, D, Hoeks, A, Struijker Boudier, H, De Mey, J, Reneman, R, Reduced aorta compliance precedes high blood pressure in spontaneoulsy hypertensive rats (SHR), FASEB Journal, 10 (3), 1598, 1996 
Van Gorp AW, Van Ingen Schenau DS, Willegers J, Hoeks APG, De Mey JGR, Struijker Boudier HAJ, Reneman RS. A technique to assess aortic distensibility and compliance in anesthetized and awake rats. Am. J. Physiol. 270:H780H786, 1996

Van Gorp AW, Van Ingen Schenau DS, Hoeks APG, Struijker Boudier HAJ, Reneman RS, De Mey JGR. Effects of smooth muscle tone on aortic compliance in conscious normotensive and spontaneously hypertensive rats. $\mathrm{Ph} . \mathrm{D}$. thesis Maastricht chapter 3, 1999
Van Gorp AW, Van Ingen Schenau DS, Hoeks APG, Struijker Boudier HAJ, Reneman RS, De Mey JGR. Arterial stiffening in hypertensive mREN-2 transgenic rats.. Ph.D. thesis Maastricht chapter 8, 1999

Wallenstein S, Zucker CL, Fleiss JL. Some statistical methods useful in circulation research. Circ. Res. 47:1-9, 1980

Zanchi A, Stergiopulos N, Brunner HR, Hayoz D. Differences in the mechanical properties of the rat carotid artery in vivo, in situ, and in vitro. Hypertension 32:180-185, 1998 


\section{CHAPTER}

\section{ARTERIAL STIFFENING IN HYPERTENSIVE MREN-2 TRANSGENIC RATS}

Ad W. Van Gorp

Arnold P.G. Hoeks

Jo G.R.De Mey

Robert S. Reneman

Harry A.J. Struijker Boudier 


\section{ABSTRACT}

The purpose of this study was to investigate the effect of enhanced vascular reninangiotensin activity on the elastic behavior of the aorta. Three months old transgenic (mREN-2) 27 rats (renin TGR), spontaneously hypertensive rats (SHR) as well as their respective normotensive controls were studied. Dynamic mechanical properties of the aorta were determined with a non-invasive ultrasound technique. Animals were studied at in vivo conscious operating blood pressure as well as during anesthesia-induced isobaric blood pressures. The mechanical behavior was related to structural characteristics of the aorta. In both hypertensive strains, aorta compliance and distensibility were significantly reduced. The reduction of aorta compliance and distensibility was significantly more pronounced in TGR than in SHR. In both hypertensive strains, aorta media cross sectional area was increased, with significantly stronger degree of hypertrophy in TGR. The incremental elastic modulus was significantly higher in TGR than in SHR or the normotensive strains, both at operating pressure and under isobaric conditions. The collagen density of TGR aorta was reduced in comparison to that of SHR or the normotensive strains. These results show a strong impairment of the buffering capacity of the aorta in TGR. The aorta stiffening in this model of chronic exposure to high vascular levels of Ang II is at least partly pressure independent. We propose that the reduced buffering capacity of the aorta is due to a change in intrinsic elastic properties of wall components other than collagen.

\section{INTRODUCTION}

The renin-angiotensin system is an important mediator of changes in vascular structure and function in hypertension. Angiotensin II (Ang II) has multiple actions on arterial structure and function, including an increase in smooth muscle tone, enhanced vascular smooth muscle cell growth and increased extracellular matrix deposition (Campbell-Bosswell $\mathrm{M}$ et al., 1981; Geisterfer AAT et al., 1988;Daemen MJAP et al.,1991). These actions are partly independent of the blood pressure elevating effect of Ang II and have been attributed to an autocrine/paracrine action of Ang II on the vessel wall (Griffin SA et al., 1991). Studies in which arteries were isolated from the systemic circulation confirm a potential autocrine/paracrine role of Ang II in vascular pathobiology (Stefas L et al., 1991; Levy BI et al., 1990). Invivo gene transfer of $\mathrm{ACE}$ into intact rat carotid arteries causes vascular hypertrophy independent of systemic factors or hemodynamic effects (Morishita $R$ et al.,1994).
The recent introduction of renin transgenic rats (TGR) has provided a powerful tool to study the potential role of the renin-angiotensin system in the control of vascular function (Mullins JJ et al.,1990; Paul M et al., 1994). In renin TGR, an additional mouse Ren-2 gene has been integrated into the genome, resulting in a marked increase in blood pressure (Mullins $\mathrm{JJ}$ et al.,1990). In this transgenic strain, plasma renin activity is low, but its local expression and activity in various tissues, including the vasculature, is high (Paul $\mathrm{M}$ et al., 1994;.Hilgers KF et al., 1992; Bachmann S et al., 1992; Zhao Y et al., 1993). This high expression is associated with a strong degree of smooth muscle hypertrophy at the level of mesenteric arteries (Struijker Boudier HAJ et al., 1996;.Dunn WR et al., 1997) However, the functional consequences of these vascular changes in the intact animal have not yet been studied.

In the present investigation, we determined the in-vivo dynamic mechanical properties of the thoracic aorta in renin TGR. The elastic properties of the aorta are a primary determinant of cardiac afterload (Westerhof $\mathrm{N}$ et al., 1969). These 
properties result from the relative amounts and the elastic behavior of the different constituents of the vessel wall (Dobrin PB et al., 1969; Armentano RL et al., 1991) and the actual pressure level in the aorta. We have recently developed a technique to determine the dynamic mechanical behavior of the aorta on a non-invasive basis in intact rats (Van Gorp A et al.,1996). This technique was applied in renin TGR with age-matched Sprague Dawley rats from the appropriate Hannover strain (SDH) as controls. Spontaneously hypertensive rats (SHR) and Wistar Kyoto rats (WKY) were used as additional controls. The mechanical aorta wall properties were compared at in-vivo conscious operating blood pressure and during acute anesthesia-induced isobaric blood pressure (Van Gorp AW et al.,1995). The mechanical behavior was related to structural characteristics of the thoracic aorta.

\section{MATERIAL AND METHODS}

\section{Animals}

The study was performed on 8 TGR and 8 SDH rats which were obtained from the Center for Genomic Research (Edinburgh, Scotland; Dr. J. Mullins: TGR) and from the Zentralinstitut fr VerSuchstierkunde (Hannover, Germany: SDH) at the age of 6 weeks. 8 SHR and 6 WKY rats were obtained from the animal facilities of the Maastricht University at the age of 6 weeks. The rats were maintained in separate cages and were housed under standard conditions $\left(20^{\circ} \mathrm{C}, 12 \mathrm{~h}\right.$ light/dark cycle) with free access to standard chow (Hope Farms) and tap water. The experimental procedures were performed according to institutional guide-lines and approved by the Ethical Committee for the Use of Experimental Animals of Maastricht University (The Netherlands). From the age of 6 weeks the animals were accustomed to a restrainer for hemodynamic measurements during 5 days a week for a period of 6 weeks 18 .

\section{Blood pressure measurement}

A polyethylene catheter (PE-10;ID 0.28 $\mathrm{mm}, \mathrm{OD} 0.61 \mathrm{~mm}$ ), filled with heparinized saline, was implanted in the aorta under pentobarbital sodium anesthesia (100 $\mathrm{ml} / 100 \mathrm{~g}$ body wt; $60 \mathrm{mg} / \mathrm{ml}$ ) for the recording of blood pressure. The catheter was advanced through a femoral artery to just below the bifurcation of the renal artery. The catheter was guided underneath the skin and exteriorized at the base of the skull. Aortic pressure was measured with an external pressure transducer (CP-01, Century Technology, Inglewood, CA). The delay in the pressure-measuring system was $12 \mathrm{msec}$, indicating a frequency response beyond $50 \mathrm{~Hz}$. After two days the studies on the mechanical and structural properties of the thoracic aorta were started.

\section{Ultrasound assessment of aorta diameter and wall movement}

The ultrasound device to assess diastolic aortic diameter (d) and diameter changes of the aorta during the cardiac cycle $(\Delta \mathrm{d})$ consists of a vessel wall-tracking system (WTS) combined with a conventional Bmode ( $\mathrm{B}$, brightness) ultrasound system (Pie 480, 7.5 MHz Linear array, Pie Medical, Maastricht, The Netherlands) and has been described in detail before (Van Gorp A et al.,1996). In short, the rats were shaved at the site of measurement, and the ultrasound probe was placed on the thorax slightly to the left of the sternum; ultrasonic gel was applied between probe and skin. The thoracic aorta was then visualized in B-mode $10 \mathrm{~mm}$ proximal to the diaphragm and the probe was positioned so that the $\mathrm{M}$-line ( $\mathrm{M}$, motion) was perpendicular to the vessel wall. Then the ultrasound system was switched to Mmode and ultrasound was emitted and received along the selected line of sight at 
a programmable emission trigger frequency.

The WTS is based on a data acquisition system, capable of capturing the received and amplified radio frequency signals synchronously with the emission trigger at a programmable sample frequency of up to $30 \mathrm{Mhz}$. The position and width of the range of interest are programmable (on the average 20 and 10 $\mathrm{mm}$, respectively, in the present study). Blood pressure is synchronously sampled with the emission trigger. At an emission repetition frequency of $1653 \mathrm{~Hz}$, the $1 \mathrm{Mb}$ memory will hold $2.5 \mathrm{~s}$ of data, corresponding to approximately 16 cardiac and 4 respiration cycles under the current experimental conditions. Because of the higher heart rate, in the awake rats the sampling frequency was doubled, resulting in data collection for $1.2 \mathrm{~s}$.

After completion of the data acquisition the data were transferred to a PC (486 DX2/66). The first line acquired was graphically presented on a display, allowing manual identification of the anterior and posterior wall boundaries by placing two markers, representing the sample windows for data processing. Once the walls were identified, the remaining data were transferred and processed on the fly.

\section{Protocol}

The animals were connected to the pressure transducer for blood pressure measurements under conscious freely moving conditions. Three pressure measurements in a 15 -minute period were taken and the average of these measurements was taken as the animal's reading. Then, the rats were placed in restrainers and 15 minutes later, aortic d and $\Delta \mathrm{d}$ and blood pressure were measured. In the last part of the experiments, the animals were anesthetized with ketamine/xylazine $(10: 50 \mathrm{mg} / \mathrm{ml} ; 100$ $\mathrm{ml} / 100 \mathrm{~g}$ body weight). After $30 \mathrm{~min}$ of equilibration, when blood pressure and heart rate had stabilized, 6 consecutive measurements of blood pressure and aortic $\mathrm{d}$ and $\Delta \mathrm{d}$ were made.

Calculation of compliance and distensibility

Arterial compliance is defined as the absolute increase in volume $(\Delta \mathrm{V})$ for a given increase in arterial blood pressure (pulse pressure $=\Delta \mathrm{P}$ ). Distensibility, on the other hand, is the relative increase in volume $(\Delta \mathrm{V} / \mathrm{V})$ for a given $\Delta \mathrm{P}$. Assuming that a volumetric increase is due to radial distension rather than longitudinal elongation (Reneman RS et al.,1986; Renemans RS et al.,1996) and that the vascular crosssection is perfectly circular, compliance (CC) and distensibility coefficients (DC) can be approached as follows:

$\mathrm{CC}=\Delta \mathrm{V} / \Delta \mathrm{P} \approx \Delta \mathrm{A} / \Delta \mathrm{P} \approx\left(\pi \mathrm{d}_{\text {dia }} \Delta \mathrm{d}\right) /(2 \Delta \mathrm{P})(1)$

$\mathrm{DC}=(\Delta \mathrm{V} / \mathrm{V}) / \Delta \mathrm{P} \approx\left(\Delta \mathrm{A} / \mathrm{A}_{\mathrm{dia}}\right) / \Delta \mathrm{P}$

$\approx\left(2 \Delta \mathrm{d} / \mathrm{d}_{\text {dia }}\right) / \Delta \mathrm{P}(2)$

Where $d_{\text {dia }}$ and $A_{\text {dia }}$ stand for the enddiastolic diameter and area, respectively; $\Delta \mathrm{d}$ and $\Delta \mathrm{A}$ represent the change in diameter and lumen area from end diastole to peak systole, respectively.

\section{Structural measurements}

At the end of each experiment the rats were killed and a 10-mm segment of the middle part of the thoracic aorta was excised. The extent of longitudinal retraction upon isolation was assessed by pre $\left(\mathrm{L}_{\mathrm{i}}\right)$ and post $\left(\mathrm{L}_{\mathrm{e}}\right)$ excision measurement of the segment length. The excised vessel was fixed by immersion in $4 \%$ phosphate buffered formalin before being embedded in paraffin.

Post-excision media crosssectional area $\left(\mathrm{CSA}_{\mathrm{e}}\right)$, defined as the area between the internal and external elastic lamina, was determined by semiautomated morphometry (JAVA 1.21 Jandel Scientific, Corte Madera, CA, 
USA) on $4 \mu \mathrm{m}$ cross-sections stained with Lawson's solution (a classic elastin stain), using an axioplan microscope (Zeiss) equipped with a standard CCD camera (Stemmer, Germany) (Boonen HCM et al., 1993). This value was converted to the expected in vivo $\mathrm{CSA}\left(\mathrm{CSA}_{i}\right)$, assuming that vascular mass is constant, by accounting for vascular retraction upon isolation, i.e.:

$$
\mathrm{CSA}_{\mathrm{i}}=\mathrm{CSA}_{\mathrm{e}} \cdot \mathrm{L}_{\mathrm{e}} / \mathrm{L}_{\mathrm{i}}
$$

$\mathrm{CSA}_{\mathrm{i}}$ and ddia were used to calculate media thickness (Mt) according to:

$$
\mathrm{Mt}=-\mathrm{d}_{\mathrm{dia}} / 2+\left[\left(\mathrm{d}_{\mathrm{dia}} / 2\right) 2+\mathrm{CSAi} / \pi\right]^{1 / 2}(4)
$$

Furthermore, the incremental elastic modulus $\left(\mathrm{E}_{\text {inc }}\right)$, was calculated as:

$$
\mathrm{E}_{\text {inc }}=\mathrm{d}_{\text {dia }} / \text { (Mt. DC) }
$$

\section{Collagen density}

Paraffin embedded, $4 \mu \mathrm{m}$ thick sections, were also used to determine collagen area. The sections were stained with Sirius red solution, which highlights collagen. The collagen occupied area, enclosed by the external and internal elastic lamina, was determined as described previously (Brouwers-Ceiler DL et al.,1997). The data are presented as media collagen density, i.e. the collagen volume as percentage of the total tissue volume in the section. Total media collagen density was obtained by multiplying the relative density with CSA.

\section{Statistical analysis}

The recordings of pressure, $d$ and Dd were obtained and characteristics were calculated for each individual cardiac cycle. Mean values were calculated for each recording, these values were averaged for each individual animal and eventually a group mean was obtained for each strain.
The data are presented as means \pm SD. Comparison between different strains under conscious and anesthetized conditions were performed with ANOVA followed by a Tukey test for multiple comparison (Zarr JH,1984). Differences between the conscious and anesthetized state were compared with the unpaired ttest.

\section{RESULTS}

\section{Baseline characteristics}

Table 8.1 summarizes body weights of the various strains at an age of 3 months and baseline hemodynamics in conscious freely moving conditions. SDH rats had significantly higher body weights as compared to TGR, WKY or SHR rats. There was no significant difference in body weight between TGR, SHR and WKY. Conscious unrestrained diastolic blood pressure was significantly increased in both hypertensive strains, as compared to SDH and WKY rats. Conscious unrestrained pulse pressure was significantly larger in TGR rats as compared to SDH. Pulse pressure was significantly smaller in SDH when compared to WKY. There was no significant difference in pulse pressure between WKY and SHR.

\section{Mechanical and structural properties of} the aorta in conscious restrained animals Conscious restrained diastolic blood pressure was significantly increased in both hypertensive strains, TGR and SHR, as compared to SDH and WKY rats (Fig. 8.1 , a). Conscious restrained pulse pressure was significantly larger in TGR as compared to both SDH and SHR (Fig. $8.1, \mathrm{~b})$. There was no significant difference in pulse pressure between WKY and SHR. The pulse pressure was significantly smaller in SDH rats as compared to the other strains. 

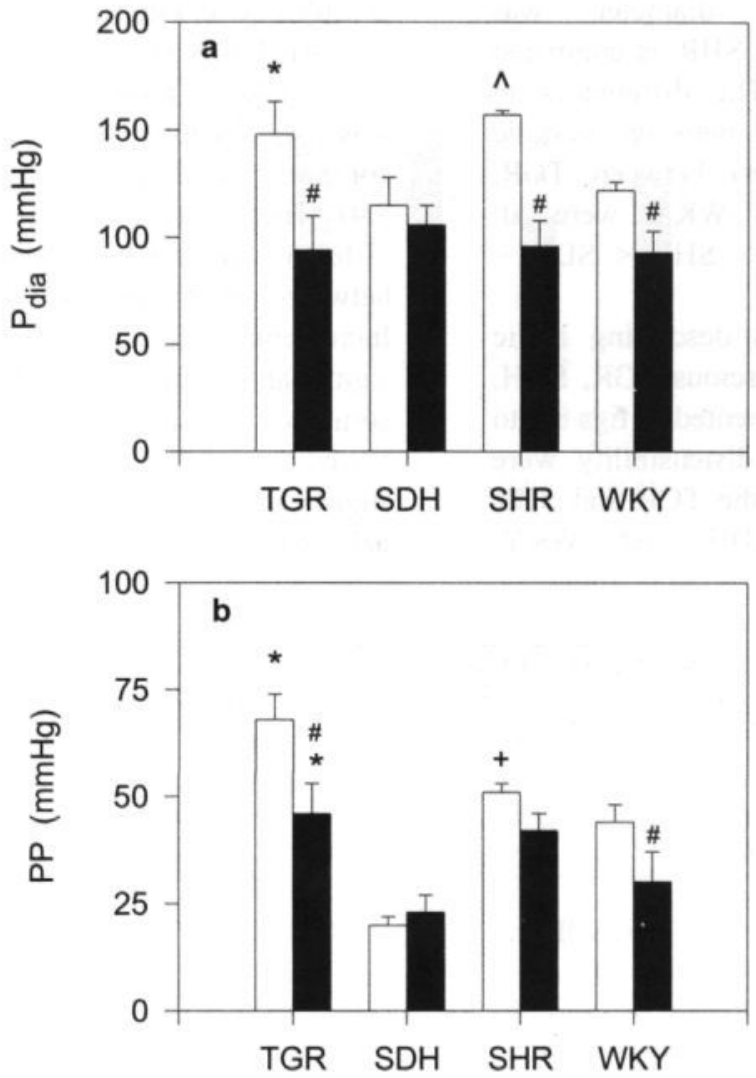

Fig. 8.1. Bar graphs showing conscious (open bars) and anesthetized (closed bars) diastolic blood pressure (a) and pulse pressure (b) in renin transgenic rats (TGR, $n=8$ ), Sprague Dawley Hannover rats $(\mathrm{SDH}, \mathrm{n}=8)$, spontaneously hypertensive rats $(\mathrm{SHR}, \mathrm{n}=8)$ and Wistar Kyoto rats $(\mathrm{WKY}, \mathrm{n}=6)$. Mean $\pm \mathrm{SD}$.

* significantly different from SDH $\mathrm{p}<0.05$.

+ significantly different from TGR, $\mathrm{p}<0.05$

^significantly different from WKY, $\mathrm{p}<0.05$.

\# significantly different between conscious and anesthetized animals, $\mathrm{p}<0.05$ 
The conscious restrained diastolic aorta diameter was not significantly different between TGR and SDH, and between SHR and WKY (Fig. 8.2, a). Conscious diastolic diameter was significantly smaller in SHR as compared to TGR and SDH. The differences in distension (difference between systolic and diastolic diameter) between TGR, SHR and SDH and WKY were all significant with $\mathrm{TGR}<\mathrm{SHR}<\mathrm{SDH}<$ WKY (fig 2, b).

The parameters describing aortic wall mechanics in conscious TGR, SDH, SHR and WKY are presented in figs 8.3 to 8.5. Compliance and distensibility were significantly lower in the TGR and SHR as compared to SDH and WKY, respectively (Fig. 8.3). TGR showed a signififcantly lower compliance and distensibility as compared to SHR (Fig. 8.3). WKY showed a significantly lower compliance and distensibility as compared to SDH (Fig. 8.3).

In-vivo media cross-sectional area was significantly larger in TGR as compared to SDH, SHR and WKY (Fig. 8.4). There was a slight, but significant difference in in-vivo cross-sectional area between SHR and WKY (Fig. 8.4). Incremental elastic modulus was significantly larger in TGR and SHR as compared to SDH and WKY (Fig. 8.5). Incremental elastic modulus was significantly larger in TGR as compared to SHR (Fig. 8.5).

\begin{tabular}{|lllll|}
\hline \multicolumn{5}{|l|}{ Table 8.1: Body weight and resting hemodynamics of the rat strains used } \\
\hline variable & TGR $(\mathrm{n}=8)$ & SDH $(\mathrm{n}=8)$ & SHR $(\mathrm{n}=8)$ & WKY $(\mathrm{n}=6)$ \\
\hline $\mathrm{n}$ & 8 & 8 & 8 & 6 \\
Body weight $(\mathrm{g})$ & $306 \pm 32$ & $447 \pm 39^{*}$ & $277 \pm 28$ & $299 \pm 27$ \\
$\mathrm{P}_{\text {dia }}(\mathrm{mmHg})$ & $151 \pm 22^{*}$ & $95 \pm 10$ & $153 \pm 14^{*}$ & $98 \pm 5$ \\
$\mathrm{PP}(\mathrm{mmHg})$ & $69 \pm 13^{*}$ & $21 \pm 3^{*}$ & $50 \pm 14$ & $40 \pm 6$ \\
\hline
\end{tabular}

Values are mean \pm SD.

* Significantly different from TGR, SHR and WKY; $<<0.05$

+ Significantly different from SDH; $<<0.05$

\# Significantly different from WKY; $<<0.05$ 

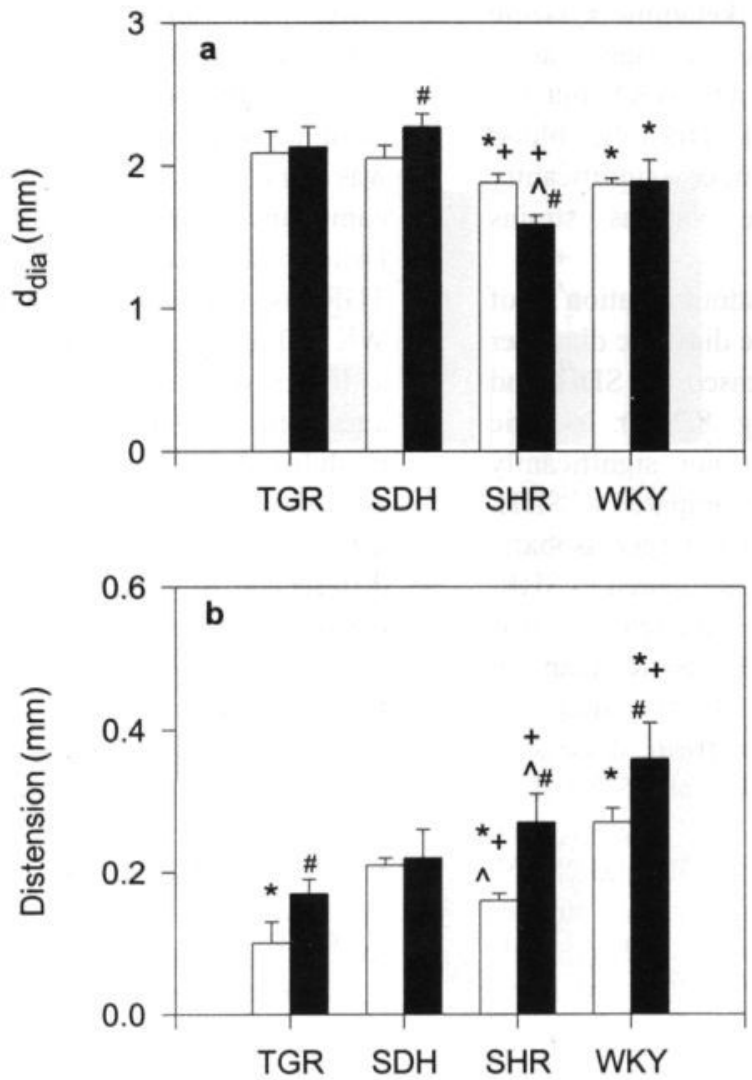

Fig. 8.2. Bar graphs showing conscious (open bars) and anesthetized (closed bars) aorta diastolic diameter (a) and distension (b) in renin transgenic rats (TGR, $n=8$ ), Sprague Dawley Hannover rats $(\mathrm{SDH}, \mathrm{n}=8)$, spontaneously hypertensive rats $(\mathrm{SHR}, \mathrm{n}=8)$ and Wistar Kyoto rats $(\mathrm{WKY}, \mathrm{n}=6)$. Mean $\pm \mathrm{SD}$.

* significantly different from $\mathrm{SDH} \mathrm{p}<0.05$.

+ significantly different from TGR, $\mathrm{p}<0.05$

^ significantly different from WKY, $\mathrm{p}<0.05$.

\# significantly different between conscious and anesthetized animals, $\mathrm{p}<0.05$ 
Mechanical properties of the aorta at comparable pressure

After the transition from conscious to anesthetized state caused by the administration of ketamine/xylazine diastolic blood pressure was significantly reduced in TGR, SHR and WKY but not in SDH (Fig. 8.1, a). Diastolic blood pressure was no longer significantly different between the various strains during anesthesia.

After the administration of ketamine/xylazine aortic diastolic diameter was significantly increased in SDH and decreased in SHR. (Fig. 8.2, a). Isobaric diastolic diameter was not significantly different in TGR when compared to SDH. TGR had a significantly larger isobaric diastolic diameter when compared to SHR. Isobaric diastolic diameter was significantly smaller in SHR than in WKY. (Fig. 8.2a). There was no significant difference in aortic distension between anesthetized TGR and SDH (Fig. 8.2, b). Distension was significantly smaller in TGR than in SHR and WKY. SDH showed a significantly smaller distension as compared to WKY. SHR showed a significantly smaller distension than WKY.
The administration of ketamine/ xylazine increased compliance and distensibility in TGR, SHR and in WKY (Fig. 8.3). Compliance was significantly lower in anesthetized TGR when compared to SDH, SHR and WKY (Fig. 8.3 , a). SHR showed a significantly lower compliance as compared to WKY. There was no significant difference in compliance between SDH and WKY. Distensibility was significantly lower in TGR as compared to SDH, SHR and WKY (Fig. 8.3, b). SDH and SHR showed a lower distensibility than WKY. The anesthetized aortic incremental elastic modulus was significantly larger in TGR as compared to SDH, SHR and WKY (Fig. 8.5). There was no significant difference in anesthetized incremental elastic modulus between SHR and WKY.

\section{Collagen levels}

The relative and absolute levels of collagen in the aortic media in the various strains studied are given in table 2. Both relative and absolute collagen density were significantly lower in TGR than in SDH. In SHR, when compared to WKY, collagen density was raised, but not to a statistically significant degree.

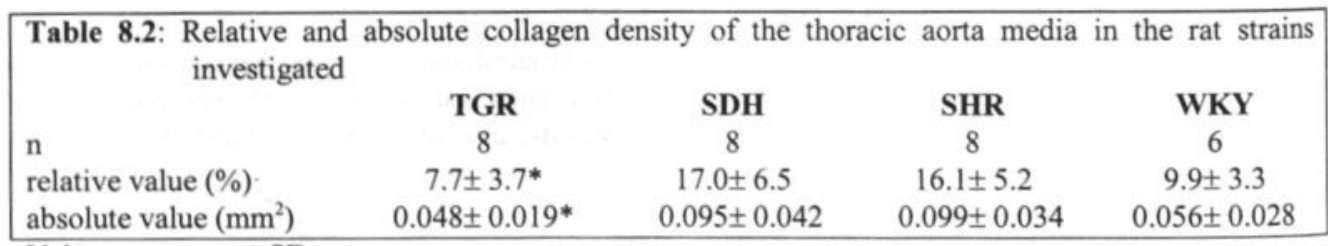

Values are mean \pm SD

* significantly different from SDH $\mathrm{p}<0.05$ 

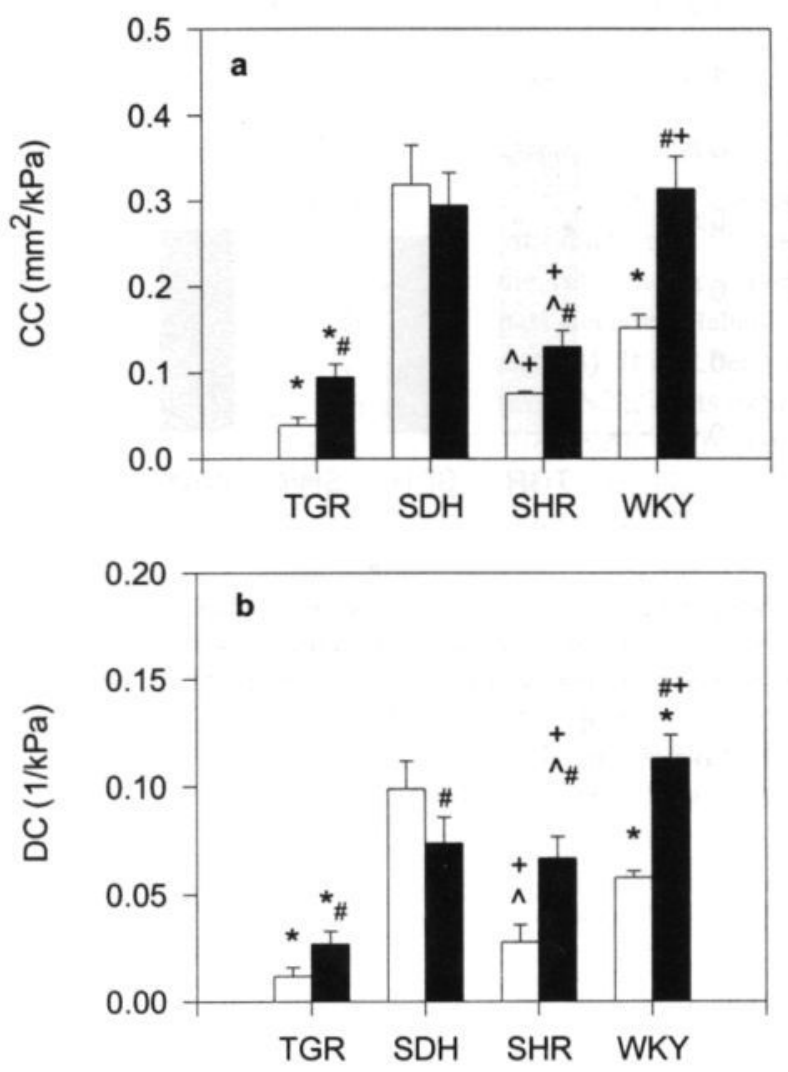

Fig. 8.3 Bar graphs showing (open bars) and anesthetized (closed bars)aorta compliance (a ) and distensibility (b) in renin transgenic rats (TGR, $n=8$ ), Sprague Dawley Hannover rats $(\mathrm{SDH}, \mathrm{n}=8)$, spontaneously hypertensive rats $(\mathrm{SHR}, \mathrm{n}=8)$ and Wistar Kyoto rats (WKY, $\mathrm{n}=6$ ). Mean \pm SD.

* significantly different from $\mathrm{SDH}, \mathrm{p}<0.05$.

+ significantly different from TGR, $\mathrm{p}<0.05$

^ significantly different from WKY, $\mathrm{p}<0.05$.

\# significantly different between conscious and anesthetized animals, $\mathrm{p}<0.05$ 


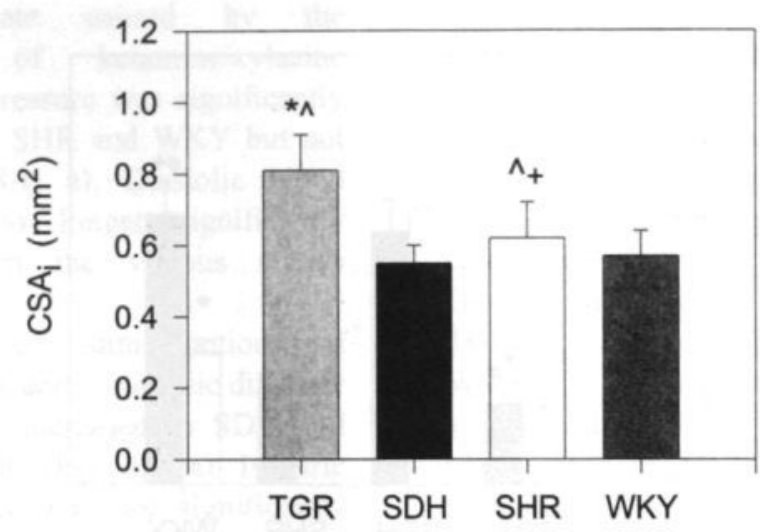

Fig. 8.4. Bar graphs showing in vivo aorta media cross-sectional area $\left(\mathrm{CSA}_{i}\right)$ in renin transgenic rats (TGR, n=8), Sprague Dawley Hannover rats $(\mathrm{SDH}, \mathrm{n}=8)$, spontaneously hypertensive rats $(\mathrm{SHR}, \mathrm{n}=8)$ and Wistar Kyoto rats $(\mathrm{WKY}, \mathrm{n}=6)$. Mean \pm SD.

* significantly different from SDH $\mathrm{p}<0.05$.

+ significantly different from TGR, $\mathrm{p}<0.05$

^ significantly different from WKY, $\mathrm{p}<0.05$.

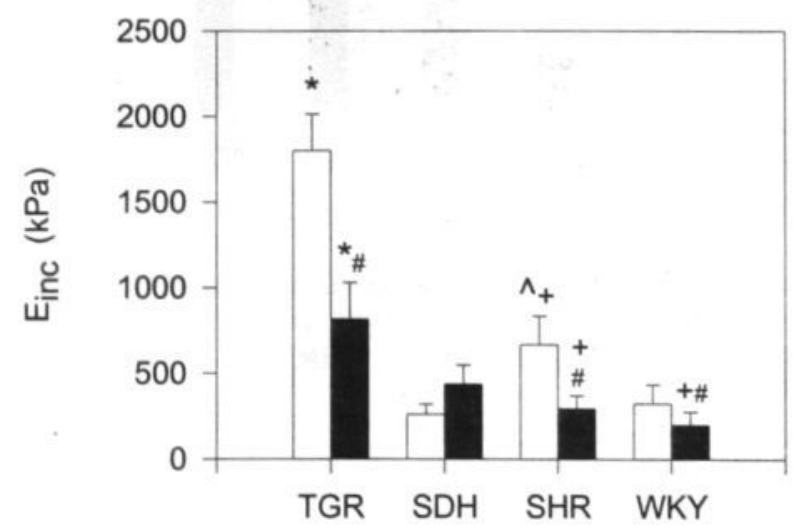

Fig. 8.5. Bar graphs showing (open bars) and anesthetized (closed bars) aorta incremental elastic modulus $\left(\mathrm{E}_{\text {inc }}\right)$ in renin transgenic rats $(\mathrm{TGR}, \mathrm{n}=8)$, Sprague Dawley Hannover rats $(\mathrm{SDH}$ , $\mathrm{n}=8$ ), spontaneously hypertensive rats $(\mathrm{SHR}, \mathrm{n}=8)$ and Wistar Kyoto rats (WKY, $\mathrm{n}=6$ ). Mean \pm SD.

* significantly different from $\mathrm{SDH} p<0.05$.

+ significantly different from TGR, $\mathrm{p}<0.05$

^ significantly different from WKY, $\mathrm{p}<0.05$.

\# significantly different between conscious and anesthetized animals, $p<0.05$ 


\section{DISCUSSION}

This study shows that enhanced expression of renin in a transgenic rat model impairs the buffering capacity of the thoracic aorta. This reduced buffering capacity occurs at least partly independent of the pressure elevation in TGR since it is observed both at in-vivo operating and isobaric blood pressures. Furthermore, aortic compliance and distensibility are reduced more in TGR than in SHR, whereas the degree of hypertension is comparable in both hypertensive strains. Our results suggest that the reduced buffering capacity is due to a change in intrinsic elastic properties of wall components. An increased smooth muscle tone or increased aortic collagen density are not responsible for the reduced buffering capacity of the aorta of TGR.

The experiments in this study were performed using a novel non-invasive ultrasound approach to assess dynamic mechanical properties of the aorta in intact animals (Van Gorp A et al.,1996). Ultrasonography has been used in the study of large artery mechanics of hypertensive humans (Laurent S et al.,1994; Hayoz D et al.,1992). A major issue in these studies has been the comparison of mechanical properties at operating versus isobaric pressure levels. In our study we performed experiments in conscious animals, allowing the assessment of mechanical properties at operating pressure levels. We had to restrain the animals for this purpose, which can still be a stressful experience, in spite of a 6weeks training period. Therefore, in the second part of our study, we performed experiments using ketamine/xylazine anesthesia to reach isobaric conditions (Van Gorp AW et al.,1995). This anesthetic cocktail inhibits vasomotor tone by an action in the central nervous system, a prejunctional effect on sympathetic neurotransmission and an endothelium- dependent mechanism (Van Zwieten PA et al.,1983; Vanhoutte PM e al.,1989). These effects reduced blood pressure in both hypertensive strains to normotensive levels. The combination of approaches used allows us to separate pressuredependent and -independent influences on aorta dynamic mechanical properties.

The consequences of the introduction of the mouse Ren-2 gene into the rat genome have been studied in the past decade (Mullins JJ et al.,1990; Paul M et al.,1994). It has been established that TGR (mREN2)27 rats exhibit hypertension soon after birth with parallel development of left ventricular and vascular wall media hypertrophy (Paul M et al.,1994; Hilgers KF et al.,1992; Bachmann S et al.,1992; Zhao Y et al., 1993; Struijker Boudier HAJ, 1996; Dunn WR et al.,1997). These rats do not have an enhanced circulating or renal renin activity. However, vascular expression of renin is high and inhibition of vascular actions of angiotensin II prevents the development of hypertension (Paul $\mathrm{M}$ et al.,1994; Hilgers KF et al.,1992; Bachmann S et al.,1992; Zhao Y et al., 1993; Struijker Boudier HAJ,1996; Dunn WR et al.,1997; Montgomery HE et al.,1998). A recent study suggests that the vascular injury, e.g. intimal fibrosis and fibroid necrosis, in the malignant phase of this form of hypertension depends on local actions of angiotensin II rather than high blood pressure as such (Montgomery HE $e t$ al.,1998). We have previously shown that TGR (mREN2)27 rats display a degree of arterial media hypertrophy in excess of that which normally occurs in hypertension to maintain normal circumferential wall stress distribution (Struijker Boudier HAJ,1996). The present observations confirm that at least part of the vascular changes occur through a pressure-independent local action of the renin-angiotensin system.

Other recent approaches to distinguish local from systemic, or indirect pressure-mediated actions of Ang II include the use of in-vivo gene transfer to 
increase local vascular expression of angiotensin converting enzyme7 and chronic perivascular infusions of Ang II in doses that are not systemically active (Scheidegger KJ et al.,1997). Altogether the results of those studies as well as our data indicate that Ang II causes arterial injury due to a local action. The nature of this injury depends on the type of vessel studied, the local concentration of Ang II, the duration to its exposure and the presence of concomitant hemodynamic changes. The most prominent feature of Ang II induced large artery injury is the increase in wall mass, in particular due to adventitial thickening (Montgomery HE et al.,1998; Scheidegger KJ et al.,1997). Our data show that the wall hypertrophy in TGR is not accompanied by a decrease in aorta diameter. Both at in-vivo operating pressures and under isobaric conditions, aorta diameter was not significantly different between TGR and SDH. This is in contrast to SHR, which have a significantly smaller aorta diastolic diameter than WKY under isobaric conditions. The lower aorta diameters of SHR and WKY when compared to TGR and SDH is most likely due to a strain difference (Wistar versus Sprague Dawley rats).

The major purpose of our study was to investigate the functional consequences of enhanced vascular reninangiotensin II activity. Since the aorta's major function is its buffering capacity, we focussed on distension-related properties. Our data show a strong decrease of aorta compliance and distensibility of TGR when compared to normotensive rats both under in vivo operating and isobaric pressures. The incremental modulus which characterizes material properties of the vessel wall (Renemans RS et al,1996; Mulvany MJ.et al.,1992) - was higher in TGR than in either of the normotensive strains. It was also considerably higher in TGR than in SHR, suggesting that an important degree of the aorta stiffening in this transgenic model results from a reduction of the elastic properties of the wall.

Previous work on local effects of Ang II on large artery mechanics concentrated on static parameters obtained by studying pressure-diameter relationships in arterial segments (Stefas L et al,1991; Levy BI et al.,1990). Although such studies cover a pressure range from 0 $200 \mathrm{mmHg}$, they are particularly suited to describe compliance and distensibility in the lower pressure range. This is due to the nature of the static pressure-diameter curve, which is steepest in the lower pressure range. The studies by Levy and co-workers (Stefas L et al,1991; Levy BI et al.,1990) have established a static compliance reducing action of Ang II. Levy and co-workers have suggested the involvement of both endotheliumdependent influences of Ang II on vascular smooth muscle tone and effects of Ang II on collagen deposition (Levy BI er al., 1988; Levy BI et al.,1990; Stefas L et al,1991). Our data indicate that other factors play a more decisive role in the reduction of dynamic compliance at the operating pressure level. In particular, the strong degree of aorta wall hypertrophy may play a crucial role. In a previous study we showed that TGR have a degree of wall hypertrophy in the mesenteric artery that is disproportionate to the degree necessary to maintain normal circumferential wall stress distribution (Struijker Boudier HAJ et al.,1996). The present study extends this observation to the level of the aorta, although we have not made actual measurements of wall stress. Our data show a degree of increase in aortic media cross-sectional area in TGR which is in excess of that in SHR, although both strains are exposed to a comparable degree of arterial pressure increase. A recent series of studies in both hypertensive humans and animal models of hypertension has suggested that adaptive responses of the aorta and more peripheral arteries are directed to maintain 
compliance and stress-strain relationships of the vessel wall (Laurent S el al., 1994; Hayoz D el al.,1992; Sumitani M et al., 1997; Safar ME et al.,1996) TGR, with their enhanced vascular Ang II activity and excessive wall hypertrophy are an exception to this adaptive behavior.

In addition to increased wall mass other factors related to the material properties may have contributed to aortic stiffening in TGR. In contrast to the observations by Levy and co-workers (Levy BI et al.,1988) in renal hypertensive rats we did not observe a rise in vascular collagen levels in TGR. This does not exclude that other matrix components, not measured in this study, play an essential role in the compliance reduction. In fact, a recent study from our group showed that two weeks infusion of Ang II into normal rats did not affect isobaric mechanical behavior of the thoracic aorta, despite significant media hypertrophy (BrouwersCeiler DL et al. 1997). These data imply that an increased wall mass as such may not be sufficient to alter mechanical behavior. TGR are exposed to a longer period of local high concentrations of Ang II with subsequent additional injury to the vessel wall.
In conclusion, a decisive factor in the vascular effects caused by Ang II seems the duration of its local exposure. We can now distinguish at least three "waves" of action of this local mediator. The first is the classical acute vasoconstrictor action, either directly through Ang II receptors in the vessel wall or more indirectly through the enhanced action of the sympathetic nervous system. The second wave is associated with an exposure in the order of days to weeks. It is characterized by enhanced DNA and protein synthesis in the vessel wall, leading to a growth response of vascular smooth muscle cells and subsequent vessel wall hypertrophy and neovascularization. Finally, the third wave occurs during chronic (weeks to months) exposure to Ang II and is associated with severe vascular injury and large artery stiffening. In humans this phase is often observed in malignant hypertension, usually associated with decreased renal function and raised levels of renin and Ang II. TGR (mREN2) 27 rats provide a useful model to study the vascular injury caused by long-term exposure to high local levels of Ang II. Our data show that this condition leads to aortic stiffening, which is partly independent of the rise in blood pressure. 


\section{REFERENCES}

Armentano RL, Levenson J, Barra JG, Fischer EIC, Breitbart GJ, Pichel RH, Simon A. Assessment of elastin and collagen contribution to aortic elasticity in conscious dogs. Am J Physiol 260:H1870H1877, 1991

Bachmann S, Peters J, Engler E, Ganten D, Mullins J. Transgenic rats carrying the mouse renin gene-morphological characterization of a low-renin hypertension model. Kidney Int 41:24-36, 1992

Boonen HCM, Daemen MJAP, Eerdmans PHA, Fazzi GE, Van Kleef EM, Schiffers PMH, De Mey JGR. Mesenteric small artery changes after vasoconstrictor infusion in young rats. $J$ Cardiovasc Pharmacol 22:388-395, 1993

Brouwers-Ceiler DL, Nelissen-Vrancken HJMG, Smits JFM, De Mey JGR. The influence of angiotensin II-induced increase in aortic wall mass on compliance in rats in vivo. Cardiovasc Res 33:478-484, 1997

Campbell-Bosswell M, Robertson AL. Effects of angiotensin II and vasopressin on human smooth muscle cells in vitro. Exp Mol Pathol 35:265-276, 1981

Daemen MJAP, Lombardi DM, Bosman FT, Schwartz SM. Angiotensin II induces smooth muscle cell proliferation in the normal and injured rat arterial wall. Circ Res 68:450-456, 1991

Dobrin PB, Rovick AA. Influence of vascular smooth muscle on contractile mechanics and elasticity of arteries. Am J Physiol 217:1644-1651, 1969

Dunn WR, Gardiner SM. Differential alteration in vascular structure of resistance arteries isolated from the cerebral and mesenteric vascular beds of transgenic [(mRen-2)27], hypertensive rats. Hypertension 29:1140-1147, 1997

Geisterfer AAT, Peach MJ, Owens GK. Angiotensin II induces hypertrophy, but not hyperplasia of cultured rat aortic smooth muscle cells. Circ Res 62:749756,1988

Griffin SA, Brown WCB, MacPherson F, McGrath JC, Wilson VG, Korsgaard N,
Mulvany MJ, MJ, Lever AF. Angiotensin II causes vascular hypertrophy in part by a non-pressor mechanism. Hypertension 17:626-635, 1991

Hilgers KF, Peters J, Veelken R, Sommer M, Rupprecht G, Ganten D, Luft FC, Mann JFE. Increased vascular angiotensin formation in female rats harboring the mouse Ren-2 gene. Hypertension 19:687. 691, 1992

Hayoz D, Rutschmann B, Perret F, Niederberger M, Tardy Y, Mooser V, Nussberger J, Waeber B, Brunner HR. Conduit artery compliance and distensibility are not necessarily reduced in hypertension. Hypertension 20:1-6, 1992

Laurent S, Girerd X, Mourad J-J, Lacolley P, Beck L, Boutouyrie P, Mignot J-P, Safar M. Elastic modulus of the radial artery wall material is not increased in patients with essential hypertension. Arterioscler thromb 14:1223-1231, 1994

Levy BI, Michel JB, Salzman JL Azizi M, Poitevin P, Safar M, Camilleri JP. Effects of chronic inhibition of converting enzyme on mechanical and structural properties of arteries in rat renovascular hypertension. Circ Res 63:227-239, 1988

Levy BI, Benessiano J, Poitevin P, Safar ME. Endothelium-dependent mechanical proper-ties of the carotid artery in WKY and SHR: Role of ACE inhibition. Circ Res 66:321-328, 1990

Montgomery HE, Kiernan LA, Whitworth CE, Fleming S, Unger T, Gohlke P, Mullins $\mathrm{JJ}, \mathrm{McEwan}$ JR. Inhibition of tissue angiotensin converting enzyme activity prevents malignant hypertension in TGR(mREN2)27. J Hypert 16:635-643, 1998

Morishita, R, Gibbons GH, Ellison KE, Lee W, Zhang L, Yu H, Kaneda Y, Ogihara T, Dzau VJ. Evidence for direct local effect of angiotensin in vascular hypertrophy. $J$ Clin Invest 94:978-984, 1994

Mullins JJ, Peters J, Ganten D. Fulminant hypertension in transgenic rats harbouring the mouse Ren-2 gene. Nature 244:541544,1990

Mulvany MJ. A reduced elastic modulus of vascular wall components in hypertension? Hypertension 20:7-9, 1992 
Paul M, Wagner J. Transgenic rats: New experimental models for the study of candidate genes in hypertension research. Annu Rev Physiol 56:811-829, 1994

Reneman RS, Van Merode T, Hick P, Muytjens AMM, Hoeks APG. Agerelated changes in carotid artery wall properties in men. Ultrasound Med Biol 12:465-471, 1986

Reneman RS, Hoeks APG, Westerhof N. Noninvasive assessment of artery wall properties in humans - methods and interpretation. $J$ Vasc Invest 2:53-64, 1996

Safar ME, Girerd X, Laurent S. Structural changes of large conduit arteries in hypertension. J Hypertens 14:545-555, 1996

Scheidegger KJ, Wood JM. Local application of angiotensin II to the rat carotid artery induces adventitial thickening. $J$ Vasc Res 34:436-446, 1997

Stefas L, Levy BI. Effects of saralasin on arterial compliance in normotensive and hypertensive rats. Hypertension $\mathbf{1 8}$ [suppl II]:II-30-II-36, 1991

Struijker Boudier HAJ, van Essen H, Fazzi G, De Mey JGR, Qui HY, Levy BI. Disproportional arterial hypertrophy in hypertensive mRen-2 transgenic rats. Hypertension 28:779-784, 1996

Sumitani M, Cabral AMS, Michelini LC, Krieger EM. In vivo adaptive responses of the aorta to hypertension and aging. Am J Physiol 273:H96-H103, 1997
Van Gorp AW, Van Ingen Schenau DS, Hoeks APG, Struijker Boudier HAJ, Reneman RS, De Mey JGR. Aortic wall properties in normotensive and hypertensive rats of various ages in vivo. Hypertension 26:363-368, 1995

Van Gorp A, Van Ingen Schenau D, Willigers J, Hoeks APG, De Mey JGR, Struijker Boudier HAJ, Reneman RS. A technique to assess aortic distensibility and compliance in anesthetized and awake rats. Am J Physiol 270:H780-H786, 1996

Vanhoutte PM, Miller VM. Alpha-2 adrenoceptors and endothelium-derived relaxing factor. Am J Med 87 (suppl):1-5, 1989

Van Zwieten PA, Thoolen MJMC, Timmermans PBMWM. The pharmacology of centrally acting antihypertensive drugs. Brit $J$ Clin Pharmacol 15(suppl):455-462, 1983

Westerhof N, Bosman F, de Vries CJ, Noordergraaf A. Analog studies of the human systemic arterial tree. $J$ Biochem 2:121-143, 1969

Zarr JH. Biostatistical analysis. Englewood Cliffs, New York, Prentice Hall Inc, 1984.

Zhao Y, Bader M, Kreutz R, Fernadez-Alfonso M, Zimmermann F, Ganten U, Metzger R, Ganten D, Mullins JJ, Peters J. Ontogenetic regulation of mouse Ren-2d renin gene in transgenic hypertensive rats, TGR(mREN2)27. Am $J$ Physiol 265:E699-E707, 1993 


\section{Chapter 9}

GeneRAL DISCUSSION 
In concert with the peripheral vascular resistance, the buffering capacity of the aorta determines diastolic and systolic blood pressure and, therefore, in large part the afterload on the heart. A reduction in buffering capacity elevates systolic blood pressure that induces left ventricular hypertrophy and may result in heart failure and arrhythmias. In hypertension and with ageing, hypertrophy of the heart has been observed (Lakatta EG.,1987), and hypertrophy may be the result of a reduction in buffering capacity of the aorta (Safar ME et al.,1987), in which most of the systemic compliance resides (Westerhof $\mathrm{N}$ et al.,1969).

The buffering capacity of the thoracic aorta is defined by the diastolic diameter and the elastic properties of the aortic wall. The diameter is determined by the structural properties, the activity of the smooth muscle cells and the operating blood pressure. Factors that are believed to influence the elastic properties are the arterial wall components, wall thickness, and the operating blood pressure. Controversy exists on the exact way in which pulsatile elastic behavior of the arterial wall is determined. In previous studies opposite conclusions were drawn regarding the effects of vascular tone on the elastic properties of large arteries. The relationship between collagen and elastin and elastic properties of large arteries has been approached in several descriptive studies, but the exact role of these scleroproteins in arterial elastic behavior of arteries is not clear. The relative and absolute amounts of collagen and elastin and their isoforms as well as the degree of cross-linking can be important determinants of the elastic characteristics of blood vessels. Conflicting results were obtained concerning the influence of an increased wall thickness on buffering capacity and elastic properties. It has been proposed that in the human carotid artery an increase in wall thickness increases incremental elastic modulus with ageing (Riley WA et al.,1992) and decreases distensibility of the carotid artery in hypertensive patients (Roman MJ et al.,1992). In another study on the carotid artery in SHR, an increase in media thickness was not accompanied by alterations in buffering capacity and incremental elastic modulus (Hayoz D et al.,1992). In a study of Brouwers et al. (Brouwers-Ceiler DL et al.,1997), a two weeks infusion of angiotensin II induced an increase in the media mass of the thoracic aorta, but did not affect its buffering capacity and elastic properties.

The structural organization of large arteries displays remarkable alterations with ageing (Learoyd BM et al.,1966; Bader H.,1967; Wolinsky H.,1972; Berry CL et al.,1975; Kohn RR.,1977; Pagani M et al.,1979; Reneman RS et al.,1985; Sumitani M et al.,1986; Safar M.1990; Forieri C et al.,1992; Benetos A et al.,1993; Hansen F et al.,1995) and in hypertension (Cox RH.,1979a; Levy BI et al.,1988a; Levy BI et al.,1990; Mulvany JMJ. et al.,1990), because of continuous rearrangements of cells and extracellular matrix components. It remains to be established, however, whether these alterations are related to the deterioration of the buffering capacity due to changes in elastic properties observed in certain large arteries with ageing and in hypertension. In addition, it is yet unclear whether structural alterations observed in hypertension are a direct consequence of elevated blood pressure or result from the (neurohormonal) mechanisms that are responsible for the development of the chronic state of high blood pressure. It has been proposed that hypertension accelerates the ageing of the arterial mechanical properties. The accelerating role of hypertension, however, can be questioned because conflicting results have been reported.

Buffering capacity and elastic properties of arteries can be improved by the administration of drugs by a blood 
pressure lowering effect and/or by a direct effect on the vessel wall. It is of interest to note that not all antihypertensive compounds have the same effect on buffering capacity, elastic properties and structure of arteries, despite a comparable blood pressure lowering effect (Achimastos A et al.,1987; Bouthier JA et al.,1986; Maarek BL et al.,1986; Laurent S et al.,1990; Van Bortel LM et al.,1995). Investigating the effects of antihypertensive agents on the buffering and elastic properties of large arteries is not only of interest from a therapeutic point of view, but may give insight into the regulatory mechanisms responsible for the modulation and adaptation of the buffering capacity, and the role played by the different wall components.

Spontaneously hypertensive rats (SHR) are characterized by hemodynamic properties that resemble those encountered in human essential hypertension (Trippodo NC et al.,1981). Therefore, SHR are considered a valid model to investigate the effect of hypertension on mechanical and structural properties of the thoracic aorta. The SHR were developed by Okamoto and co-workers (Okamoto K et al.,.1963) by selection of WKY with increased blood pressure and, therefore, normotensive WKY should serve as controls for the SHR. Several early studies imply that the activities of the sympathetic nervous and renin-angiotensin system are increased and that hypertrophy of the vascular system is present before an elevation in blood pressure can be detected (Judy WV et al.,1976; Mulvany MJ et al.,1980; Simpson P et al..,1982; Bevan D,1984; Head RJ et al.1986; Smeda JS et al.,1988; Kong JQ et al.,1991; Saavedra JM et al.,1992; Rizzoni D et al.,1994; Daemen MJAP et al.,1995), but in other studies the opposite was found (Daemen MJAP et al.,1995). The sympathetic nervous and renin-angiotensin system can induce aortic wall hypertrophy and influence structure and mechanical properties of the aortic wall (Bevan RD,1975; Campbell-Bosswell M et al..,1981; Simpson P et al..,1982; Bevan D,1984;
Bevan RD et al.,1985; Geisterfer A.A et al.,1988; Daemen M.J.A.P et al.,1991; Griffin S.A et al.,1991; Todd ME et al.,1991; Schiffers PMH et al.,1993; Daemen MJAP et al.,1995; Boonen $\mathrm{H}$ et al.,1993; Lacolley P et al.,1995; Brouwers-Ceiler $e t$ al.,1997). Young, prehypertensive SHR allow to investigate the putative role of the sympathetic nervous and renin-angiotensin system and the dependency on blood pressure elevation of structure and mechanical properties of the aortic wall. Additionally, the enhanced expression of renin in transgenic rats (TGR) (Mullins JJ et al.,1990; Paul M et al.,1994) has provided a powerful tool to study the potential role of the renin-angiotensin system in the control of vascular function and serves as a good model to investigate the effect of the renin angiotensin system on the buffering capacity of the thoracic aorta. In renin TGR, an additional mouse Ren- 2 gene has been integrated into the genome, resulting in a marked increase in blood pressure (Mullins JJ et al.,1990). In this transgenic strain, plasma renin activity is low, but its local expression and activity in various tissues, including the vasculature, is high (Bachmann S et al.,1992; Hilgers KF et al.,1992; Zhao Y et al.,1993; Paul M et al.,1994).

In view of the above, the aims of the present study were as follows:

Aim 1: to investigate effects of smooth muscle tone on the mechanical properties of the thoracic aorta in conscious normotensive and hypertensive rats. Smooth muscle activity was altered by modulation of $\alpha_{1}$-adrenergic and angiotensin II receptor activity.

Aim 2: to study the relationship between aortic media structure and mechanical properties in hypertension and ageing. The structural part of the study focused on media thickness and cross-sectional area, and on collagen and elastin content and density. The functional part focused on compliance and distensibility of the 
thoracic aorta, and its incremental elastic or Young's modulus.

Aim 3: to investigate the aggravating effect of hypertension, if any, on the changes in mechanical properties observed with ageing.

Aim 4: to study the effects of long term antihypertensive therapy on the aortic mechanical properties in hypertensive rats during the development of high blood pressure. This approach allows the investigation of the influence of aortic blood pressure and the activity of neurohormonal systems on mechanical and structural properties.

$\operatorname{Aim}$ 5: to examine the influence of the enhanced expression of renin on the structural and mechanical properties of the thoracic aorta.

The wall material of arteries shows viscoelastic behavior and, therefore, exhibits phenomena as hysteresis, stress relaxation and creep (Westerhof $\mathrm{N}$ et al.,1970; Nichols WW et al.,1990). This time dependence and the oscillating behavior of the cardiovascular system make it necessary to measure arterial wall mechanics under dynamic conditions. In order to preserve the arterial wall integrity, which is important when determining mechanical properties of conduit arteries (Zanchi A et al.,1998), a non-invasive method is preferred. Therefore, a technique to assess dynamic aortic distensibility and compliance in intact anesthetized and awake rats was developed. The findings in chapter 2 show that basic parameters, like aortic diameter, the change in aortic diameter during the cardiac cycle, and aortic pulse pressure, required to calculate aortic distensibility and compliance, can be determined reliably in both anesthetized and awake rats by means of an ultrasonic vessel wall-tracking system attached to a conventional B-mode imager combined with an implanted pressure catheter.

Buffering capacity is partially determined by the elastic properties of the arterial wall. Elastic properties describe the intrinsic characteristics of materials that determine the relationship between imposed load or stress (a force acting across a given plane in a body) and the resulting displacement or strain (ratio of deformation to the initial form). In the case of blood vessels in vivo, the imposed loads consist primarily of transmural pressure. The relationship between stress and strain is called the elastic or Young's modulus and describes the intrinsic properties of the material (Reneman R.S et al.,1996). In the general case of a material composed of a number of components with different mechanical properties like arteries, the mechanics of such a composite material depends on the mechanical properties of the individual components in a complex way, i.e., their relative content and the manner in which the components are coupled (Cox R.H.,1989). This results in a nonlinear stress-strain relationship and an elastic modulus that depends on the level of stress or strain. Therefore, Bergel (Bergel $\mathrm{DL}, 1961)$ introduced the incremental elastic modulus, defined as the local slope of the stress-strain relation.

The nonlinear elastic behavior of the arterial wall makes it desirable to determine incremental elastic modulus under a condition of comparable stress or blood pressure. Excluding one parameter that determines the nonlinear incremental elastic modulus provides the opportunity to get an impression on the intrinsic elastic properties that may result from structural alterations. In this thesis, this condition was achieved by the administration of ketamine/xylazine. 
THE EFFECT OF AGEING ON

\section{BUFFERING CAPACITY OF THE} THORACIC AORTA

During the first 6 months of life, compliance of the thoracic aorta is not altered in both normotensive and hypertensive rats (Fig. 9.1a and chapter 4); distensibility is reduced and incremental elastic modulus increased in both WKY and SHR (Fig. 9.1b, 9.2 and chapter 4). Surprisingly, compliance increases between 6 and 9 months of age in both normotensive and hypertensive rats concomitantly with an increase in distensibility and a reduction of the incremental elastic modulus (Fig. 9.1b, 9.2 and chapter 4-6). In the normotensive rats, compliance is reduced between 9 and 15 months of age, but remains higher than the compliance found in the young normotensive animals (1.5 through 6 months of age) (Fig. 9.1 a and chapter 4-6).
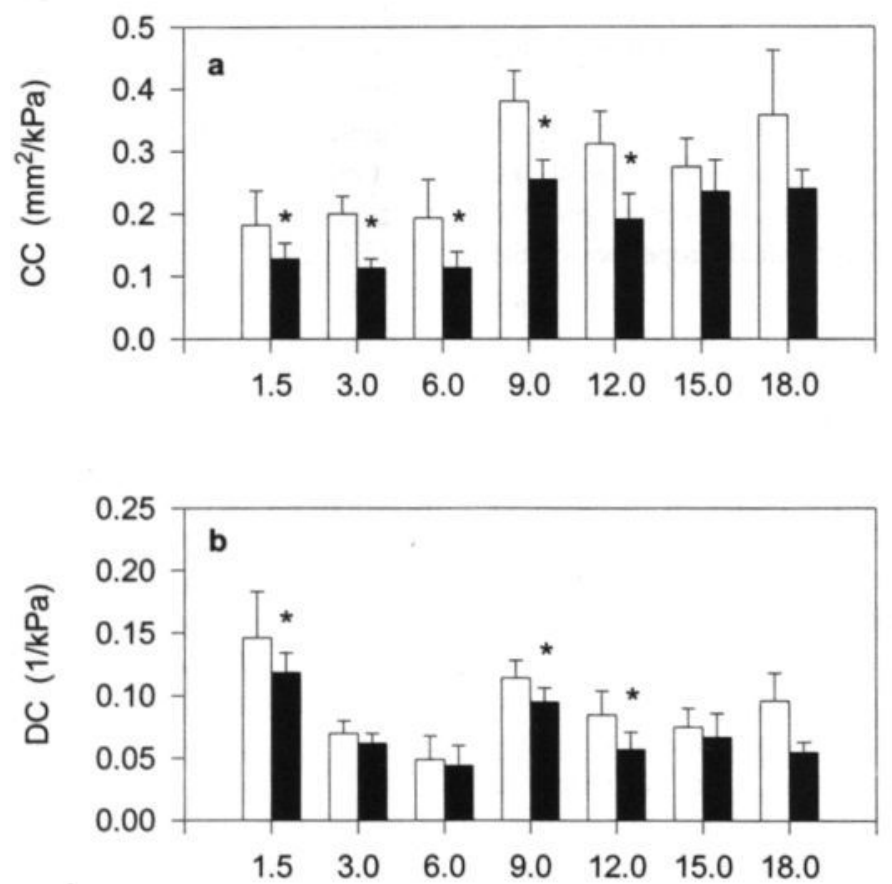

Age in months

Fig. 9.1. Compliance coefficient (a) $\left(\mathrm{mm}^{2} / \mathrm{kPa}\right)$ and distensibility coefficient (b) $(1 / \mathrm{kPa})$ during anesthesia with ketamine/xylazine in Wistar Kyoto rats (WKY; open bars) and spontaneously hypertensive rats (SHR; closed bars) as a function of age. Mean \pm SD $(\mathrm{n}=12)$.

* significantly different from WKY of the same age.

At 18 months of age, compliance increases as compared to 15 months of age (Fig. 9.1a and chapter 6). Compliance does not change in SHR with advancing age (9 through 15 months of age) (Fig. 9.1a and chapter 6), despite a decrease in 
distensibility of the thoracic aorta (Fig. $9.1 \mathrm{~b}$ and chapter 6 ). Compliance is higher in the aged SHR than in the young hypertensive animals (1.5 through 6 months of age) (Fig. 9a and chapter 6). Intrinsic elastic properties do not change with advancing age in both normotensive and hypertensive rats (Fig. 9.2 and chapter 6). Ageing, therefore, does not reduce the buffering capacity and elastic properties in normotensive and hypertensive rats. It may be concluded that hypertension does not accelerate or aggravate an ageing related reduction in thoracic aortic wall elasticity and buffering capacity.

The finding that ageing does not reduce thoracic aortic wall elasticity and buffering capacity and that hypertension in combination with ageing does not accelerate or aggravate an ageing related reduction in thoracic aortic wall elasticity and buffering capacity is in agreement with other studies in ageing SHR (Waeber B et al.,1992) and renal hypertensive rats (Sumitani M et al.,1997; Zanchi A et al.,1997) and their control rats. In a recent study of renal hypertensive rats, however, advancing age resulted in a decrease in distensibility concomitantly with hypertrophy of the carotid artery (Zanchi A et al.,1997). A progressive increase in blood pressure was noted and could explain the differences found as compared with the results in the present study in which blood pressure is elevated in SHR as compared to WKY but does not change further with increasing age. The severity of the blood pressure elevation and the rate with which it develops may be important in the induction of structural alteration in the aortic wall (Wolinsky H.,1972; Fisher GM.,1976)

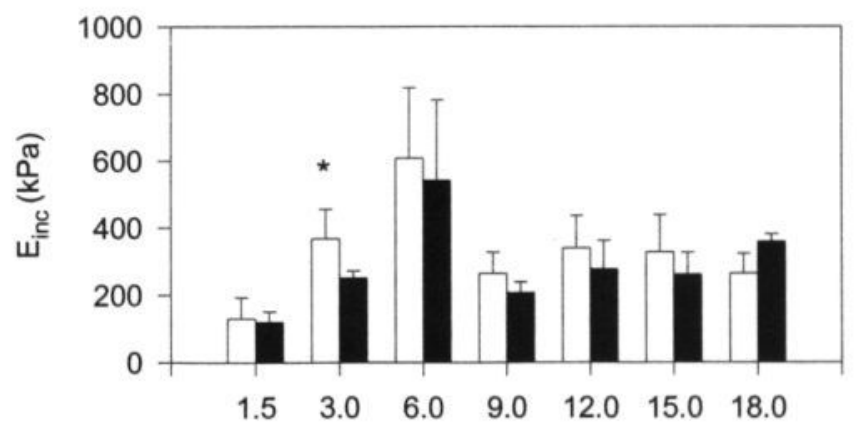

Age in months

Fig. 9.2. Incremental elastic modulus ( $\mathrm{kPa}$ ) in Wistar Kyoto rats (WKY; open bars) and spontaneously hypertensive rats (SHR; closed bars) as a function of age. Mean \pm $\mathrm{SD}(\mathrm{n}=12)$.

* significantly different from WKY of the same age.

\section{SMOOTH MUSCLE ACTIVITY}

The findings in this part of the study indicate that acute interference with smooth muscle activity in the thoracic aorta does not influence the buffering capacity and elastic behavior of the thoracic aorta in conscious normotensive and hypertensive rats (Chapter 3). Our findings are in agreement with the study of Barra et al. (Barra et al.,1993), in which it 
was concluded that under normal physiological conditions smooth muscle cells of the thoracic aorta of conscious dog develop a small degree of activity, which does not affect the dynamic incremental elastic modulus. Bauer et al. (Bauer et al.,1982) reported that, in contrast to the static incremental elastic modulus, the dynamic elastic modulus of various arterial segments was virtually uninfluenced under conditions of activation and relaxation. Bank et al. (Bank AJ et al.,1995; Bank AJ et al.,1998) on the other hand determined the effects of nitroglycerine and norepinephrine on the mechanical properties of the brachial artery in humans without the confounding effects of blood pressure on the mechanical properties. Nitroglycerine decreased and norepinephrine increased incremental elastic modulus under isometric conditions. This discrepancy may be explained by the different location and properties of the artery under investigation, i.e. elastic versus muscular arteries.

\section{THORACIC AORTA STRUCTURE}

\section{Media mass}

A clear relationship between the mechanical properties of large conduit arteries and the enlargement of media mass has not been established yet. With advancing age ( 9 through 15 months of age) media mass increased but compliance was not modified in SHR (Fig. 9.3 and chapter 6). In adult and aged SHR media mass is enlarged as compared to age matched WKY (Fig. 9.3 and chapter 6). In 15 month old SHR, however, an increase in media mass is not accompanied by a difference in compliance as compared to WKY (Fig. 9.3 and chapter 6). 9 and 18 months old WKY show comparable compliances but media mass is enlarged in 18 month old normotensive rats (Fig. 9.1a, 9.3 and chapter 6 ). These findings exclude the possibility that the enlargement in media mass reduces the buffering capacity of the thoracic aorta.

The result on media mass and buffering capacity described in this thesis are in agreement with studies on the carotid artery of SHR (Hayoz D et al.,1992; Delacrétaz E et al ,1994) and the thoracic aorta of conscious renal hypertensive rats (Sumitani W et al.,1997). In these studies, distensibility was not reduced concomitantly with the increase in media mass as compared to their normotensive controls. In a study by Brouwers et al. (Brouwers D et al.,1997), a two weeks infusion of angiotensin II resulted in an increase in media cross-sectional area and media thickness but did not have an effect on collagen and elastin density and dynamic mechanical properties of the thoracic aorta monitored at the original normotensive blood pressure.

The mechanism responsible for the increase in media thickness in SHR is as yet unknown. The increase in media mass could be a response to the elevated blood pressure. In prehypertensive SHR, however, a larger media mass is accompanied by a lower distensibility and compliance of the thoracic aorta at comparable blood pressure as compared to WKY and occurs without a difference in conscious diastolic and systolic blood pressure (chapter 4). At 3 and 6 months of age, blood pressure is increased in SHR without an enlargement in media crosssectional area (chapter 5). Advancing age (chapter 6) is accompanied by a progressive increase in media mass in both normotensive and hypertensive rats, despite the fact that blood pressure is not increased in normotensive rats and does not further increase in the hypertensive rats. The increase in media mass, however, is more pronounced in SHR than in WKY. From the results described in chapter 8 , it can be concluded that blood pressure elevation is not the sole determinant of 
media hypertrophy, because SHR and TGR have comparable blood pressures but media mass is significantly larger in the renin transgenic rats.
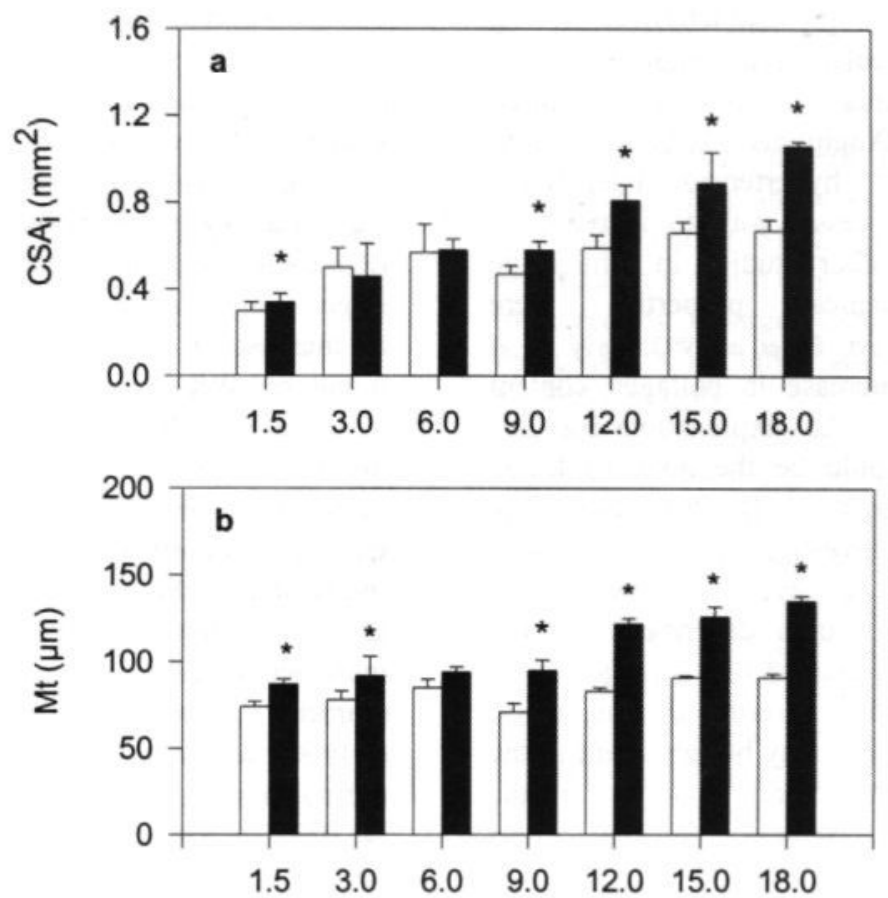

Age in months

Fig. 9.3. Media cross-sectional area $\left(\mathrm{mm}^{2}\right)(\mathrm{a})$ and media thickness $(\mu \mathrm{m})(\mathrm{b})$ in Wistar Kyoto rats (WKY; open bars) and spontaneously hypertensive rats (SHR; closed bars) as a function of age. Mean $\pm \operatorname{SD}(n=12)$.

${ }^{*}$ significantly different from WKY of the same age.

\section{Collagen and elastin}

Collagen density, measured with a sirius red staining method (James J $e t$ al.,1990) does not show differences with advancing age in the thoracic aorta of both normotensive and hypertensive rats and between WKY and SHR. The amount of noncross-linked and cross-linked collagen, and the amount of elastin, determined biochemically by measuring the hydroxyproline content, do not change with advancing age in both normotensive and hypertensive rats and do not differ between WKY and SHR. These findings are in accordance with the absence of alterations in incremental elastic modulus with advancing age ( 9 through 15 months of age) in both normotensive and hypertensive rats and between WKY and SHR.

In a recent study in SHR, Bezie et al (Bezie Y et al.,1998) showed no abnormal collagen density in SHR aorta, whereas the number of cell surface contacts with the elastic lamellae in SHR aortas was increased compared to that in normotensive rats. The situation in SHR 
may be different from that in renovascular hypertension (Sosa-Melgerejo JA et al.,1996; Zanchi A et al,1997) or in renin transgenic hypertension in rats (chapter 8). In these two models, both characterized by an elevated vascular renin-angiotensin II activity, vascular stiffness is increased dramatically. Angiotensin II thus seems to have a direct, hypertension-independent effect on the vessel wall to increase its stiffness. In other studies in which the static mechanical properties were determined (Levy BI et al.,1993; Levy BI et al.,1994), an increase in collagen content was described. An explanation for this discrepancy could be the level of blood pressure rise in the SHR strain used. The SHR strains investigated in the present study showed a level of hypertension, which is lower than described in other SHR studies (Greenwald SE et al.,1978; Levy BI et al.,1994). The severity of the blood pressure elevation may be important in the induction of structural alteration in the aortic wall (Wolinsky H.,1972; Fisher GM.,1976).

\section{LUMEN DIAMETER}

In the previous sections we concluded that the buffering capacity of the thoracic aorta is not reduced with advancing age in both normotensive and hypertensive rats. Despite the decrease of the thoracic aorta elasticity during the first 6 months of life, compliance is not altered in both normotensive and hypertensive rats due to an increase in diastolic diameter (Fig. 9.4 and chapter 4). Between 6 and 9 months of age compliance increases in both normotensive and hypertensive rats as a result of an increased elasticity of the thoracic aorta (Fig. 9.2 and chapter 4-6). Advancing age decreases compliance in WKY, but at 18 months of age compliance increases in WKY as compared to 15 month old animals. In these age groups no further increase in diastolic diameter is measured. In SHR, compliance is not altered concomitantly with an increase in diastolic diameter.

These findings indicate that compliance is held constant by an increase in diastolic diameter. This hypothesis of a regulated compliance by an increase in diameter was previously proposed in other studies (Reneman RS et al.,1986; Laurent S.,1995). In a study by Benetos et al. on the carotid artery of 18 month old WKY rats (Benetos A et al.,1993; Michel JB et al.,1994), a larger compliance was found as a result of an increase in diameter as compared to 3 month old WKY.

It may be of interest that the rats, during the first 6 months of life, gained more body weight and are known to exhibit a significant increase in cardiac output during this time interval (Smith TL et al.,1979). It has been reported that chronic increases in flow increase arterial lumen diameter (Langille BL et al.,1986; Langille BL et al.,1990) probably as a mechanism to normalize wall shear stress (Mulvany $\mathrm{M}$ et al.,1996). An increase in diameter, however, results in an enlargement of the circumferential wall stress. According to the law of Laplace, this enlargement of wall stress can be normalized by an increase in media thickness. In this respect, the geometry of the vessel wall is determined by two conflicting stresses, shear and circumferential wall stress resulting in an increase in diameter and media thickness, respectively. The increase in media thickness and cross-sectional area with advancing age in SHR and to a lesser extent in WKY (Fig. 9.3 and chapter 4-6) goes together with an increase in diastolic diameter (Fig. 9.4 and chapter 4-6). The increase in media mass compensates the enlargement in circumferential wall stress induced by the increasing diastolic diameter. This is confirmed by the results described in chapter 8 , SHR and TGR have comparable conscious blood pressures but media mass and diastolic diameter are 
significantly larger in the renin transgenic rats.

However, between 1.5 and 6 months of age, media thickness does not increase in both normotensive and hypertensive rats (Fig. 9.3b and chapter 4). The increased wall stress is not compensated for by an increase in media thickness and the nonlinear stress-strain relationship for blood vessels explains the reduced elasticity, i.e. the increase in incremental elastic modulus.

Between 6 and 9 months of age the elasticity of the thoracic aorta decreases, while compliance and distensibility increases in both normotensive and hypertensive rats (Fig. 9.1, 9.2 and chapter 4-6). The reduced stiffness may be the result of a lower stress caused by alteration in the organization of the media components. From previous sections it is concluded that this is not the result of changes in absolute amounts of collagen or elastin. Alterations in the number of cell surface contacts (Bezie Y et al.,1998), that are the major site of anchorage between the smooth muscle cells and extracellular matrix, may be responsible for the increased elasticity between 6 and 9 months of age in both WKY and SHR. We should, however, take into consideration that structural properties in this thesis are obtained from the media of the thoracic aorta, but that the in vivo dynamic properties are determined of the entire aortic wall, including the scarcely investigated adventitia.

In conclusion, compliance does not decrease in both normotensive and hypertensive rats with advancing age and this is due to an increase in diastolic diameter. The enlargement of the media mass is most probably a mechanism to compensate for the increased circumferential wall stress resulting from the increase in diastolic diameter.
THE EFFECT OF ELEVATED BLOOD PRESSURE ON AORTIC FUNCTIONAL AND STRUCTURAL PROPERTIES

\section{WKY VERSUS SHR}

In conscious animals, no difference in diastolic diameter could be detected between 3 month old SHR and WKY. The lower compliance and distensibility in the conscious young SHR, as compared to WKY, are the result of a lower elasticity as indicated by a larger incremental elastic modulus. After the administration of ketamine/xylazie, which creates a condition of comparable blood pressure, elasticity is enlarged in both SHR and WKY. This illustrates the nonlinear elastic behavior of the aortic wall at different blood pressure levels. The incremental elastic modulus obtained under anesthesia was not significantly different between SHR and WKY in most of the studies described in this thesis. Differences in elastic properties are thus most probably the result of the nonlinear elastic behavior of the aortic wall and the higher blood pressure in SHR and suggests that the composition of the aortic media is not different between SHR and WKY. This assumption is supported by the finding that collagen and elastin contents and densities normalized for media cross-sectional area, which are important determinants of artery wall elasticity (Cox R.H.,1989), are not significantly different between SHR and WKY.

The persisting lower compliance in anesthetized SHR as compared to age matched anesthetized WKY, described in chapter 4, 5 and 6 , is the result of a smaller diastolic diameter (Fig. 9.1a and 9.4). At 1.5 months of age, the lower compliance is not accompanied by a difference in diameter and may be explained by a larger media mass in SHR. The reduced compliance was not accompanied by alterations in elastic properties and differences in collagen and elastin content 
at the different age groups. The observed lower compliance in SHR is in accordance with studies on the carotid artery of SHR (Cox RH.,1979a; Benetos A et al.,1992), but are in disagreement with studies of Hayoz et al (Hayoz D et al.,1992) on the carotid artery of SHR and the aorta of renal hypertensive rats (Sumitani W et al.,1997). In the latter studies, showing no difference in compliance between normotensive and hypertensive rats, generally larger diameters were found in the hypertensive rats.

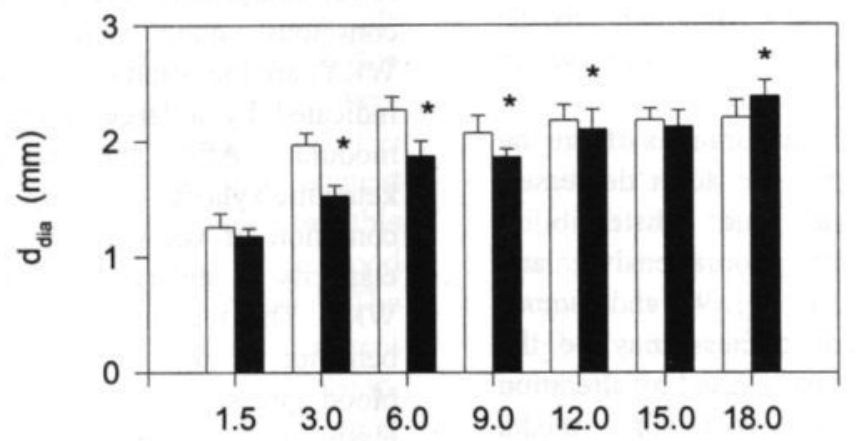

Age in months

Fig. 9.4. Diastolic diameter $(\mathrm{mm})$ after anesthesia with ketamine/xylazine in Wistar Kyoto rats (WKY; open bars) and spontaneously hypertensive rats (SHR; closed bars) as a function of age. Mean $\pm \operatorname{SD}(n=12)$.

* significantly different from WKY of the same age.

\section{PhaRMACOLOGICAL INTERVENTION}

Treatment of moderately hypertensive SHR with the calcium entry blocker nifedipine or with the vasodilator hydralazine reduced the blood pressure and enhanced the buffering capacity concomitantly with a reduction in media mass but without an effect on incremental elastic modulus (chapter 7). In SHR, the inhibition of the angiotensin converting enzyme with a low concentration of captopril caused a reduction in blood pressure concomitantly with a decrease in media mass, but had no effect on the buffering capacity or elastic properties of the thoracic aorta. Treatment with a high, antihypertensive dose of captopril improved the buffering capacity of the thoracic aorta in SHR. In these animals reduction of the blood pressure enhanced the buffering capacity and reduced the media mass of the thoracic aorta.

The improvement of the thoracic aortic buffering capacity by the different antihypertensive drugs used in this thesis, is the result of the blood pressure lowering effect and most probably not the result of the reduction of the media mass. This conclusion is based on the fact that a low dose of captopril reduced media mass but did not improve the buffering capacity of the thoracic aorta.

Inhibition of angiotensin II production, by the administration of ACEinhibitors restored aortic mechanical and structural properties in this thesis as in several earlier studies (Levy BI et al.,1988b; Levy BI et al.,1989; Benetos A et al.,1994). 


\section{RENIN TRANSGENIC RATS}

In the study described in chapter 8 , the relationship between the thoracic aortic buffering capacity and the activity of the renin-angiotensin system was further investigated. This study shows that in transgenic rats with overexpression of renin the buffering capacity of the thoracic aorta is deranged at in vivo operating and comparable blood pressures accomplished by the anesthesia with ketamine/xylazine. The reduction of the buffering capacity is the result of a loss of intrinsic elastic properties as indicated by the increase in incremental elastic modulus of the aortic wall compared with normotensive control rats at comparable blood pressure. Surprisingly, renin transgenic rats have a lower collagen density as compared to their controls. This illustrates that the structural organization may be a more important determinant of aortic elastic behavior than the amount of collagen per se. The media mass of the thoracic aorta was significantly larger in the transgenic rats than in the control animals. The enlargement of the media mass may be the result of an enhanced activity of the renin-angiotensin system and not exclusively the consequence of the elevated blood pressure. This conclusion is confirmed by the observation that at comparable blood pressures the buffering capacity is higher in SHR, but that media mass is smaller as compared to the transgenic rats. In previous studies the augmented activity of the renin-angiotensin system and the relationship with large artery mechanical behavior was investigated in renal hypertensive rats in which plasma angiotensin II levels are elevated (Cox RH.,1979b; Levy BI et al.,1989). In accordance with the present thesis these studies reported a reduced elasticity of the carotid artery and hypertrophy of the media. These investigators, however, found an increased quantity of collagen, which may be explained by the difference in activity of the local and systemic renin-angiotensin system in the different models used or the different arteries investigated.

\section{OVERALL CONCLUSIONS}

The aim of this thesis was to investigate the relationship between structural and in vivo dynamic mechanical properties of the thoracic aorta in ageing and hypertensive rats. The reduced buffering capacity in the conscious hypertensive rats is most probably the result of the nonlinear elastic behavior of the aortic wall and is not caused by alterations in the amount or organization of the different wall components. This conclusion is supported by the fact that smooth muscle activity does not influence the mechanical properties of the thoracic aorta (chapter 2), and that collagen and elastin content and the intrinsic elastic properties at comparable blood pressure are not different between SHR and WKY (chapter 3-8). The difference in buffering capacity of the thoracic aorta obtained under comparable blood pressure conditions is the result of a smaller diameter in the hypertensive rats (chapter 3-7).

Ageing does not reduce the buffering capacity or elastic properties of the thoracic aorta in normotensive and hypertensive rats (chapter 4-6). Ageing in normotensive and hypertensive rats is accompanied by an increase in aortic lumen diameter and by an enlargement in media mass. Only at 1.5 months of age an enlargement of the media mass may affect the buffering capacity of the thoracic aorta (chapter 4), in all other age categories the enlargement of the media mass does most probably not affect the buffering capacity of the thoracic aorta (chapter 4-6). The enhanced activity of the local reninangiotensin system, that is known to be present already before the onset of blood pressure elevation in SHR (Saavedra J.M. 
et al.,1992), enlarges media mass (chapter 7 and 8 ) and reduces the elasticity of the thoracic aorta by the enhanced expression of renin (chapter 8). Therefore, the enhanced activity of the renin-angiotensin system could be responsible for the increase in media mass in 1.5 months old SHR as compared to WKY.

The detected enlargement in media mass of the thoracic aorta in SHR is not the result of the elevated blood pressure (chapter 3-7), because the initial elevation in blood pressure in 3 months old SHR is not accompanied by an enlargement in media mass and a progressive increase in media mass with advancing age is not accompanied by a progressive increase in blood pressure. From the results described in chapter 8 , it can be concluded that an elevated blood pressure has little effect on media mass, because SHR and TGR have comparable blood pressures but media mass is significantly larger in the renin transgenic rats. The enlargement of the media mass is most probably a mechanism to compensate for the increased circumferential wall stress resulting from the increase in diastolic diameter.

Early onset treatment of SHR with different antihypertensive drugs inhibits the development of hypertension, and normalizes aorta wall mechanics and media mass. The drugs achieve this effect by their blood pressure lowering effect and not by a direct effect on aortic diameter or vascular elasticity (chapter 7 ).

\section{FUTURE PERSPECTIVES}

A putative loss of compliance seems to be compensated for by an increase in diastolic diameter. In this thesis the question of what triggers the increase in diastolic diameter remains unanswered. The mechanism responsible for the increase in diastolic diameter could be outward remodeling as a response to control the shear stress of the thoracic aorta. In order to answer this question the diastolic diameter should be investigated under conditions of chronically manipulated cardiac output. Cardiac output, blood pressure and the diastolic diameter of the thoracic aorta should be measured and the buffering capacity, elastic properties, media mass and shear stress should be determined. In such a study it would be interesting to investigate the structural properties of the tunica adventitia as well.

The progressive increase in media mass in both normotensive and hypertensive rats is not related to the blood pressure level but could be a mechanism to reduce the circumferential wall stress induced by the increasing diastolic diameter. Neurohormonal and/or vasoactive systems may play a role in the induction and progression of the enlargement of the media mass in response to the increased diastolic diameter. It would be interesting to investigate the relationship between the enlargement of the diastolic diameter and media mass, and the activity of the sympathetic and angiotensin-renin system, and other vasoactive systems like the NO-system, in ageing WKY and SHR.

In this thesis the effects of smooth muscle tone on the buffering capacity and elastic properties of the thoracic aorta were only determined at 3 months of age in both SHR and WKY. The acute intervention with vasoactive compounds to investigate the role of smooth muscle activity on the buffering capacity and elastic properties of the thoracic aorta should, also, be performed in aged SHR and WKY.

In this thesis, the SHR strain used shows a moderate increase in blood pressure. Alteration in structure and elastic properties may appear in SHR strains with a more severe increase in blood pressure. The dynamic mechanical and structural properties of the thoracic aorta should be measured in these animals starting at 1.5 
months of age and further on at 6 and 15 months of age.

The reduced compliance observed in the SHR as compared to WKY is the result of the increased blood pressure and the nonlinear elastic properties of the thoracic aortic wall. Antihypertensive treatment can, therefore, enhance the buffering capacity of the thoracic aorta by their blood pressure lowering effect, and may reduce the load on the heart resulting in a lower incidence of hypertrophy and arrhythmias. 


\section{REFERENCES}

Achimastos A, Girerd X, Simon AC, PithoisMerli I, Levenson J. The efficacy of transdermal formulation of clonidine in mild to moderate hypertension and its effects on the arterial and venous vasculature of the forearm. Eur. J. Pharmacol. 33:111-114, 1987

Bachmann S, Peters J, Engler E, Ganten D, Mullins J. Transgenic rats carrying the mouse renin gene-morphological characterization of a low-renin hypertension model. Kidney Int 41:2436, 1992

Bader H. Dependence of wall stress in the human thoracic aorta on age and pressure. Circ. Res. 20:354-361 1967

Bank AJ, Wilson RF, Kubo SH, Holte JE, Dresling TJ, Wang H. Direct effects of smooth muscle relaxation and contraction on in vivo human brachial artery elastic properties. Circ. Res. 77:1008-1016, 1995

Bank AJ, Kaiser DR. Smooth muscle relaxation:effects on compliance, distensibility, elastic modulus, and pulse wave velocity. Hypertension 32:356359,1998

Barra JG, Armentano RL, Levenson J, Cabrera, Fischer EI, Pichel RH, Simon

A. Assessment of smooth muscle contribution to descending thoracic aortic elastic mechanics in conscious dogs. Circ. Res. 73:1040-1050, !993

Bauer RD, Busse R, Schabert A. Mechanical properties of arteries. Biorheology 19:409-424, 1982

Benetos A, Bouaziz H, Albaladejo P, Levy BI, Safar ME. Physiological and pharmacological changes in the carotid artery pressure-volume curve in situ in rats. J. Hypertens. 10(Suppl 6):S127S131, 1992

Benetos A, Huguet F, Albaladejo P, Brisac AM, Pappo M, Safar ME, Levy BI. Role of adrenergic tone in mechanical and functional properties of carotid artery during ageing. Am. J. Physiol. 265:H1 132-H1 138, 1993

Benetos A, Albaladejo P, Levy BI, Safar ME. Acute and long-term effects of angiotensin converting

enzyme inhibition on larger arteries and cardiac hypertrophy: mechanical and structural parameters. J. Hypertens. 12:S21-29, 1994

Bergel DL. The static elastic properties of the arterial wall. J. Physiol. 156:445-457, 1961

Berry CL, Greenwald SE, Rivett JF. Static mechanical properties of the developing and mature rat aorta. Cardiovasc. Res. 9:669-678, 1975

Bevan RD. Effects of sympathetic denervation on smooth muscle cell proliferation in the growing rabbit ear artery. Circ. Res. 37:14-19, 1975

Bevan D. Trophic effects of peripheral adrenergic nerves on vascular structure. Hypertension 6 (suppl III):III19-III26, 1984.

Bevan RD, Tsuru H. Functional and structural changes in the rabbit ear artery after sympathetic denervation. Circ. Res. 49: 478-485, 1985

Bezie Y, Lacolley P, Laurent S, Gabella G. Connection of smooth muscle cells to elastic lamellae in aorta of spontaneously hypertensive rats. Hypertension 32:166-169, 1998

Boonen HCM, Daemen MJAP, Eerdmans PE, Fazzi GE, Van Kleef E, Schiffers PMH, De Mey JGR. Mesenteric small artery changes following vasoconstrictor infusion in young rats. J. Cardiovasc. Pharmacol. 22:388-395, 1993.

Bouthier JA, Safar ME, Curien ND, London GM, Levenson JA, Simon AC. Effect of cadralazine on brachial artery hemodynamics and forearm venous tone in essential hypertension. Clin. Pharmacol. Ther. 39:82-88, 1986

Brouwers-Ceiler DL, Nelissen-Vrancken JIJMG, Smits JFM, De Mey JGR. The influence of angiotensin II induced hypertrophy on aortic compliance in rats in vivo. Cardiovasc. Res. 33:478-484, 1997

Campbell-Bosswell M., Robertson AL. Effects of angiotensin II and vasopressin on human smooth muscle cells in vitro. Exp. Mol. Pathol. 35:265-276, 1981.

Cox RH. Comparison of arterial wall mechanics in normotensive and 
spontaneously hypertensive rats. Am. J. Physiol. 237:H159-H167, 1979a

Cox RH. Alterations in active and passive mechanics of rat carotid artery with experimental hypertension. Am. J. Physiol. 237:H597-H605, 1979b

Cox R.H., Mechanical properties of arteries in hypertension. In: Blood vessel changes in hypertension: structure and function. Volume 1, chapter 4. CRC Press Inc., Boca raton, Florida, pp65-95, 1989

Daemen MJAP. Lombardi DM, Bosman FT, Schwartz SM. Angiotensin II induces smooth muscle cell proliferation in the normal and injured rat arterial wall. Circ. Res. 68:450-456, 1991

Daemen MJAP, De Mey JGR. Regional heterogeneity of arterial structural changes. Hypertension 25:464-473, 1995

Delacretaz E, Hayoz D, Osterfeld MC, Genton CY, Brunner HR, Waeber B. Long-term Nitric Oxide synthase inhibition and distensibility of carotid artery in intact rats. Hypertension 23:967-970, 1994

Fisher GM. Effects of spontaneous hypertension and age on arterial connective tissue in the rat. Exp. Gerontol. 11:209, 1976

Forieri C, Quaglino D, Mori G. Role of the extracellular matrix in age-related modification of the rat aorta: Ultrastructural, morphometric and enzymatic evaluations. Arterioscler. Thromb. 12:1008-1016, 1992

Geisterfer AA, Peach MJ, Owens GK. Angiotensin II induces hypertrophy, but not hyperplasia, of cultured rat aortic smooth muscle cells. Circ. Res. 62:749$756,1988$.

Greenwald SE, Berry CL. Static mechanical properties and chemical composition of the aorta of spontaneously hypertensive rats: a comparison with the effects of induced hypertension. Cardiovas. Res. 12:364-372, 1978.

Griffin S.A., W.B.C. Brown, F. MacPherson, J.C. McGrath, V.G. Wilson, N. Korsgaard, M.J. Mulvany, A.F. Lever. Angiotensin II causes vascular hypertrophy in part by a non-pressor mechanism. Hypertension 17:626-635, 1991
Hansen F, Mangell P, Sonesson B, Lann T, Diameter and compliance in the human common carotid artery - variations with age and sex. Ultrasound Med. Biol. 21:1-9, 1995

Hayoz D, Rutschmann B, Perret F, Niederberger M, Tardy Y, Mooser V, Nussberger J, Waeber B, Brunner H. Conduit artery compliance and distensibility are not necessarily reduced in hypertension. Hypertension 20:16,1992

Head RJ. Hypernoradrenergic innervation: its relationship to functional and hyperplastic changes in the vasculature of spontaneously hypertensive rat. Blood vessels 26:1-20, 1986.

Hilgers KF, Peters J, Veelken R, Sommer M, Rupprecht G, Ganten D, Luft FC, Mann JFE. Increased vascular angiotensin formation in female rats harboring the mouse Ren-2 gene. Hypertension 19:687-691, 1992

James JJ, Bosch KS, Aronson DC, Houtkooper JM. Sirius red histophotometry and spectrophotometry of sections in the assessment of the collagen content of liver tissue and its application in growing rat liver. Liver 10:1-5, 1990

Judy WV, Watanabe QM, Henry DB, Besch HR, Murphy WR, Hockel GM. Sympathetic nerve activity: role of blood pressure in the spontaneously hyertensive rat. Circ. Res. 38(Suppl. II):21-29, 1976.

Kohn RR. Heart and cardiovascular system. In: Finch CE, Hyflick $\mathrm{L}$ (eds.). Handbook of biology and aging. New York: Van Nostrand Reinhold 281-317, 1977

Kong JQ, Taylor DA, Fleming WW. Mesenteric vascular responses of young spontaneously hypertensive rats. $J$. Pharmacol. Exp. Ther. 258:13-17, 1991.

Lacolley P, Glaser E, Challande P, Boutouyrie P, Mignot JP, Duriez M, Levy BI, Safar ME, Laurent S. Structural changes and in situ aortic pressure-diameter relationship in long-term chemicalsympathectomized rats. Am. J. Physiol. 269:H407-H416, 1995 
Lakatta EG. Do hypertension and aging have similar effect on the myocardium? Circulation. 75 (suppl.I):I69-I77, 1987

Langille BL, O'Donnel F. Reductions in arterial diameter produced by chronic decreases in blood flow are endothelium dependent. Science 231:405-407, 1986

Langille BL, Brownlee RD, Adamson SL. Perinatal aortic growth in lambs: relation to blood flow changes at birth. Am.J. Physiol. 259:H1247-H1253, 1990

Laurent S, Lacolley PM, Cuche JL, Safar ME. Influence of diuretics on brachial artery diameter and distensibility in hypertensive patients. Fundam. Clin. Pharmacol. 4:685-693, 1990

Laurent S. Arterial wall hypertrophy and stiffness in essential hypertensive patients. Hypertension 26:3550-362, 1995

Learoyd BM, Taylor MG. Alterations with age in the viscoelastic properties of human arterial walls. Circ. Res. 18:278-292, 1966

Levy BI, Michel JB, Salzman JL, Azizi M, Poitevin P, Safar M, Camilleri JP. Effects of chronic inhibition of converting enzyme on mechanical and structural properties of arteries in rat renovascular hypertension. Circ. Res. 63:227-229, 1988a

Levy BI, Michel JB, Salzman JL, Azizi M, Piotevin P, Camilleri JP, Safar ME. Arterial effects of angiotensin converting enzyme inhibition in renovascular and spontaneously hypertensive rats. J. Hypertens. 6 suppl. 6:S23-25, 1988b

Levy BI, Michel JB, Salzman JL, Devissaguet M, Camilleri JP, Safar ME. Effects of chronic converting enzyme inhibition on the structure and function of large arteries in the rat. Clin. Exp. Hypertens. A. 11 suppl 2:487-498, 1989

Levy BI, Benessiano J, Poitevin P, Safar ME. Endothelium dependent mechanical properties of the carotid artery in WKY and SHR. Role of angiotensin converting enzyme inhibition. Circ. Res. 66:321-328, 1990

Levy BI, Michel JB, Salzmann JL et al. Longterm effects of angiotensin-converting enzyme inhibition on the arterial wall of adult spontaneously hypertensive rats. Am. J. Cardiol. 71:8E-16E, 1993

Levy BI, Duriez M, Phillipe M, Poitevin P, Michel JB. Effects of chronic dihydropyridine (isradipine) on the large arterial wall of spontaneously hypertensive rats. Circulation 90:30243033, 1994

Maarek BL, Bouthier JA, Simon AC, Levenson JA, Safar ME. Comparative effects of propranolol and pindolol on small and large arteries and veins of the forearm circulation in hypertensive man. J. Cardiovasc. Pharmacol. 8(Suppl. 4):S61-S66, 1986

Michel JB, Heudes D, Michel O, Poitevin PP, Scalbert E, Corman B, Levy BI. Effect of chronic ANGI-converting enzyme inhibition on aging processes. II. Large arteries. Am. J. Physiol. 267:R124R135, 1994

Mullins JJ, Peters J, Ganten D. Fulminant hypertension in transgenic rats harbouring the mouse Ren-2 gene. Nature 244:541-544, 1990

Mulvany MJ, Aalkjaer C, Christensen J. Changes in noradrenaline sensitivity and morphology of arterial resistance vessels during development of high blood pressure in spontaneously hypertensive rats. $\mathrm{Br}$. J. Pharmacol. 71:585-596, 1980.

Mulvany J.M.J., Aalkjaer C. Structure and function of small arteries. Physiol. Rev. 70: $921-961,1990$

Mulvany M, Baumbach GL, Aalkjaer C, Heagerty AM. Vascular remodeling. Hypertension 28:505-506, 1996

Nichols WW, O'Rourke MF. McDonald's blood flow in arteries. third edition.. Edward Amold. London Melbourne Auckland CH 4, pp 77-114, 1990

Okamoto K, Aoki K. Development of a strain of spontaneously hypertensive rats. Jap. Circ. J. 27:202-293, 1963.

Pagani M, Mirsky I, Baig H, Manders WT, Kerkhof P, vatner SF. Effects of age on aortic pressure-diameter and elastic stiffness-stress relationship in unanesthetized sheep. Circ. Res. 44:4204291979

Paul M, Wagner J. Transgenic rats: New experimental models for the study of 
candidate genes in hypertension research. Anmu Rev Physiol 56:811-829, 1994

Reneman RS, Van Merode T, Hick P, Hoeks APG. Flow velocity patterns in and distensibility of the carotid artery bulb in subjects of various ages. Circulation 71:500-509, 1985

Reneman RS, T. Van Merode, P. Hick, A.M.M. Muytjens, A.P.G. Hoeks. Agerelated changes in carotid artery wall properties in men. Ultrasound Med. Biol. 12:465-471, 1986

Reneman RS, Hoeks APG, Westerhof N. Noninvasive assessment of artery wall properties in humans; methods and interpretation. J. Vascular Investigation 2:53-64, 1996

Riley WA, Barnes R, Evans GW, Burke GL. Ultrasonic measurement of the elastic modulus of the common carotid artery: the atherosclerosis risk in mommunities (ARIC) study. Stroke 23:952-956,1992

Rizzoni D, Castellano M, Porteri E, Bettoni G, Muiesan ML, Agabiti Rosei E. Vascular structural and functional alterations before and after the development of hypertension in SHR. Am. J. Hypertens. 7:193-200, 1994.

Roman MJ, Saba PS, Pini R, Spitzer M, Pickering TG, Rosen S, Alderman M, Devereux R. Parallel cardiac and vascular adaptation in hypertension. Circulation 86: 1909-1918,1992

Saavedra J.M., F.M.A. Correa, A. Seltzer, J.E.B. Pinto, P. Viglione, K. Tsutsumi. Enhanced angiotensin converting enzyme binding in arteries from spontaneously hypertensive rats. $J$. Hypertens. 10:1353-1359, 1992

Safar ME, Toto-Moukouo JJ, Bouthier MD, Asmar RE, Levenson JA, Simon AC, London GM. Arterial dynamics, cardiac hypertrophy, and antihypertensive treatment. Circulation 75(suppl I):I156I162, 1987

Safar M. Ageing and its effect on cardiovascular system. Drugs 39:suppl. 1:1-8 1990

Schiffers PMH, Van der Heijden HAMD, Fazzi GE, Struijker Boudier HAJ, De Mey JGR. Tonic tone in arteries exposed continuously to angiotensin II in vitro. J. Pharmacol. Exp. Ther. 266:1520-1527, 1993

Simpson P, Mcgrath A, Savion S. Myocyte hypertrophy in neonatal rat heart cultures and its regulation by serum and by catecholamines. Circ. Res. 51:787801, 1982.

Smeda JS, Lee RM, Forrest JB. Structural and reactivity alterations of the renal vasculature of spontaneously hypertensive rats prior to and during established hypertension. Circ. Res. 63:518-533, 1988.

Smith TL, Hutchins PM. Central hemodynamics in the developmental stages of spontaneously hypertension in the unanesthetized rat. Hypertension 1:508-517, 1979

Sosa-Melgarejo JA, Berry CL. Cell to stroma contacts in the tunica media of the hypertensive rat thoracic aorta. Arch. Med. Res. 27:123-126, 1996

Sumitani M, Michelini LC, Krieger EM. Long-term analysis of dynamics in growing conscious rats. Hypertension 8: suppl I:I200-I204, 1986

Sumitani M, Cabral AMS, Michelini LC, Krieger EM. In vivo adaptive responses of the aorta to hypertension and aging. Am. J. Physiol. 273:H96-H103, 1997

Todd ME, Gowen B. Arterial wall and smooth muscle cell development in young Wistar rats and the effect of surgical denervation. Circ. Res. 69:438-446, 1991

Trippodo NC, Frohlich ED. Similarities of genetic (spontaneous) hypertension. Man and rat. Circ. Res. 48:309-319, 1981

Van Bortel LM, Kool MJ, Struijker Boudier HA. Effects of antihypertensive agents on local arterial distensibility and compliance. Hypertension 26:531-534, 1995

Waeber B, Hayoz D, Evequoz D, Brunner HR. Arterial compliance and distensibility in spontaneously hypertensive rats. $J$. Hypertension 10 (suppl 6) S79-S81, 1992

Westerhof N, Bosman F, De Vries CJ, Noordergraaf A. Analog studies of the human systemic arterial tree. $J$. Biomechanics 2:121-143,1969 
Westerhof N, Noordergraaf A. Arterial viscoelasticity: a generalized model. $J$. Biomechanics 3:357-379, 1970

Wolinsky H. Long-term effects of hypertension on the rat aortic wall and their relation to concurrent aging changes. Circ. Res. 30:301-309, 1972

Zanchi A, Wiesel P, Aubert JF, Brunner HR, Hayoz D. Time course of changes of the mechanical properties of the carotid artery in renal hypertensive rats. Hypertension 29:1199-1203, 1997

Zanchi A, Stergiopulos N, Brunner HR, Hayoz D. Differences in the mechanical properties of the rat carotid artery in vivo, in situ and in vitro. Hypertension 32: $180-185,1998$

Zhao Y, Bader M, Kreutz R, Fernadez-Alfonso M, Zimmermann F, Ganten U, Metzger R, Ganten D, Mullins JJ, Peters J. Ontogenetic regulation of mouse Ren$2 \mathrm{~d}$ renin gene in transgenic hypertensive rats, TGR(mREN2)27. Am J Physiol 265:E699-E707, 1993 
SUMMARY 


\section{SUMMARY}

A reduction in the buffering capacity of the thoracic aorta with ageing and in hypertension may induce left ventricular hypertrophy and may result in heart failure and cardiac arrhythmias. The buffering capacity of the thoracic aorta is defined by the diastolic diameter and the elastic properties of the aortic wall. Factors that are believed to influence the elastic properties and diameter of the thoracic aorta are the arterial wall components, wall thickness, and the operating blood pressure. The structural organization of large arteries displays remarkable alterations with ageing and in hypertension, but it remains to be established whether these alterations are directly related to the deterioration of the buffering capacity.

Spontaneously hypertensive rats (SHR) are characterized by hemodynamic properties that resemble those encountered in human essential hypertension. Therefore, SHR are considered a valid model to investigate the effect of hypertension on mechanical and structural properties of the thoracic aorta.

In view of the above, the aims of the present study were as follows:

Aim 1: to investigate effects of smooth muscle tone on the mechanical properties of the thoracic aorta in conscious normotensive and hypertensive rats. Smooth muscle activity was altered by modulation of $\alpha_{1}$-adrenergic and angiotensin II receptor activity.

$\operatorname{Aim}$ 2: to study the relationship between aortic media structure and mechanical properties in hypertension and ageing. The structural part of the study focusses on media thickness and cross-sectional area, and on collagen and elastin content and density. The functional part focusses on compliance and distensibility of the thoracic aorta, and its incremental elastic or Young's modulus.

Aim 3: to investigate the aggravating effect of hypertension, if any, on the changes in mechanical properties observed with ageing.

Aim 4: to study the effects of long term antihypertensive therapy on the aortic mechanical properties in hypertensive rats during the development of high blood pressure. This approach allows the investigation of the influence of aortic blood pressure and the activity of neurohormonal systems on mechanical and structural properties.

$\operatorname{Aim}$ 5: to examine the influence of the enhanced expression of renin on the structural and mechanical properties of the thoracic aorta.

The wall material of arteries shows viscoelastic behavior which makes it necessary to measure arterial wall mechanics under dynamic conditions. Therefore, a technique to assess dynamic aortic distensibility and compliance in intact anesthetized and awake rats is developed. In Chapter 2 a non-invasive ultrasonic technique is presented, which is based upon tracking of the arterial wall displacements with a vessel wail tracking device attached to a conventional B-mode imager, to assess end-diastolic aortic diameter (d) and on aortic diameter changes during the cardiac cycle $(\Delta \mathrm{d})$ in anesthetized and awake rats. From these parameters and the simultaneous invasively measured aortic pulse pressure $(\Delta \mathrm{P})$, aortic distensibility and compliance, the relative and absolute increase in lumen cross-sectional area for a given increase in blood pressure (P), can be calculated. $\mathrm{d}, \Delta \mathrm{d}$ and $\Delta \mathrm{P}$ could be determined with good intra-session (variations per day) and intersession (variations between days) coefficients of variation (CV). The CV's for $\Delta \mathrm{d}$ were smaller in awake $(4.6-6.0 \%)$ than in anesthetized rats $(7.9-11.0 \%)$, probably due to variations in $\Delta \mathrm{P}$ during 
anesthesia (CV: 9.0-12.3\%). The CV's for $\mathrm{d}$ in awake (3.3-6.5\%) and anesthetized rats (2.6-5.0\%) were comparable. In awake rats the CV for $\Delta d$, but not for $d$, increased after implantation of the aortic catheter. It is concluded that $\mathrm{d}, \Delta \mathrm{d}$ and $\Delta \mathrm{P}$ of the aorta can be reliably measured noninvasively in anesthetized and awake rats, allowing the in vivo assessment of aortic distensibility and compliance. Furthermore the technique was found to be sensitive enough to detect acute effects of pharmacological agents on aortic wall properties.

In chapter 3 we evaluate whether smooth muscle tone modulates elastic properties of the aorta in conscious rats. We, therefore, applied ultrasound wall tracking at the level of the thoracic aorta in conscious restrained normotensive WKY and SHR during intravenous administration of vasoactive agents. In WKY, the $\alpha_{1}$ adrenoceptor antagonist prazosin ( 0.2 to 5.0 $\mu \mathrm{g} / \mathrm{kg} \cdot \mathrm{min}$ ) significantly increased the diastolic lumen area of the aorta $\left(\mathrm{A}_{\text {dia }}+\right.$ $20 \%$ at the highest dose), but did not modify the compliance (CC) or distensibility (DC) of the vessel. Similarly, the $\mathrm{AT}_{1}$-receptor antagonist losartan (30 $\mu \mathrm{g} / \mathrm{kg} \cdot \mathrm{min})$ increased $\mathrm{A}_{\text {dia }}(+19 \%)$, but did not modify CC or DC. Low doses of the $\alpha_{1}$ adrenoceptor agonist phenylephrine $(0.08$ to $2.0 \mu \mathrm{g} / \mathrm{kg} \cdot \mathrm{min}$ ) did not modify blood pressure $(\mathrm{P})$ nor the $\mathrm{A}_{\text {dia }}, \mathrm{CC}$ or DC of the aorta. At higher doses of phenylephrine (10 $\mu \mathrm{g} / \mathrm{kg}$.min), both $\mathrm{P}$ and $\mathrm{A}_{\text {dia }}(+36 \%)$ were increased and $\mathrm{CC}$ and DC were reduced. Similar effects were observed with angiotensin II (4 to $100 \mathrm{ng} / \mathrm{kg} \cdot \mathrm{min}$ ). In SHR the vasopressor agonists induced qualitatively similar effects: low doses were without effect on the aorta, while high doses caused increases in both $\mathrm{P}$ and $\mathrm{A}_{\text {dia }}$ and decreases in CC and DC. Losartan (30 $\mu \mathrm{g} / \mathrm{kg}$.min) did not elicit significant responses in SHR, while prazosin (5.0 $\mu \mathrm{g} / \mathrm{kg}$.min) induced a marked reduction of $\mathrm{P}$ that was accompanied by a fall of $\mathrm{A}_{\text {dia }}$ and a significant increase in CC. Prazosin abolished the difference in blood pressure between WKY and SHR, while phenylephrine and angiotensin II raised $\mathrm{P}$ in WKY to the level seen in SHR. In each of these isobaric conditions, $\mathrm{A}_{\mathrm{dia}}$ and $\mathrm{CC}$ were significantly smaller in SHR than in WKY, while the elastic modulus was comparable in both strains. These results suggest that in conscious restrained rats, the thoracic aorta is in a state of active vasoconstriction (most likely due to endogenous catecholamines) and that this activity of the aortic smooth muscle does not influence the dynamic in vivo mechanics of the vessel. The results furthermore confirm that the compliance of the rat aorta is primarily dependent upon blood pressure and that pressureindependent differences between WKY and SHR are largely due to the smaller aortic lumen in the hypertensive rats.

In hypertension, arterial wall properties may not solely depend on increased blood pressure. In chapter 4 we investigated the relationship between the development of hypertension and thoracic aortic wall properties in 1.5, 3 and 6 month old SHR and WKY. During ketamine/xylazine anesthesia, compliance and distensibility were assessed by means of the noninvasive ultrasound technique combined with invasive blood pressure measurements. The type of anesthesia used acutely abolished the difference in blood pressure between both strains. Morphometric measurements provided in vivo media cross-sectional area and thickness, allowing the calculation of the incremental elastic modulus. Extracellular matrix protein contents were determined as well. At the age of 1.5 month, conscious blood pressure was not significantly different in SHR and WKY, but compliance and distensibility were significantly lower in SHR. Incremental elastic modulus was not significantly different between SHR and WKY at this age. Media thickness was 
significantly larger in SHR than in WKY, but there was no significant difference in collagen density and content. The findings in this study show that in SHR alterations in dynamic in vivo mechanical aortic wall properties precede the development of hypertension. The decrease in compliance and distensibility at young age most likely results from an increase in media thickness rather than a change in intrinsic elastic properties. It may be worthwhile to test in future experiments that these early alterations result from a mismatch between the growth of the arterial lumen and that of the arterial wall mass during fetal development.

In chapter 5 aortic wall properties in 3-and 6- month old normotensive WKY and SHR were during acute normalization of blood pressures in vivo. During ketamine/xylazine anesthesia we performed ultrasound arterial wall tracking and invasive pressure measurements to determine, at the level of the thoracic aorta, diastolic pressure, diastolic lumen area, changes in pressure and lumen area during the cardiac cycle, and aortic compliance and distensibility. These observations were combined with histological measurements for the assessment of media cross-sectional area and thickness and the incremental elastic modulus under conditions as expected in situ. Anesthesia abolished the difference in diastolic pressure between SHR and WKY. In WKY, diastolic area and incremental elastic modulus increased significantly, distensibility decreased significantly, and all other recorded variables did not change significantly between 3 and 6 months of age. In SHR, diastolic area and incremental elastic modulus increased, distensibility decreased, and all other mechanical and structural properties of the aortic wall did not change significantly between 3 and 6 months of age. At both ages diastolic area and compliance were significantly smaller in SHR than in WKY. The other mechanical and structural properties measured or calculated at comparable pressure did not differ between strains. Therefore, differences between the aorta of 3 and 6 month old rats and between strains observed in vivo at comparable pressures can largely be attributed to differences in lumen caliber. These may represent the first findings concerning inward remodeling of the aorta in intact rats.

In humans, compliance and distensibility of the elastic arteries decrease with age. It has been proposed that hypertension has an accelerating effect on the decline of elasticity of arteries and on the structural changes as seen with ageing. In Chapter 6, the effect of hypertension on aortic wall properties in ageing SHR and age matched WKY is described. During ketamine/xylazine anesthesia compliance and distensibility were assessed by means of the noninvasive ultrasound technique combined with invasive blood pressure measurements. Morphometric measurements provided in vivo media cross-sectional area and thickness, allowing the calculation of the incremental elastic modulus. Extracellular matrix protein contents were determined as well. The findings in this study show that the compliance of the thoracic aorta is lower in aged than in the adult WKY, due to a decrease in distensibility. On the other hand in SHR the compliance does not change with age, despite a decrease in distensibility of the thoracic aorta. In SHR the decrease in compliance seems to be compensated for by an increase in diameter. Progressive increases in media mass, as indicated by the larger media cross-sectional area and thickness, were found in both strains, but were more pronounced in SHR than in WKY. The elastic properties of the thoracic aorta did not change with increasing age in both strains, as indicated by the absence of significant differences in the incremental elastic modulus between age categories. Altogether these observations indicate that 
hypertension does not aggravate the changes in aortic wall properties and structure as occurring with increasing age. The collagen content and density did not change with increasing age in both strains. Therefore, collagen cannot be held responsible for the changes in wall properties and structure as observed with age. A change in elastin content can probably not be held responsible for the changes in wall properties either, because in both strains its content increases with age. A major drawback of these analyses is that they were limited to 18 months of age while age-related arterial dysfunction in humans develop over several decades.

In chapter 7 it is investigated whether the buffering capacity and elastic properties of arteries can be improved by the administration of drugs by a blood pressure lowering effect and/or by a direct effect on the vessel wall. It is of interest to note that not all antihypertensive compounds have the same effect on buffering capacity, elastic properties and structure of arteries, despite a comparable blood pressure lowering effect. Investigating the effects of antihypertensive agents on the buffering and elastic properties of large arteries is not only of interest from a therapeutic point of view, but may give insight into the regulatory mechanisms responsible for the modulation and adaptation of the buffering capacity, and the role played by the different wall components.

The dynamic mechanical properties of large arteries change in hypertensive disease. These changes are related to the pressure increase as such, but could also be caused by pressureindependent factors (e.g. see chapter 4). One way to test the role of pressureindependent mechanisms is to compare the effects of different regimens of druginduced blood pressure reduction. In this study we investigated the effects of a 6 week treatment of young SHR with the
ACE-inhibitor captopril, the calcium entry blocker nifedipine and the arterial vasodilator hydralazine. At the end of the treatment period we measured in conscious animals the diameter of the thoracic aorta and its changes during the cardiac cycle using the non-invasive ultrasound technique. Blood pressure was simultaneously measured via an intra-aortic catheter. These measurements allowed the calculation of aorta compliance and distensibility. After these measurements, animals were sacrificed to determine the media cross sectional area of the thoracic aorta. This allowed the calculation of the incremental elastic modulus of the aorta. The results of our measurements show that (i) diastolic diameter of the aorta was not influenced significantly by any of the drug treatments, except for a small reduction following hydralazine; (ii) aortic compliance and distensibility were increased by all antihypertensive drugs; (iii) the antihypertensives did not influence incremental elastic modulus of the aorta and (iv) the media cross-sectional area of the aorta was reduced to a comparable degree by the various antihypertensive agents. From these data we conclude that the effects of antihypertensive drugs on dynamic mechanical properties of the aorta of SHR are primarily due to their pressure lowering effect rather than to direct effects on aorta diameter or vascular stiffness.

In chapter 8 the effect of enhanced vascular renin activity on the elastic behavior of the aorta is described. Three months old transgenic (mREN-2) rats (renin TGR), SHR and their respective normotensive controls were studied. Dynamic mechanical properties of the aorta were determined with the non-invasive ultrasound technique combined with invasive aortic blood pressure measurements. Animals were studied in vivo at conscious operating blood pressure as well as during anesthesia-induced isobaric blood pressures. The mechanical 
behavior was related to structural characteristics of the aorta. In both hypertensive strains aortic compliance and distensibility were significantly reduced compared to normotensive controls. The reduction of aortic compliance and distensibility was significantly more pronounced in TGR than in SHR. In both hypertensive strains, aorta media cross sectional area was increased, with a significantly stronger degree of hypertrophy in TGR. The incremental elastic modulus was significantly larger in TGR than in SHR or the normotensive strains, at both operating pressure and under isobaric conditions. The collagen density of TGR aorta was paradoxically reduced in comparison to that of SHR and the normotensive strains. These results show a strong impairment of the buffering capacity of the aorta in TGR. The aorta stiffening in this model of chronic exposure to high vascular levels of Ang II is at least partly pressure independent. We propose that the reduced buffering capacity of the aorta is due to a change in intrinsic elastic properties of wall components other than collagen.

In the general discussion (chapter 9) it is concluded that: 1). The reduced buffering capacity in the conscious spontaneously hypertensive rats is most probably the result of the nonlinear elastic behavior of the aortic wall and is not caused by alterations in the amount or organization of the different wall components. This conclusion is supported by the fact that smooth muscle activity does not influence the mechanical properties of the thoracic aorta (chapter 2), and that collagen and elastin content and the intrinsic elastic properties at comparable blood pressure are not different between SHR and WKY (chapter 3-8). The difference in buffering capacity of the thoracic aorta obtained under comparable blood pressure conditions is the result of a smaller diameter (inward remodeling) in the hypertensive rats (chapter 3-7).

The detected enlargement in media mass of the thoracic aorta in SHR is not the result of the elevated blood pressure (chapter 3-7), but is rather caused by an enhanced local renin-angiotensin or catecholamine activity. The enhanced activity of the local renin-angiotensin system, that is known to be present already before the onset of blood pressure elevation in SHR, enlarges media mass (chapter 7 and 8 ) and reduces the elasticity of the thoracic aorta by the enhanced expression of renin (chapter 8 ).

2). Ageing does not reduce the buffering capacity or elastic properties of the thoracic aorta in normotensive and hypertensive rats (chapter 4-6). Ageing in normotensive and hypertensive rats is accompanied by an increase in aortic lumen diameter and by an enlargement in media mass. The enlargment of the diameter may be a mechanism to regulate the buffering capacity of the aorta. Only at 1.5 months of age buffering capacity is lower in SHR and is most probably explained by the enlarged media mass. In all other studies, the enlargement of the media mass does not affect the buffering capacity of the thoracic aorta (chapter 4-6) and is most probably a mechanism to compensate for the increased circumferential wall stress resulting from the increase in diastolic diameter.

3). Early onset treatment of SHR with different antihypertensive drugs inhibits the development of hypertension, and normalizes aorta wall mechanics and media mass. The drugs achieve this effect by their blood pressure lowering effect and not by a direct effect on aortic diameter or vascular elasticity (chapter 7 ). 
SAMENVATTING 
Het materiaal waaruit de vaatwand is opgebouwd vertoont viscoelastisch gedrag, waardoor het noodzakelijk wordt de arteriële vaatwandmechanica te meten onder dynamische condities. Hiervoor is een techniek ontwikkeld die het mogelijk maakt om de dynamische aorta compliantie en distensibiliteit te bepalen in intacte wakkere en verdoofde ratten. In hoofdstuk 2 wordt deze niet invasieve ultrageluidstechniek besproken. De techniek is gebaseerd op het volgen van de vaatwandbewegingen en het zodoende mogelijk is de diastole diameter en diameter veranderingen tijdens de hartslag te meten (dus het verschil in diameter tussen systole en diastole). De diastole diameter en diameter veranderingen in combinatie met de invasief gemeten aorta pulsdruk zijn de uitgangswaarden om de relatieve en absolute toename in het lumen oppervlak van de aorta voor een gegeven toename in bloeddruk te berekenen, m.a.w. respectievelijk de distensibiliteit en compliantie. De diastole diameter, de diameter veranderingen en de pulsdruk kunnen bepaald worden met goede intrasessie (variantie per dag) en inter-sessie (variantie tussen dagen) variabiliteitscoëfficiënten. De variabiliteitscoëfficiënten voor de diameter veranderingen zijn kleiner in wakkere (4.6$6.0 \%$ ) dan in geanesthetiseerde ratten (7.9$11.0 \%$ ), waarschijnlijk door de variaties in de pulsdruk gedurende de anesthesie (variabiliteitscoëfficiënten: 9.0-12.3\%). De variabiliteitscoëfficiënten voor de diastole diameter in wakkere (3.3-6.5\%) en geanesthetiseerde ratten (2.6-5.0\%) zijn vergelijkbaar. $\mathrm{Na}$ de implantatie van de bloeddrukcatheter neemt de variantiecoëfficiënt voor de diameter veranderingen toe in wakkere ratten. Dit geldt echter niet voor de diastole diameter.

Uit dit onderzoek kan worden geconcludeerd dat met de niet-invasieve ultrageluidstechniek de diastole diameter en de diameter veranderingen van, en de pulsdruk in de aorta betrouwbaar gemeten kunnen worden in wakkere en geanesthetiseerde ratten. Hierdoor is het mogelijk geworden de in vivo dynamische compliantie en distensibiliteit van de aorta te bepalen en het effect van medicijnen hierop te bestuderen.

In hoofdstuk 3 wordt het modulerende effect van de gladde spiercel tonus op de elastische eigenschappen van de aorta in wakkere ratten bestudeerd. De niet-invasieve ultrageluidstechniek wordt daarvoor gebruikt bij wakkere WKY en SHR gedurende de intraveneuze toediening van vasoactieve stoffen. In de WKY ratten veroorzaakt de $\alpha_{1}$-adrenoceptor antagonist prazosine ( 0.2 to $5.0 \mu \mathrm{g} / \mathrm{kg}$.min) een significante toename van het diastolisch lumen oppervlak van de aorta $(+20 \%$ bij de hoogste dosis), terwijl de compliantie en distensibiliteit van het vat niet veranderen. Soortgelijke resultaten worden gevonden na het toedienen van de $\mathrm{AT}_{1}$-receptor antagonist losartan (30 $\mu \mathrm{g} / \mathrm{kg} \cdot \mathrm{min})$. De $\alpha_{1}$ adrenoceptor agonist phenylephrine heeft in lage doses ( 0.08 to $2.0 \mu \mathrm{g} / \mathrm{kg}$.min) geen effect op de bloeddruk, het diastolisch lumen oppervlak, de compliantie en de distensibiliteit van de aorta. De toediening van hogere doses phenylephrine (10 $\mu \mathrm{g} / \mathrm{kg}$.min), resulteert echter in een toename van de bloeddruk en het diastolisch lumen oppervlak $(+36 \%)$ en in een afname van de compliantie en de distensibiliteit. Vergelijkbare resultaten worden gevonden bij het toedienen van angiotensin II (4 to $100 \mathrm{ng} / \mathrm{kg} \cdot \mathrm{min}$ ). In SHR heeft losartan $(30 \mu \mathrm{g} / \mathrm{kg} \cdot \mathrm{min})$ geen effect, terwijl prazosine $(5.0 \mu \mathrm{g} / \mathrm{kg}$.min $)$ een markante verlaging van de bloeddruk veroorzaakt. Deze verlaging gaat vergezeld met een verkleining van het diastolisch lumen oppervlak en een significante toename in de compliantie. In SHR hebben de vasopressor agonisten kwalitatief effecten vergelijkbaar met die in de WKY gevonden zijn: lage doses hebben geen effect, terwijl hoge doses een toename in 
de bloeddruk en in het diastolisch lumen oppervlak, en een afname van de compliantie en distensibiliteit veroorzaken.

Prazosine zorgt ervoor dat het initiële verschil in bloeddruk tussen WKY en SHR verdwijnt, terwijl phenylephrine en angiotensine II de bloeddruk verhogen in WKY tot het niveau gevonden in SHR. Omdat door deze farmacologische interventies de bloeddrukken in beide groepen nu vergelijkbaar zijn, kunnen de dynamische in vivo mechanische eigenschappen van de aorta onafhankelijk van de bloeddruk worden bestudeerd. $\mathrm{Bij}$ vergelijkbare bloeddrukken, is het diastolische lumen oppervlak significant kleiner en de compliantie significant lager in SHR dan in WKY, terwijl de elasticiteitsmodulus vergelijkbaar is in beide stammen. Deze resultaten suggereren dat in wakkere ratten de aorta in een actieve vasoconstrictoire status verkeert en dat de gladde spiercellen van de aorta geen invloed uitoefenen op de dynamische mechanische eigenschappen van dit vat. De hier gevonden resultaten bevestigen de bevinding dat de compliantie van de aorta van de rat primair afhankelijk is van de bloeddruk en dat de drukonafhankelijke verschillen tussen WKY en SHR hoofdzakelijk veroorzaakt worden door het kleiner lumen van de aorta in de hypertensieve ratten.

Tijdens een toestand van verhoogde bloeddruk kunnen veranderingen in de vaatwandelasticiteit het gevolg zijn van zowel het niet-lineaire elastische gedrag van de vaatwand als van structurele vaatwand veranderingen. Daarom is in hoofdstuk 4 de relatie tussen de ontwikkeling van hypertensie en de structurele en mechanische eigenschappen van de aorta in 1.5, 3 en 6 maanden oude SHR en WKY onderzocht. De ketamine/xylazine anesthesie die we gebruikten creeërt een toestand waarbij de bloeddrukken van de beide stammen tijdens de meetsessies vergelijkbaar worden. De compliantie en distensibiliteit worden bepaald m.b.v. de niet-invasieve ultrageluidtechniek en invasieve bloeddruk metingen. Morfometrisch bepalingen leveren de dikte en het oppervlak van de dwarsdoorsnede van de tunica media zodat de incrementele elasticiteitsmodulus kan worden berekend. De hoeveelheid extracellulaire matrix eiwitten is ook bepaald. $\mathrm{Bij}$ een leeftijd van 1.5 maand is de wakkere bloeddruk niet significant verschillend tusssen SHR en WKY, maar zijn compliantie en distensibiliteit significant lager in SHR. De incrementele elasticiteitsmodulus is niet significant verschillend tussen SHR en WKY van 1.5 maand oud. Media dikte is significant groter in SHR dan in WKY, maar er is geen significant verschil in collageen dichtheid en gehalte. De resultaten leiden tot de opvallende conclusie dat in SHR veranderingen in dynamische mechanische eigenschappen van de aorta voorafgaan aan de ontwikkeling van de verhoogde bloeddruk. De afname in compliantie en distensibiliteit op jonge leeftijd is waarschijnlijk het gevolg van een toename in media dikte en wordt niet veroorzaakt door een verandering in de intrinsieke elastische eigenschappen van de aorta.

In hoofdstuk 5 zijn onder vergelijkbare bloeddrukken de dynamische in vivo mechanische eigenschappen van de aorta in 3 en 6 maanden oude WKY .en SHR bestudeerd. Tussen de leeftijd van 3 en 6 maanden wordt er in WKY een toename gevonden in diastolisch lumen oppervlak en de incrementele elasticiteitsmodulus, maar een afname in distensibiliteit. Alle andere verkregen variabelen zijn niet significant veranderd. In deze leeftijdsperiode wordt in aorta van de SHR dezelfde trend waargenomen. Wanneer bij deze leeftijden beide stammen met elkaar worden vergeleken hebben de SHR een significant kleiner diastolisch lumen oppervlak en lagere compliantie. Alle andere onder vergelijkbare druk 
gemeten of berekende mechanische en structurele eigenschappen zijn niet verschillend tussen beide stammen. Onder condities van vergelijkbare bloeddrukken kunnen de verschillen in aorta eigenschappen, gevonden tussen 3 en 6 maanden oude ratten en tussen beide stammen, hoofdzakelijk toegeschreven worden aan de verschillen in aorta lumen diameter.

In mensen gaat veroudering gepaard met een afname in de compliantie en distensibiliteit van de elastische arteriën. Hypertensie zou daarbij een versnellend effect kunnen hebben op de afname van arteriële elasticiteit en op de structurele veranderingen. In hoofdstuk 6 wordt het effect van hypertensie op de structurele en mechanische eigenschappen van de aorta onderzocht in oudere SHR en WKY $(9 \mathrm{t} / \mathrm{m}$ 18 maanden). De resultaten gevonden in dit hoofdstuk laten zien dat de compliantie van de aorta lager is in oudere dan in volwassen WKY, een afname die veroorzaakt wordt door een afname in distensibiliteit. Dit in tegenstelling tot de bevindingen in SHR waar de compliantie niet verandert met de leeftijd, ondanks de afname in distensibiliteit van de aorta. De verwachte verlaging van de compliantie in SHR wordt gecompenseerd door de toename in diameter met de leeftijd. Een vergelijkbare progressieve toename in media massa, weergegeven door een toename van de dikte en het oppervlak van de dwarsdoorsnede van de media, wordt gevonden in beide stammen, maar is meer uitgesproken in SHR dan in WKY. De elastische eigenschappen van de aorta veranderen niet met de toename in leeftijd in beide stammen, zoals afgeleid mag worden uit de afwezigheid van significante verschillen in de incrementele elasticiteitsmodulus tussen de verschillende leeftijdscategorieën. Deze bevindingen geven aan dat hypertensie de veranderingen van de mechanische en structurele eigenschappen van de aorta, zoals plaats vindt bij veroudering, niet verergeren. De gehalten en dichtheden van collageen en elastine veranderen niet met het toenemen van de leeftijd in beide stammen. Hieruit kan de conclusie getrokken worden dat de collageen en elastine gehalten en dichtheden niet verantwoordelijk zijn voor de veranderingen in de mechanische eigenschappen van de aorta met de toename van de leeftijd.

In hoofdstuk 7 is onderzocht of de bufferende capaciteit en de elastische eigenschappen van de aorta verbeterd kunnen worden door het toedienen van bloeddruk verlagende medicijnen, hetzij door een direct effect van de bloeddruk verlaging of door indirecte effecten op de aortawand. Uit andere studies kan worden afgeleid dat niet alle bloeddruk verlagende middelen dezelfde effecten hebben op de bufferende capaciteit, elastische eigenschappen en structuur van verschillende arteriën, ondanks vergelijkbare bloeddruk verlagende effecten. Onderzoek naar de effecten van antihypertensieve medicijnen op de bufferende en elastische eigenschappen van grote arteriën is niet alleen interessant vanuit een therapeutisch oogpunt maar kan ook inzicht geven in de regelmechanismen die verantwoordelijk zijn voor de veranderingen en aanpassingen van de bufferende capaciteit en de rol die hierin gespeeld worden door de verschillende componenten van de vaatwand. In dit hoofdstuk zijn de effecten van een 6 weken durende behandeling van jonge SHR met de ACE-inhibitor captopril, de calcium antagonist nifedipine en de arteriële vasodilator hydralazine bestudeerd. De resultaten van deze metingen laten zien dat (i) de diastolische diameter van de aorta niet significant wordt beïnvloed door de verschillende behandelingen, met uitzondering van een kleine vermindering als gevolg van de hydralazine behandeling; (ii) de aorta compliantie en distensibiliteit 
niet toenemen als gevolg van de behandeling met de verschillende antihypertensieve middelen; (iii) de antihypertensieve middelen geen effect hebben op de incrementele elasticiteitsmodulus van de aorta en (iv) het oppervlak van de media dwarsdoorsnede van de aorta gereduceerd is tot een vergelijkbare grootte na de behandeling met de verschillende antihypertensieve medicijnen. Hieruit kan geconcludeerd worden dat de effecten van verschillende antihypertensieve middelen op de dynamische mechanische eigenschappen van de aorta van SHR het gevolg zijn van hun druk verlagende effect in plaats van directe effecten op de diameter en/of elastische eigenschappen van de aorta.

In hoofdstuk 8 is het effect van een verhoogde vasculaire renin-angiotensine activiteit op het elastische gedrag van de aorta beschreven in wakkere en geanesthetiseerde ratten. Drie maanden oude renine transgene (mREN-2) ratten (renin TGR) en SHR, alsmede hun bijbehorende normotensieve controles zijn bestudeerd. De compliantie en distensibiliteit van de aorta is in beide hypertensieve stammen significant verminderd. Deze vermindering in compliantie en distensibiliteit is significant meer uitgesproken in TGR dan in SHR. In beide hypertensieve stammen is het oppervlak van de media dwarsdoorsnede van de aorta toegenomen, maar de toename is significant groter in TGR. De incrementele elasticiteitsmodulus is significant groter in TGR dan in SHR of in vergelijking met de normotensieve stammen, zowel onder heersende als onder vergelijkbare bloeddruk condities. De collageen dichtheid van de aorta van de TGR is verminderd in vergelijking met die van SHR of in vergelijking met de normotensieve stammen. Deze resultaten laten een sterke verlaging zien van de bufferende capaciteit van de aorta in TGR. De verlaging van de elasticiteit van de aorta in dit model van chronische blootstelling aan hoge vasculaire concentraties angiotensine II is slechts gedeeltelijk afhankelijk van de bloeddruk. Geconcludeerd kan worden dat de reductie van de bufferende capaciteit van de aorta het gevolg is van een verandering in de intrinsieke elastische eigenschappen van de aortawand.

In de algemene discussie (hoofdstuk 9) worden de volgende conclusies getrokken:

1). De hoeveelheid en de organisatie van de verschillende componenten van de aortawand zijn niet verschillend tussen WKY en SHR. De gereduceerde bufferende capaciteit in de wakkere hypertensieve ratten is daarom waarschijnlijk het gevolg van het niet lineair elastische gedrag van de aortawand. Deze conclusie is onderbouwd door het feit dat gladde spiercel activiteit geen invloed heeft op mechanische eigenschappen van de aorta (hoofdstuk 2), en dat collageen en elastine gehalte en de intrinsieke elastische eigenschappen bij vergelijkbare bloeddrukken niet verschillend zijn tussen SHR en WKY (hoofdstuk 3-8). Het verschil in bufferende capaciteit van de aorta verkregen onder condities van vergelijkbare bloeddruk is het gevolg van een kleinere diameter in de hypertensieve ratten (hoofdstuk 3-7).

2). De bufferende capaciteit en/of elastische eigenschappen van de aorta in normotensieve en hypertensieve ratten wordt niet gereduceerd door veroudering (hoofdstuk 4-6). Veroudering gaat in beide rattenstammen gepaard met een toename in de aorta lumen diameter en vergroting van de massa van de media. Deze vergroting van de massa van de media beïnvloedt de bufferende capaciteit van de aorta waarschijnlijk niet (hoofdstuk 4-6). De toename in de massa van de media van de aorta in SHR is niet het gevolg van de toegenomen bloeddruk (hoofdstuk 3-7), maar eerder van een toename in de 
activiteit van het locale renine-angiotensine systeem. Een verhoogde activiteit van dit systeem is in de SHR al aanwezig voordat er sprake is van een verhoogde bloeddruk, en kan de massa van de media vergroten (hoofdstuk 7 en 8). Daarnaast kan het een rol spelen bij de vermindering van de elasticiteit van de aorta, hetgeen is aangetoond bij een verhoogde expressie van renine (hoofdstuk 8). De toename in de massa van de media is waarschijnlijk een mechanisme om de toename in wandspanning als gevolg van de vergroting van de aortadiameter te compenseren.

3). Behandeling van SHR in de prehypertensieve fase m.b.v verschillende antihypertensieve medicijnen remt de ontwikkeling van de toename in bloeddruk, en normaliseert de mechanische eigenschappen en de massa van de aorta media. Deze medicijnen ontlenen deze effecten aan het feit dat ze de bloeddruk verlagen en niet aan een direct effect op diameter of elasticiteit van de aorta (hoofdstuk 7). 


\section{CURRICULUM VITAE LIST OF PUBLICATIONS}




\section{CURRICULUM VITAE}

4 februari 1963

1988-1993

1993-1997

1997-1998

1998
Geboren in Tilburg.

Studie Biologie aan de Universiteit Utrecht.

A.I.O. Vakgroep Fysiologie, Rijksuniversiteit Limburg, Maastricht.

Post-doc, Moleculaire Oncologie, Universiteit Leuven

Post-doc, Instituut voor Neurobiologie, Universiteit van

Amsterdam

\section{Publications}

\section{Articles}

Van Gorp, A., Van Ingen Schenau, D, Hoeks, A, Struijker Boudier, H, Reneman, R, De Mey, J, Aortic wall properties in normotensive and hypertensive rats of various ages. Hypertension, 26, 363$368,1995$.

Van Gorp, A., Van Ingen Schenau, Willigers, J D, Hoeks, A, Struijker Boudier, H, De Mey, J, Reneman, R, A technique to assess aortic distensibility and compliance in anesthetized and awake rat. Am. J. Physiol., 270 (heart Circ. Physiol. 39), H780-H786, 1996.

Slangen, B, Van Ingen Schenau, D, Van Gorp, A., De Mey, J, Peters, L, Aortic distensibility and compliance in conscious pregnant rats. Am. J. Physiol., 272 (Heart Circ. Physiol 41), H1260-H1265, 1997.

Van Gorp, A., Van Ingen Schenau, D, Hoeks, A, Struijker Boudier, H, Reneman, R, De Mey, J, Effects of smooth muscle tone on aortic compliance in conscious normotensive and spontaneously hypertensive rats.submitted for publication in Am. J. Physiol.

Van Gorp, A., Van Ingen Schenau, D, Hoeks, A, Struijker Boudier, H, De Mey, J, Reneman, R, Alterations in spontaneously hypertensive rats in aortic wall properties precede the development of hypertension. submitted for publication in Am. J. Physiol.

Van Gorp, A., Van Ingen Schenau, D, Hoeks, A, Struijker Boudier, H, De Mey, J, Reneman, R, Arterial stiffning in hypertensive mREN-2 transgenic rats. submitted for publication .

Van Gorp, A., Van Ingen Schenau, D, Hoeks, A, Struijker Boudier, H, De Mey, J, Reneman, R, Hypertension does not aggravate the changes in artery wall properties and structure with advancing age in older rats. submitted for publication.

Van Gorp, A., Van Ingen Schenau, D, Hoeks, A, Struijker Boudier, H, Reneman, R, De Mey, J, The influence of anti-hypertenisve medication on the conscious in vivo dynamic mechanical properties of the thoracic aorta in spontaneously hypertensive rats. submitted for publication.

Van Gorp A, Willigers JD, Hoeks APH, Reneman RS. The visco-elastic behavior of the thoracic aortic wall in WKY and SHR. In preperation. 


\section{ABSTRACTS}

Van Gorp, A., Van Ingen Schenau, D, Hoeks, A, Struijker Boudier, H, De Mey, J, Reneman, R, Mechanical and morphometric aortic wall properties in 3 and 6 months old Wistar Kyoto and Spontaneously hypertensive rats at identical blood pressure in vivo. FASEB Journal, 9 (3), 3247, 1995.

Reneman, R, Van Gorp, A., Van Ingen Schenau, D, Hoeks, A, De Mey, J, Struijker Boudier, H, Willigers,J, Aortic distensibility and compliance in anesthetized and awake rats. FASEB Journal, 9 (3), 3252, 1995.

Van Gorp, A., Van Ingen Schenau, D, Hoeks, A, Struijker Boudier, H, Reneman, R, De Mey, J, Comparison of the elastic properties of the aorta of spontaneously hypertensive (SH) and Wistar Kyoto rats (WKY) in intact conscious and anesthetized animals. European Journal of Physiology, 430 (4 suppl), 74, 1995.

Van Gorp, A., Van Ingen Schenau, D, Hoeks, A, Struijker Boudier, H, De Mey, J, Reneman, R, Reduced aorta compliance preceds high blood pressure in Spontaneoulsy hypertensive rats (SHR). FASEB Journal, 10 (3), 1598, 1996.

De Mey, J, Van Gorp, A., Van Ingen Schenau, D, Hoeks, A, Reneman, R, Struijker Boudier, H, Role of pressure in the reduced compliance of the aorta in conscious Spontaneously hypertensive rats. FASEB Journal, 10 (3), 1599, 1996.

Van Gorp, A., Van Ingen Schenau, D, Hoeks, A, Struijker Boudier, H, De Mey, J, Reneman, R, Compliance and collagen content in aorta of Spontaneously hypertensive rats (SHR)", Journal of Vascular Research, 33 (suppl 1) ), 404, 1996.

Van Gorp, A., Van Ingen Schenau, D, Hoeks, A, Struijker Boudier, H, De Mey, J, Reneman, R. Arterial stiffning in hypertensive mREN-2 transgenic rats. FASEB Journal, 1999. 
NAWOORD 


\section{DANKWOORD}

Tsjaaa......... het dankwoord.

Tsjaaa..........hoe moet ik dat aanpakken.

De wreed tikkende seconden verdreven de tijd met nauwlettendheid. Alles vervloeiend tot een herinnering. Rest het mijmeren.

Iedereen bedankt voor de leerzame en gezellige tijd in Maastricht en voor de bijdrage(n) aan dit proefschrift.

Ad van Gorp 
